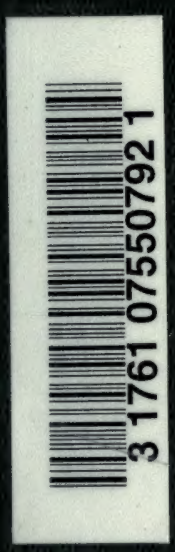

SD 553 D54 





\section{Aus Württemberg}

\section{Unsere}

Forstwirtschaft im 20. Jahrhundert

In zwanglosen Heften herausgegeben von

C. Wagner.

\section{V.}

Die Elementeder Wertsmehrung in der Waldwirtsehaft

von

\section{Dr. Victor Dieterich,}

Forstamtmann.

Mit zwei Kurven.

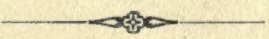

Tübingen

Verlag der H. L a u p p'schen Buchhandlung 1911.

\section{LIBRARY}

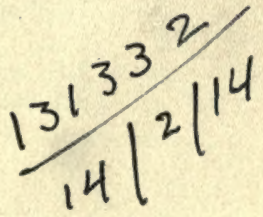




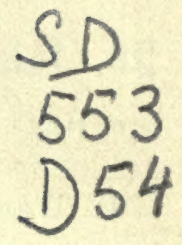

Alle Rechte vorbehalten.

Druck von H. L a up jr in Tübingen. 


\section{- III -}

\section{Inhalt.}

Einleitung und Vorbemerkungen . . . 1-11

a) Die Bedeutung und die Aufgaben entwicklungsgeschichtlicher Studien über die Waldwerte . . . . 1

b) Die Verwendbarkeit statistischer Zahlenreihen zu vergleichenden Untersuchungen . . . . . . 5

c) Umgrenzung und Gliederung des Stoffs . . . . . 9

I. Teil. Die Mehrung der Massenertragsfähigkeit . . . 12-60

1. Beispiele aus der Ertrags-und Forsteinrichtungstatistik . . . . . .

a) Untersuchungen auf Grund der Statistik der badischen Staatsforstverwaltung . . . . . . .

b) Untersuchungen auf Grund statistischer Angaben aus der sächsischen Staatsforstverwaltung . . .

c) Untersuchungen auf Grund der württembergischen Forststatistik

aa) an der Hand der Forsteinrichtungsstatistik . .

bb) an der Hand der Ertragsstatistik . . . . .

cc) Vergleich der Ergebnisse der Einrichtungs- und. Ertragsstatistik insbesondere hinsichtlich des Verhältnisses von dermaliger Vornutzung und künftiger Haubarkeitsnutzung . . . . . . 42

2. Folgerungen . . . . . . . . . . . . . 47

II. Teil. Die Mehrung des Einheitswerts der Waldrente . $61-165$

Gliederung . . . . . . . . . . . . 61

I. Abschnitt. Die $Q u$ alitätsmehrung.63-93

1. Das Nutzholzprozent als Weiser der Wertsmehrung . . . . . . . . . . . .

2. Das Wertsverhältnis der Holz- und Betriebsarten.

3. Das Wertsverhältnis der Sortimente (Sortimentsstatistik) . . . . . . . . . . . .

a) Allgemeines betr. Bedeutung und Form der Sortimentsstatistik

b) Spezielle Erhebungen über Sortimentsanfall und Sortimentswertsverhältnis (Sortimentsstatistik nach Nutzungsart und Altersklassen) . . . 
4. Folgerungen . . . . . . . . . . 88

II. A bschnitt. Die Preisentwicklung. $93-125$

1. Die bisherige Preissteigerung im Licht der Preisgesetze . . . . . . . . . . . . . 93

2. Methoden zur Feststellung der Holzpreisveränderung (Preisstatistik) • • • • • • •

3. Ergebnisse und Nutzanwendung der Preisstatistik besprochen an einem typischen Beispiel (insbesondere die Preisspannung der Nadelholzlangholz-Sortimente)

4. Folgerungen
III. Abschnitt. Die Entwickiung des

Prod u k t ons a f w a $\mathrm{nds}$ hinsichtlich ihrer Bedeutung für die Wertsmehrung . . . . . . 126-165

1. Allgemeines (Intensitätssteigerung und Lohnerhöhung) . . . . . . . . . . . .

2. Die Lohnerhöhung und andere in der Lebensverteuerung beruhende Ursachen der Ausgabenmehrung im besonderen

. Das Maß des Arbeits- und Kapitalaufwands im besondern, besprochen für die wichtigsten Ausgabentitel im einzelnen . . . . . . . . . . . 135

a) die Werbungskosten . . . . . . . . . 139

b) der Kulturaufwand . . . . . . . . . 142

c) der Wegbauaufwand . . . . . . . . . . . 151

d) der Verwaltungskostenaufwand . . . . . . 158

4. Folgerungen . . . . . . . . . . 161

$\mathrm{R}$ ü $\mathbf{c k l i} \mathbf{c k}$. 


\section{Einleitung und Vorbemerkungen.}

a) Die Bedeutung und die Aufgaben entwicklungsgeschichtlicher Studien über die Waldwerte.

Eine Entwicklungsgeschichte der heutigen Waldwerte zu schreiben, müßte eine dankenswerte Aufgabe sein, nutzbringend für wissenschaftliche Forschungen und für Lösung praktischer Verwaltungsfragen. Je größer die Anforderungen geworden sind, welche das moderne Leben an die privaten und öffentlichen Vermögen stellt, umsomehr hat sich auch das Bedürfnis geltend gemacht, den ${ }^{\mathbf{1}}$ ) Wert und die Nutzbarkeit der Waldungen kennen zu lernen. Die großen forstlichen Streitfragen bewegen sich meist auf diesem Gebiet und zeigen zugleich, daß der W e rdegang der Waldwerte noch recht wenig geklärt ist. Man hat sich häufig zu einseitig in $\mathrm{Z} \mathrm{u}$ $\mathrm{k} u \mathrm{nfts} \mathrm{rechnungen}$ ergangen und hiebei gelegentlich Zahlen benützt, welche in geschichtlicher Beleuchtung ein wesentlich anderes Bild zeigen, als in der Uniform der mathematischen Formel (z. B. Zinsfuß). Es muß deshalb als großes Verdienst des Professor Dr. M a r t i n gerühmt werden, daß er den Schwerpunkt der forststatischen Untersuchungen in die Gegenwart verlegt und dadurch diesen Wissenszweig der Praxis mehr mundgerecht gemacht hat. Wenn er in seinem Lehr-

1) So hat z. B. die württembergische Abgeordnetenkammer aus Anlaß der Forstetatsberatungen im Jahr 1907 um Auskunft über die ungefähre Höhe des Werts der Staatswaldungen ersucht.

Forstwirtschaft. V. Dieterich, Elemente d. Wertsmehrung. 
buch ,Die forstliche Statik“die, das Verhältnis des jährlichen Ertrags zum Produktionsfonds bezeichnende, Formel $\frac{A+D-(c+v)}{B+N}$ als die für den nachhaltigen Großbetrieb wichtigste erklärt, so ist damit zugleich der Weg gewiesen, auf dem man dem Verständnis der Waldwertsentwicklung näher kommen kann, eben durch Erforschung des Werdegangs der im Zähler sowohl als im Nenner jenes Bruchs stehenden Wertsgrößen und der Beziehungen, welche zwischen den beiden, steter Wechselwirkung unterworfenen, Faktoren besteht. Gl e i $\mathrm{ch}$ wie die Stärke der forstlichen Technik auf eingehender Beobachtung der Naturvorgänge beruht, so vermögen wir in das Verständnis der wirtschaftlichen Fragen a u ch n r dureh sorgfältiges Studium des bisherigen Verlaufs der Dinge einzudringen.

Daß im vergangenen Jahrhundert eine Werts me h$\mathrm{r}$ u $\mathrm{n}$ in der Waldwirtschaft sich abgespielt hat, wird allgemein angenommen und mit Einsetzung eines, im Vergleich zum landesüblichen, niedrigeren ${ }^{1}$ ) Zinsfußes in den forstmathematischen Formeln quittiert. Sicher nachweisbar ist aber meist nur die fortgesetzte Erhöhung ${ }^{2}$ ) der Walderträge, also des Zählers in jenem Bruch, während über die im Nenner stehenden Größen, insbesondere die Größe N, und deren E r-

1) Vergl. hiezu die diesbezüglichen Aeußerungen von $\mathrm{J}$ ud e i c h, PreBler, H y er, Lehr, W i m m e n a e r, Endres, B a ur, Stötzer, M artin, Kraft, wie sie in dem Aufsatz von P i l z über ,Starkholzerziehung und Bodenreinertragswirtschaft" (A. F. und J. Z. 1904 S. 7 ff.) übersichtlich zusammengestellt sind.

2) Aus der sächsischen Statistik läßt sich die Zunahme des Waldkapitalwerts unmittelbar entnehmen; derselbe war im Durchschnitt des Zeitraums 1854/63 zu 1156 M. pro ha, 1884/93 zu 1859, 1894/1903 zu ca. 2030 M. veranschlagt (vergl. die Schrift „Die Entwicklung der Staatsforstwirtschaft im Königreich Sachsen"“ (1897) Tab. 6 Sp. 17 und die Reinertragsübersichten der K. Sächs. Staatsforstverwaltung, welche alljährlich im Thar. Forstl. Jahrbuch veröffentlicht werden. 
$\mathrm{t} \mathrm{r}$ a $\mathrm{g}$ s $\mathrm{f}$ ä $\mathrm{h}$ i g k e it vielfach widersprechende Anschauungen bestehen. Es genügt ein Hinweis auf die Erörterungen und literarischen Fehden, welche der Antrag $\mathrm{T}$ ö r r in g in Bayern und weit über die Grenzen seiner engeren Heimat hinaus ausgelöst hat. Aehnliche Fragen sind dann auch in Württemberg aus Anlaß der Erneuerung des Forstreservefondsgesetzes, in Baden aus Anlaß der Forstetatsberatungen Gegenstand der Besprechung in der Fach- und Tagespresse, sowie in den Parlamenten geworden ${ }^{1}$ ).

Aus diesem sehr lebhaften Meinungsaustausch drängt sich dem Unbeteiligten, mag er sonst beliebiger Richtung huldigen, d e r Eindruck mit Bestimmtheit auf, den $W$ a $g$ n e ${ }^{2}$ ) mit den Worten kennzeichnet: „Was uns also noch fehlt neben

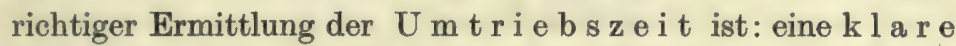
Trennung von Kapital und Rente im Forst-

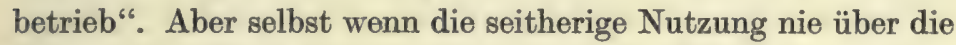
Grenzen der Rente hinausgewachsen wäre, könnte angesichts der fortgesetzten Ertragssteigerung leicht vertrauensvolle Sicherheit Platz greifen; man müßte deshalb zunächst untersuchen, ob es sich hiebei nur um vorübergehende Erscheinungen handelt, ob und inwieweit sie a Berhalb des Bereichs der forstwirtschaftichen Einwirkung liegen oder in die Hand des Forstrerwaltungsbea $m$ te $n$ ge geben sind. Da eine Periode glänzenden Aufschwungs in Handel und Gewerbe, Technik und Verkehr hinter uns liegt, kann als wahrscheinlich angenommen werden,

1) In der Schrift des badischen Oberförsters F i e s e r ,Die Modernisierung der badischen Domänen- und Gemeindewaldwirtschaft" (Freiburg 1910) sind die meisten der diesbezüglichen $\mathbf{A b -}$ handlungen teils erwähnt teils zitiert, daneben private Veröffentlichungen und Broschüren, Sitzungsberichte aus den Parlamenten und Werke amtlichen Charakters, wie die Allg. Mitteil. über die forstlichen Verhältnisse Badens für 1907 im Auszug mitgeteilt. 2) "Unsere Forstwirtschaft im 20. Jahrhundert" I. S. 22. 
daß die Forstwirtschaft die Steigerung ihrer Erträge nicht zum größten Teil sich selbst zu gut schreiben darf, vielmehr als glückliches, vom 19. Jahrhundert überkommenes Erbteil anzusehen hat. Die Erhaltung und weitere Mehrung der heutigen Werte wird sich künftig vielleicht weniger mühelos gestalten und teilweise in anderen Bahnen zu bewegen haben. Soll es der Forstwirtschaft gelingen, die Gesetze der Wertsmehrung den zeitgemäßen Zwecken, den mannigfaltigen Bedürfnissen und hohen Anforderungen des 20. Jahrhunderts dienstbar zu machen, so muß erst das Wesen und Zusammenwirken der treibenden Elemente klar erkannt sein. Wissenschaft und Praxis müssen sich hiebei gegenseitig unterstützen: während erstere die einfachsten Methoden zur Untersuchung jener Elemente ausfindig zu machen hat, ist es Sache der wirtschaftenden Praktiker, die erforderlichen Hilfsmittel und Rechnungsgrundlagen zur Verfügung zu stellen; diese Hilfeleistung ist vielfach noch recht unvollkommen: das gebotene Zahlenmaterial teils spärlich, teils wenig geordnet, häufig schwer vergleichbar. Spärlich z. B. sind die Angaben der Forststatistik über die wichtigsten Wertsbildner der Waldwirtschaft, den Zuwachs und die Holzsortimente, wenig geordnet manche Teile der Buchführung, deren Gliederung oft weniger auf die Erfassung der maßgebenden Wertselemente als auf gewisse kameralistische Rücksichten abgerichtet ist, ebenso einzelne Tabellen der Statistik, die wesensverschiedene Dinge in sich vereinigen und deshalb mehr nur dekorative Bedeutung haben. Häufige Aenderungen in der Flächenausdehnung und Einteilung der Waldbesitze, im Meßverfahren, Sortierung u. s. f. haben endlich das Thrige dazu beigetragen, die Nutzbarkeit der Statistik für wissenschaftliche Forschungen zu beschränken.

Eine EntwicklungsgeschichtederWaldwerte müBte also vor allem der Statistik und Buchführung die Wege weisen, auf denen sie mit mehr Sicherheitals bislang, 
die Vorgängeder Wertsbildung und Wertsmehrung verfolgen lassen.

Die vorliegende Arbeit soll eine entwicklungsgeschichtlichestudiesein, ihre A ufgabewird darin bestehen, an Beispielen die wichtigsten Elementeder Wertsmehrung in der Waldwirtsehaft und deren Wirkung z u erörtern, L ücken und Hindernissezu weisen, diesolehen Untersuchungen vielfach noch entgegenstehen, Anregung zur Beseitigung derselbenzu geben, und soweit möglich Schlußfolgerungen für den weiteren Entwicklungsgang und für wichtige A u f a bender Forstwirtschaft unserer Tage anzudeuten.

Verfasser wird dabei insbesondere auf die ihm näher bekannten Verhältnisse der württembergischen Staatsforste Bezug nehmen; sie lassen das Bedürfnis nach solchen Untersuchungen besonders dringlich erscheinen; denn die Erörterungen und Beratungen über das ${ }^{1}$ ) Forstreservefondsgesetz haben auf eine Fülle ungelöster Waldwertsfragen hingewiesen und auch die neue Fassung dieses Gesetzes (vom 25. Juli 1910) ist nach den Ausführungen des Herrn Finanzministers nur mehr als Provisorium zu betrachten.

b) Die Verwendbarkeit statistischer Zahlenreihen zu vergleichenden Untersuc hungen.

Bei Untersuchungen über Wertsbildung und Wertsmehrung ist es erforderlich, die in Zahlen ausgedrückten Ergebnisse der Wirtschaft oder Aufnahmen miteinander zu vergleichen, teils durch Gegenüberstellung verschiedener Waldgebiete, Ver-

1) Vergl. die Berichte im Oktober- und Novemberheft des F. Zentrbl. 1910 . 
waltungen u. s. f., teils, in zeitlicher Richtung, durch Gegenüberstellung einzelner Jahre oder Perioden. Daß die betreffenden Zahlengrößen vergleichbar sein müssen, ist an sich selbstverständlich, aber nicht immer beachtet worden, weder bei Einrichtung und Fortführung, noch bei der Anwendung der Statistik. Vor allem müssen die Maße vergleichbar, die Größen an einander meßbar sein. Die Maße, mit denen es die Waldwirtschaft zu tun hat, sind in den deutschen Forsten nunmehr größtenteils einheitlich geregelt, aber die maßgebenden Begriffe haben zum Teil noch verschiedenen Sinn: so bezieht sich die Flächeneinheit bald auf Gesamtbesitz, bald auf Gesamtholzboden, bald nur auf ertragsfähigen Holzgrund; die Abnutzungssätze sind bald in Derbholz-Festmetern, bald nach Gesamtholzanfall einschließlich oder ausschließlich Stockholz angegeben, die Erlös-Einheiten bald auf diesen oder jenen Begriff angewendet (s. die diesbezüglichen Bemerkungen in Endres Forstpolitik S. 96, 102, 118, 121, 126, 129, 130). Der deutsche Forstwirtschaftsrat hat in sehr verdienstlicher Weise eine einheitliche Ertragsstatistik für die deutschen Forste eingeleitet, die, von $\mathrm{S} \mathrm{ch}$ w a p a $\mathrm{ch}$ redigiert, in den Mitteilungen des Deutschen Forstvereins veröffentlicht werden; das bedeutet einen wesentlichen Fortschritt im Ausbau der Ertragsstatistik.

Störender aber als örtliche Ungleichartigkeit der Behandlung sind Aenderungen in ner halb desselben Beob a chtungsgebiets, da sie die Kontinuität der Statistik gefährden; dieser Gesichtspunkt darf gegenüber dem Bestreben nach Vereinheitlichung nicht außer Acht gelassen werden; liegt ein Bedürfnis zur Aenderung der Maße, Begriffe oder Gliederung statistischer Erhebungen vor, so sollten zur Herstellung des Anschlusses Umrechnungszahlen angegeben bezw. die wichtigsten seitherigen Angaben in der alten Anordnung und Benennung noch einige Zeit nebenher fortgeführt werden; man könnte vielleicht auch von Zeit zu Zeit wieder auf die alte Einteilung zurückgreifen. 
Auch die vielfachen Aenderungen in der organisatorischen und wirtschaftlichen Einteilung des Waldganzen lassen häufig, die mühevollen statistischen Arbeiten als beinahe wertlos erscheinen; man hat neuerdings diese Tatsache anerkannt, aber in der Praxis, zumal bei Abgrenzung und Benennung der Distrikte und Abteilungen, noch nicht genügend berücksichtigt.

Bei Anwendung statistischer Quellen ist die Vergleichbarkeit der einzelnen Posten jedenfalls in der angedeuteten Richtung zu prüfen, ehe Schlußfolgerungen abgeleitet werden.

Verfolgt man eine Statistik auf längere Zeit zurück, so tritt neben den bald kleineren, bald größeren Schwankungen eine den Gesamtverlauf kennzeichnende Richtung (Tendenz) mehr oder weniger deutlich heraus; will man diese Richtung herausgestalten, so dürfen natürlich nicht b e l i e b i g a Zeitabschnitte zur Vergleichung einander gegenübergestellt werden (zu vergl. Le hr , Beiträge zur Statistik der Preise S. 47 ff.). $\mathrm{L}$ e h r hat, um die „Preisänderungen eines ganzen Zeitabschnitts unabhängig von den einzelnen jährlichen Schwankungen" zu ermitteln (S. 51), die Methode der kleinsten Quadrate empfohlen, wonach eine Näherungsgleichung für die Kurve berechnet wird, welche sich den graphisch aufgetragenen Punkten der notierten Preissätze am engsten anschmiegt. Es fragt sich aber, ob die Feinheit dieses umständlichen Verfahrens nicht zum Genauigkeitsgrad der Grundlagen sowohl als zum Endzweck derartiger Berechnungen in einem Mißverhältnis steht, zumal wenn man die Ermittlung auf lange, weit zurückliegende Zeiträume ausdehnt. Es kann ja wohl überhaupt $\mathrm{nicht}$ in Frage kommen, die i m seitherigen Entwicklungsgang liegende Gesetzmä Bigkeit mathematisch genau festzulegen, oder gar, wie es einst $\mathrm{G}$. H e y e $\mathrm{r}^{1}$ ) bezüglich der Holzpreise vor-

1) Handbuch der forstl. Statik S. 45. 
schlug, die künftige Gestaltung auf diese Weise zu ermitteln; handelt es sich doch hier nicht um exakte Gesetzmäßigkeiten sondern nur um "T end e $\mathrm{nz}$ en", wie es $\mathrm{N}$ e u $\mathrm{m}$ a $\mathrm{n} n$ in einer Abhandlung über ,Naturgesetz und Wirtschaftsgesetz " $^{1}$ ) ausdrückt.

Vergl. auch M a rti n, Forstl. Statistik S. 17, und die dort zitierte Aeußerung von $\mathbf{R}$ os ch er über die Anwendung der mathematischen Methode in der Volkswirtschaft.

Um sich ein Bild von den Aenderungsprozessen zu machen, dürfte vielmehr das von $\mathrm{L}$ e h r abgelehnte ${ }^{2}$ ) Verfahren der Berechnung von Durchschnittszahlen aus kleineren oder gröBeren Zeitabschnitten genügen, ohne Auslassung von Jahren abnormer Erscheinung. Dagegen wird es sich allerdings empfehlen, zu vergleichenden Untersuchungen Zeitabschnitte mit besonders abnormen Einzeljahren nicht heranzuziehen; jedenfalls aber muß auf graphischem Weg die Vergleichbarkeit der Zeitabschnitte geprüft werden, indem man eine die Höhen- und Tiefenpunkte des Linienzugs annähernd ausgleichende Kurve einzeichnet. Bei Zusammenfassung mehrerer Jahre zur Bildung von Durchschnittszahlen ist ferner darauf zu achten, daß nicht solche Jahre aus dem Zusammenhang losgerissen werden, welche die Heilung vorheriger Abnormität bringen, oder eine in den nächsten Jahren ausgeglichene Abnormität aufweisen. Dies gilt z. B. für die einzelnen Abschnitte der Massenertragsstatistik, sofern auf Jahre besonders hoher, durch Katastrophen (Sturm o. ä.) veranlaßter Uebernutzungen teilweise Einsparungen zu folgen pflegen. Anders ist zu verfahren, wenn nicht die Gesamtentwicklung, sondern die periodischen Schwankungen gekennzeichnet werden sollen, z. B. die Perioden der Hausse und Baisse.

So finden wir in E ndres Forstpolitik S. 120 die Jahre der Aufwärtsbewegung und der sinkenden Tendenz sehr zweckmäßig zu Abschnitten zusammengestellt.

1) Zeitschrift für die gesamte Staatswissenschaft $1892 \mathrm{~S} .405 \mathrm{ff}$.

2) S. 49 der „Beiträge“" u. s. f. 
Daß es zur Beobachtung des Gesamtentwicklungsgangs von größtem Wert ist, möglichst lange Zeiträume beobachten zu können, liegt in der Natur der Sache.

Es schien notwendig, diese Ausführungen allgemeiner Art hier vorauszuschicken, weil im Lauf der weiteren Erörterungen immer wieder vergleichende Zusammenstellungen statistischen Materials vorzunehmen sein werden, und weil man häufig, auch in sonst gediegenen Ausführungen, die Beobachtung machen kann, daß Einzeljahre oder Zeitabschnitte willkürlich aus dem Zusammenhang herausgerissen oder daß viel zu kurze Zeiträume verglichen werden. Die Statistik kommt durch solche Fehlgriffe leicht in Mißkredit; so ist die häufig gebrauchte Phrase, daß sich mit der Statistik alles beweisen lasse, lediglich auf derart unrichtige Anwendung derselben zu beziehen.

Zu bemerken ist noch, daß zur Darstellung der Wertsänderung entweder Vergleichsgrößen berechnet werden können, indem man ein Glied der Zahlenreihe $=1$ oder $=100$ setzt, oder Prozentsätze, bezogen auf $1 \mathrm{Jahr}$ der Zwischenzeit, wobei dann am zweckmäßigsten die von Pressler empfohlene Nährungsformel $\mathrm{p}=\frac{200}{\mathrm{n}} \times \frac{\mathrm{M}-\mathrm{m}}{\mathrm{M}+\mathrm{m}}$ benützt wird. $(\mathrm{n}=\mathrm{Zahl}$ der Jahre von Periodenmitte zu Periodenmitte.)

c) Umgrenzung und Gliederung des $S t$ of $f$ s.

Lassen wir die ideellen Werte des Waldes, als nicht meßbar und diefreie Verfügung über das Waldkapital vielfach beschränkend, außer Betracht, so haben wir es in der vorliegenden Arbeit, der üblichen Begriffsbestimmung entsprechend, zu tun mit der Bedeutung, welehe den Waldungen mit Beziehung auf die Befriedigung der materiellen Bedürfnisse oder Wahrung materieller Interessen des Besitzers zukommt. Fürden Großwald besitzer, von dem hier in erster Linie die Rede ist, für Staat, Gemeinde, Standesherrschaft $u$. s. f. ist diese Bedeutung des Waldver- 
mögens vorwiegend von Einfluß auf die Führung seines Haushalts und teilweise auch auf seinen Kredit; s i e lä Bt s i c h demnach ermessen an der Fähigkeit des Waldes, regelmäßige, annähernd gleiche oder womöglich steigende Erträge abzuw e r f e n (natürlich einschließlich der Zinsen eines ev. Reservefonds). Die Untersuchung der Wertsmeh rung wird demnach immer auf die Frage einzuweisen sein, ob eine Verbesserung oder Verschlechterung dieser Fähigkeit eingetreten is t.

Unterstellt man zunächst, daß die bisherigen Reinerträge als der tatsächlichen Ertragsfähigkeit entsprechende volle $\mathrm{R}$ e n te n zu gelten hätten, so könnte man die Wertsmehrung einfach durch Vergleich der jeweiligen Rentierungswerte berechnen, wobei nur die sinkende Tendenz des der Kapitalisierung zu Grund zu legenden landesüblichen ${ }^{1}$ ) Zinsfußes zu berücksichtigen wäre.

Stellt man derartige Berechnungen für die Staatsforste von Preußen, Sachsen, Württemberg und Baden an, indem man die durchschnittlichen Reinerträge ${ }^{2}$ ) der Jahre 1850/59 und 1895/1904 in Vergleich setzt und als Kapitalisierungszinsfuß ${ }^{3}$ ) 4 bezw. $3 \frac{1}{2} \%$ wählt, so ergeben sich folgende durchschnittliche Wertsmehrungsprozente berechnet auf $1 \mathrm{Jahr}$ der Zwischenzeit: für Preußen rund $2,5 \%$, Sachsen 2,1\%, Württemberg $2,5 \%$, Baden $2,1 \%$.

1) Die a b olut e $\mathrm{H}$ ö $\mathrm{h}$ des Zinsfußes ist, solange es sich nur um Feststellung der Mehrung handelt, nebensächlich, dagegen muß, zumal beim Vergleich weit auseinandergelegener Zeiträume, jene sinkende Tendenz berücksichtigt werden.

2) Nach der Zusammenstellung im Handbuch der Forstpolitik von Endres S. 116 und 117, ergänzt durch die entsprechenden Zahlen der neueren Statistik betrugen die durchschnittlichen Reinerträge (auf 1 ha) in Preußen, Sachsen, Württemberg, Baden $\begin{array}{lllll}\text { 1850/59 Mark: } & 5,40 & 19,40 & 15,80 & 17,90\end{array}$ 1895/1904 Mark: $\quad 16,80 \quad 48,10 \quad 47,60 \quad 43,90$ Die Vergleichbarkeit der beiden Zeitabschnitte läßt sich graphisch nachweisen.

3) Dieses Verhältnis von $4 \mathrm{zu} 3 \frac{1}{2}$ entspricht ungefähr der Entwicklung, welche Dr. E. V o y e (in der Sammlung nationalökonom.-statist. Abhandlungen von $\mathrm{Con} \mathbf{r}$ a d) mit Bezug auf die preußischen Staatspapiere nachgewiesen hat. 
Man hätte nun die Ursachen zu ermitteln, welche die Reinertragsmehrung veranlaßt haben und zu untersuchen, welche dieser Ursachen als weiterwirkend angenommen werden können; dabei sollte sich auch herausstellen, ob die jeweiligen Reinerträge ein richtiges Bild der Ertragsfähigkeit geben bezw. welche Abweichungen angenommen werden müssen, ob die Rente nicht voll bezogen ward oder ob Kapitaleingriffe vorliegen.

Nach diesen Gesichtspunkten sind die Elemente der Wertsmehrung zu behandeln, und zwar von vornherein getrennt nach den 2 Wertskomponenten, Holzmasse und Finheitswert derselben. Man muß sich aber dessen bewußt bleiben, daß nur die $\mathrm{T}$ e $\mathrm{n} \mathbf{d}$ e $\mathrm{nz}$ des einzelnen Elements feststellbar ist, deren Wirkung durch andere aufgehoben, abgeschwächt oder verstärkt werden kann; das Zusammenwirken der verschiedenerlei Elemente muß deshalb stets im Auge behalten werden. 


\section{Teil.}

\section{Die Mehrung der Massenertragsfähigkeit.}

(Die Wertsmehrung auf Seiten des Holzmasse-Komponenten.)

1. Beispiele aus der Ertrags- und Forsteinrichtungsstatistik.

Die Forststatistik der deutschen Staatsforstverwaltungen läßt, von einigen noch zu besprechenden Ausnahmen abgesehen, im allgemeinen nur die Entwicklung der $M$ a s s e n e r t r ä g e von längerer Zeit her verfolgen (graphische Darstellung ${ }^{1}$ ) Fig. 1 siehe nächste Seite).

Die Steigerung erfolgte demnach ziemlich ungleichmäßig, in Sachsen z. B. hauptsächlich zwischen 1850/59 und 1880/89, in Württemberg zwischen $1830 / 39$ und $1850 / 59$, dann wieder zwischen 1880/89 und 1895/1904; der Durchschnittsertrag 1905/08 enthält außerordentliche Nutzungen für den Reservefonds; bei Preußen darf - wegen des Zugangs der neuen Provinzen - streng genommen erst die Zeit nach 1868 berücksichtigt werden.

Es mag von Interesse sein, die Massenertragssteigerung noch in Beziehung zu setzen zur Reinertragszunahme: Stellt man wiederum die Zeiträume 1850/59 und 1895/1904 einander gegenüber, so ergibt sich als durchschnittliches jährliches Steigerungsprozent nach der Statistik d. Staatsforstverwaltungen v.

PreuB. Sachs. Württ.

beim Reinertrag p. ha : $2,3 \% \quad 1,9 \% \quad 2,2 \%$

b. d. Derbh. Nutz. ", ", : $\quad 1,4 \% \quad 1,1 \% \quad 0,8 \%$

b. Reinertr p. Fm Derbh. : $\quad 0,9 \% \quad 0,8 \% \quad \mathbf{1 , 4} \%$

1) Nach der Tabelle in $\mathbf{E} \mathbf{n} \mathbf{d} \mathbf{r}$ e $\mathbf{s}$ Forstpolitik S. 96 ergänzt aus der neueren Statistik beziehen sich die Abnutzungssätze der wiirttemberg. Staatsforstverwaltung durchweg auf Gesamtwald- 


\section{$-13-$}

Figur 1. Derbholzanfall

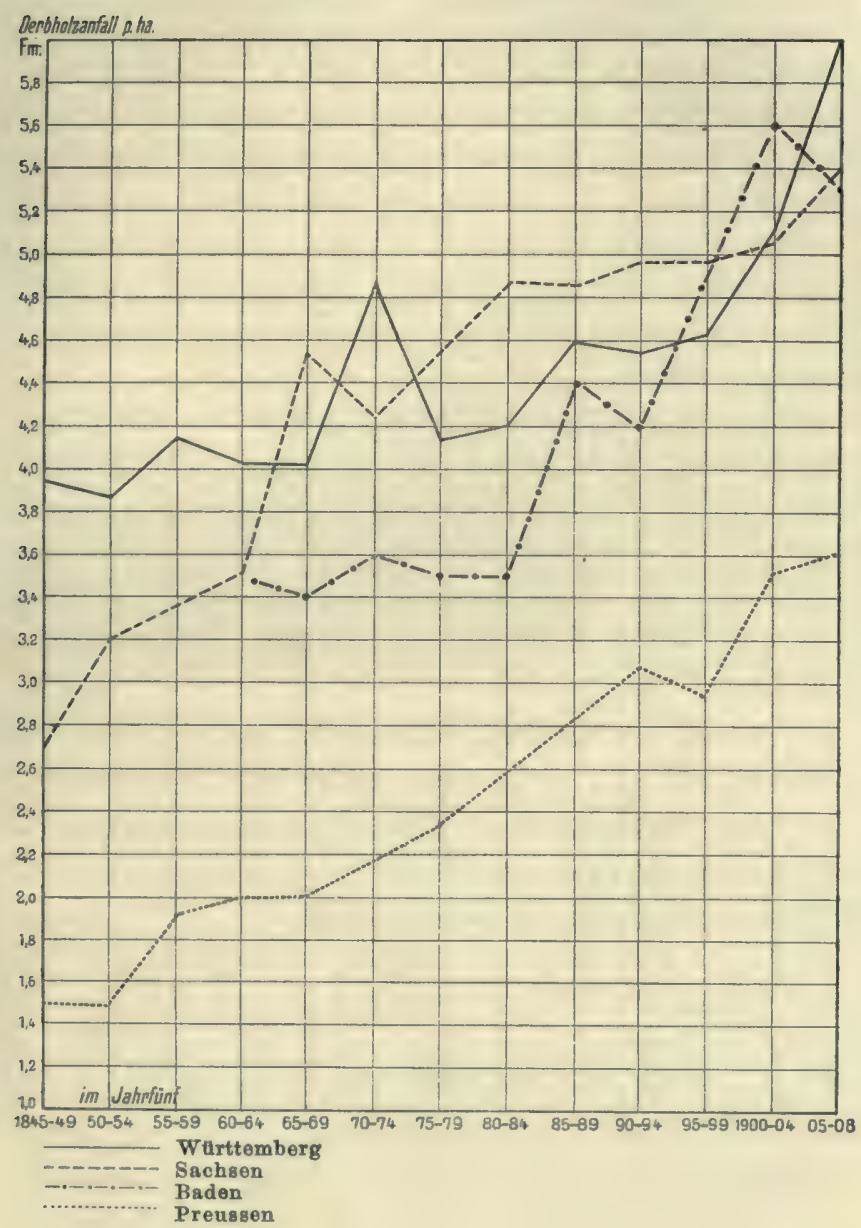


Diese Berechnung gibt, wenn auch nicht ganz einwandfrei, doch ein ungefähres Bild der Verteilung des Reinertragszuwachses auf den Massen- und den Geldwerts-Komponenten; der erstere schlägt vor bei Preußen und Sachsen, der letztere bei Württemberg.

Die in Fig. 1 zum Ausdruck kommende stetige Nutzungserhöhung scheint die gelegentlich ertönenden Eulenrufe ${ }^{\mathbf{1}}$ ) von der Rückgängigkeit der Waldwirtschaft Lügen zu strafen und mehr dem Optimismus derer Recht zu geben, welche an die Steigerungsfähigkeit ihrer Erträge glauben und in der bisherigen Aufwärtsbewegung gewissermaßen eine gesetzmäßige Erscheinung sehen.

So sagt M a $\mathrm{rtin}{ }^{2}$ ): Trotzdem (nämlich trotz Cottas Pessimismus) gilt die Regel, daß die Menge der Erzeugnisse zunimmt, für das ganze Gebiet der Bodenkultur . . . . . . und Dr. Eberhard ${ }^{3}$ ) will offenbar mit Bezug auf den wuirttembergischen Staatswald trotz seiner gelegentlichen Hinweise auf die Rückgängigkeit größerer Bodenflächen in einzelnen Teilen des Schwarzwalds (Enztal) die seither wahrzunehmende Nutzungssteigerung auch für die Zukunft in Anspruch genommen wissen, da die Waldungen im vergangenen Jahrhundert ertragsreicher gemacht worden seien.

Die schon erwähnten literarischen und teilweise parlamentarischen Fehden wegen der Höhe der Abnutzungssätze und der Altholzvorräte in Bayern, Württemberg und Baden zeigen ja, daß der Leistungsfähigkeit der Waldwirtschaft vielfach noch wesentlich mehr zugetraut wird.

Will man nun, nach der eingangs angegebenen Methode, aus der seitherigen Ertragssteigerung heraus über die Frage nach der Steigerung des Ertragsvermögens entscheiden, so müßte man zunächst die Wirkungen feststellen, welche die bisherige Holzmassenabnutzung auf den Zustand des Waldes ausgeübt hat, d. h. di e Ertrags statis tik in Beziehung zu den Waldinventarauf-

fläche, wie es bis 1879 in der Statistik gehandhabt wurde; der Vergleichbarkeit halber wurden die Zahlen von 1880 an entsprechend reduziert.

1) So Cotta (vergl. Martin, Statik S. 168), v. Benth e im (Anregungen zur Fortbildung u. s. f. Trier 1901 S. 17).

2) Statik S. 168.

3) S. A. F. und J. Z. 1910 (Augustheft) S. 298. 
$\mathrm{n}$ a h m e n s e tz en. Zu diesem Zweck werden solche Forstverwaltungen näher ins Auge zu fassen sein, deren Forsteinrichtungswerke auf Vorratsberechnungen aufgebaut sind (Baden) oder wo zur Kontrolle des auf andere Weise (nach der Flächenabnutzung) ermittelten Hiebssatzes derartige Erhebungen angestellt werden müssen (Sachsen, Hessen, Oesterreich).

a) Untersuchungen auf Grund der Statistik der badisehen Staatsforstrerwaltung.

Nach den Anlagen 8-10 der Statistischen Nachweisungen des Großherzogtums Baden 1907 (bearbeitet aus Anlaß der deutschen Forstversammlung in Heidelberg) sind in der folgenden Tabelle (Tab. 1) die entsprechenden Zahlen über Vorrat, Zuwachs und jährlichen Abgabesatz der Hochwaldsbetriebsklasse für die Jahre 1862, 1876, 1888 und 1902 zusammengestellt; die allmähliche Zunahme der bezüglichen Größen ist durch Verhältniszahlen berechnet auf das Jahr 1862 (= 100 gesetzt) angedeutet.

Tabelle 1.

(Aus der Forststatistik Badens)

\begin{tabular}{|c|c|c|c|c|c|c|c|c|c|c|}
\hline \multirow[t]{2}{*}{ Jahr } & \multicolumn{2}{|c|}{$\begin{array}{l}\text { Holzvorrat } \\
\text { auf } 1 \text { Hektar }\end{array}$} & \multicolumn{2}{|c|}{$\begin{array}{c}\text { wirkl. Haupt- } \\
\text { bestandszu- } \\
\text { wachs } \\
\text { auf } 1 \text { Hektar }\end{array}$} & \multicolumn{2}{|c|}{$\begin{array}{l}\text { jahrl. Gesamt- } \\
\text { Abgabesatz } \\
\text { auf } 1 \text { Hektar }\end{array}$} & \multicolumn{2}{|c|}{$\begin{array}{c}\text { Hievon } \\
\text { Haubarkeits- } \\
\text { nutzung }\end{array}$} & \multicolumn{2}{|c|}{$\begin{array}{l}\text { Zwischen- } \\
\text { nutzung. }\end{array}$} \\
\hline & $\mathrm{Fm}$ & |Verh.Z. & $\mathrm{Fm}$ & Verh.Z. & Fm & Verh.Z. & $\mathrm{Fm}$ & Verh.Z. & Fm & |Verh.Z. \\
\hline 1862 & 218 & 100 & 4,3 & 100 & 4,5 & 100 & 3,8 & 100 & 0,7 & 100 \\
\hline 1876 & 223 & 102 & 4,3 & 100 & 4,4 & 98 & 3,7 & 97 & 0,7 & 100 \\
\hline 1888 & 244 & 112 & 4,5 & 105 & 4,75 & 106 & 3,6 & 95 & 1,15 & 164 \\
\hline 1902 & 280 & 124 & 4,9 & 114 & 5,9 & 131 & 4,3 & 113 & 1,6 & 229 \\
\hline
\end{tabular}

Man ersieht aus der Tabelle, daß Holzvorrat, Zuwachs und Abnutzungssatz zugenommen haben; die Haubarkeitsnutzung ist zwar zeitenweise zurückgegangen, dafür haben die Zwischennutzungen höhere Massenerträge abgeworfen. Die Zahlen der Tabelle dürfen aber nicht kritiklos zur Berechnung der Ertragsfähigkeit herangezogen werden; insbesondere ist Anla $B$ vorhanden, die Vorrats- und $\mathrm{Zuwachs}$ an- 
gaben der badischen Statistik zu beanstanden; wenigstens haben sich neuerdings zahlreiche Stimmen erhoben, welche auf die schwachen Punkte jener Zahlen aufmerksam machen; die Mängel der badischen Forsttaxation sind, abgesehen von früherer Beurteilung durch $\mathrm{E} n \mathrm{~d} r \in \mathrm{s}^{\mathbf{1}}$ ), besonders durch die Verhandlungen der badischen Forstversammlung ${ }^{2}$ ) in Mannheim 1907 (Thema: „Der heutige Stand der Forsteinrichtungsfrage" etc.), ferner durch die Ausführungen von $\mathrm{N} u ̈$ s s $l \mathrm{e}^{3}$ ) und $\mathrm{Phili} \mathrm{p}^{4}$ ) beleuchtet und in ziemlich überzeugender Weise dargetan worden. Daß der $\mathrm{H}$ a $\mathrm{u} \mathrm{pt}$ b e s t and s z uw a chs kein brauchbarer Maßstab für die Leistungsfähigkeit einer fortgeschrittenen Waldwirtschaft sein kann, ist ja auch von anderen Autoren, so $\mathrm{Martin}{ }^{5}$ ) und $\mathrm{Schwap}$ p a ch (Fichte 1902) ausdrücklich betont und bewiesen worden. Die Vorratsberechnungen ferner sind wegen mangelnder Einheitlichkeit des Ermittlungsverfahrens nur von sehr beschränkter Zuverlässigkeit; denn während früher die Holzvorräte nach ihrem ,tatsächlichen Vorhandensein“ ermittelt wurden (F.Zentrbl. 1907 S. 155) ist man in neuester Zeit allmählich dazu übergegangen, die Holzvorräte nach Durchschnittszuwachs und Alter zu berechnen. Diese ziemlich zweifelhafte Ermittlungsart und die Ungleichheit der Berechnungsweise wirken zusammen, um die an sich sehr interessanten Notizen über die Inventaraufnahmen der badischen Staatsforstverwaltung als wenig zuverlässig, jedenfalls nicht als beweiskräftig erscheinen $\mathrm{zu}$ lassen. Aber angenommen, die Zahlen der Tab. 1 enthalten keine erhebliche Unrichtigkeit, so könnte man daraus schließen, daß die seitherige Nutzungssteigerung (bis 1902) jedenfalls $\mathrm{nicht}$ auf Kosten des

1) 3. Heft der Mündener Forstl. Hefte 1893.

2) Vergl. die Besprechungen in F. Zentrbl. $1907 \mathrm{~S} .546 \mathrm{ff}$., ferner in Fies er (a. a. O.) S. $99 \mathrm{ff}$.

3) Vergl. F. Zentrbl. 1907 S. $143 \mathrm{ff.}$

4) Vergl. die forstl. Verhältnisse Badens (Freiburg 1909).

5) Vergl. insbesondere, ,Kritische Vergleiche“" Z. f. F. und J. W. 1902 S. 138. 
Massen vor rats gegangen ist, viclmehr offenbar nicht stark genug eingesetzt und deshalb zu Vorratsanhäufungen geführt hat. Die stetige Zunahme des Vorrats, wie auch der Abstand zwischen $\mathrm{Haubarkeitszuwahs-}$ und $\mathrm{Nut}$ z ung zeigen, daß der wirkliche laufendjährliche Zuwachs während der ganzen Zeit offenbar nie genutzt worden ist; $o b$ er jeweils in voller Höhe hätte genutzt werden können ist freilich, mangels einer Altersklassennachweisung, nicht ersichtlich; dagegen kann aus der verhältnismäßig stärkeren Zunahme des Vorrats (Hauptbestandsvorrat) im Vergleich zur $\mathrm{H}$ a u b a r keitsnutzung, also a us dem Sinken des, von Eberbach ${ }^{1}$ ) in den forstlichen Sprachgebrauch eingeführten, Massenz ins f u B es $\left(\right.$ von $\frac{3,8}{218} \times 100=$ ca. 1,8 auf $\frac{4,3}{280} \times 100$ $=$ ca. $1,5 \%$ ) a u allmähliche Erhöhung des tatsächlichen Abtriebsalters (des mittleren Umtriebs) geschlossen werden, d. h. sofern diese Aenderung der Wirtschaftsweise nicht ausdrücklich beabsichtigt war, auf Nutzungseinsparungen. Der ,Massenzinsfuß $B^{\text {c }}$ eignet sich recht wohl zur Beurteilung des Einflusses der seitherigen Abnutzungssätze auf den Waldzustand in dem eben angedeuteten $\operatorname{Sinn}^{1}$ ).

Das Ergebnis des der ba dis chen Statistik entnommenen Beispiels ist somit ein negatives, insofern wir $\mathrm{k}$ e i $\mathrm{n} \mathbf{e} \mathbf{n}$ sicheren Aufschluß über die Zunahme der E r t r a g s f ä h i gk e it daraus entnehmen können; immerhin läßt der Abstand

1) Die $\mathbf{E}$ b e r b a $\mathrm{ch}$ sche Lehre vom Massenzinsfuß ist im F. Zentrbl. 1907 S. $552 \mathrm{ff}$., 1908 S. 368 ff. sowie in F i e s e r (a. a. O.) S. 104 u. ff. erläutert; ob diese Verhältniszahl als selbständiger Weiser der $\mathbf{k}$ ü $\mathbf{n} \mathbf{f} \mathbf{t}$ i g e $\mathbf{n}$ Hiebssätze dienen kann, dürfte vorläufig zum mindesten als zweifelhaft erscheinen (vergl. Kritik von $H$ a us ath im F. Zentrbl. 1907 S. 551 ff.).

Forstwirtschaft. V. Di et exich, Elemente d. Wertsmehrung. 
zwischen Haubarkeitsnutzung und Haubarkeitszuwachs (nach der Statistik von 1902) vermuten, daß noch weitere Steigerung des Massenertrags im Lauf der weiteren Entwicklung zu erwarten sein dürfte.

b) Untersuchungen a uf Grundstatistischer Angaben aus der sächsischen Staatsforstverwaltung.

Zuverlässigere Anhaltspunkte zur Beurteilung der jeweiligen Waldertragsfähigkeit bietet die Forststatistik der s ä c h s is chen Staatsforstverwaltung; dank der schon seit lange durchgeführten Zentralisation des Forsteinrichtungsdienstes verfügt diese Verwaltung über ein umfassendes, nach einheitlicher Rechnungsmethode ermitteltes Zahlenmaterial betr. Holzvorrat und Zuwachs, umso zuverlässiger, weil nicht formelmäßig aus angenommenen Zahlen abgeleitet, sondern unmittelbar durch Einschätzung seitens geübter Taxatoren erhoben. Wir besitzen eine vorzügliche, aus dem Schoß der Forsteinrichtungsanstalt stammende statistische Arbeit ${ }^{1}$ ) ,Die Entwicklung der Staatsforstwirtschaft im Königreich Sachsen", welcher die folgenden Angaben über Holzvorrat und $\mathbf{A b}$ nutzungssätze entnommen sind.

Tab. 2.

\begin{tabular}{|c|c|c|c|c|c|c|}
\hline \multirow{3}{*}{ Zeitraum } & \multirow{2}{*}{\multicolumn{2}{|c|}{$\begin{array}{c}\text { Holzvorrat } \\
\text { (Gesamtmasse) }\end{array}$}} & \multicolumn{4}{|c|}{ Abnutzungsmasse } \\
\hline & & & \multicolumn{2}{|c|}{ Derbholz } & \multicolumn{2}{|c|}{ Gesamtmasse } \\
\hline & $\mathbf{F m}$ & Vergl. - Zife. & Fm & Vergl.- Ziff. & Fm & Vergl. - Ziff. \\
\hline $1844 / 53$ & 152 & 100 & 3,01 & 100 & 3,76 & 100 \\
\hline $1854 / 63$ & 162 & 107 & 3,44 & 114 & 4,18 & 111 \\
\hline $1864 / 73$ & 177 & 117 & 4,28 & 143 & 5,18 & 138 \\
\hline $1874 / 83$ & 189 & 124 & 4,72 & 157 & $\mathbf{5 , 9 8}$ & 159 \\
\hline $1884 / 93$ & 187 & 124 & 4,88 & 163 & 6,03 & 160 \\
\hline$\left.{ }^{2}\right) 1894 / 1903$ & 189 & 124 & 4,97 & 165 & 6,03 & 160 \\
\hline
\end{tabular}

1) Sonderabdruck aus dem Tharandter Jahrbuch 47. Bd. 1897.

2) Ergänzt nach den alljährlich im Thar. Jahrb. erscheinenden Mitteilungen über die Ergebnisse u. s. f. 
Im Vergleich zu den Ergebnissen der badischen Statistik (Tab. 1) fällt die erheblich stärkere Zunahme der Massenerträge überhaupt, sowie insbesondere im Verhältnis zur Holzvorratsmehrung auf; das Anwachsen des Massenzinsfußes von $\frac{3,76}{152} \times 100=2,5 \%$ auf $\frac{6,03}{189} \times 100 \%=3,2 \%$, weist auf a $11 \mathrm{mähliche} \mathrm{Herabsetzung} \mathrm{der} \mathrm{Umtriebs-}$ $\mathrm{z}$ e it hin. Diese Annahme findet ihre Bestätigung auf S. 7 der genannten Statistik, wo es heißt: ,Die Flächenabnutzung“" (nicht näher ausgeführt) ,des Jahrzehnts 1864/73 entspricht einem 116jährigen Umtrieb, diejenige von 1874/83 einem 90jährigen, die von 1884/93 einem 85jährigen Umtrieb, während als normal ein $80 j a ̈ h r i g e r$ Umtrieb angenommen werden kann." Daneben dürfte aber auch, da trotz Umtriebsherabsetzung der Holzvorrat zugenommen hat, a u f V o r g än ge der Zuwachssteigerung zu sehließen sein. Als Beleg hiefür mag die Bonitäten-Ueberschrift Tab. 3 jener Arbeit dienen, wonach die geringsten $\mathrm{B}$ estandes bon ität en - 4. und namentlich 5., - ferner die Blößen, im Flächenanteil zu Gunsten der besseren zurückgegangen sind. Die Zuwachsverhältnisse selbst sind nur für den Zeitraum 1884/93 dargelegt; man kann sich aber über den seitherigen Zuwachsgang durch folgende Erwägung ein ungefähres Bild machen: A ls wirklicher, 1 a ufender $\mathrm{Zuw}$ a c h s e in es $\mathrm{Z}$ eit a bs chnitts (z. B. der 10jährigen Perioden, wie sie in Tab. 2 oben gebildet sind) $\mathrm{kann} \mathrm{doch} \mathrm{wohl}$ die Gesamtnutzung vermehrtoder vermindert um die Vorratszu- bezw. abnahmeangenommen werden, als ${ }^{1}$ )

$1 \mathrm{dz}_{10}=\mathrm{N}_{10}+\mathrm{V}_{\mathrm{n}+10}-\mathrm{V}_{\mathrm{n}}$.

Nach dieser Rechnungsweise (,,durch Vergleich zweier Inventaraufnahmen", $\mathrm{Z}=\mathrm{V}_{1}-\mathrm{V}_{2}+\mathrm{N}$ ) bemißt auch die ,Kontrollme-

1) $\mathrm{ldz}_{10}=$ durchschnittlicher laufendjährlicher Zuwachs der 10 jährigen Periode, $\mathrm{N}_{10}=$ Gesamtnutzung, $\mathrm{V}_{\mathrm{n}}=$ Vorrat zu Beginn derselben, $\mathbf{V}_{\mathbf{n}}+10=$ Vorrat zu Beginn der nächsten Periode. 


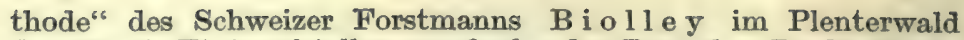
den für die Etatsaufstellung maßgebenden Zuwachs. Dr. M. W e r$\mathrm{n}$ i $\mathrm{c} \mathrm{k}^{1}$ ) hat die Kontrollmethode eingehend besprochen und dabei auch gewisse, von verschiedener Seite geltend gemachte, Bedenken zu Wort kommen lassen; doch hat sie selbst einem gewiegten Spezialisten auf dem Gebiet der Ertragslehre wie Fl u r y, das Urteil abgewonnen (S. 358 A. F. und J. Z. 1910), daß sie , das Beste sei, ,was wir für die Einrichtung des Plenterwaldes bis jetzt be-

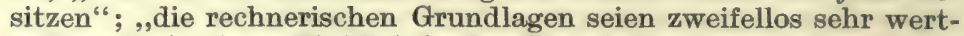
voll, weil sie einen Einblick in den Entwicklungsgang einer jeden Abteilung gewähren". Sie bietet also gerade das, was wir hier, zwar nicht für die einzelne Abteilung, aber für das Ganze einer Betriebsklasse oder eines größeren Waldverbands erforschen möchten. Die Betriebsklasse trägt ja auch, sofern sie alle Bestandesalter umfaßt, gewissermaßen einen dem Plenterwald eigentümlichen Charakterzug. Ja es scheint, als ob sich jene Formel auf eine ganze Hochwaldbetriebsklasse noch viel besser anwenden läßt, als auf den einzelnen Plenterwald; denn die Ungenauigkeit der Inventaraufnahmen, welche von Fl u r y als gewichtiger Anstand geltend gemacht wird, trifft auf sie viel weniger $z u$, ,da die Ausgleichung der Fehler (nach Flu r y s ${ }^{2}$ ) eigener Ausführung) bei Anwendung der Kontrollmethode für große Flächen" möglich ist. Die übrigen Bemängelungen der Formel, welche von W e r$\mathbf{n}$ i c k erwähnt werden, gelten großenteils nicht so sehr ihrem Prinzip als der Art und Weise ihrer Anwendung (Benutzung eines ,tarif conventionnel unique" und, ,der Sylve", Art der Ausscheidung von Stärkeklassen, Nichtberücksichtigung der sog. ,,Nebenmasse"); einige Beanstandungen sind nicht zutreffend, so die (von W e r n i c k abgetane) Einwendung (S. 354) $\mathrm{Ch}$ ris t e $\mathrm{n} \mathrm{s}$, welcher auch d e $n$ Zuwachs berücksichtigt wissen will, ,der an den geschlagenen Vorräten noch erfolgt wäre", und ebenso die von W e r n i c k selbst der Formel unterschobene Unstimmigkeit bezüglich des Zeitpunkts der Nutzungserhebung (S. 355). Dieser Gesichtspunkt spielt allerdings, wie ganz richtig ausgeführt wird (S. 357), f ür B e m e s s ung d es Zuwachsprozents e i $\mathrm{n}$ e Rolle, nicht aber für Veranschlagung des a b soluten $\mathrm{Zuw}$ a c h s etrags. Wernick fällt in den entgegengesetzten Fehler wie $\mathrm{Ch}$ riste $\mathrm{n}$, indem er nur den Zuwachs des sog. Z u k u $\mathrm{ntsm}$ at e ri a ls (einschl. des ,Zugangs zur Hauptmasse") bei der Zuwachsberechnung gelten läßt. Wenn wir erfahren wollen, was a 11 es im Lauf der Periode zugewachsen ist, muß aber doch auch d e r Zuwachsteil berücksichtigt werden, der bis zum Augenblick der Nutzungserhebung (im Nachhaltbetrieb auf Periodenmitte konzentriert zu denken) an dem hiefür bestimmten Material sich angelegt hat (von W e r-

1) ,Plenterwald eine Studie“" von Dr. M a r t i n W e r n i c k (Juli-Oktoberheft der A. F. und J. Z. 1910, vergl. insbesondere den Abschnitt über Zuwachsberechnung S. 315 f. und die Beurteilung der Methode S. 353 ff.).

2) Vergl. ebenda S. 357. 
n i c k mit ZN bezeichnet). Somit berechnet sich bei Anwendung der Formel auf die Hochwaldbetriebsklasse der Gesamtzuwachs

des Wirtschaftszeitraums als ${ }^{1}$ ) -

$\mathrm{G}$ (bezw. I d z) $=\mathrm{V}_{2}-\mathrm{Y}$;

$\mathrm{Y}$ aber ist $=\mathrm{V}_{1}-(\mathrm{N}-\mathrm{ZN})$ somit

$\mathrm{G}=\mathrm{V}_{2}-\left[\mathrm{V}_{1}-(\mathrm{N}-\mathrm{ZN})\right]=\mathrm{V}_{2}-\mathrm{V}_{1}+\mathrm{N}-\mathrm{ZN}+\mathrm{ZN}=\mathrm{V}_{2}$ $-\nabla_{1}+\mathbf{N}$ (q. e. d.).

Die rechnerische Richtigkeit der Zuwachsformel dürfte sonach nicht zu beanstanden sein, ihre Anwendung auf die ganze Hochwaldbetriebsklasse aber wesentlich zuverlässigere Resultate als im einzelnen Plenterwald ergeben, zumal innerhalb des Bereichs einer Forstverwaltung wie der $\mathrm{s}$ ä $\mathrm{chs}$ is $\mathrm{chen}$, wo einheitliche und durch erprobte Verfahren ermittelte Inventaraufnahmen schon lange in Uebung stehen.

Zum Zweck der Inventaraufnahme und Zuwachsberechnung zerlegt die Kontrollmethode das Bestandesmaterial nach Holzarten und Stärkeklassen (Starkholz, Mittelholz, Schwachholz) A. F. und J. Z. 1910 S. 315 f. - ; bei sinngemäßer Anwendung derselben auf die Hochwaldbetriebsklasse müBte entsprechend der Vorrat und Zuwachs getrennt nach A.ltersklassen ermittelt werden. Hierauf wird im weiteren Verlauf der Besprechung noch näher einzugehen sein.

Will man genaue Untersuchungen anstellen, so wird für größere Wirtschaftsverbände allerdings der Zuwachs nicht unmittelbar nach der eben besprochenen Methode berechnet werden dürfen, weil die Inventaraufnahme, die als Zusammenfassung der während eines längeren (im allgemeinen 10jährigen) Zeitraums in den einzelnen Revieren ermittelten Vorräte erscheint, sich $\mathrm{n} i \mathrm{ch} t$ auf einen b e s $\mathrm{t}$ i $\mathrm{m} \mathrm{m}$ t e n (gemeinsamen) Zeitpunkt bezieht. Man wird deshalb den laufenden Zuwachs größerer Waldverbände als die Summe der Zuwüchse aller einzelnen Reviere berechnen müssen. Um aber doch jene statistischen Vorratsangaben aus Sachsen, wenigstens als Rechenbeispiel, hier benützen zu können, wur-

1) Nach W e r n i c k s Bezeichnung bedeutet $V_{1}$ das gesamte Anfangsmaterial, $\mathbf{Y}$ das hierin enthaltene Zukunftsmaterial (d. h. das am Ende der Periode noch vorhandene), $\nabla_{2}$ das Endmaterial (einschließlich des lediglich mit der Nichtberücksichtigung der ,Nebenmasse" zusammenhängenden sog. ,Zugangs zur Hauptmasse ") $\mathbf{N}$ die Nutzung und ZN den Zuwachs, welcher sich an den genutzten Stämmen, diese auf $\mathbf{N}$ bringend, bis zum Zeitpunkt der Nutzung angelegt hat. 
den durch Interpolation aus den für d i e $\mathrm{M}$ i t t e der 10jährigen Zeitabschnitte maßgebenden Vorratsgrößen der Tab. 2 (oben) die entsprechenden Beträge $\mathrm{f} \ddot{\mathrm{u}} \mathrm{r} \mathrm{B}$ e g i n $\mathrm{n}$ derselben (also die Jahre 1844, 54, 64 u. s. f.) ermittelt. Hieraus ergibt sich folgende Reihe (gegebene Größen mit gewöhnlichem, interpolierte mit fettem Druck wiedergegeben)

bezogen auf das Jahr: 18441849185418591864186918741879 $\begin{array}{lllllllll}\text { Vorrat auf } 1 \text { ha in Fm: } & 152 & 157 & 162 & 169,5 & 177 & 183 & 189\end{array}$ bezogen auf das Jahr: 1884188918941899 Vorrat auf 1 ha in Fm: $188 \quad 187 \quad 188 \quad 189$

Die Zuwüchse der 10jährigen Zeiträume 1854/63 ff. erhält man nun als Differenz der interpolierten Vorratsgrößen zuzüglich des 10fachen Betrags der in Tab. 2 vorgetragenen Abnutzungssätze (Gesamtnutzung); entsprechend wurden auch die $\mathrm{Zu}$ wachsbeträge der Jahrfünfe 1849/53 und 1894/99 ermittelt. Tab. 3.

\begin{tabular}{|c|c|c|c|c|c|c|c|}
\hline \multirow{3}{*}{$\begin{array}{l}\text { Zeit- } \\
\text { raum }\end{array}$} & \multicolumn{7}{|c|}{ je bezogen auf 1 ha Waldfläche } \\
\hline & \multirow{2}{*}{$\begin{array}{c}\frac{V_{\mathbf{n}}+{ }^{10}}{V_{\mathbf{n}}} \\
\mathrm{Fm}\end{array}$} & \multirow[b]{2}{*}{$\begin{array}{l}\mathbf{A}_{10} \\
\mathbf{F m}\end{array}$} & \multicolumn{2}{|c|}{$\begin{array}{c}\text { laufend. jahrl. } \\
\text { Durchsch. Zuwachs }\end{array}$} & \multicolumn{3}{|c|}{ Verhaltniszahlen des } \\
\hline & & & $\begin{array}{c}\text { Der } \\
\text { Periode } \\
\text { Fm }\end{array}$ & $\begin{array}{l}\text { berech. } \\
\text { auf } 1 \mathrm{~J} \text {. } \\
\text { Fm }\end{array}$ & Vorrats & $\begin{array}{c}\mathrm{Zu}- \\
\text { wachses }\end{array}$ & $\begin{array}{l}\text { Abnut- } \\
\text { zungs- } \\
\text { satres }\end{array}$ \\
\hline $1849 / 53$ & 5,0 & 18,8 & 23,8 & 4,76 & 97 & 88 & 90 \\
\hline $1854 / 63$ & 12,5 & 41,8 & 54,3 & 5,43 & 100 & 100 & 100 \\
\hline $1864 / 73$ & 13,5 & 51,8 & 65,3 & 6,53 & 108 & 120 & 124 \\
\hline $1874 / 83$ & 5,0 & 59,8 & 64,8 & 6,48 & 117 & 119 & 143 \\
\hline $1884 / 93$ & & 60,3 & 60,3 & 6,03 & 119 & 111 & 144 \\
\hline $1894 / 98$ & 0,5 & 30,2 & 30,7 & 3,07 & 119 & 113 & 144 \\
\hline
\end{tabular}

Durch die Tabelle findet die oben vertretene Annahme einer $\mathrm{Zuw}$ a chssteigeru ng im Bereich der sächsischen Staatswaldungen weitere Bestätigung; der mit dem Zeitraum 1884/93 einsetzende Rückschlag dürfte wohl auf die ,,5000 ha umfassenden Ankäufe" zurückzuführen sein, womit in jener statistischen Schrift (,Die Entwicklung“" u. s. f. S. 8 f.) der unbedeutende 1884/93 zu konstatierende Vorratsrückgang erklärt wird.

Weiterhin zeigt die Tabelle, daß von 1884 a n d e r I a u f e ndjährliche Zuwachs voll genutzt wurde, nachdem bis dahin die Nutzung sich durchweg unter dieser Obergrenze gehalten hatte. Zu dem gleichen Ergebnis kommt der Verfasser jener Statistik, indem er schreibt (S. 10): ,Aus alledem läßt sich schliessen, da $B$ die gegenwärtige Abnutzung den Zuwachs nahezu absorbiert"; es betrug zwar der, ,jährliche Zuwachs an 
A btriebsnutzung a uf 1 has (bezogen auf den Zeit-

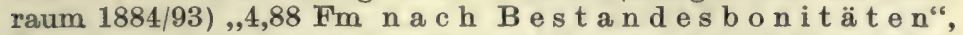
der, ,tatsächliche Verschlag an Abtriebsnutzung dagegen nur 4,51 F m.6. Mit Bezug hierauf heißt es aber (S. 10) weiter: ,Man wird jedoch bei der Unsicherheit, die derartigen Zuwachsberechnungen unvermeidlich anhaftet, sich schwerlich auf dieselben stützen." $\mathrm{DaB}$ mit dem $\mathrm{H}$ a u b a r$\mathrm{k}$ e i $\mathrm{t} \mathrm{s} \mathrm{z}$ w a $\mathrm{ch} \mathrm{s}$ - jedenfalls unter komplizierteren Waldverhältnissen als sie Sachsen aufweist, bei vorwiegendem Mischwald, ungleichaltrigen Bestandesformen u. s. f. - ferner bei intensiver Bestandeserziehung heutzutage nicht mehr auszukommen ist, wurde schon oben erwähnt ${ }^{1}$ ).

Ueberblicken wir die bisher auf Grund jener sächsischen Statistik festgestellten Mehrungserscheinungen, so kann als ein Element der Steigerung des Massenertragsvermögens jedenfalls die zuletzt besprochene $\mathrm{Z}$ u w a c h s f ö r d e r u n g nachgewiesen werden, wie dies ja auch für Baden zutrifft, sofern der Hauptbestandszuwachs als Maßstab hiefür angenommen werden darf. Auf einen weiteren Mehrungsvorgang deutet in der sächsischen Statistik der Umstand hin, daß das fortgesetzte Zurückbleiben der Nutzung hinter dem laufenden Zuwachs $n$ icht $z u$ einer Altholzanhä ufung, wie in Baden, führte, sondern mit a $11 \mathrm{mäh} \mathrm{i}$ e h er Herabsetzung der Umtriebszeit Hand in Hand gegangen ist; daraus läßt sich doch offenbar schließen, $d$ a $B$ der laufende Zuwachs in früheren Zeiträumen gar nicht im vollen Betrag hätte g e n u tzt werden d ürfen, weil entweder das Altersklassenverhältnis Störungen aufzuweisen hatte oder weil die Bestockung der nutzbaren Bestände mangelhaft war. Gerade in letzterer Hinsicht scheint eine $\mathrm{B}$ esseru $\mathrm{ng}$, so $\mathrm{mit}$ eine Mehrung der Ertragsfähigkeit, eingetreten zu sein; andernfalls hätte sich angesichts der Mindernutzung in früheren Zeiträumen eine Zunahme der Flächen

1) Vergl. auch insbesondere die diesbezüglichen Aeußerungen M a r t i n s (Z. für F. und J. W. 1902 S. 134 f.). M a $x$ t i f fübrt dort aus, daß ,man von der bestehenden Praxis“", der Behandlung des Zuwachses" beim preußischen und sächsischen Forsteinrichtungsverfahren unbefriedigt bleibe. 
haubarer Bestände herausgestalten müssen, was für die sächsischen Staatswaldungen nicht zutrifft; im Gegenteil ergibt sich aus Tabelle 2 (Altersklassenentwicklung) der ,Entwicklung der Staatsforstwirtschaft" usf. ein Flächenrückgang in der ältesten Klasse (1854/63: 14\%, 1884/93: 11\%) und das Verschwinden der gleichfalls, wenn auch in bescheidenem Maß, zur Erfüllung der Jahresnutzung in Betracht kommenden Mittel- und Niederwaldungen.

Inwieweit die Bestockung der nutzbaren Bestände sich gebessert hat, läßt sich aus jener Statistik nicht ersehen, weil sie keinerlei Angaben über die Verteilung des Vorrats auf die einzelnen Altersklassen enthält. Die sächsischen Einrichtungswerke geben hierüber Aufschluß ${ }^{1}$ ): denn zur Hiebssatzbegründung müssen für jede Altersklasse getrennt nach Betriebsklassen - die Bestandesbonität, der Vorrat und der wirkliche Zuwachs nach der Bonitierungsskala ${ }^{2}$ ) dargestellt worden. Man ist somit in der Lage, nicht nur die Vorratsentwicklung des einzelnen Reviers im ganzen, sondern auch das jeweilige MaB der Nutzbarkeit des $\mathrm{Zuwachses}$ zu verfolgen. Bezüglich der Höhe des laufenden Zuwachses selbst verfügt zwar die sächsische Forsteinrichtungsanstalt ${ }^{3}$ ) über ein reiches Zahlenmaterial gesondert nach Altersklassen; es müßte aber auch ein leichtes sein, nach der oben angegebenen Methode aus den eingehenden Vorratsangaben verglichen mit den Nutzungsergebnissen die jeweiligen Zu w üchseder Altersklassen $\mathrm{zu}$ berechnen, sofern nur die Buchung der Massenerträge in altersklassenweiser ${ }^{4}$ ) Ordnung erfolgte. J e d e n f a 11 s w ird

1) Beilagen C und E zu I. ,Revisionsbefund und Ergebnisse der Wirtschaftsführung."

2) Vergl. auch Dr. K ö nig, ,Die Altersklassen und ihre Bedeutung für die Nutzung im schlagweisen Hochwaldbetrieb" (S. $37-39$ ).

3) Vergl. M a r ti n, Z. für F. und J. W. 1902 S. 135.

4) Diese Art der Geschäftsbehandlung wurde schon von v. B e n theim in seiner sehr beachtenswerten Schrift ,An- 
jene Rechnungsweise unter wechselvolleren Waldverhältnissen die beste Lösung fürdie Fragenach derdurchsehnittlichen Leistungsfähigkeit der Waldwirtschaft a b geben.

Wie solche Erhebungen am einfachsten durchführbar sind, wird nachher noch zu zeigen sein; dagegen ist hier noch darauf aufmerksam zu machen, daß wir mit der Frage über die $\mathrm{N}$ u t zb a r m a c h u n g des Zuwachses an der Grenze der Wirkungssphäre des Massenkomponenten angelangt sind; denn für die Nutzbarkeit des Zuwachses sowohl in Form von Abtriebserträgen als durch Erhebung von Vornutzungen sind doch in erster Linie ökonomische, finanzielle Gesi c h t s p u nkte, d. h. im Gebiet des Geldwertskomponenten liegende, bestimmend. Das Maß der Nutzbarkeit hängt somit wesentlich auch von der Entwicklung des Geldwerts der Hölzer ab.

c) Untersuchungen auf Grund der württembergischen Forststatistik.

aa) An der Hand der Forsteinrichtungsstatistik.

Die Entwicklung des Holzvorrats und des laufenden (wirklichen) Zuwachses läßt die württembergische Statistik nicht verfolgen; neuerdings sind allerdings Versuche unternommen worden, den Holzvorrat, oder wenigstens die sog. Vorratsüberschüsse zu ermitteln ${ }^{1}$ ), ohne daß eine befriedigende Klärung

regungen zur Fortbildung von Forstwirtschaft und Forstwissenschaft im 20. Jahrhundert" (Trier 1901) S. 110 emapfohlen - vergl. auch unten $\mathrm{S}$. $39 \mathrm{f}$.

1) Vergl. die Kapitalwertsberechnung in der Anlage zum Forstetat für 1909/10, wo der Holzvorrat zu etwa 40 Mill. Fm veranschlagt wird, die Aufsätze von Oberforstrat M ü 11 e r ,Ueber die Holznutzung und den Altersklassenstand in den württ. Staatsforsten, sowie ,Ueber Holzvorratsüberschüsse etc." (A. F. und J. Z. 1909 August und September), ferner die Begründung zum Regierungsentwurf betr. das Forstreservefondsgesetz 1910 (s. Bericht hierüber im F. Zentrbl. 1910 Oktoberheft), endlich auch den Artikel von Dr. E b e r h a r d in A. F. und J. Z. 1910, Augustheft. 
über diese wichtigen Fragen eingetreten wäre; das darf allerdings nicht gerade wundernehmen, da ja auch in Baden, wie wir oben hörten, der Holzvorrat recht verschieden eingeschätzt wird, trotzdem er hier schon lange einen wesentlichen Bestandteil der Forsteinrichtungsgrundlagen bildet. Die Ergebnisse der Forsteinrichtung, für den gesamten Staatswaldbesitz, eingehend dargestellt in den Forststatistischen Mitteilungen 1908, erschöpfen sich fast ganz in Flächen-Ziff ern; ähnliche, wenn auch weniger ausführliche Arbeiten liegen vor vom Jahr 1894 und 1884, ferner in den Mitteilungen von 1887, wo die Grundlagen der Steuereinschätzung angegeben sind und endlich in der Schrift „,Die Forstlichen Verhältnisse Württembergs " von $\mathbf{1 8 8 0}^{1}$ ). Ueberblicken wir dieses statistische Material, so muß zunächst bemerkt werden, daß die Vergleichbarkeit der bezüglichen Zahlen und ihre Verwendbarkeit für die vorliegenden Untersuchungen nichteinwandfrei ist, weildie Grundlagender Forsteinrichtung meist durch ungenügend geschulte (jedenfalls nicht speziell vorgebildete) Taxatoren ohne einheitliche Leitung, weder zeitlich noch örtlichnach den gleichen Grundsätzen festgestellt.worden sind. Erst seit Mitte der 90er Jahre des vorigen Jahrhunderts wird die Ausscheidung nach Holzart, Alter, Bonität auf Anregung des um die württembergische Forsteinrichtung und Forstverwaltung hoch verdienten + Forstdirektors v. S p e id el gründlicher und eingehender - aber noch nicht einheitlich — vorgenommen ${ }^{2}$ ). Vorbehältlich dieser Einschränkung läßt sich

1) Vergl. insbesondere S. $177 \mathrm{ff} .(\S 49)$ und $185 \mathrm{ff}$. (§. 51).

2) Die schon von d. + Forstdir. v. S p e i d e l geplante Schaffung einer Forsteinrichtungsanstalt, wird wohl demnächst der Verwirklichung entgegengehen und die bisher vermiBte Einheitlichkeit anbahnen. 
aus der Forsteinrichtungsstatistik im einzelnen etwa folgendes entnehmen:

1. Die Uebersicht über die Vertretung der Holzarten ( $D_{1}$ der Statistik 1908) läßt in ihren Endsummen eine $\mathrm{merkliche} \mathrm{Zun}$ ahme der $\mathrm{Nadelholz-}$ bestockung erkennen (1908: Nadelholz 70, 1887: $64 \%$ der ertragsfähigen Holzgrundfläche); die e r trag sr e i c h e re n Nadelhölzer Fichte und Tanne weisen außerdem noch eine besondere Zunahme (von 50 auf $60 \%$ ) zu Ungunsten von Forche und Lärche auf. Diese Veränderung der Bestockungsverhältnisse bedeutet nun wohl ein Element der Wertsmehrung mit Bezug auf die Holzmassenleistung. Da aber nur der $\mathrm{n} u \mathrm{tz}$ b a r e Zuwachs für die jeweilige Ertragsfähigkeit maßgebend ist, muß

2. die Uebersicht über die Bestandesa ltersklassen zu Rat gezogen werden $\left(\mathrm{D}_{2}\right)$ : die Vertretung derselben im ganzen und getrennt nach den wichtigsten Holzartengruppen wird hier mit 20jähriger Altersklassenabstufung vorgetragen. Um die Veränderung gegenüber den früheren Erhebungen deutlich zu machen, ist am Schluß das Altersklassenverhältnis nach dem Stand von 1884 und 1894 angefügt. Außerdem kann man, unter Zuhilfenahme der anderen statistischen Quellen, die frühere Altersklassenverteilung auch getrennt nach den 3 Holzartengruppen: Fichte-Tanne, Forche, Buche zur Darstellung bringen.

Endlich könnte man auch noch den Anteil der Altersklassen je der einzelnen Holzart an der Gesamtfläche berechnen. Eine solche Berechnung wurde für Fichte und Tanne durchgeführt, um das $\mathrm{U}$ e berhand $\mathrm{n} \in \mathrm{h} \mathrm{m} \in \mathrm{n}$ der $\mathrm{N}$ adelholz bestockung besonders zum Ausdruck zu bringen. Aus eben diesem Grund wurden die entsprechenden Zahlen außer für den Gesamtstaatswaldbesitz, auch im einzelnen noch für die 2 Waldgebiete Alb und Unterland ermittelt, weil in diesen - L $\mathrm{a} u \mathrm{bholzg}$ ebieten - jener Vor- 
gang der Bestockungsänderung in besonderem Maß sich abspielt (Tab. 4): die Alb weist nach dem Stand von 1880 ca. 23, 1908 schon 37, das Unterland 1880: 18, 1908: 32\% Fichtenund Tannenwald auf.

Tab. 4. Altersklassen-Uebersicht im Verhältnis zur Gesamt $\mathrm{flä} \mathrm{ch}$.

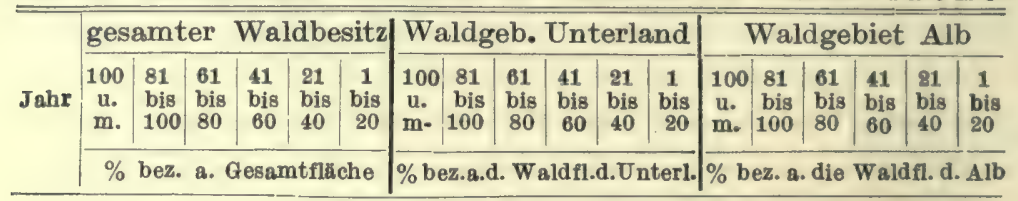

a) Der Fichten-Tannen-Bestockung.

\begin{tabular}{|l|l|l|l|l|l|l|l|l|l|l|l|l|l|l|l|l|l|l|}
1880 & 7,0 & 6,0 & 7,5 & 6,0 & 8,5 & 15,0 & 1,3 & 1,2 & 0,9 & 2,6 & 5,6 & 6,4 & 0,5 & 0,3 & 1,6 & 2,7 & 6.0 & 12,0
\end{tabular}

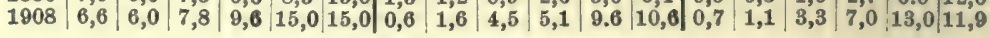
b) Der Gesamtbestockung.

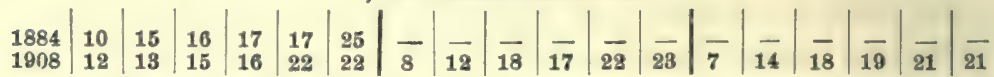

Aus der Uebersicht a) geht, zumal beim Vergleich mit der Gesamt-Altersklassentabelle, die deshalb unter b) angefügt ist, ganz unzweideutig hervor, $d$ a $\beta d i e$ FichtenTannenbestockung fortgesetzt zugenommen hat und in noeh höherem $M$ a $B$ in den jüngeren Altersklassen um sich greift; besteht doch die Altersklasse 4l-60jährig a uf der Alb z u 7/19, die 20-40 jährigezu 13/21, die 1-20jährige zu 12/21 a us Fichte und Tanne. Da $B$ dieser Vorgang als massenertragsteigerndes Elementeine bedeutsame Rolle spielt, bedarf keines weiteren Bewe is es. Genaue Berechnungen über die Wirkung dieser Wertsmehrungstendenz festzustellen, erlaubt uns freilich die württembergische Einrichtungsstatistik nicht, weil für die einzelnen Altersklassen weder eine $\mathrm{mittl}$ ere $\mathrm{B}$ estandesb o n i t ä $t$ angegeben ist, wie es in den sächsischen Forsteinrichtungswerken geübt wird, noch die von Dr. Kö nig ${ }^{1}$ ) (Die Altersklassen etc.) empfohlenen durchschnittlichen Werts-

1) a. a. O. S. 84 . 
zahlen berechnet sind. Tabelle $\mathrm{D}_{3}$ der neuesten Forststatistischen Mitteilungen enthält wohl

3. $\theta$ ine Uebersicht über die Standorts$\mathrm{k} l$ a s s e n, wie solche schon in den Jahren 1880/81 als Grundlage zur Einschätzung der in die Steuerkataster aufzunehmen-

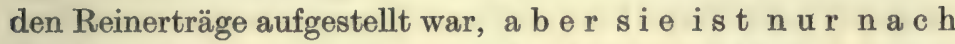
Holzarten, nicht $n$ ach Altersklassen gegliedert und gibt nur Standortsbonitäten an. Um die für die tatsächliche Ertragsfähigkeit allein maßgebende $\mathrm{B}$ estandesbonität einzuschätzen, ist man genötigt, Reduktionsfaktoren (den sog. mittleren Vollkommenheitsgrad) einzuführen, das heißt, der Rechnungswillkür Tür und Tor zu öffnen, die auch bezüglich der Annahme von Durchschnittsbonitäten für die einzelnen Altersklassen freies Spielfeld hat. Da $B$ man dietatsächliche jeweilige Nutzbarkeit eines Waldbesitzes nur an der Hand sorgfältiger Altersklassen-Aufstellung beurteilenkann, ist schon längst a $\mathrm{n}$ e $\mathrm{r} \mathrm{k}$ a $\mathrm{n} \mathrm{n} \mathrm{t}$ und wird neuerdings auch von badischen Forstleuten zur Reformierung ihres auf Vorratsmethoden beruhenden Einrichtungswesens gefordert ${ }^{1}$ ); di e will k ü rli c h e Einschätzung der Bestandesbonität einzelner Altersklassen steht aber mit der hiefür zu fordernden Sorgfalt nicht gerade i m E inklang ${ }^{2}$ ).

Ein Vergleich der Standortstabellen läßt wohl, wenigstens für Fichte und Tanne, eine Besserung erkennen, die auf $\mathrm{Zu}$ wachsmehrung hinweist; aber der Einfluß dieses Elements

1) cfr. N üs $s$ l e (F. Zentrbl. 1907 S. 143 ff.).

2) Die Instruktion für die Wirtschaftseinrichtung in den württ. Staats- und Körperschaftswaldungen nach der Fassung vom 25. VI. 1898 schreibt in Z. 5 c a lt e r s t u f e $\mathrm{n} w$ e is e U e b e rsicht der Standortsklassen vor; in der Forste i n $r$ i c h t u n g s t a $t$ is $t$ i $k$ ist diese Vorschrift aber $n$ i c ht beachtet worden. 
auf die dermalige Ertragsfähigkeit kann ohne al terskl a s s enweise Gliederung nicht ermessen werden.

4. Die Uebersicht über die Nutzungen und Ertragsverhältnisse (Tab. $D_{4}$ ) vermag in dieser Beziehung keine weitere Aufklärung zu bringen, weil in der früheren Einrichtungsstatistik nur die Massenabnutzung berücksichtigt war; a u ch die Leis tu $\mathrm{ngsf}$ ähigkeit der nach dem neuesten Stand zur Nutzung herangezogenen Flächen läßt sich nur in Bausch und Bogen berechnen, da die Ertragsziffern weder nach Holzart noch nach Altersklassegetrennt angegeben sind, während andererseits zur Beurteilung der altersklassenweise vorgetragenen Abnutzungs f $\mathrm{l}$ ä $\mathrm{e} \mathrm{h}$ e $\mathrm{n}$ Angaben über deren $\mathrm{H} \mathrm{ol} \mathrm{z-}$ artenverteilung und Bestandesbonität (bezw. Wertsziffer, oder Vollkommenheitsgrad und Standortsbonität) fehlen; $\mathrm{man}$ ist deshalb nicht einmal in der Lage, den Holzvorrat der zur Abnutzung heranstehenden Altersklassenzuverlässig berechnen zu können.

Die w ürttembergische Einrichtungsstatistik leidet an einseitiger Berücksichtigung des Flächenfaktors, bildet deshalb zwar ein unbegrenztes Uebungsfeld für allerhand Kalkulationen über Vorrat, Vorratsüberschüsse, Zuwachs und dergl., aber keine soliden Grundlagen zur Erforschung dieser Wertselemente. Alle Gutachten, welche lediglich auf jenen Tabellen der Forsteinrichtungs-Statistik aufgebaut sind, müssen deshalb mit Vorsicht aufgenommen werden, so vor allem die Begründung des Forstreservefondsgesetzes vom Jahr 1910 und die im Forstetat für 1909/10 gegebene Waldwertsberechnung. Aus einzelnen Forsteinrichtungswerken ${ }^{1}$ ) lassen sich - allerdings eben

1) So ist z. B. in dem Muster-Wirtschaftsplan für Bebenhausen, der den Mitgliedern der XXV. Versammlung deutscher Forst- 
nur für e in z eln e Bezirke - wesentlich genauere Anhaltspunkte entnehmen; aber mangels einheitlicher Organisation des Forsteinrichtungsdienstes gehen die zum Teil mit viel Fleiß und Mühe zusammengetragenen taxatorischen Berechnungen für das Ganze des Staatswaldbesitzes leider verloren.

Die empfohlene Vorsicht ist gegenüber der Einrichtungsstatistik umso mehr am Platz, als a u ch die Flä chengrundlagen a us den oben (S. 26) erwähnten Gründen kein rechtes Vertrauen einflößen $\mathrm{k}$ ö $\mathrm{n} n \in \mathrm{n}$, insbesondere was die Reduktion der Verjüngungsflächen des Schirmschlag- und Femelschlagbetriebs betrifft. Wird doch selbst von zuständiger Stelle - in der Begründung des Reservefondsgesetzes - mit Rücksicht auf letzteren Punkt die Richtigkeit der Angaben über die Abnutzungsflächen ${ }^{1}$ ) in Zweifel gezogen. Wenn die Vergleichbarkeit der neuesten und der älteren Flächenangaben, insbesondere betreffend die Altersklasseneinteilung beanstandet wird, könnte man sich wenigstens aus den neuesten Uebersichten heraus ein Bild des früheren Waldzustands rekonstruieren; aber auch diese von Oberforstrat $M \ddot{u} 11$ e $\mathrm{r}^{2}$ ) angewendete, immerhin zuverlässigere Rechnungsweise stößt auf Hindernisse in den statistischen Grundlagen; es fehlt $\mathrm{nämlich}$ eine genaue Nachweisung der erfolgten Flächenv e r ä nd er ung en: weder über die Art des $\mathrm{Zu}$ - oder $\mathrm{Ab}$ gangs an Fläche im ganzen, noch viel weniger über den Ein-

männer im Jahr 1897 gewidmet war, eine Uebersicht über Standortsbonität und Vollkommenheitsgrad wenigstens für 3 Altersklassen gegeben (vergl. auch die Ausführungen von Dr. K ö $\mathbf{n}$ i g , „Die Altersklassen" etc. S. 30 ff. und die vorhin zitierten Absätze der Württ. Einrichtungsinstruktion, die leider nicht allgemein befolgt werden).

1) ,Es muß nämlich darauf hingewiesen werden, daß die in den Wirtschaftsplänen vorgetragenen Abnutzungsflächen überall dann, wenn es sich nicht um reine Flächenabtriebe handelt, auf Schätzung beruhen und die Erfahrung lehrt, daß bei dieser Schätzung die Abnutzungsflächen meist zu nieder in Ansatz gebracht werden."

2) A. F. und I. Z. Aug. H. 1909. 
fluß dieser Verschiebungen auf das Altersklassenverhältnis erhalten wir Aufschluß 1): Aufforstungen staatseigentümlicher Wiesen, Oedungen etc., Zukäufe holzloser oder bestockter Waldungen, Abtretungen zu Wegbauten u. a., Exkatastrierung ertragsloser Flächen, all diese wichtigen Veränderungen sind in Dunkel gehüllt. Die Tragweite dieser Lückenhaftigkeit der Statistik mag nur an einem Beispiel beleuchtet sein:

In der Begründung des Reservefondsgesetzes heißt es auf S. 2, anschließend an den eben (s. S. 31) zitierten Satz:

,Dafür, daß die tatsächliche dermalige Abnutzungsfläche im Durchschnitt der Staatswaldungen des Landes höher ist als der ziffernmäßige Stand nach den Wirtschaftsplänen aufweist, zeugt der Umstand, daß schon bisher und zwar unter der Herrschaft einer noch namhaft niedrigeren Nutzung als es die heutige ist, sich die Flächenanteile der beiden jüngsten 20jährigen Altersstufen im Betrag von je $22 \%$ angesammelt haben".

Ehe solche Schlußfolgerungen gezogen werden, müßte erst eine genaue Nachweisung über die Flächen veränderung gegeben werden: Im Vergleich zu der 1884er Statistik läßt sich feststellen, daß die ertragsfähige Holzgrundfläche seither um $(186124-180881=) 5243$ ha zugenommen hat. Wenn auf S. 108 der neuesten Statistik Tab. D ${ }^{1}$ die für den Vergleich doch wohl nicht in Betracht kommende ,steuerbare Waldfläche nach dem Stand vom 1. April 1887 mit einer Flächenziffer von $186176 \mathrm{ha}$ dem damaligen Flächenstand gegenübergestellt ist, so wir d dadurch der tatsächlich in den letzten 20 Jahren durch Zukauf und A ufforstungen erfolgte Flächenzuwachs verschleiert. Aus den 2 Schriften: „Die Forstlichen Verhältnisse Württembergs" von 1880 und „Die Forstverwaltung Württembergs“" von Dr. F. G r an e r 1910 läßt sich der im Zeitraum 1880-1900 durch Erwerbungen erfolgte Flächenzuwachs abzüglich der Veräußerungen ziemlich genau feststellen: Nach S. 126 der letztgenannten Schrift berechnet sich für 1864-1900 der Ueberschuß an Erwerbungen auf (11 391-3374 =) $8017 \mathrm{ha}$; zieht man hiervon die entsprechende Flächensumme des Zeitraums 1864/1879 ab, nämlich laut S. 168 des ersteren Buchs $(6523-2419=)$ 4104, so bleiben für $1880 / 1900$ noch übrig $(8017-4104=) 3913 \mathrm{ha}$. D i es e r B et r a g a 11 e in macht schon mehr als $2 \%$ des ertragsfähigen Holzgrunds a us; über den Umfang der Aufforstungen früher ertragsloser oder in anderer Kulturart bewirtschafteter Flächen fehlt leider jeglicher Anhaltspunkt. Die Tatsache, daß die Erwerbungen größtenteils ,im abgeholzten Zustand oder

1) In dem M ü 1 l e r schen Aufsatz a. a. O. ist dieser Gesichtspunkt durch entsprechende Berichtigung der Altersklassenziffern berücksichtigt worden. 
doch mit Vorbehalt der nachträglichen Abholzung auf Rechnung des seitherigen Besitzers" (,Die Forstverw. Württ." S. 125) erfolgen, läßt sie gleichzeitig als A ufforstungsflä chen erscheinen und beweist, $d$ a $B$ die dermaligen Kulturflächen. nicht ohne weiteres als die Abnutzungsflächen der vergangenen Wirtschaftsperiode ${ }^{1}$ ) angesehen werden dürfen. Hiezu kommen noch die ${ }^{1}$ ) ,,miBglückten Kulturen ", Abgänge durch Schneedruck u. dergl., welch letztere im erwähnten Zeitabschnitt allein auf $2157 \mathrm{ha}^{2}$ ) (meist 20-60-jähriger Bestände) eine Neubestockung nötig machten.

Dieses Beispiel allein mag zeigen, w i w e $\mathbf{n}$ i $\mathrm{z} u$ v e rlässig eine lediglich auf die Flächenangaben gestützte Berechnung über dieseitherige $N$ utzung und deren EinfluB a f die Gestaltung der Waldwerte ist, wie dringend nötig andererseits eine Verbesserungder Flächenstatistikin der Richtung erscheint, daß, wenn auch nicht alljährlich, sodoch periodisch, etwa im Ansch 1 uB an eine Einrichtungsstatistikgenaue Abrechnung überdie Flächenveränderungen des abgelaufenen Zeitabschnitts gegeben w i r d; dabei sollte man ehrlich genug sein, auch die Flächen der mißglückten Kulturen oder aus anderer Ursache nicht in die nächste Altersstufe vorrückenden Bestände anzugeben; [so werden z. B. in den ${ }^{3}$ ) Vorarbeiten zur Hauptrevision der s ä c h s i s c h e n Staatsforstreviere die,,mißratenen Flächen“ der abgelaufenen Wirtschaftsperiode ausdrücklich festgelegt].

Flächennachweisungen enthält auch die $\mathrm{b}$ a dis che Forststatistik (Tab. I 2), wenigstens bezüglich der Waldaus-

1) S. M ü 11 e r a. a. O. S. 265 .

2) S. Forststatist. Mitt. von 1887 ; leider ist dort $\mathrm{n}$ i c h t auch die vom Schneedruck betroffene Fläche getrennt nach Altersklassen angegeben; doch mögen die neu zu bestockenden Flächen zum großen Teil der Altersklasse 20-40 angehört haben.

3) Verf. entnimmt dies einem Schema, das ihm anläßlich einer Studienreise im Sommer 1907 von einem Beamten der Forsteinrichtungsanstalt gütigst zur Verfügung gestellt worden ist.

Forgtwirtgchaft. V. D 1 e terich, Elemente d. Wertamehrung. 
stockungen und Neuanlagen, ferner die bra u $\mathrm{nschwei-}$ $\mathrm{g}$ i s c h e Statistik in I 1 (S. 4 allerdings mit einer für größeren Waldbesitz nicht denkbaren Ausführlichkeit).

Die w ürtembergische Forsteinrichtungsstatistik gibt nach den bisherigen A usführungen keine befriedigende Auskunft über die Zunahmeder Ertragsfähigkeit der Staatswald ungen; nachweisen läßt sich das Vorhandensein gewisser Mehrungselemente, so die $\mathrm{Zu}$ nahme der Nadelholzbestockung, die Zunahme der durchschnittlichen Standortsgüte; aber eine quantitative Analyse der Wertsmehrung ist ausgeschlossen. Versuchen wir deshalb auch hier an den Fr ü c hten den Wertscharakter der Waldungen zu studieren.

bb) An der Hand der Ertragsstatistik.

Die Entwicklung des $\mathrm{Holzmassenertrags} \mathrm{der}$ württembergischen Staatsforste läßt sich bis zum Jahr 1823 zurück verfolgen. Die Derbholznutzung ist, wie aus Figur 1 ersichtlich, fortgesetzt gestiegen, ziemlich rasch in der ersten Hälfte des 19. Jahrhunderts (insbesondere zwischen 1830-45), dann nach einem längeren, nur durch den Sturmholzanfall zu Beginn der 1870er Jahre unterbrochenen Beharrungszeitraum, lebhafter wieder etwa von 1880 an (1825-29: 2,73; $1855-59: 4,15 ; 1880-84: 4,21 ; 1900-1904: 5,13 \mathrm{Fm}$ auf $\left.1 \mathrm{ha}^{1}\right)$. Die letzten Jahre brachten noch weitere erhebliche Erhöhungen $(1906: 5,82 ; 1907: 6,02 ; 1908: 5,65)$, die jedoch in der Hauptsache als außerordentliche Nutzungen für den Reservefonds (also Vorratsaufzehrung) anzusehen sind.

Liegen nun Anzeichen dafür vor, daß diese $\mathrm{Ertrags-}$ steigerung Folge höherer Ertragsfähigkeit der Waldungen ist? Die Ertragssteigerung kann auf zweierlei

1) Gesamtfläche vergl. die Bem. S. $12^{1}$ ). 
Ursachen zurückzuführen sein: teils darauf, daß man allmählich mehr Fläche zur Nutzung herangezogen hat bezw. nach Maßgabe der jeweiligen Altersklassen- und Bestockungsverhältnisse sowohl als der ökonomischen Rücksichten heranziehen konnte, teils darauf, daß sich die Wirtschaft im Lauf der Zeit nach Räumung ${ }^{1}$ ) der unvollkommensten Bestände und infolge Umwandlung holzarmer Waldformen und Betriebsarten in immer massenreicheren Beständen bewegen kann. Diese beiden Ursachen getrennt zu untersuchen, gestattet die württembergische Ertragsstatistik nicht, $d$ a sie - i m geraden Gegensatz zur Einrichtungsstatistik-den Flächenfaktor gar nicht ber ü cksichtigt. Man könnte sich immerhin auf Grund des derzeitigen Altersklassenverhältnisses den Verjüngungsgang rekonstruieren; in Anbetracht der oben geschilderten Unsicherheiten dieser Rechnungsmethode und mit Rücksicht darauf, daß die Durchforstungserträge erst vom Jahr 1880 an getrennt behandelt werden, wird man freilich kein ganz zutreffendes Bild erhalten. Immerhin mag die nach dieser Methode aufgestellte Berechnung in dem wiederholt schon zitierten Aufsatz von Oberforstrat Müller den Entwicklungsgang wenigstens insoweit kennzeichnen, als sie zeigt, da $B$ offenbar beide Ursachen mitim Spiele w a r e ${ }^{2}$ ). Für den Vorgang der Wertsmehrung ist damit noch nicht viel gesagt, denn beide Ursachen können sowohl wertsmehrend als wertszehrend wirken: die Zunahme des $\mathrm{H}$ ol z a n f $11 \mathrm{~s}$ auf der Flächeneinheit kann als Weiser der allgemeinen Verbesserung des Waldzustands erscheinen, even-

1) S. Fußnote in A.F. und J.Z. 1909 S. 266 (Aufsatz von M ü 11 e r).

2) A. F. und J.Z. 1909 S. 266 Tabelle 1 durchschnittl. Holzanfall pro ha durchschnittl. AbnutzungsAbnutzungsfläche in Fm $1830 / 49 \quad$ ca. 435 $1890 / 1909$ ca. 525 fläche ha in $1 \mathrm{Jahr}$

ca. 140

ca. 195 (enthaltend außerord. bezw. $1880 / 99 \quad$ ca. 495 ca. 175 Nutzung von 1906 an). 
tuell aber auch nur daher rühren, daß der Waldbesitzer mehr von den fetten Teilen die Nutzung erhebt, der Zukunft die mageren überlassend; die Ausdehnung der A b n u t z u ng s$\mathrm{f} l \mathrm{la} \mathrm{che}$ andererseits - Hand in Hand mit allmählicher Herabsetzung der Umtriebszeit gehend - kann auf Abtragung früher angesammelter Holzvorräte hinweisen, zugleich aber auch wertsmehrende Tendenz insoweit in sich tragen, als $\mathrm{Z} u$ w a c h s förd e r u n g (Erhöhung des Eberbachschen Massenzinsfußes mit nachhaltiger Wirkung) damit verbunden ist.

Tab. 5.

Uebersicht aber den Derbholzanfall ge-

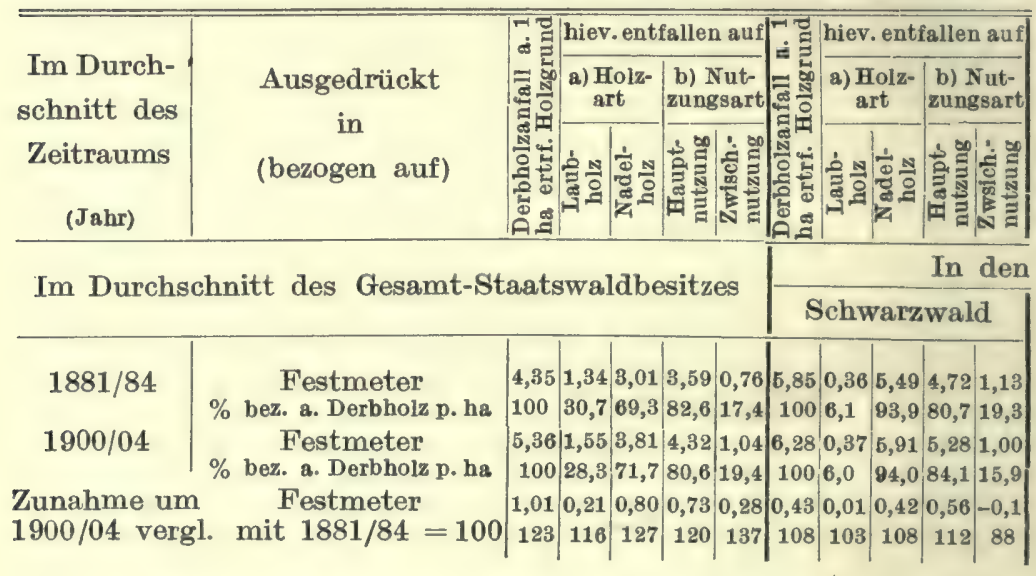

Die Ertragsstatistik läßt nur auf sehr kurze Zeit zurück in dieser Richtung einige Wahrscheinlichkeitsschlüsse ziehen: Wir sind in der Lage, vom Jahr 1880 bezw. 1875 an den Derbholzanfall getrennt nach Laubholz und Nadelholn sowohl als $\mathrm{nach}$ Haupt- und Zwischennutzung nachzuweisen. Werden solche Erhebungen auch auf die einzelnen Waldgebiete ausgedehnt, so läßt sich der Entwicklungsgang noch deutlicher verfolgen. Tabelle 5 enthält die entsprechenden Durchschnittserträge, je auf 1 ha Holzboden berechnet. Da- 
bei sind die fünf in der württembergischen Statistik ausgeschiedenen Waldgebiete: a) 3 Nadelholzgebiete: S c h w a r zwald, Nordostland (Hall-Ellwanger Gegend) und O bers chwaben; b) 2 Laubholzgebiete: Unterland und Alb getrennt vorgetragen ${ }^{\mathbf{1}}$ ).

Was zunächst die Verteilung der Nutzung auf $\mathrm{L} a \mathrm{u}$ b$\mathrm{holz}$ und $\mathrm{Nadelholz}$ anlangt, so hat sich ganz offenkundig eine Verschiebung zugunsten des letzteren ergeben (1881/84: 69,1, 1900/04: 71,7\%). Auffallend ist das verschiedene

\section{trennt nach Holzart und Nutzungsart.}

\begin{tabular}{|c|c|c|c|c|c|c|c|c|c|c|c|}
\hline \multirow{3}{*}{ 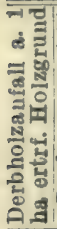 } & \multicolumn{2}{|c|}{ hiev. entfallen auf } & \multirow{3}{*}{ 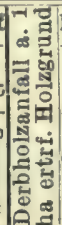 } & \multicolumn{2}{|c|}{ hiev. entfallen auf } & \multirow{3}{*}{ 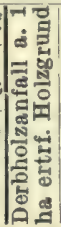 } & \multicolumn{2}{|c|}{ hiev, entfallen auf } & \multirow{3}{*}{ 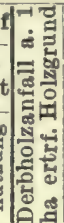 } & \multicolumn{2}{|c|}{ hiev.entfallen auf } \\
\hline & $\begin{array}{l}\text { a) } \\
\text { art }\end{array}$ & & & & & & & & & & \\
\hline & 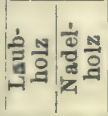 & 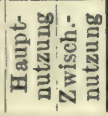 & & 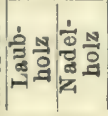 & 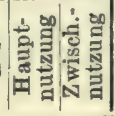 & & 象 & 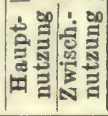 & & 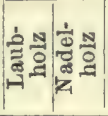 & 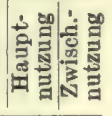 \\
\hline
\end{tabular}

einzelnen Waldgebieten

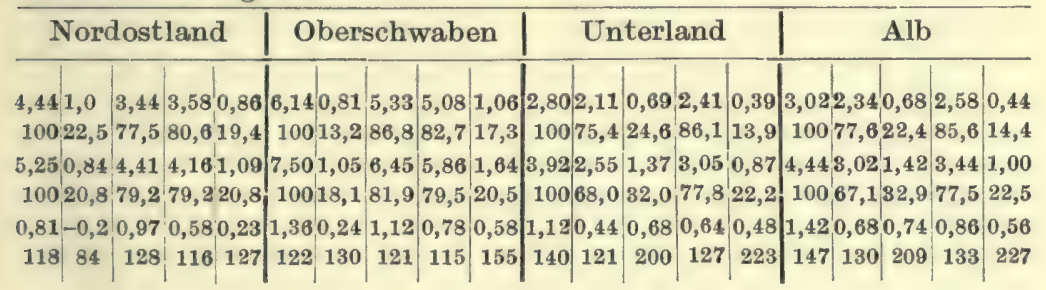

Verhalten der einzelnen Gebiete: während in dem Nadelholzgebiet von Oberschwaben die $\mathrm{L}$ a u b holznutzung mehr aufgekommen ist $(18,1$ gegen $13,2 \%$ ) z e i g en die $\mathrm{L}$ a u bholzgebiete eine ganz erhebliche Zunahme der Nadelholznutzung (Unterland von 100

1) Es soll nicht versäumt werden, darauf hinzuweisen, daß infolge der Organisationsveränderungen teilweise kleine Verschiebungen eingetreten sind, die aber für die vorliegende Darstellung als belanglos außer acht gelassen werden können (da für den Zeitraum 1881/84 auch nicht alle Einzelzahlen zur Verfügung stehen, ist die Berücksichtigung jenes Umstands nicht ohne weiteres möglich). 
auf 200, Alb von 100 auf 209) und gleichzeitig eine wesentlich über dem Landesdurehschnit stehende der Gesamtnutzung (auf 140 bezw. 147 gegen 123 Landesdurchschnitt); im Schwarzwald, der Nadelholz- und Altholz-Domäne ist dagegen die Nutzung nur auf 108 angestiegen. Wenn die Erhöhung der Gesamtjahresnutzung auf rund $190000 \mathrm{Fm}$ gegenüber 1881/84 angegeben werden kann, so entfallen hievon ca. 109000 (=57\%) auf Unterland und Alb bei einem Flächenanteil von $(23+22)=45 \%$, und 60000 (rund 1/3) allein auf die $\mathrm{Nade} 1 \mathrm{~h} \mathrm{olz} \mathrm{n} \mathrm{u} \mathrm{t} \mathrm{zung}$ dieser Gebiete. Diese Zahlen lassen, wenn ihnen auch keine Beweiskraft innewohnt, doch als sehr wahrscheinlich vermuten, daß als Element der Ertragssteigerung das Uebergreifen der Wirtsehaft a uf die - massenreicheren - Nadelholzbestände einewesentliche Rolle spielt. Da B dieser Entwicklungsgang in den jeweiligen Bestockungsverhältnissen begründet liegt, und von weiterer nach altiger Wirkung begleitet sein dürte, wurde schon o b e $n$ a $n g$ ed e u t e t (S. 28). Zahlenmäßig läßt sich diese Einwirkung zunächst nicht feststellen, weil der Massenfaktor in der Einrichtungs-, der Flächenfaktor in der Ertragsstatistik zu wenig zum Ausdruck gebracht wird. F ü r d i e w ü r ttembergische Forstrerwaltung müßte es aber von größtem Interesse sein, dieses Wertsmehrungselement genau zu ergründen, da es berufen ist, als Gegengewicht gegen die Störung des Altersklassenverhältnisseszu dienen, das an sich spätere Nutzungsrückgänge, insbesondere im Schwarzwald, befürchten läß ${ }^{1}$ ).

1) Vergl. auch die diesbezüglichen Andeutungen in der Begründung des Reservefondsgesetzes von 1910. 
In Tabelle 5 ist ferner auch $d$ as $V$ erhä $l \mathrm{tn}$ is $v$ on Haupt- und Z $\mathrm{Z}$ ischennutzungserträgen dargestellt: die letzteren lassen erheblich höhere Steigerung erkennen (Hauptnutzung auf 120, Zwischennutzung auf 137) und betragen 1900/04: 19,4\% (gegen 17,4 i. 1880/84) der Gesamtnutzung.

Auch in dieser Hinsicht ist das verschiedenartige Verhalten der fünf Waldgebiete sehr bemerkenswert: im Schwarzwald sind die Durchforstungserträge nicht bloß prozentual im Vergleich zur Hauptnutzung, sondern auch nach dem absoluten Betrag (von 1,13 auf 1,00 Fm pro ha) zurückgegangen, wenig haben sie im Nordostland, erheblich mehr in Oberschwaben, weitaus am meisten wiederum im Unterland und auf der Alb (von 100 auf $₹ 23$ bezw. 227) zugenommen. Begründet sind diese gegensätzlichen Erscheinungen einerseits in dem für den Schwarzwald z. Zt. besonders charakteristischen Abmangel an mittelalten Hölzern, andererseits in dem Heranwachsén von Fichtenbaum- und Stangenhölzern auf der Alb und im Unterland (s. Tab. 4). Der Unterschied zwischen Nordostland und Oberschwaben erklärt sich teils aus dem stärkeren Vorherrschen der Fichte in letzterem Gebiet teils - und wohl noch mehr - aus dem Umstand, daß bei den günstigeren Standortsverhältnissen Oberschwabens (Fichte I/II Bon.) die stark besetzte Altersklasse 21-40jährig schon jetzt mehrenden Einfluß auf den Derbholz-Zwischennutzungsertrag geltend macht, während dieser Gesichtspunkt für das Nordostland wegen der geringeren Bonität (II. und III.) weniger ins Gewicht fällt.

$\mathrm{Ob}$ auch die Durchforstungsintensität als Ursache der Ertragserhöhung in Frage kommt, läßt sich aus der Statistik nicht erheben; wohl enthält die Uebersicht des Holzmassenertrags (Tab. II der Forststat. Mitt.) bei „Durchforstungen" eine Spalte „Nutzungsfläche“ und eine Angabe über den Derbholzertrag auf 1 ha Nutzungsfläche; aber als Vergleichsmaßstab können diese Zahlen nicht dienen, weil weder der Anteil der Holzarten (Laub- und Nadelholz) noch der der Altersklassen aus der Statistik ersichtlich ist. Auch in der Buchführung (Fällungsnachweisung, Wirtschaftsbücher) ist eine solche Ausscheidung nicht vorgesehen. Der Gedanke v. Bentheims, daß ${ }^{1}$ ), ,f ortlaufend überwach t“

1) Vergl. (oben S. $24^{4}$ ) v. $\mathrm{B}$ en the i m, Anregungen etc. S. 110, insbesondere hinsichtlich Durchforstungsergebnisse die Mustertabelle S. 111. Auch Dr. K ö n i g weist in seiner Schrift 
werden soll, ,in welehem Ma $B$ sich die einzelnen Altersklassen an der Erfüllung des Gesamtabnutzungssatzes beteiligen, ist leider bis jetzt auch eine von den vielen guten Anregungen geblieben, denen sehr langwährende Keimruhe beschieden ist.

Soviel aber läßt sich hinsichtlich der Durchforstungsintensität sagen, da $B$ sie noch recht wohl steigerungsfähig ist; betrug doch der Zwischennutzungsertrag vom Jahr 1900/04 noch nicht einmal ganz $20 \%$ der Gesamtnutzung.

Nach den Dr. E b e r h a r d schen ${ }^{1}$ ) Tafeln, welche Derbholzvorerträge für mittelstarken Durchforstungsbetrieb angeben, würde sich unter Annahme einer Umtriebszeit $\mathrm{u}=100$ Jahre folgender gewissermaßen normaler Derbholzvorertrag berechnen:

bei durchschn. Standortsbonität: Für Fichte, Tanne, Forche, Buche,

$\begin{array}{lllll}\text { II. } & 35 & 35 & 48 & 35 \\ \text { III. } & 37 & 33 & 50 & 30\end{array}$

$\%$ des Gesamtderbholzertrags

auf Grund der 1908er Uebersicht über die Holzartenvertretung zusammen also bei durchschnittlich II. Bonität $36 \%$, bei III. $34 \%$. In Anbetracht des Abmangels an 41-80jährigen Beständen dürfte allerdings eine Reduktion angezeigt sein, wiewohl andererseits auch $80-100$ jährige und über 100jährige Bestände teilweise noch für Erhebung der Vornutzungen in Betracht kommen; denn nach Abzug der in die I. Periode eingestellten Flächen (Tab. D * der Einrichtungsstatistik von 1908) zeigt das Altersklassenverhältnis der württ. Staatswaldungen ungefähr folgendes Bild:

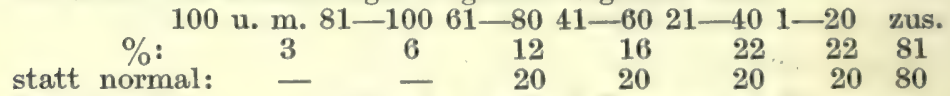

(bei $\mathrm{u}=100) \quad(19 \%$ sind in die I. Per. eingestellt).

Die Durchforstungserträge aus $81-100$ und mehrjährigen Beständen vermögen freilich diejenigen aus 41 - 80 jährigen nicht voll $\mathrm{zu}$ ersetzen, aber der große Abstand zwischen 20 und $35 \%$ Vornutzungsertrag ist hiedurch allein noch nicht begründet, es sei denn, daß man die Gesamtnutzung bezw. die Hauptnutzung als abnorm hoch angesetzt erachten wollte (1900/04 5,36 bezw. 4,32; nach der Einrichtungsstatistik von 1908 5,7 bezw. 4,6).

,Die Altersklassen u. s.f." (a. a. O. S. 75 ff.) darauf hin, daß die Ermittlung der Zwischennutzungserträge sich am einfachsten gestalte, wenn diejenigen des abgelaufenen Zeitraums nach Altersklassen getrennt berechnet werden.

1) Tafeln zur Bonitierung und Ertragsbestimmung von Dr. E b e r h a r d (2. Aufl. 1909). 
Auch ein Vergleich mit anderen Staatsforstverwaltungen läßt die bisherigen Durchforstungserträge und in s b e o $\mathrm{nd} \mathrm{e} \mathrm{r} \mathrm{e}$ die Entwicklung derselben seit 1880/84 als sehr mäßig erscheinen. In $\mathrm{Pr}$ e $\mathrm{u}$ e $\mathbf{n}^{\mathbf{1}}$ ) beliefen sich die Durchforstungserträge $\mathbf{1 8 8 5 / 9 0}$ auf $\mathbf{2 6 , 6} \%, \mathbf{1 9 0 0 / 0 4}$ auf $\mathbf{3 2 , 9}$, neuerdings sogar auf $39,5 \%$. Die b a y e r is c he $\mathbf{n}^{2}$ ) Staatsforste ergeben:

1880 - 1889: $17 \%$ Hiebei ist allerdings zu beachten, daß auch 1890-1899: 19,4\% die ,zufälligen Ergebnisse" (Scheidholz, To1900-1905: 23,4\% talität) unter den Vornutzungserträgen in-

In $\mathbf{B}$ a $\mathrm{d}$ e $\mathrm{n}$ und $\mathrm{H}$ es s e $\mathbf{n}$ werden die Erträge für Gesamtmasse (Derbholz und Reisig) statistisch behandelt, können deshalb nicht ohne weiteres zum Vergleich herangezogen werden; aber mit Rücksicht auf den Entwicklungsgang, auf den es hier in erster Linie ankommt, mögen die betr. Zahlen Erwähnung finden:

in $\mathrm{B}$ a de $\mathrm{n}^{3}$ ) betrugen die Vornutzungserträge 1878/82 ca. $20,1903 / 07$ ca. $29 \%$,

in $H$ esse $n^{*}$ ) betrugen die Vornutzungserträge 1880/84 ca. 40, 1900/04 ca. $60 \%$ der Gesamtnutzung. Im Bereich der sächsischen Forstverwaltung ${ }^{5}$ ) sollen die Vornutzungen z. Zt. ca. $31 \%$ der Gesamtnutzung ausmachen.

Große Bedeutung dürfte allerdings solchen Vergleichen nicht beizulegen sein, weil Holzartenverteilung, Altersklassenverhältnis und Standortsgüte allein schon wesentliche Verschiedenheit des Durchforstungsanfalls bedingen können. Immerhin mag die Vermutung daran angeknüpft werden, daß eine Steigerung der Durchforstungsintensität und damit der Vornutzungserträge in den w ürttembergischen Staatswaldungen noch recht wohl $\mathrm{d}$ e $\mathrm{nkb}$ a $\mathrm{r}$ is t. Zieht man vollends das Altersklassenverhältnis mit seiner reichen Ausstattung an 1-40jährigen Beständen insbesondere an Fichten- und Tannenbestockung

1) Nach H a g e - D o n n e r, Die forstl. Verhältnisse Preußens 2. Bd. bezw. die neuesten Hefte der Amtlichen Mitteilungen usw.

2) S. S c h ü p f e r, ,Die Entwicklung des DurchforstungsBetriebs in Theorie und Praxis" (S. 84).

3) S. Statist. Nachweisungen aus der Forstverwaltung Badens.

4) S. Mitteilungen aus der Forst- und Kameralverwaltung von Hessen.

5) S. F. Zentrbl. 1910 S. 160 (Aufsatz von E i c h h o r n). 
(Tab. 4 oben) in Betracht, so läßt sich eine sehr erhebliche, fortgesetzte Mehrung der Zwischennutzungserträge (mit der Zeit etwa auf das Doppelte, also ca. 2,0-2,2 Fm pro ha Waldfläche) in Aussicht nehmen. Die Klarstellung dieses Prozesses ist von Wichtigkeit für Lösung der Frage, ob die Derbholznutzung des Zeitraums 1900/04 (mit 5,36) bezw. die in der Einrichtungsstatistik zu 5,7 Fm pro ha berechnete noch weiterhin wird bezogen werden können, oder ob die dermalige Höhe der Nutzung bereits den Keim künftigen Rückgangs in sich trägt. Nach obiger Rechnung könnte die $\mathrm{H}$ a u p t nutzung im Lauf der nächsten 20-50 Jahre allmählich von 4,32 (Stand von 1900/04) bezw. 4,6 (Soll der Einrichtungsstatistik von 1908) auf $(4,32-1,04=) 3,28$ bezw. $(4,6-1,1=) 3,5 \mathrm{Fm}$ pro ha herabsinken, ohne die Höhe der Gesamt nutzung nachteilig $\mathrm{zu}$ beeinflussen.

Diese sehr wichtigen Fragen einwandfreizuklären, dürte alseinederdringendsten Aufgaben der württembergisehen Forsteinrichtung zu betrachten sein. Zur Zeit ist einebefriedigende Lösung mangels zuverlässigen und einheitlichen Grundlagenmaterials noeh nicht möglich.

ce) Vergleich der Ergebnisse der Einrichtungs-und Ertragsstatistik, insbesondere hinsichtlich des Verhältnisses von derm maliger Vornutzung und künftiger Haubarkeitsnutzung.

Vergleichen wir die Ergebnisse der württembergischen Einrichtungs- mit denen der Ertragsstatistik, so können wir die gleichen Mehrungselemente hier wie dort nachweisen; vor allem macht sich die oben gezeichnete ertragsmehrende Wirkung der Bestockungsänderung in der bisherigen Nutzung durch Uebergreifen in die massenreicheren $\mathrm{Nadelholz-}$ 
bestände schon deutlich bemerkbar. Wir müssen aber zugleich einen Widerstreit dieser auf Ertragssteigerung gerichteten Tendenz mit Elementen der Wertsminderung feststellen, sofern das Altersklassenverhältnis auf künftigen Rückgang des Haubarkeitsertrags hinweist; die Entscheidung mußte als noch ungewiß bezeichnet werden.

Besonders instruktiv für die Beziehung zwischen der seitherigen und der künftigen Ertragsgestaltung ist das zuletzt besprochene Beispiel, weil es Gelegenheit gibt, ein weiteres den inneren Zusammenhang in der Entwicklung der Waldwirtschaft herstellendes Element zu beleuchten, d e n D u r c hfors tung s b e tri e b, dessen Anteil am bisherigen Massenertrag und seinen Einfluß auf die ferneren Nutzungssätze. Bei der Wichtigkeit dieser, in der modernen forstlichen Literatur viel erörterten, Frage soll noch kurz darauf eingegangen sein.

Für die Höhe der Vornutzungserträg e sind in der Hauptsache dreierlei, gleichzeitig auch die künftigen Haubarkeitsergebnisse beeinflussende Ursachen entscheidend, welche teils in der Ertrags- teils in der Forsteinrichtungsstatistik zum Ausdruck kommen sollten:

a) Die Bestockungsverbesserung, welche nach dem eben besprochenen Beispiel in den Waldgebieten Alb und Unterland auffallende Zunahme der Vor- und Gesamtnutzung veranlaßt hat, zugleich ein zuverlässiger $W$ e iser der Erhöhung künftiger Haubarkeitserträge und des Massenertragsvermögens, sofern sie durch alle Altersklassen, also vor allem auch in den jüngsten zum Vorschein kommt.

b) Die Verschiebung des Altersklassenverhälthisses: Der verhältnismäßig niedere Durchforstungsertrag der württembergischen Staatswaldungen wurde teilweise mit dem Abmangel an mittelalten Hölzern erklärt und der voraussichtlich künftige, eben hiedurch bedingte, Rückgang der Haubarkeitserträge als möglicherweise ausgleichbar 
durch höhere Durchforstungserträge bezeichnet. Wenn die zeitweilige Störung des Altersklassenverhältnisses nach $u$ nten und oben annähernd gleichmäßige Abweichungen a ufuweisen hat, kann der Vornutzungsanfall als selbsttätiger Regulator des Gleichgewichts der Gesamtn u tzung dienen. Eine durch das Altersklassenverhältnis bedingte Erhöhung der Durchforstungserträge würde gleichfalls auf künftige, allerdings vorübergehende, Steigerungsfähigkeit der Abtriebsnutzung hinweisen.

c) Als dritte Ursache endlich kommt in Betracht die A enderung der Wirtschaftsgrundsätze, insbesondere bezüglich der Durchforstungsinten sität. Hier ist zunächst nur zu untersuchen, ob die Erhöhung der Vornutzungserträge eine Steigerung der Massenertragsfähigkeit bedeutet oder obsieals Vorwegnahme von Haubarkeitse r trägen anzusehen ist. Nach dem neuesten Stand der Forstwissenschaft trifft das letztere zu: Schon L o r e y ${ }^{1}$ ) hat ein negatives Ergebnis bezüglich des Einflusses der Durchforstungsgrade A-C auf die Gesamtzuwachsleistung festgestellt. Durch die neuesten Ertragstafelaufstellungen der prouBischen Versuchsanstalt ist weitere Klärung geschaffen worden: $\mathrm{S} c \mathrm{~h} w \mathrm{ap} \mathrm{pach}{ }^{2}$ ) hat für Fichte und Kiefer nachgewiesen, daß infolge Erhöhung der Durchforstungsmassen die Haubarkeitserträge des verbleibenden Bestandes entsprechend gemindert werden; er betont dabei ausdrücklich, daß sich der Uebergang zu intensiverer Bestandspflege gewissermaßen als Entnahme von „Ersparnissen früherer Zeiten“ (also wie eine Herabsetzung der Umtriebszeit) darstelle, da ,die Altbestände heute erheblich massenreicher sind als sie in Zukunft sein

1) Ertragstafel für die Fichte (1899) S. 108.

2) Vergl., ,Wachstum und Ertrag normaler Fichtenbestände" (1902) insbesondere S. 100-104; ,Die Kiefer, wirtschaftliche und statische Untersuchungen" etc. (1908) S. 63-65. 
werden, wenn sie unter dem Regime intensiverer Bestandespflege erwachsen."

Diese theoretisch wohl begründeten Folgerungen wirken in der Praxis nicht so einschneidend, weil die Uebergänge sich, zumal in großen Verwaltungen, meist se h r a $11 \mathrm{mählich}$ vollziehen und gleichzeitig -- was von einer geordneten Forstwirtschaft wenigstens verlangt werden kann - an sich massenreichere Bestände infolge Umwandlung ertragsarmer Holzund Betriebsarten heranwachsen (vergl. das oben besprochene Beispiel der schwäbischen Alb und des Unterlands). Dagegen muß noch auf einen Punkt hingewiesen werden, der aus Anlaß der Beratungen des deutschen Forstvereins über das Thema Starkholzzucht ${ }^{1}$ ) usw. von dem Referenten, Oberforstmeister Fricke, betont wurde: daß bei zu rasch und kräftig vorgehenden Lichtungshieben dem verbleibenden Bestand die Möglichkeit entzogen werde, die Produktionskraft des Bodens voll auszunützen. Auch von dem Mitberichterstatter, Forstrat Dr. Speidel, wurde mit Bezug auf Buchenwaldungen der schwäbischen Alb nachgewiesen, daß durch stärkere Eingriffe (nach Seebach) die Gesamtderbholzerzeugung heruntergedrückt und möglicherweise auch die Bodenkraft geschädigt werde. Diese Gesichtspunkte lassen klar und deutlich die w e r t smindernde Tendenz einer U eberspannung der D u r c h forst ungsintensität erkennen.

Da, wie S chwa p a ch ausführt, als Bestimmungsgründe für schärfere Durchforstungsgrade in erster Linie „q u a lit a t i ve Momente" ausschlaggebend sind, wird die eben gestreifte Frage im nächsten Abschnitt wieder aufgerollt und dort mehr die we r t s me hre nde Wirkung zum Ausdruck gebracht werden können.

Die Besprechung des Einflusses, den der Durchforstungsbetrieb auf die Massenertragsfähigkeit des Waldes geltend macht, kann nicht geschlossen werden, ohne daß noch kurz zu der Streitfrage Stellung genommen wird, ob sich in der Materialkontrolle

1) 1910 in Ulm. 
die Trennung von Vornutzung und Hauptnutzung empfiehlt. Aus der großen Zahl von Schriftstellern, welche sich hierüber geäuBert haben, sollen insbesondere $\mathrm{Sch}$ w a $\mathrm{p} \mathrm{p}$ a $\mathrm{c} \mathrm{h}{ }^{1}$ ), M a r-

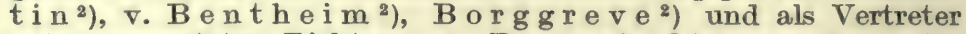
entgegengesetzter Richtung $v$. B o r n sted $t^{2}$ ) erwähnt sein.

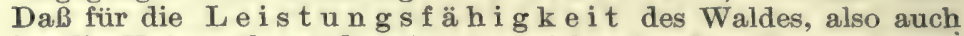
für die Untersuchung der etwa vor sich gehenden Wertsmehrung nur der G es a m ertrag maßgebend sein kann, geht, ganz abgesehen von der Schwierigkeit einer genauen Trennung der Begriffe Haupt- und Zwischennutzung, aus dem eben Ausgeführten deutlich hervor, insbesondere aus den unter b) und c) dargelegten Wechselbeziehungen zwischen Haubarkeits- und Zwischennutzung. Während $\mathbf{S} \mathrm{ch} \mathbf{h} \mathrm{p} \mathrm{pach}$ besonders die unter c) besprochene Vorwegnahme künftiger Haubarkeitsnutzung als Begründung heranzieht, dürfte unter anderen Verhältnissen (so insbesondere für die württembergischen Staatsforste) der Nachdruck mehr auf den unter b) besprochenen Einfluß g est ö r t e r Alterskassenanordnung a f die Versehiebung der Erträge zwischen den beiden Nutzungsarte $\mathbf{n}$ zu legen sein.

Sofern bei der Ertragsregelung der Grundsatz eingehalten wird, daß nur der $\mathrm{G}$ es a m t a b n t z u n s s a $\mathrm{tz}$, nicht der Hauptnutzungsertrag allein, maßgebend sein darf, dürfte die Art der Materialkontrolle örtlich und zeitlich verschieden $\mathrm{zu}$ handhaben sein, je nachdem mehr oder weniger strenge Aufsicht darüber erforderlich erscheint, $\mathrm{daB}^{\mathrm{s}}$ ) , die Durchforstungen in dem wirtschaftlich gebotenen Umfang nach Fläche und Masse regelmäßig zur Ausführung kommen"; Durchforstungs m e h r erträge einfach als Freibeute zu betrachten, wie es in Württemberg bisher üblich war, dürfte jedenfalls nicht gerechtfertigt sein. Uebrigens findet man in der neueren forstlichen Literatur zahlreiche Anzeichen, welche darauf hindeuten, daß nicht alle Forstverwaltungen reif fü A ufhebung jener Trennung s in d: der Antrag Tör r i n g bemängelt ja doch unter anderem die auch aus den oben mitgeteilten Zahlen ersichtliche Rückständigkeit des Durchforstungsbetriebs in den bayrischen Staatswaldungen und in den Aeußerungen von $\mathrm{Ph}$ ili p p, $\mathrm{Fi}$ eser, $\mathrm{Eb}$ e r b a $\mathrm{ch}$ finden wir ähnliche auf die badischen Forste sich beziehende Andeutungen. Daß auch die Durchforstungsergebnisse der württembergischen Staatswaldungen nicht ganz auf der Höhe der Zeit stehen dürften, zeigen die oben mitgeteilten Zahlen. Dagegen scheint man in Hessen, soviel aus der gleichfalls angeführten Entwicklung der Vornutzungserträge hervorgeht, mehr dem Fortschritt im Durchforstungsbetrieb zu huldigen und

1) Wachstum und Ertrag normaler Fichtenbestände (S. 105).

2) Vergl. die Aeußerungen dieser Herrn in Z. f. F. und J. W. 1903 bezw. von M a r t i n 1902 S. 78, 405. 1903).

3) S. v. B o r n s t e d t a. a. O. (S. 69 d. Z. f. d. F. und J. W. 
den preuBischen Staatsforsten stellt $\mathbf{S} \mathbf{c h} \mathbf{h}$ a $p$ a $\mathbf{c h} \mathbf{h}^{\mathbf{1}}$ ) das Zeugnis aus, ,daß der Durchforstungsbetrieb gegenwärtig bereits in großen Wirtschaftsgebieten ungefähr ebenso intensiv betrieben wird, wie auf den Versuchsflächen."

\section{Folgerungen.}

Entsprechend der Aufgabe, welche sich die vorliegende Arbeit gestellt hat, sind die Ergebnisse der bisherigen Ausführungen in folgende 2 Fragen zusammenzufassen, deren Lösung hier in wenigen Sätzen zu geben versucht werden soll:

a) Worin zeigt sich das Vorhandensein und die Wirkung wertsmehrender Elemente mit Bezug auf die Massenertragsfähigkeit ?

b) Wie kann der Effekt dieser Wertsmehrungsvorgänge ermessen und von der forstlichen Buchführung bezw. Statistik zum Ausdruck gebracht werden?

a) Weder der Holzvorrat noch die jeweils erhobene oder zur Erhebung vorgesehene $\mathrm{Nu}$ tz u $\mathrm{n}$ g s $\mathrm{m}$ a s s e können als maßgebende Weiser der Wertsmehrung angesehen werden.

Eine Erhöhung des Holzvorrats rührt ja im Grund lediglich daher, daß der 1 a u fende $\mathrm{Zuw}$ a e h s der letzten J a h re (weil nicht richtig erkannt oder nicht voll nutzbar) nicht in seinem ganzen Betrag erhoben w u r d e. Denkbar ist, z. B. bei Herabsetzung der Umtriebszeit, dauernde Erhöhung des zulässigen Nutzungsquantums (abgesehen von erheblich höherer Nutzungssteigerung während der Uebergangszeit) unter gleichzeitiger Abnahme des Holzvorratskapitals; im Gegensatz hiezu bietet die Ansammlung von Vorratsüberschüssen keine Gewähr für dauernde Mehrung der Ertragsfähigkeit, trägt vielmehr, wie aus dem württembergischen Beispiel ersichtlich, durch Störung des Altersklassenverhältnisses eine gewisse Unsicherheit und die Besorgnis künftiger Nutzungsrückgänge in die Wirtschaft

1) a. a. O. S. 104. 
herein, die hohen dermaligen Erträge mit einer Risikoprämie belastend. Auch fortgesetzte Nutzungserhöhung läßt nicht ohne weiteres auf Wertsmehrung schließen; denn möglicherweise ist der Abnutzungssatz früher hinter der Ertragsfähigkeit der Waldwirtschaft zurückgeblieben oder rührt die Erhöhung lediglich daher, daß die Nutzung den Holzvorrat angreift bezw. wie eben ausgeführt, durch Vorwegnahme von Haubarkeitserträgen in der Form stärkerer Durchforstungseingriffe sich bereichert. Immerhin lassen sich aus der Vorratsund Nutzungsentwicklung allerhand Schlußfolgerungen bezüglich der Gestaltung der künftigen Massenerträge ableiten, wie es oben an den Beispielen aus der badischen und sächsischen Staatsforstverwaltung dargelegt worden ist.

Als einzig zuverlässiger Maßstab der Ertragsfähigkeit und somit auch der Wertsmehrung auf seiten des Massenkomponente $n$ wird der laufende Gesamtzuwachs an Holzmasse gelten können, soweit er jeweils in nutzbarem Holz d em Wald besitzer zur Verfügung steht; weitere Ertragssteigerung ist nur insoweit in Aussicht zu nehmen, als Zuwachsmehrung feststellbar ist und gleichzeitig die Nutzbarkeit des Zuwachses sich erweitert. Die Elemente der Ertragsteigerung lassen sich demnach in 2 Gruppen gliedern: zur einen gehören alle diejenigen Vorgänge in der Waldwirtschaft, welchedurch bessere Ausnützung der Produkti o nskraft des Bodens (vollkommenere Bestände, massenreichere Holz- und Betriebsarten) oder d u r ch Verbesserungderstandortseigenschaften eine Förderung des Gesamtzuwachses herbeizuführen vermögen, während die andere Gruppejene Elemente umfaßt, welehe die Nutzbarmachung des laufenden Zu- 
wachseszu erleichtern und zu beschleunig en vermögen, so die Gestaltung des Altersklassenverhältnisses, die Umtriebszeit, der Durchforstungsbetrieb. Immer müssen Elemente beider Gruppen zusammentreffen, wenn die Massenerträge noch weiterer Steigerung fähig sein sollen.

b) Die Lösung der anderen Frage wird dem ach zu la ten haben:

Den Effekt der Wertsmehrung in dem hier besprochenen Sinn vermögen wir nur dann richtig und zuverlässigzuermessen, wenn die forstliche Buchführung bezw. Statistik den Zuwachsgang der Waldbestände von Zeitabschnittzu Zeitabschnitt verfolgen 1 äßt und darüber Aufklärung gibt, inwieweit der Gesamtzuwach jeweils in nutzbarer Ware zur Verfügung steht.

Zuverlässiges Zahlenmaterial erhalten wir nur dann, wenn das Ermittlungsverfahren den Boden der $m$ e $\mathrm{Bb}$ a $\mathrm{r}$ en W i r k l i c h k e it nicht verläßt; meßbare Größen der Waldwirtschaft aber sind: Fläche, Alter, Vorrat und die Nutzungsergebnisse; aus diesen Faktoren läßt sich nach der oben besprochenen Methode der Zuwachs ${ }^{1}$ ) der abgelaufenen Periode berechnen und der Grad seiner Nutzbarkeit veranschaulichen. Die Zuwachsberechnung nach der Formel $l d z=V_{n}+{ }_{10}-V_{n}+$ $\mathrm{N}_{10}$ setzt eingehende, die ganze Betriebsklasse umfassende Holzvorratsermittlungen vora us und zur Beurteilung der Nutzbarkeit des Zuwachses istaltersklassenweise Gliederung derselben erforderlich.

1) Indem wir aus Vorrat und Nutzungsergebnissen den $\mathrm{Zu}$ wachs berechnen und die Berechnung nach Altersklassen getrennt durchführen, sind die als Weiser der nachhaltigen Leistungsfähigkeit zu bezeichnenden Faktoren Vorrat, Zuwachs, Altersklassenverhältnis alle berücksichtigt (vergl. auch $\mathrm{N}$ üs s l e im F. Zentrbl. 1907 S. 161).

Forstwirtschaft. V. Di e terich, Elemente d. Wertsmehrung. 
Daß die Zuwachs-Erhebungen im Rahmen der einzelnen Betriebsklassen (bezw. Reviere) anzustellen sind und für größere Waldverbände (Großwaldbesitzungen) erst mittelbar aus den Einzelresultaten zusammengestellt werden können, wurde schon erwähnt ${ }^{1}$ ). Die weiteren Ausführungen beziehen sich deshalb zunächst nur auf Feststellung der Mehrung des Massenertragsvermögens in $\mathrm{nerhalb}$ der $\mathrm{Betriebsklasse.}$

Die Buchung der Ergebnisse der Holzvorratsaufnahmen, die Inventarisierung, erfolgt am zweckmäßigsten durch Eintrag der einzelnen Bestände in die nach Holzart bezw. Holzartengruppe gesonderte $\mathrm{Holzv}$ or ats- und Alters-

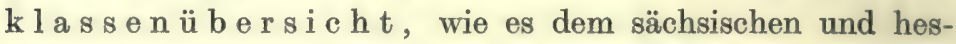
sischen Forsteinrichtungswesen längst geläufig ist ${ }^{2}$ ).

Ob nun der Vorrat nach Derbholz allein oder nach Derbholz einschließlich Reisig (wie z. B. in Hessen und Baden üblich) aufgenommen wird, kommt auf die Nutzungsgebräuche der einzelnen Verwaltungen an - Einheitlichkeit wäre allerdings erwünscht mit Rücksicht auf vergleichende Untersuchungen -; bildet im allgemeinen nur das Derbholz den Gegenstand der Materialkontrolle (wie z. B. in Württemberg), so dürfte sich jedenfalls für die beiden jüngsten Altersklassen gesonderte Angabe des Derbholzund Reisigvorrats empfehlen, wenn man sich über den Zuwachsgang derselben im großen und ganzen orientieren will.

Sollen nun die frühere und die neueste Inventaraufnahme in Beziehung gesetzt werden zu den Nutzungsergebnissen des zwischenliegenden Wirtschaftszeitraums, so muß die Buchung der letzteren natürlich in ähnlicher Form, also auch a 1 t e r sklassenweise erfolgen. Wir hörten ja schon oben ${ }^{3}$ ),

1) S. oben S. 21.

2) Als Muster könntee twa das im hessischen Forsteinrichtungsdienst eingeführte Schema dienen (vergl. M a r t i n, Betriebsregulierung im Großherzogtum Hessen, Z. f. F. und J. W. 1902 S. 454). Am zweckmäßigsten werden wohl 2 Hälften vorgesehen, in deren eine die Laubhölzer, in der anderen die Nadelhölzer einzutragen wären, oder man bestimmt in reinen Nadelholzrevieren die linke Hälfte für Fichte und Tanne, die rechte für Forche o. ä.; weitere Unterscheidungen (z. B. Eiche, Buche etc.) können durch Verwendung verschiedenartiger Tinten zum Ausdruck gebracht werden.

3) S. S. 24 u. $39 \mathrm{f}$. 
daß eine derartige Behandlungsweise die bisherige Nutzung (speziell mit Bezug auf den Durchforstungsbetrieb) am besten zu charakterisieren vermöge; sie ist aber unumgängliches Erfordernis, soll die Zuwachsformel auch auf die einzelnen Altersklassen angewendet werden: wir können so am einfachsten auch die A b nutzung sflä chen der einzelnen Altersklassen ermitteln (vergl. Tab. 6 unten) und erfahren, in welchen Teilen der Betriebsklasse die Mehrung bezw. Minderung des Ertragsvermögens erfolgt ist; außerdem läßt sich die Nutzbarkeit des Gesamtzuwachses auf Grund der neuen Holzvorrats- und Altersklassenübersicht nur dann ormessen, wenn uns Anhaltspunkte über die Zuwüchse der einzelnen Altersklassen zur Verfügung stehen; denn nutzbar sind ja nicht bloß die dermaligen Holzmassen der hiebsreifen Bestände, sondern bei Annahme streng nachhaltiger Massenabnutzung, die durch Zuwachs bis Periodenmitte vermehrten Beträge (bei 10jährigem Einrichtungszeitraum also zuzüglich 5jährigen Zuwachses u. 8. f.)

Um auf die in der württ. Staatsforstverwaltung eingeführte Buchungsweise zu exemplifizieren, so würde sich die Ausscheidung von Altersklassen etwa folgendermaßen ohne erheblichen Zeitaufwand und ohne einschneidende Abänderung der bestehenden Einrichtungen durchführen lassen: Die einzelnen Hiebsanträge bezw. Schlagergebnisse wären im Nutzungsplan ${ }^{1}$ ) bezw. in der gegenüberstehenden Fällungsnachweisung nicht, wie bisher meist üblich, rein nach der Reihenfolge der Abteilungsnummer, sondern nach Altersklassen geordnet vorzutragen; außerdem müßten Holzarten-Rubriken an Stelle der Sortimentseinteilung in der Fällungsnachweisung treten (als Sortimentsübersicht dient ja ohnehin ein anderes Formular, die Derbholzübersicht). Spalten für Eintrag der Abnutzungsfläche sind bezüglich der Hauptnutzungserträge im allgemeinen entbehrlich, da hierüber erst am Schluß des Einrichtungszeitraums abgerechnet wird (s. Tab. 6 unten: $\mathbf{N}_{10} \mathbf{A b}$ nutzungsfläche). Die jährlich e Nutzungsfläche ist ja nur beim Kahlschlagbetrieb eine klar abgegrenzte Größe ${ }^{2}$ ). Dagegen

1 Muster VII der gedruckten Vorschriften für die Wirtschaftseinrichtung in württ. Staats- und Körperschaftswaldungen von 1898 .

2) ,Nach dem hessischen Verfahren läuft neben dem jährlichen M a s s e n hiebssatz für Haupt- und Zwischennutzungen ein jährlich ziemlich gleicher Flächensatz" (zitiert aus einem Aufsatz von T h a 1 e $\mathrm{r}$ in der A. F. und J. Z. 1909 S. 90). 
wären die Durchforstungen nach Fläche und Masse (wie bisher üblich), im übrigen aber wie die Hauptnutzungen, zu buchen. Das Jahresergebnis würde dann altersklassenweise in eine der Holzvorrats- und Altersklassentabelle entsprechende Ertragsnachweisung eingestellt, die, innerhalb des Wirtschaftszeitraums fortlaufend geführt, mit ihren Endzahlen am Schluß desselben die Größen $\mathrm{N}_{10}$ der Zuwachsformel lieferte.

Es ist nun die Anwendung jener Formel zu besprechen: Die Ermittlung des Gesamtzuwachses der Betrie bs klass e als $l d z=V_{n}+{ }_{10}-V_{n}+N_{10}$ macht weiter keine Schwierigkeiten. Bei Abrechnung über die absoluten Zuwachsbeträge der einzelnen Altersklassen ist aber zu berücksichtigen, daß die Teilgrößen $V_{n+10}$ und $V_{n}$

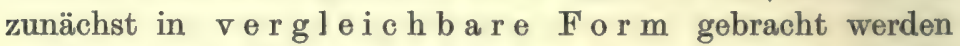
müssen, da die Fächer der $\mathrm{n}$ e u e n Altersklassentabelle die Betriebsklasse teilweise in anderer Zusammenordnung der $\mathrm{Be}$ stände erscheinen lassen. Man muß deshalb zunächst etwaige Abgänge an Waldareal durch Abtretung etc. am alten Stand, etwaige Zugänge durch Ankauf u. s. f. am neuen Stand in Abzug bringen; daß eine derartige Flächenabrechnung erforderlich ist, wurde schon früher ${ }^{1}$ ) erwähnt. Am einfachsten gestaltet sich die Berechnung, wenn sowohl die Altersklassenund Holzvorratsübersicht (wie in den sächsischen Forsteinrichtungswerken) als auch die Nachweisung über die Nutzungs-

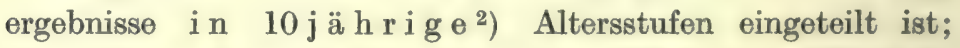
dann ist nur die neue Altersklassen- und Holzvorratsübersicht $\left(V_{n}+{ }_{10}\right)$ der alten $\left(V_{n}\right)$ in der Weise gegenüberzustellen, daß die einzelnen Altersstufen je um eine zurückgesetzt erscheinen, nachdem zuvor die sog. ,mißratenen Kulturen“ oder sonstige nicht vorrückende Bestände ausgeschieden worden sind; ebenso wären auch die eine Stufe überspringenden (z. B. Weißtannen- oder Buchenverjüngungen) getrennt zu behandeln. Werden dagegen nur $20 \mathrm{j} \ddot{\mathrm{h}} \mathrm{r}$ i g e Altersklassen bei einem

1 S. oben S. 32 und 33.

2) Vergl. hierüber auch die Ausführungen von Dr. K ö n i g in seiner Schrift, ,Die Altersklassen "6 u. S. f. (a. a. O.) S. 35 ff. und $\mathrm{J}$ u dei ch, Forsteinrichtung S. 99. 
auf $10 \mathrm{~J}$ a h re sich erstreckenden Berechnungszeitraum ausgeschieden, so kann man sich etwa folgendermaßen helfen: (s. Tab. 6) Die Altersklassen- und Holzvorratsübersicht wird in 2 Teilen angelegt, deren einer A) für $d$ i e $v$ e $r$ b l e i b e nd en (d. h. in der seitherigen Altersklasse zurückbleibenden) Bestände bestimmt ist, während unter B) die (in die nächst höhere Altersklasse) v o r r ü c k e n d e n vorzutragen wären. Die Summe der beiderseitigen Endzahlen ergibt den neuesten Stand der Altersklassen- und Holzvorratsübersicht (vergl. in Z. 2 der Tab. 6: $V_{\mathbf{n}}+{ }_{10}$ ). Werden aber die einzelnen Altersrubriken von B) mit ihren Endsummen, je um eine Klasse (also auf den alten Stand) zurückgesetzt und unter die Endsummen von A gestellt - Z. 3 der Tabelle -, so erhält man durch Addition von A und B die Altersklassenverteilung des abgelaufenen Einrichtungswerks mit, um den 10jährigen $\mathrm{Zu}$ wachs vermehrten und gleichzeitig um die Nutzung dieses Zeitraums verminderten Vorräten $\left(V_{n}+{ }_{10}\right.$ in $Z .3$ der Tab. 6 siehe nächste Seite).

Hat man die Größe $\mathrm{Vn}_{\mathrm{n}+10}$ in, mit $\mathrm{Vn}$ a $1 \mathrm{tersk}$ a ss e n w e is e vergleichbare Form gebracht, so kann die Formel $\mathrm{ld} z=\mathrm{V}_{\mathrm{n}+10}-\mathrm{V}_{\mathrm{n}}+\mathrm{N}_{10}$ zur Ermittlung der im abgelaufenen Zeitraum angelegten Zuwüchse der einzelnen Altersklassen angewendet werden. In der $\mathrm{Fl}$ ä c h en differenz von $\mathrm{V}_{\mathbf{n}+10}$ (in der Form von $\mathrm{Z} .3$ der Tabelle) und $\mathrm{V}_{\mathrm{n}}$ erhält man zugleich die Abnutzungsflächen, gleichfalls in altersklassenweiser Gliederung.

Soll nun weiterhin der $\mathrm{Zuwachs} d e r$ Flächeneinheit oder das Massenzuwachsprozent der einzelnen Altersklassen berechnet werden, so ist daran zu denken, daß sowohl die Flä chen, wenigstens soweit Flächenabnutzung stattgefunden hat, als die Vorräte der e inzelnen Altersklassen keine festen, sondern sozusagen flüssige Größen sind: War $F_{n}$ die Flächengröße einer Altersklasse zu Beginn des verflossenen Zeitraums (1900 in 


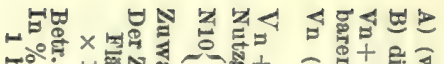

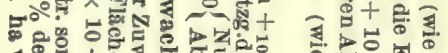

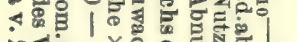

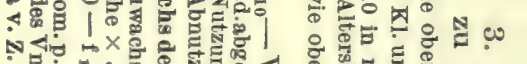

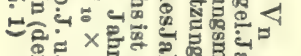
禺

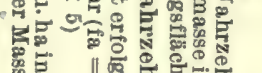

急管

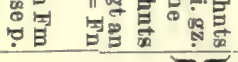

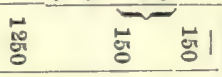

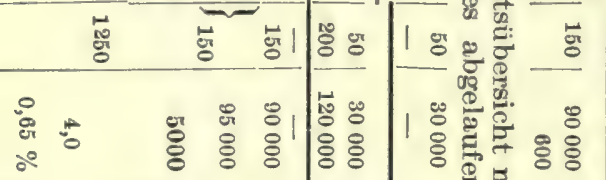

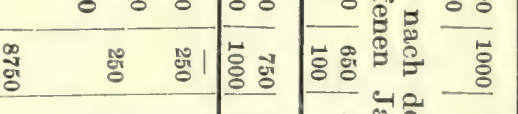

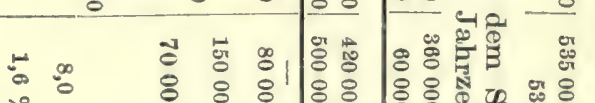
$\therefore$ 悉

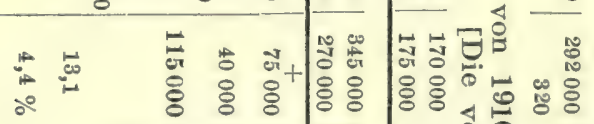

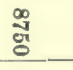

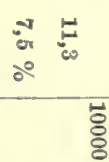

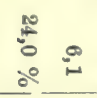
.

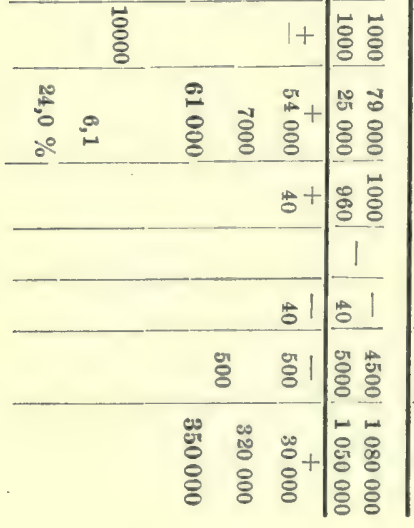

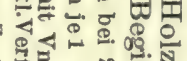

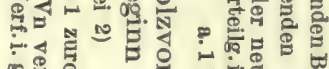

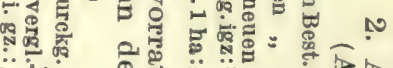

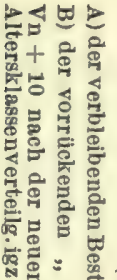

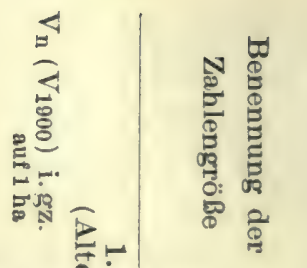
政—

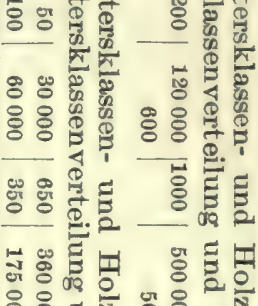

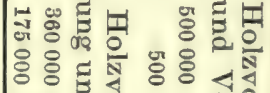
इ 은 80 屌势

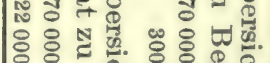
8.

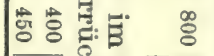
政

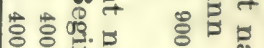

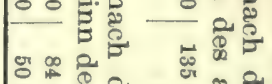

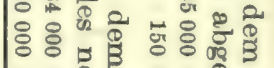

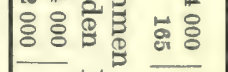

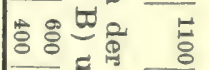

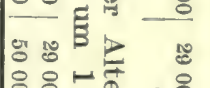
: 80 : No

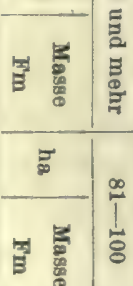

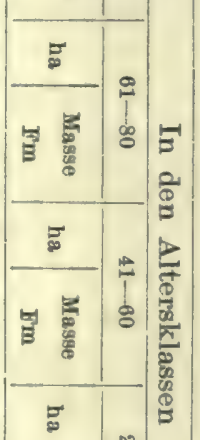

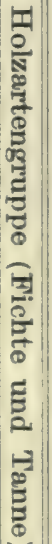

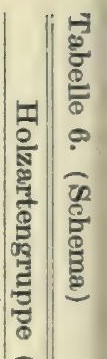

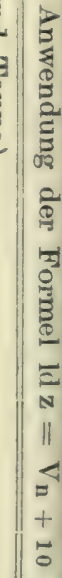

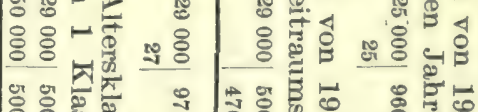
붑

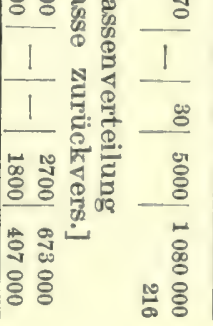

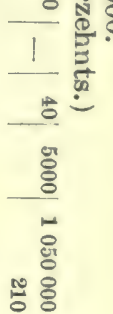

Masse

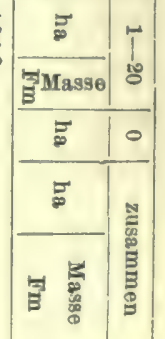


dem Beispiel der Tab. 6) und $\mathrm{f}_{10}$ die Flächenabnutzung, so ist jetzt nur noch die Fläche $F_{n+10}=F_{n}-f_{10}$ übrig. Der Altersklassenzuwachs setzt sich somit zusammen aus dem 10jährigen Zuwachs auf der Fläche $\mathrm{F}_{\mathbf{n}}-\mathrm{f}_{10}$ und dem 5jährigen der Flächen $f_{10}$, sofern man bei nachhaltiger Nutzung den gesamten Massenertrag als in Perioden-Mitte erhoben sich vorstellen kann, was umso eher zutreffen dürfte, je größer die Betriebsklasse ist. Der $\mathrm{durchschnittliche} \mathrm{Jah-}$ reszuwachs der Flächeneinheit berechnet sich hienach als Gesamtzuwachs der Altersklasse dividiert durch die Größefa= $10\left(\mathrm{~F}_{\mathrm{n}}-\mathrm{f}_{10}\right)+5 \mathrm{f}_{\mathbf{1 0}}=10 \mathrm{~F}_{\mathrm{n}}-5 \mathrm{f}_{\mathbf{1 0}}$ (in dem Beispiel der Tab. 6. $\frac{5000}{1250}=4,0 ; \frac{70000}{8750}=8,0$ u. s. f.).

Diese Beträge, in Beziehung gesetzt zu den durchschnittlichen Vorräten der Flächeneinheit zu Beginn des abgelaufenen Jahrzehnts ( $\mathrm{Vn}$ in Z. 1 der Tab. ber. auf $1 \mathrm{ha}$ ), ergeben bei Annahme einfacher Verzinsung das $d \mathrm{u} \mathrm{r} \mathrm{h} \mathrm{s} \mathrm{c} \mathrm{h} \mathrm{n} \mathrm{it} \mathrm{t} \mathrm{l} \mathrm{i} \mathrm{c} \mathrm{h} \mathrm{e}$ Massenzuwachsprozent je der einzelnen Altersklassen; ebenso gut kann die Berechnung, wenn man es für richtiger hält, nach der Preßlerschen Näherungsformel durchgeführt werden. (Hienach berechnete sich in dem Beispiel der Tabelle 6 für die Altersklasse $81-100$ bei $V_{\mathrm{n}}=500,1 \mathrm{dz}=$ $10 \times 8$ pro ha: $p=\frac{580-500}{580+500} \times 20=1,5 \%$ gegen $1,6 \%$ bei Annahme einfacher Verzinsung).

$\mathrm{Zu}$ bemerken ist noch, daß der im Beispiel Tab. 6 eingeschlagene Umweg über die Ausscheidung von A) und B) ganz von selbst zur Abstufung in 10jährige Altersfächer führt, indem die ,verbleibenden" je als Altersstufe 11-20, 31-40 u. s. f., die vorrückenden als $1-10$ etc. angesehen werden können. Es fragt sich nur, ob die Ausscheidung 10jähriger Altersstufen auch in der Kontrollbuchf üh r ng nicht als $\mathrm{zu}$ schwerfällig empfunden wird. 
Die nach der eben beschriebenen Rechnungsweise ermittelten Zuwachsbeträge des abgelaufenen Wirtschaftszeitraums bilden beim Vergleich mit früheren bezw. späteren gleichartigen Erhebungen und in Verbindung mit der Holzvorrats- und Altersklassenübersicht den z u v e r 1 äs s i gsten Maßstab für die seitherige Entwickl u n g (Mehrung oder Minderung) d e r M a s s e n ertragsf äh ig k it; sie lassen sich aber auch zur Beurteilung der künftigen Ertragsfähigkeit und zur Bemessung der i m $\mathrm{n}$ e u e n Wirtschaftszeitraum zu beziehenden Massenrentesowiezur A s scheidung zwisehen dermaliger ordentlicher und a 3 erordentlicher Nutzung nach Maßgabeder gewählten Umtriebszeit verwenden. Denn man wird im allgemeinen unterstellen können, daß wenigstens im nächstfolgenden Jahrzehnt der laufende Zuwachs der Betriebsklasse bezw. Holzartengruppe, sowohl im ganzen als bezüglich der homologen und zumal der älteren Bestandesklassen, prozentisch sich annähernd gleich bleiben wird; vollziehen sich doch die auf die Zuwachsbildung einwirkenden Umgestaltungen im Großen und Ganzen der Waldwirtschaft nur allmählich und auch die durchschnittliche Beschaffenheit der zur Nutzung heranstehenden Bestände (der gleichen Holzartengruppe) ändern nur schrittweise, unter dem Einfluß der wirtschaftlichen Behandlung, ihren Charakter. Immerhin wird man durch $\mathrm{Zu}$ wachsuntersuchungen und durch Bonitätsnachweisungen in altersklassenweiser Gliederung die Zulässigkeit jener Unterstellung kontrollieren müssen.

Aus den Zuwüchsen der einzelnen Betriebsklassen (bezw. Reviere) berechnet man dann den Zuwachs des größeren Waldverbands; altersklassenweis ${ }^{\mathbf{1}}$ ) getrennte Nutzungsnachweisung

1) Es könnte sich höchstens darum handeln, die Durchforstungserträge auch in der Ertragsstatistik über den ganzen Waldbesitz nach Altersklassen getrennt (wenigstens für über 40jährig und unter 40jährig) vorzutragen. 
ist hiefür entbehrlich; dagegen sollte die Altersklassen- und Holzvorratsübersicht in der Einrichtungsstatistik auch für die größeren Waldgebiete und den ganzen Waldbesitz zusammengestellt werden, damit auch die Nutzbarkeit der ermittelten Zuwachsbeträge beurteilt werden kann.

Voraussetzung für Anwendung dieser auf Ergründung alles Meßbaren und Nutzbarmachung der Ertragsstatistik sich stützenden Methode ist die zuverlässige Ermittlung nicht bloß der Nutzungsergebnisse sondern auch der Inventarfaktoren Fläche, Alter und Vorrat und zwar je in vergleichbaren Maßen und Zahlbegriffen. Vorratsermittlungen werden bislang vielfach, so nach den württembergischen Vorschriften, in der Hauptsache auf Bestände der I. Periode beschränkt; man wird also in den betr. Verwaltungen zunächst möglichst einfache und doch genau arbeitende Verfahren zur Ermit $\mathrm{m}$ lung des Gesamtholzvorrats ausfindig machen und erproben müssen, ohne sich auf e in Verfahren festzulegen; es wird sich vielmehr empfehlen, in freiester Anwendung der vielerlei, anderwärts erprobten Verfahren je nach Waldverhältnissen bald dieses bald jenes, bald Okularschätzung baild stammweise Aufnahmen, bald Probeflächen- bald Probestamm-Verfahren bei der Wald-Inventarisierung zu benützen. Ferner ist mit Rücksicht auf die Vergleichbarkeit der Vorratsgrößen mit den Nutzungsergebnissen tunlichste Ausgleichung etwaiger in der $\mathrm{Verschiedenartigkeit} \mathrm{der} \mathrm{MaBe}$ begründeter (Festmaß, Raummaß, Stückmaß etc., entrindet, in der Rinde u. ä.) oder durch n a türlich e Fehl erque l] e n (Fällungs- oder Ernteverluste) bedingter Differenzen anzustreben durch Festsetzung von Reduktionsfaktoren, Abzugsprozenten ${ }^{1}$ ) u. dergl., sowie durch fortgesetzte Prüfung und Verbesserung dieser Hilfszahlen.

1) In den, Massentafeln zur Bestimmung des Holzgehalts stehender Waldbäume und Waldbestände" von Gr u n d n e r $\mathrm{Sch}$ a p p a h (1906) ist $\mathrm{S}$. 6/7 auf solche Kürzungen hingewiesen, deren Größe an der Hand der Erfahrung einzuschätzen sei. 
Für solche Zwecke sowie zur Vereinfachung und Verfeinerung der Inventaraufnahmen eignet sich ganz besonders die Anlegung von sog. ,Weiserbeständen“" ${ }^{1}$ ) wie sie in Hessen (früher auch in Baden), ferner als "Lagerbuchsbestände“ in Sachsen und in gewissem Sinn auch in den österreichischen ${ }^{2}$ ) Staatsforsten eingeführt sind. In solchen Probebeständen können die zuverlässigsten Verfahren und die einfachsten Arbeitsformen erprobt, Erfahrungszahlen für die Masseneinschätzung (insbesondere betr. Formhöhe) und für Zuwachsermittlungen gesammelt sowie die eben erwähnten Reduktionsfaktoren ermittelt werden. Aus den Ergebnissen der Weiserbestandsaufnahmen lassen sich Lokalertragstafeln ${ }^{2}$ ) zusammenstellen, was insbesondere für lokale Wuchsgebiete und für besondere Bestandesformen (Mischwald) zu empfehlen wäre. Denn bei aller Hochachtung vor den Normalertragstafeln der Versuchsanstalten muB doch betont werden, daß ihrer Verwendbarkeit für die Zweckeder Forsteinrichtung und Waldwertsberechnung manche Grenzen in örtlicher und zeitlicher Beziehung gesetzt sind. Die Ansichten hierüber sind zwar geteilt: während z. B. T h a 1 e ${ }^{3}$ ) und $\mathrm{E} \mathrm{b}$ e r h a r d die große Beliebtheit der Ertragstafeln betonen, sprechen sich $\mathrm{M}$ a r t i ${ }^{3}$ ), $\mathrm{Ostw}$ a l d u. a. weniger in diesem Sinne aus.

1) In Baden aufgegeben (s. P h i l i p p, Die Forstl. Verh. etc. a. a. O. S. 5); bezüglich Hessen vergl. A. F. und J. Z. 1909 S. 92 (T h a 1 e r); bezüglich Sachsen vergl. Tharander Forstl. Jahrbuch Band 48 vom Jahr 1898 S. 255, wo die betr. Vorschriften abgedruckt sind.

2) Vergl, die in vieler Hinsicht nachahmenswerten Vorschriften über die Einrichtung der österreichischen Staatsforste ( $\$ 32$ der Instruktion), durch welche die Aufstellung von Lokalertragstafeln für jedes einzurichtende Revier angeordnet wird zum Zweck der Erhebung von Vorrat-, Massen- und Wertzuwachs (besprochen von M a rtin, Z. f. F. und J. W. 1902 S. 712 ff. und in der Forsteinrichtung S. 119 f.).

3) $\mathrm{Th}$ a le r in A. F. und J. Z. 1909 S. 92; E ber h a r d in A. F. und J. Z. 1909 S. 172 (die praktische Brauchbarkeit ist eine 
Insbesondere mag auch der erhebliche Unterschied in den Ergebnissen einzelner den gleichen Stoff behandelnder Ertragstafelwerke (so Tanne-Lorey und Tanne-Schuberg) ferner die Vergleichung alter und neuer Ausgaben (z. B. Fichte und Kiefer in Preußen) zu Zweifeln Anlaß geben. Daß die Normalertragstafeln soweit als irgend möglich für die Waldinventaraufnahmen nutzbar gemacht werden müssen, liegt schon im Sinne tunlichster Geschäftsvereinfachung; man wird sich vielfach darauf beschränken können, aus den Weiserbestandsaufnahmen Reduktionsziffern für Anwendung der Normalertragstafeln zu gewinnen.

Zuverlässige und innerhalb größerer Waldgebiete vergleichbare Inventaraufnahmen, zweckmäßige Weiterausbildung der besten und einfachsten Verfahren setzen aber voraus, daß diese Arbeiten von Beamten ausgeführt und überwacht werden, welche durch Spezialausbildung die nötigen Erfahrungen und praktische Routine sich angeeignet haben, wie es sich bei zentral organisiertem ${ }^{1}$ ) Forsteinrichtungsdienst von selbst ergibt. Mit Rücksicht auf die Bedeutung, welche der Ertragsstatistik für die Erfassung der Massenertragsfähigkeit des Waldes zukommt, dürfte der Forsteinrichtungsanstalt auch das Arbeitsgebiet der Statistik ${ }^{2}$ ) zu übertragen sein, ,das Sammeln und volle $\mathrm{Nutzb}$ ar$\mathrm{mach} \in \mathrm{n}$ der Wirtschaftsergebnisse des abgelaufenen Zeitraums für die Zukunft" (s. W a g $n$ e ${ }^{1}$ ) S. 46 f.).

ganz außerordentliche); $\mathrm{O}$ s t w a $1 \mathrm{~d}$ Z. f. F. und J. W. 1909 S. 14 (die Ertragstafeln sind als Hilfsmittel nicht ohne weiteres zu verwenden); M a r t i n, Z. f. F. und J. W. 1902 S. $454 \mathrm{ff}$. (der Einfluß der Ertragstafeln auf die Bemessung d.nv sollte beschränkt werden).

1) Vergl. die diesbezüglichen Ausführungen von W ö r n le (A. F. und J. Z. 1907 S. 22), von M a r t i n im Februar- und Märzheft der A. F. und J. Z. 1909, von W a g n e r in ,Unsere Forstwirtschaft im 20. Jahrhundert"، II. ,Betrachtungen über den forstl. Unterricht und das Einrichtungswesen."

2) In Sachsen und Baden besteht diese Geschäftsverbindung (vergl. M a r i n, Die Forsteinrichtung 1906 S. 95 und 99). 
Jedenfalls müssen wir verlangen, daß die Forsteinrichtung und die Statistik zusammenarbeiten, um die Entwi cklung der Massenertragsfähigkeit unserer Wälder so zuverlässig als möglich nachzuweisen und so der forstlichen Produktionstechnik als Wegzeiger zur weiteren fortgesetzten Mehrung des Waldertragsvermögens zu dienen. Aehnlichen Sinn dürften die scheinbar paradox klingenden, aber sicher ein groß Korn Wahrheit enthaltenden Worte $\mathrm{N}$ ü s s l es haben ${ }^{1}$ ): „Ertragserhöhung ist heute wichtiger als Ertragsregelung."

1) F. Zentrbl. 1907 S. 192. 


\section{Teil.}

\section{Die Mehrung des Einheitswerts der Waldrente.}

(Die Mehrung auf Seiten des GeldwertsKom ponenten.)

Gliederung.

Seite 12 oben wurde für die Staatsforste von Preußen, Sachsen und Württemberg gezeigt, daß die erhebliche Steigerung der Waldreinerträge neben dem Anwachsen der Massenabnutzungssätze zu einem sehr beträchtlichen Maß der E rhöhung des Reinertrags bezogen auf die Masseneinheit ( $1 \mathrm{Fm}$ Derbholz bezw. Gesamtmasse) zu danken ist. Es wird die Aufgabe des II. Teils sein, den auf Seiten des Geldwertskomponenten mehrend bezw. mindernd wirkenden Elementen nachzugehen. Dabei ist nicht $\mathrm{zu}$ übersehen, daß die Geldwertsmehrung in engstem Zusammenhang und ständiger Wechselbeziehung zur Massenertragssteigerung steht, indem sie der ganzen $\mathrm{Holz}-$ produktion, soweit diese überhaupt als $F$ or s t w i r t s c h a f t bezeichnet werden kann, Richtlinien gegeben hat; daneben war sie auch, wie schon oben erwähnt, für den Grad der Nutzbarkeit des dem Waldbesitzer als Rente zur Verfügung stehenden laufend-jährlichen Zuwachses (die Umtriebsfestsetzung) bestimmend. Die forstliche Technik, welche unter dem Einfluß der fortgesetzten Geld-Ertragssteigerung sich mehr und mehr zu entfalten begann, hat durch intensivere Bewirtschaftung den Grund zu weitergehender Ertrags meh- 
r ung - sowohl durch Zuwachsförderung als Geldwertsverbesserung - gelegt. Inwiefern andererseits die Ausdehnung der Massenproduktion auf die Geldwertsentwicklung rückwirkend war, wird im folgenden noch zu besprechen sein.

Die auf Seiten des Geldwertskomponenten nachweisbaren Mehrungsursachen lassen sich, entwicklungsgeschichtlich betrachtet, in 5 Gruppen zusammenordnen, welche durch die nachstehenden Sätze charakterisiert werden können.

1. Nach Verdrängung früher vorhandener und zum Teil herrschender Holz- und Betriebsarten, die Hölzer von geringerem Gebrauchswert lieferten, sind wertvollere $\mathrm{H}$ öl z e r und Bestände herangewachsen;

2. in den vorhandenen, von den Vorfahren überkommenen Beständen sind unter dem Einfluß der lebhaften Entwicklung von Handel, Industrie und Verkehr, dank der Fortschritte von Wissenschaft und Technik sowie der allgemeinen Hebung des Maßes der Lebenshaltung $n$ e u e Gebra u c h s werte entstanden, manche Forstprodukte überhaupt erst verwertbar, andere einer vorteilhafteren Verwertungsart zugeführt worden (z. B. Reisig, Stockholz, Papierholz, Grubenholz);

3. die vorhandenen Gebrauchswerte bezw. Gebrauchswertsanlagen haben infolge Entwicklung der forstlichen Technik Verbesserung und feinere Ausbildung erfahren, teilweise konnte auch der Produktionszeitraum verkürzt werden, so daß bei gleichem Alter im Vergleich zu früher wertvollere Ware zur Verfügung stand;

4. die vorhandenen Gebrauchswerte haben $\mathrm{h}$ ö $\mathrm{h}$ eren Tauschwertseharakter mit Bezug auf das in den Kulturländern übliche Zahlungsmittel ,Geld“ angenommen (wobei die verschiedenartig gelöste Frage der Geldentwertung außer Betracht bleiben soll);

5. durch die Höhe des Produktions a ufwands sind die günstigen Wirkungen der Ursachen Z. 1-4 teils verstärkt, teils beeinträchtigt worden. 
Es soll nicht geleugnet werden, daß die Zertrennung des Stoffs nach den vorstehend aufgeführten, unter sich in engster Fühlung stehenden Punkten eine gewisse Willkür bedeutet; allein die Aufgabe der vorliegenden Arbeit, die einzelnen Elemente wertsmehrender Tendenz herauszuschälen, erfordert eine derartige Gliederung. Bezüglich der Wirk u ng gehören die Punkte 1-3 näher zusammen und werden deshalb unter dem Begriff Elemente der Qualitätsmehrung zusammengefaßt, während Punkt 4, hinsichtlich U r s a ch e mit 2 wahlverwandt, als $\mathrm{Pr}$ e is g e s tal t u ng, und Punkt 5 als Entwicklung des Produktionsaufw a $n d s$ zu besprechen sein wird.

\section{A bschnitt.}

\section{Die Qualitätsmehrung.}

\section{Das Nutzholzprozent als Weiser der Wertsmehrung.}

Anhaltspunkte für den Nachweis der Qualitätsmehrung bieten die Angaben der Forststatistik über die $\mathrm{Nutzholz-}$ Prozente. Nach einheitlichen Grundsätzen wird auch dieser Gegenstand in der vom Forstwirtschaftsrat ins Leben gerufenen Statistik über die Erträge der deutschen Waldungen behandelt. Eine chronologische Zusammenstellung, wie sie in Endres Handbuch der Forstpolitik enthalten ist, läßt ununterbrochenes stetiges Zunehmen des Nutzholzprozents in allen größeren deutschen Staatsforstverwaltungen erkennen; als Ursache hiefür können sowohl die unter Punkt 1 als 2 aufgeführten Momente in Betracht kommen. Inwieweit dieser Fortschritt speziell der Verdrängung geringwertigerer Holzund Betriebsarten durch wertvollere zu danken ist, kann aus der Statistik der Holzartenverteilung und aus einer nach Holzarten gegliederten Ertragsstatistik (s. Tab. 5 oben) entnommen werden.

Im I. Teil wurde mit Bezug auf die württembergischen Staatsforste gezeigt, daß der Fichten- und Tannenbestockung ein von 
Altersklasse zu Altersklasse wachsender Anteil am W a l d b est a n d zukommt, besonders auffallend in den friheren Laubholzdomänen Alb und Unterland, und daß dieser Vorgang bereits auch auf $\mathrm{d}$ i e $\mathrm{Nutz}$ u $\mathrm{g}$ insbesondere der letztgenannten Gebiete seinen Einfluß äußert. Aus der württembergischen Einrichtungsstatistik von 1908 (Tab. D 4) ist ersichtlich, daß, während im Jahr 1884 noch 2497 ha im Mittel- und Niederwaldbetrieb bewirtschaftete Waldteile vorhanden waren, diese Betriebsarten nunmehr ganz verschwunden sind. Aehnliche Bestockungsänderungen läßt z. B. auch die sächsische und badische Statistik nachweisen : der sächsische Staatsforst ${ }^{1}$ ) bestand 1834/43 noch zu $3 \%$, $1864 / 73 \mathrm{zu} 1 \%$ aus Mittel- und Niederwald; $1834 / 43$ waren noch 5115 ha Buchen-, 85 ha Eichen-, 6744 ha sonstige Laubhölzer vertreten, nach dem Stand von 1884/93 dagegen kommt die Mittelund Niederwaldklasse prozentisch nicht mehr zum Ausdruck, der Buchenwald ist auf 3445 , das sonstige Laubholz auf 1143 ha zusammengeschmolzen, während die Eich e weitere Flächen. erobert hat (1300 ha). Auch die Holzartenverteilung in den badischen ${ }^{2}$ ) Domänenwaldungen läßt ein Zusammenschrumpfen des Laubholzes von $60 \%$ (1876) auf $51 \%$ (1900) deutlich erkennen, wobei auch die Eiche (Eichenschälwald?) mit Leidtragende ist; nach der badischen Ertragsstatistik (II 2 der Stat. Nachweisungen) waren 1878: 8323,3 ha Mittel- und Niederwald mit einer Gesamtnutzung von $39262 \mathrm{Fm}$ (Derbholz und Reisig), 1907 nur mehr 4608,87 mit 22764 Fm Nutzungsmasse vorhanden. Der Einfluß, den dieser Entwicklungsprozeß auf das Nutzholzprozent äußern mußte, geht aus Seite 30 der Nachweisungen von 1907 deutlich hervor, wo das Nutzholzprozent getrennt nach Holzartenmischung und Betriebsarten angegeben wird: Hiernach war während der Periode 1878-1907 das Nutzholzprozent im ganzen von $41 \%$ auf $48 \%$ (Derbholz) bezw. von 34 auf 41 (Gesamtmasse) angestiegen teils infolge des Umsichgreifens der mit höherem Nutzholzprozent ausgestatteten Nadelhölzer (52-67\% gegen nur 16 bis 25 des Laubholzes), teils dank der höheren Nutzholzausbeute welche für die einzelnen Holz- und Betriebsarten selbst nachweisbar ist (Laubholz von 16 auf 25, Nadelholz von 52 auf 67, Hochwald von 36 auf 41, Mittel- und Niederwald von 17 auf $18 \%$ ). Auch nach der württembergischen Statistik läßt sich eine ganz erhebliche $\mathrm{Zunahme}$ der Nutzholzaus eute sämt 1 i c h e r Holzarten feststellen, der gegenüber die Bedeutung der Holzarten verschiebung im großen und ganzen zurücktritt (in den Gebieten Alb und Unterland mag auch dieses Moment wesentlich zur Erhöhung der Gesamtnutzholzziffer beigetragen haben). Dabei darf aber die Tatsache nicht verschwiegen werden, daß die an sich wertvollste Holzart, die Eiche, an der Steigerung der Gesamtnutzungsmasse nicht beteiligt war;

1) Die Entwicklung der Staatsforstwirtschaft im Königreich Sachsen S. 14 und 15.

2) Statist. Nachweisungen aus der Forstverwaltung des Großherzogtums Baden 1907, Anlage 5. 
der Anfall an Eichenderbholz ist von 1880-1904 absolut annähernd gleichgeblieben, prozentual von 7 auf $4 \%$ zurückgegangen. Genaue, das ganze Land umfassende Aufnahmen des Eichenholzvorrats liegen nicht vor, auch läßt sich der Flächenanteil der Eiche aus früheren Angaben der Forsteinrichtungsstatistik, welche nur die Laubholzfläche im ganzen berücksichtigen, nicht ermitteln. Aber die Altersklassentabelle von 1908 (D ${ }^{2}$ der Einrichtungsstatistik) zeigt einen Abmangel an älteren Eichenbeständen an, während die jüngsten Altersklassen dieser edelsten Holzart wieder reichlicher ausgestattet sind.

So interessant die Nutzholz-Statistik, zumal im Vergleich mit Nachweisungen über die Holzartenvertretung, sein mag, so ist sie doch für das e i $\mathrm{ng}$ e h e $\mathrm{nd}$ e Studium der hier zu erörternden Frage un zureich e $\mathbf{n d}$, in manchen Stücken vielleicht sogar irreführend; zahlenmäßige Anhaltspunkte vermag sie für Ermittlung der Mehrung des Geldwerts ja ohnehin nicht zu bieten. Der Nutzholzbegriff ist heutzutage überhaupt ein ziemlich vager geworden, da die Konkurrenz der Kohle das Brennholz vielfach verdrängt hat und andererseits gewerbliche Unternehmungen entstanden sind, welche selbst die geringwertigsten Holzteile zu verarbeiten vermögen, die Nachfrage nach Brennholz an manchen Orten wieder belebend. Der Revierverwalter kann deshalb in die Lage kommen, kalkulieren zu müssen, ob er einzelne Teile des Holzanfalls nicht vorteilhafter als Brennholz statt als Nutzholz aufbereiten lassen soll; man denke an Buchenschwellenholz, Grubenholz, Papierholz, Hopfenstangen u. a. Da unter dem Sammelbegriff Nutzholz Waren der größten Wertsverschiedenheit zusammengeworfen werden, kann er als zuverlässiger Wertsoder Wertsmehrungsmaßstab nicht angesehen werden. Wenn sich die Ertragsstatistik ${ }^{1}$ ) darauf beschränkt, den Holzanfall und den Holzerlös nur nach Nutzholz und Brennholz gegliedert darzustellen, so hat sie für Erfassung der waldwirtschaftlichen Werte nur sehr geringe Bedeutung.

1) So z. B. die Mitteilungen der hessischen Forstverwaltung in $\mathbf{B} 1$ und 3 .

Forstwirtschaft. V. Dieteric b, Elemente d. Wertsmehrung. 
Es wird deshalb weiterhin zu untersuchen sein, welche Wertsgrößen und Wertsbegriffe eigentlich für die Qualitätsmehrung als Maßstab dienen können und deshalb von der Buchführung bezw. Statistik zum Ausdruck gebracht werden sollten.

\section{Das Wertsverhältnis der Holz- und Betriebsarten.}

Zum Nachweis und zur Ermessung der in Gruppe 1 (S. 62) zusammengefaßten Mehrungselemente müßten Vergleichszahlen vorhanden sein, welche die Wertigkeit der verdrängten bezw. der an Verbreitung und Nutzbarkeit zunehmenden Holzart oder Betriebsart einwandfrei feststellen lassen; Anhaltspunkte könnten statistische Notizen über die Einheitse rl ö s e der einzelnen Holzarten oder Betriebsarten bieten.

So enthalten z. B. die statistischen Nachweisungen der b a$\mathrm{d}$ is chen Staatsforstverwaltung in Tab. II 3 Angaben über den Holzgeld-Ertrag getrennt nach Hochwald einerseits, Mittelund Niederwald andererseits. Für unsere $\mathrm{Z}_{\text {wecke }}$ ist damit schon deshalb nicht viel anzufangen, weil zwei so verschiedenartige Betriebsarten (wie Mittel- und Niederwald) zusammengenommen und beim Hochwald die Holzarten nicht getrennt behandelt sind.

Ungleich größere Bedeutung kommt den statistischen Nachweisungen über die $\mathrm{E}$ in heitserlös e der wichtigsten H o l z a r t e n zu, wie solche in den Beiträgen zur Forststatistik von $\mathrm{E}$ is a $\mathrm{B}$ - L ot hring en enthalten sind.

Eine derartige Uebersicht, revierweise oder nach Gebieten angelegt, charakterisiert nicht nur die wirtschaftliche ${ }^{1}$ ) Behandlung der einzelnen Holzarten, sondern läßt auch den im ganzen erreichten und ev. erreichbaren Nutzeffekt der verschiedenen Holzarten bezogen auf die Masseneinheit, annähernd vergleichen; jedenfalls sind solche Zahlen dazugeeignet, den Waldbesitzer oder dessen verantwort liche Organe zur kritischen Prüfung der Holzartenwertigkeit und der Holzartenverteilung anzuregen, vielleicht sogargeradezu herausuforder $n^{2}$ ).

1) So betrug z. B. 1907 der Durchschnittserlös für $1 \mathrm{Fm}$ Eichennutzung im Bezirk Lothringen M. 18.17, im Oberelsa $\beta$ dagegen M. 12.79, was auf größere Ausdehnung der Brennholzwirtschaft (Niederwald) im letzteren Gebiet schließen läßt.

2) Nicht die Gegensätze auszugleichen und die Disharmonien zu verschleiern, sondern die auffallenden Erscheinungen mit voller Schärfe herauszuheben, muß die Aufgabe der Statistik sein, soll sie fördernd auf die Entwicklung der Forstwirtschaft einwirken. 
Aber so häufig in Theorie und Praxis des Forstwesens Begriffe wie ,wertvolle", ,geringwertige " Holzarten u. ä. erörtert werden, so wenig sind sie im allgemeinen von der Forststatistik als meßbare Größen erfaßt worden.

Aus den württembergischen Forststatistischen Mitteilungen z. B. lassen sich entsprechende Angaben nicht entnehmen; wohl enthält das 1908er Heft zum erstenmal eine Uebersicht über den Holzgeldertrag getrennt nach Sortimenten, aber die $\mathrm{h}$ ol zartenweise Gliederung ist nicht vollständig, wie in der entsprechenden Holzmassenertragsübersicht, sondern nur für das Sortiment Stammholz durchgeführt. Auch aus der MaterialBuchführung (sog. Materialrechnung) lassen sich jene Vergleichsgrößen nicht ermitteln; es bedürfte übrigens nur der Einschiebung weiterer Erlösspalten, um, ohne nennenswerte Geschäftsvermehrung, für alle Sortimentsgruppen ${ }^{1}$ ) auch den G e l d e r tr a g g etrennt nach Ha ptholzarten zur Darstellung z u bringe $\mathrm{n}$.

Je mehrdie Waldwirtsehaft nach finanziellen Gesichtspunkten beurteiltwerden muß, umso mehr sollte auch die Geldertragsbuchführung spezifiziert und jedenfalls derjenigen über den Naturalertrag angepa $\beta$ t werden.

Die Ermittlung der Einheitserlöse der Holzarten hat natürlich weniger Bedeutung für den gesamten Waldbesitz großer Verwaltungen, als vielmehr für das einzelne $R$ e vi er und besonders für solche Waldverbände oder Gebiete, dieinsich annähernd gleichartige topographische, geologische, waldbauliche und ökonomische Verhältnisse a $u$ f $\theta$ ise ${ }^{2}$ ).

Beschränkt sich die vergleichende Untersuchung auf das einzelne Revier, so darf nicht ausschließlich von den Durchschnittserlösen ausgegangen werden, welche sich nach den Nutzungsergebnissen des einzelnen Wirtschaftsjahrs berech-

1) Stammholz, Stangen, Schichtderbholz, Reisig.

2) Z. B. innerhalb des württ. Schwarzwalds das Murgtal-, Enztal-, obere, untere Nagoldtal-Gebiet u. s. f. 
nen; kommt doch die Wertigkeit der einzelnen Holzart, zumal der in geringerer Masse anfallenden, in den Ergebnissen des Einzeljahrs nicht immer richtig zum Ausdruck, da bald mehr im stärkeren bald mehr im schwächeren $\mathrm{Holz}$, je nach waldbaulichen Bedürfnissen (Samenjahr) oder ökonomischen Erwägungen gewirtschaftet wird. Deshalb kann nur der $\mathrm{D}$ u r c hsebnittsbetrag des ganzen Wirtschaftsz eitraums die richtigen Vergleichs-Wertgrößen der jeweils zur Nutzbarkeit heranstehenden Hölzer ergeben. Aber auch für größere Verbände müßte der Durchschnitt mehrerer Jahre zugrunde gelegt werden, um den Einfluß der Preisgestaltung möglichst auszuschalten; ganz wird dies ja nicht gelingen, aber doch können g r o ß e Fehler vermieden werden, die aus der Verschiedenheit des Markts der einzelnen Holzarten und Sortimente entstehen könnten.

Zur Ermittlung der auf Holzartenverschiebung zurückzuführenden Qualitätsmehrung, könnte man sich etwa folgenden Schemas ${ }^{1}$ ) bedienen:

Tab. 7. Uebersicht über die Einheitswerte der Holzarten nach dem Gesamtholzanfall (Schema).

\begin{tabular}{|c|c|c|c|c|c|c|c|c|c|c|c|c|}
\hline \multirow{2}{*}{\multicolumn{2}{|c|}{ Zeitraum }} & \multicolumn{2}{|c|}{ Eiche } & \multicolumn{2}{|c|}{ Rotbuche } & \multicolumn{2}{|c|}{ FichteTanne } & \multicolumn{2}{|c|}{ Forche } & \multicolumn{2}{|c|}{ im ganzen } & \multirow[b]{2}{*}{ 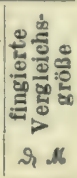 } \\
\hline & & 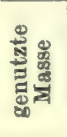 & 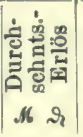 & 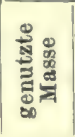 & 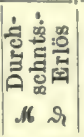 & 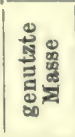 & 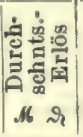 & 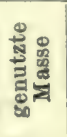 & 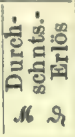 & 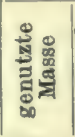 & 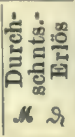 & \\
\hline $1875-84$ & $\underset{\%}{\mathrm{Fm}}$ & $\begin{array}{c}2000 \\
8,0\end{array}$ & 15.- & $\begin{array}{c}10000 \\
40,0\end{array}$ & 7. - & $\begin{array}{l}9000 \\
36,0\end{array}$ & 11. - & $\begin{array}{l}4000 \\
16,0\end{array}$ & 10.- & $\begin{array}{l}85000 \\
100\end{array}$ & 9.56 & $10.17^{2}$ \\
\hline $\begin{array}{c}1895 \text { bis } \\
1904\end{array}$ & $\underset{\%}{\mathbf{F m}}$ & $\begin{array}{r}2000 \\
6,7\end{array}$ & 25.- & $\begin{array}{l}7000 \\
23,3\end{array}$ & 11.- & $\begin{array}{c}16000 \\
53,3\end{array}$ & 18. - & $\begin{array}{l}5000 \\
16,70\end{array}$ & $15 .-$ & $\begin{array}{c}30000 \\
100\end{array}$ & 16.33 & $15.28^{\circ}$ \\
\hline
\end{tabular}

Die ges a m t e Wertsmehrung wäre gekennzeichnet durch die Zahlen 9.56 auf 16.33 , betrüge also rund für 1 Jahr $2,6 \%$. Hierin ist inbegriffen die sehr lebhafte Preissteigerung; um den letzteren Faktor zu eliminieren, und die Qualitätsmehrung isoliert

1) Es sind beliebige Zahlen eingesetzt, die etwa den nach württembergischen Verhältnissen vorliegenden Preisverhältnissen entsprechen mögen.

2) Nach dem Massenanfall von 1895-1904 und den Erlösen 1875-1884.

3) Nach dem Massenanfall von 1875-1884 und den Erlösen 1895-1904. 
zu berechnen, müssen die Einheitserlöse von 1875/84 auf die (der Holzartenverteilung nach wesentlich anders beschaffenen) Massenerträge von 1895/1904 angewendet werden; da aber das Verhältnis der Einheitserlöse sich 1895/04 anders gestaltet als 1875/84, empfiehlt es sich, daneben auch den umgekehrten Rechnungsweg einzuschlagen. Man erhält so 2 fingierte Vergleichsgrößen, welche gegenüber den tatsächlichen Durchschnittserlösen die Qualitätsmehrung annähernd ermessen lassen, soweit sie auf veränderten Holzartenanfall zurückzuführen ist, nämlich entweder M. 9.56 auf M. $10.17=0,3 \%$ für 1 Jahr berechnet oder M. 15.28 auf M. $16.33=0,33 \%$ für 1 Jahr berechnet.

Die reine Preissteigerung dagegen käme in folgenden Zahlen zum Ausdruck: M. 9.56 auf M. $15.28=2,3 \%$ oder M. 10.17 auf M. $16.33=2,27 \%$ p. Jahr.

Die Qualitätsmehrung tritt nach dem Beispiel der Tabelle 7 gegenüber der Preissteigerung recht in den Hintergrund, wiewohl eine sehr einschneidende Holzartenverschiebung vor sich gegangen ist, indem die Nutzung 1875-84 zu 40\%, 1895-1904 nur noch zu $25 \%$ aus Buche, dagegen zu $50 \%$ (gegenüber $36 \mathrm{i} .1875-84$ ) aus Fichte bestand. Die Vorgänge der Q u a litätsmehrung gehen, zumal sie ja im großen und ganzen nur allmählich wirken, unter dem beherrschenden Einfluß, den der Preisfak or auf die Wertsgestaltung ausübt, der Beobachtung leicht verloren; umsomehr besteht das Bedürnis, diese im kleinen, langsam aber sicher, tätigen Wertsmehrungselemente in der Statistik festzuhalten und gelegentlich $\mathrm{zu}$ analysieren; um rechnerisch genaue Untersuchungen kann es sich hiebei natürlich nicht handeln, wie ja auch gegen die obige Rechnungsweise allerhand Bedenken geltend gemacht werden könnten, vielmehr nur darum, die Tendenz der einzelnen Elemente zu veranschaulichen und soweit möglich, isoliert zu beobachten.

\section{Das Wertsverhältnis der Sortimente. (Sortimentsstatistik.)}

a) Allgemeines betr. Bedeutung und Form der Sortimentsstatistik.

Im Rahmen der überkommenen Holz- und Betriebsarten üben die zu Gruppe 2) und 3) (s. S. 62 f.) zusammengefaßten Elemente qualitätsmehrenden, teilweise auch qualitätsmindernden Einfluß aus; während die ersteren (2) $\mathrm{mehr}$ von a u $\beta$ en durch die Gunst oder Ungunst der allgemeinen volkswirtschaftlichen $\mathrm{Zu}$ stände in den Wald hereingetragen werden, erscheinendie anderen (3) als Folgen der forstwirtschaftlichen Tätigkeit bezw. der 
Veränderungen im Waldbestand, welche die Entwicklung der Waldwirtschaft mit sich bringt. Da es sich hiebei um Entstehung neuer Gebrauchswerte, Verfeinerung und Förderung teilweise auch Beeinträchtigung der überkommenen handelt, sind es die Sortiment $\mathrm{e}^{\mathbf{1}}$ ), die als Maßstab der Wertsveränderung dienen können.

Nachweisungen über die Sortimentsbildung sind bis jetzt von der Forststatistik noch recht stiefmütterlich behandelt worden, teils überhaupt vernachlässigt, teils auf einzelne Warengattungen oder Warengruppen beschränkt, teils sind $\mathrm{n} u \mathrm{r}$ Massenergebnisse, teils n u r Durchschnittserlöse notiert worden. Erst neuerdings hat sich ein lebhaftes Bedürfnis nach Ergänzung der Statistik in dieser Richtung geltend gemacht.

Eine vollständige Nachweisung des Massenanfalls un d der Erlöse sämtlicher Sortimente enthalten z. B. die braunschweigischen ${ }^{2}$ ) Mitteilungen; die preußische Statistik berücksichtigt nur einzelne Holzarten und Sortimentsklassen (nach Natural- und Geldertrag), die badischen Nachweisungen beschränken sich auf eingehende Angabe der Durchschnittserlöse sämtlicher Sortimente, während die Veröffentlichungen anderer Verwaltungen sich mit Ausscheidung von Nutzholz, Brennholz, Derbholz und Reisig begnügen. Zur neuesten Errungenschaft der württembergischen Statistik gehört eine ausführliche Uebersicht über den $\mathrm{D}$ e r b h o l zm as s e n e rtrag nach Sortimenten und als Parallele die oben erwähnte, nur unvollständig durchgeführte (nach der dermaligen Buchführung nur soweit durchführbare) über den $\mathrm{H}$ ol z g e lde rtrag nach Sortimenten; eine schon früher von 1884-1901 angelegte Sortimentsmassenübersicht (allerdings nur nach Sortimentsgruppen) war - ohne ersichtlichen Grund wieder aufgegeben worden ${ }^{3}$ ).

Da seit mehreren Jahren in großen Teilen Deutschlands einheitliche und im allgemeinen befriedigende Sortierungsgrundsätze, wenigstens für das Handelsholz (insbesondere Stammholz) eingeführt sind, dürfte $k$ e i $n$ H inder $n$ is

1) Vergl. hierüber M a rti n, Statik S. $103 \mathrm{ff}$.

2) Mitteilungen über die Wirtschaftsergebnisse der Herzoglich Braunschweigischen Forstverwaltung Z. 4 und 6.

3) Eine ausführliche Sortiments-Erlösstatistik mit Angabe des Massenanfalls enthält ferner (zum erstenmal) das 9. Heft der Mitt. a. d. Staatsforstverw. Bayerns v. Jahr 1909 (unter XII B). 
der a usführichen statistischen Behandlung dieses, für die Waldwertserforschung so a $\mathrm{B}$ erordentlich wiehtigen Stoffs mehr entgegenstehen, zumal weit weniger bedeutungsvolle Dinge, wie Forststraftaten u. ä., z. T. in ausführlicher Breite, dargestellt zu werden pflegen.

Tabelle 8 zeigt, wie die Sortimentsstatistik zur Untersuchung der Wertsveränderung nutzbar gemacht werden könnte.

Tab. 8. Derbholz-Sortiments-Uebersicht

(nach der württ. Forststatistik von $1884-86,1899-1901$ u. 1908).

\begin{tabular}{|c|c|c|c|c|c|c|c|c|c|}
\hline \multirow{3}{*}{$\begin{array}{l}\text { Zeit- } \\
\text { raum }\end{array}$} & \multicolumn{3}{|c|}{ Laubholz } & \multicolumn{4}{|c|}{ Nadelholz } & \multicolumn{2}{|c|}{ im ganzen } \\
\hline & $\begin{array}{l}\text { Stamm- } \\
\text { holz }\end{array}$ & $\begin{array}{l}\text { Schicht- } \\
\text { nutz- } \\
\text { holz u. } \\
\text { Stangen }\end{array}$ & $\begin{array}{l}\text { Schicht- } \\
\text { brenn- } \\
\text { holz }\end{array}$ & $\mathrm{Stamm-}^{\text {holz }}$ & $\begin{array}{c}\text { Stan- } \\
\text { gen }\end{array}$ & $\begin{array}{l}\text { Schicht- } \\
\text { nutz- } \\
\text { holz }\end{array}$ & $\begin{array}{l}\text { Schicht- } \\
\text { brenn- } \\
\text { holz }\end{array}$ & $\begin{array}{l}\text { Laub- } \\
\text { holz }\end{array}$ & $\begin{array}{c}\text { Nadel- } \\
\text { holz }\end{array}$ \\
\hline & \multicolumn{9}{|c|}{ In Prozenten des Gesamt-Derbholzanfalls. } \\
\hline & 1 & 2 & $\mathbf{3}$ & 4 & 5 & 6 & 7 & 8 & 9 \\
\hline $1884-86$ & 3,5 & 0,5 & 27,6 & 39,6 & 2,5 & 0,7 & 25,6 & 31,6 & 68,4 \\
\hline 1901 & 3,9 & 0,6 & 25,6 & 48,0 & 2,8 & 1,8 & 17,2 & 30,1 & 69,9 \\
\hline \multirow[t]{2}{*}{1908} & 4,1 & 0,7 & 22,7 & 52,4 & 3,5 & 2,1 & 14,5 & 27,5 & 72,5 \\
\hline & \multicolumn{3}{|c|}{ In \% des Laub-Derbhlz. } & \multicolumn{4}{|c|}{ In \% des Nadel-Derbholzes } & & \\
\hline $1884-86$ & 11,1 & 1,6 & 87,3 & 58,0 & 3,6 & 1,0 & 37,4 & & \\
\hline 1901 & 13,0 & 2,0 & 85,0 & 68,7 & 4,1 & 2,6 & 24,6 & & \\
\hline 1908 & 14,8 & 1,8 & 83,4 & 72,4 & 4,5 & 2,0 & 21,0 & & \\
\hline
\end{tabular}

Während sich in den Zahlen der oberen Reihen auch der allerdings wohl sehr unbedeutende - Einflu $B$ der $\mathrm{H}$ ol z a r t e nverschiebung geltend macht, lassen die unteren Reihen die Mehrung der Gebrauchswerte für die 2 Holzartengruppen getrennt erkennen: der Anteil des wertvollsten Sortiments $\mathbf{S} \mathrm{t}$ a $\mathrm{m} \mathrm{m-}$ h ol z hat mehr und mehr - auf Kosten des Schichtderbholzes zugenommen, auch die sog. Kleinnutzholzsortimente sind neuerdings reichlicher vertreten. Als Ursache der Aenderung kommen wohl in erster Linie Elemente der Gruppe 2 in Betracht: rege Entfaltung der Bautätigkeit mit der Folge gesteigerten Bedarfs an Bau- und Gerüstholz, Entstehung und Ausdehnung holzverarbeitender Gewerbe, Zellstoff-, Holzstoff-, Fabriken, WerkzeugMöbelindustrie (z. B. für Buchenholz), Ablösung der Brennholzund Besoldungsholz- Berechtigungen mit ihrem verschwenderischen Mißbrauch von Nutzholzwerten, Entwicklung der Verkehrsmittel und vor allem Ausdehnung des Waldwegenetzes. Daneben mag - eine strenge Scheidung ist natürlich nicht möglich auch sorgfältigere Ausformung beim Holzhauereibetrieb die Erhöhung der Stammholzausbeute begünstigt haben. 
Stünden Durchschnittserlöse oder Wertsziffern der Sortimentsgruppen zur Verfügung, so könnte man nach dem Vorgang der S. 68/69 angewendeten Rechnungsweise auch die in den Zahlen der Tabelle 8 zum Ausdruck kommende Qualitätsmehrung rechnerisch fixieren ${ }^{\mathbf{1}}$ ). Die württembergische Erlösstatistik beschränkt sich aber bisher auf die Nachweisung der durchschnittlichen Aufstreichserlöse weniger Sortimente, so des Eichen- und Nadelholzstammholzes, des normalen Schichtbrennholzes, der gebundenen Wellen und der Eichenglanzrinde, liefert sonach nur eine Wertsgröße für Sp. 4 der Tab. 8, nicht aber für die, gleichfalls große Holzmengen umfassenden, Sp. 3 und 7 ; denn die n ormale $\mathrm{m}$ Sortimente (Scheiter und Prügel) machen meist etwa nur die Hälfte des Schichtbrennholzanfalls aus. Ebensowenig kann man der neuesten Geldertragsübersicht (Stat. Mitt. 1908 Tab. VII Anh.) eine Verhältniszahl entnehmen, weil hier der Schichtderbholzerlös ohne Ausscheidung von Laubholz und Nadelholz vorgetragen ist.

Zuverlässige Vergleichsgrößen könnte übrigens eine nach dem Muster der Tab. 8 angelegte Sortiments-(Massen- und Erlös-) Statistik schon deshalb nicht ergeben, weil ihre $\mathbf{S}$ or $\mathrm{t}$ i m e $\mathrm{n} \mathbf{t}$ sgr u p e $n$ weitere Wertsklassen von zum Teil sehr beträchtlicher Verschiedenheit (z.B. Stammholz I./VI.) umschließen, deren Anteile selbst wiederum Veränderungen in wertsmehrender oder wertsmindernder Richtung erfahren können.

b) Spezielle Erhebungen über Sortimentsanfallund Sortimentsverhältnis.

Da für diesbezügliche Untersuchungen keine geeigneten, auf längere Zeit zurückreichenden statistischen Grundlagen aus dem Bereich größerer Forstverwaltungen zur Verfügung standen, wurden besondere Erhebungen an der Hand der Materialbuchführung eines württembergischen ${ }^{2}$ ) Forstbezirks

1) Teilt man den Gesamtholzanfall und -Erlös nur nach den 2 Kategorieen Nadelholzstammholz und sonstige Sortimente, was in Anbetracht der beherrschenden Stellung ersteren Sortiments keine allzu große Fehlerquelle umschließt, so läßt sich nach jener Rechnungsweise für den Zeitraum 18884/86 statt des tatsächlichen Erlöses von 9322077 M. (durchschn. für $1 \mathrm{Jahr}$ ) unter Annahme der günstigeren Sortimentsgruppierung von 1899-1901 ein fingierter im Betrag von 9438044 M., nach der Sortimentsverteilung 1908 ein solcher von $9499026 \mathrm{M}$. berechnen, was eine durchschnittliche Wertsmehrung um ca. $0,8 \%$ für 1 Jahr bedeutete.

2) Des Forstbezirks Baindt, eines geschlossenen über 3000 ha umfassenden Waldkomplexes ohne erhebliche Verschiedenheit der Standortsgüte (Fi I./II/. Bon.), der in den letzten 40 Jahren (bis Herbst 1910) von nennenswerten Flächenänderungen verschont geblieben ist. 
angestellt, der als für diesen Zweck besonders geeignet erschien. Die Untersuchung mußte sich in der Hauptsache auf die Sortimentsklassen des Nadelholzes beschränken, da für das Laubholzstammholz erst in jüngster Zeit eine befriedigende Sortierung geschaffen wurde, während sich das Nadelholz einer nunmehr über 40 Jahre alten Stammholzklasseneinteilung (Heilbronner Sortierung) zu erfreuen hat.

Das Ergebnis dieser Sortimentsstatistik ist in den Tabellen 9 und 10 niedergelegt; die beiden Uebersichten, welche sich der Raumersparnis halber auf Gegenüberstellung der Zeitabschnitte 1880/84 und 1900/04 beschränken, sollen zugleich zeigen, wie nach Ansicht des Verfassers die Sortimentsstatistik, entsprechend der in der württembergischen Staatsforstverwaltung üblichen Sortierung, am zweckmäßigsten gegliedert sein sollte, um als Grundlage für Erforschung der Wertsmehrung dienen zu können.

Die Veränderungen, welche ein Vergleich der beiden Zeitabschnitte erkennen läßt, sind, kurz gefaßt, die folgenden :

a) Der Ges a m t d e r b o l zan fall ist von 6,93 Fm auf 8,50 gestiegen (also von 100 auf 123 genau wie im Durchschnitt des Gesamtstaatswaldbesitzes und speziell Oberschwabens s. Tab. 5).

b) Die Verteilung der Nutzung auf $\mathrm{Nadelholz}$ und $\mathrm{L} \mathrm{a} u \mathrm{~b} \mathrm{hol} \mathrm{z}$ ist beinahe gleichgeblieben; Gruppe 1 der Mehrungselemente scheidet somit aus der weiteren Betrachtung aus. Dagegen zeigt sich auch hier, wie in Tab. 8, ein Mehranfall an Stammholz und sonstigen Nutzholzsortimenten in neverer Zeit; auffallend ist aber die verhältnismäßig unbedeutende Zunahme des Nadelholzstammholzes (von 53 auf 54,1\%) und die erhebliche Ausdehnung der KleinnutzholzAusbeute (Stangen). Das Entstehen neuer Nutzholzgebrauchswerte im Rahmen des Schichtderbholzes dürfte von unerheblichem Einfluß auf die Wertsmehrung sein, weil die Auslese des Schichtnutzholzes teilweise entwertend auf das verbleibende 


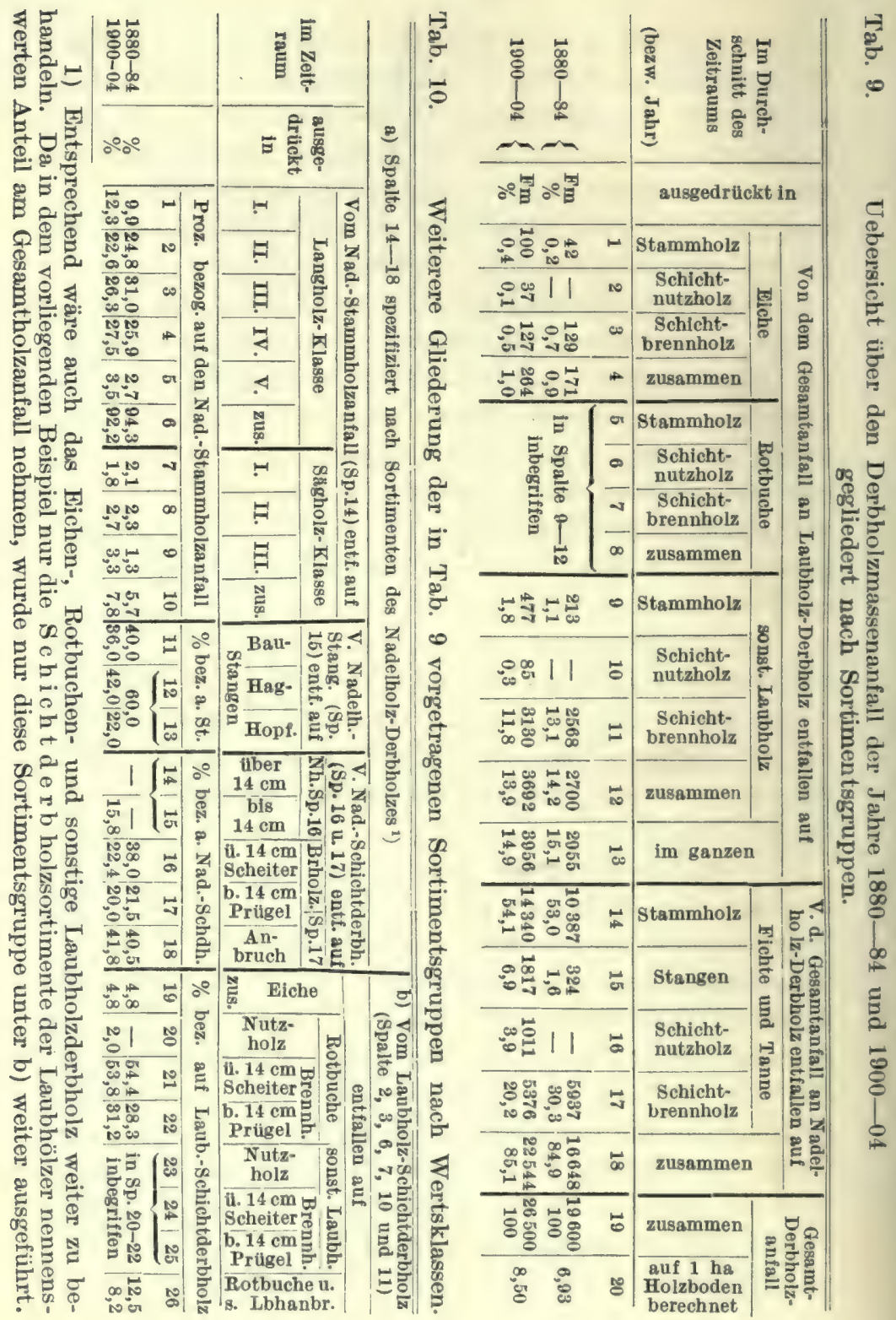


Brennholz wirkt, andererseits allerdings auch preisfördernd durch Entlastung des Brennholzmarkts; je mehr freilich das Holz als Brennmaterial in den Hintergrund tritt, umso mehr wird zur Verhinderung des Wertsrückgangs der Ausformung von Schichtnutzsortimenten Beachtung zu schenken sein.

c) Als Grundzug der in Tabellen 9/10 zum Ausdruck kommenden Aenderung der Sortimentsverteilung kann das verhältnismäßige Vorwiegen schwächerer Sortimente im Zeitraum 1900/04 bezeichnet werden: beim Nadelholzstammholz ist eine Verschiebung zugunsten der IV. und V. Langholzund der III. Sägholzklasse unverkennbar; außerdem wirkt die Zunahme der Sägholzsortimente ${ }^{1}$ ) im ganzen wertsmindernd; beim Nadelschichtderbholz ist ein bedeutendes Zurücktreten des über $14 \mathrm{~cm}$ starken Sortiments (Scheiter) festzustellen; dasselbe gilt für die Laubholz-Schichtsortimente. Das schon erwähnte Vorwiegen der Nadelholzstangen ist ein weiteres Symptom jener Erscheinung.

Elemente der Qualität s m e hrung sind demnach wohl nachweisbar (mehr Nutzholz!), desgleichen aber auch en tgegengesetzt wirkend e Momente. Es ist deshalb zum mindesten zweifelhaft, ob überhaupt die Nutzungsergebnisse von 1900/04 gegenüber denjenigen von 1880/84 qualitativ wertvoller sind, die erhebliche Steigerung des Einheitswerts derselben (von rund M. 9.50 auf M. 13.70) nicht viel mehr ausschließlich der Preiserhöhung zu danken ist; möglicherweise ${ }^{2}$ ) könnte sogar eine Wertsminderung eingetreten sein; setzt man zum Beispiel für die Nadelholzstammholzsortimente je die 1898er Taxpreise ein, so erhält man für

1) Entgegengesetzt den von Dr. Hähnle (Sortimentstafeln usw. 1905 S. 27 ff.) mitgeteilten Beobachtungen, welche eine Verminderung des Sägholzprozents erkennen lassen, vergl. auch die Mitteilungen von M a r t in auf S. 113 und 114 der Folgerungen etc. (Fichte).

2) Da nicht für alle Sortimente (so insbesondere nicht für die Ausschußsortimente des Schichtholzes) Preisaufschriebe vorliegen, kann eine genaue Berechnung nicht durchgeführt werden. 
1880/84 als Stammholzeinheitswert den Betrag von M. 17.88, für 1900/04 nur M. 17.64; aber die Tatsache, daß das Nadelholzstammholz am Gesamtderbholzertrag höher beteiligt war, gleicht diese Minderung wieder aus (denn $17.64 \times 54,1 \%$ größer als $17.88 \times 53,0)$.

Forscht man nach Gründen für die veränderte Sortimentsverteilung, so ergibt sich aus der Ertragsstatistik, daß eine auffallende Verschiebung zwischen Haubarkeitsnutzung und Durchforstungsanfall eingetreten ist: die Zwischennutzung ergab 1880/84 nur 12\%, 1900/04 dagegen 34\% des Gesamtderbholzanfalls, die Haubarkeitsnutzung ist sich annähernd gleichgeblieben (1880/84: 17 160, 1900/04: $17376 \mathrm{Fm}$ pro Jahr), während erstere von 2440 auf 9071 angestiegen ist. Es wird übrigens die Betonung weniger auf die Nutzungsart als auf d a s A l t e r der Bestände gelegt werden sollen, aus welchen die Nutzungen in den Vergleichszeiträumen erhoben wurden: der Derbholzertrag von 1900/04 wurde offenbar zu einem größeren Teil aus j ü $\mathrm{n}$ g e r e $\mathrm{n}$ Beständen entnommen.

Um die Fährte weiter verfolgen zu können, wurden die Ergebnisse je der beiden Nutzungsarten auf Grund der Fällungsnachweisungen und Materialrechnungen getrennt ermittelt: Tab, 11, siehe nächste Seite.

Aus dieser Tabelle geht deutlich hervor, d a B s o w o h l die Haubarkeitsnutzung als die $\mathrm{Zwischen-}$ nutzung qualitativ wertvollere Erträge im Zeitraum 1900/04 abgeworfen haben. Um von dem unbedeutenden Laubstammholzanfall abzusehen, so hat die Nadelholzstammholzausbeute bei beiderlei Nutzungsarten erheblich (in der Zwischennutzung sogar von 13,9 auf $28,0 \%$ des Derbholzanfalls) zugenommen und zugleich hat sich eine verhä]tnismäßig reichlichere Vertretung der wertvolleren Stammholzklassen herausgestaltet (bei H. I. und II., bei D. II. und III.). Die auch hier zu beobachtende Zunahme des Sägholzanfalls (bei $\mathrm{H}$ von 5,8 auf $9,0 \%$ ), welche den Durch- 


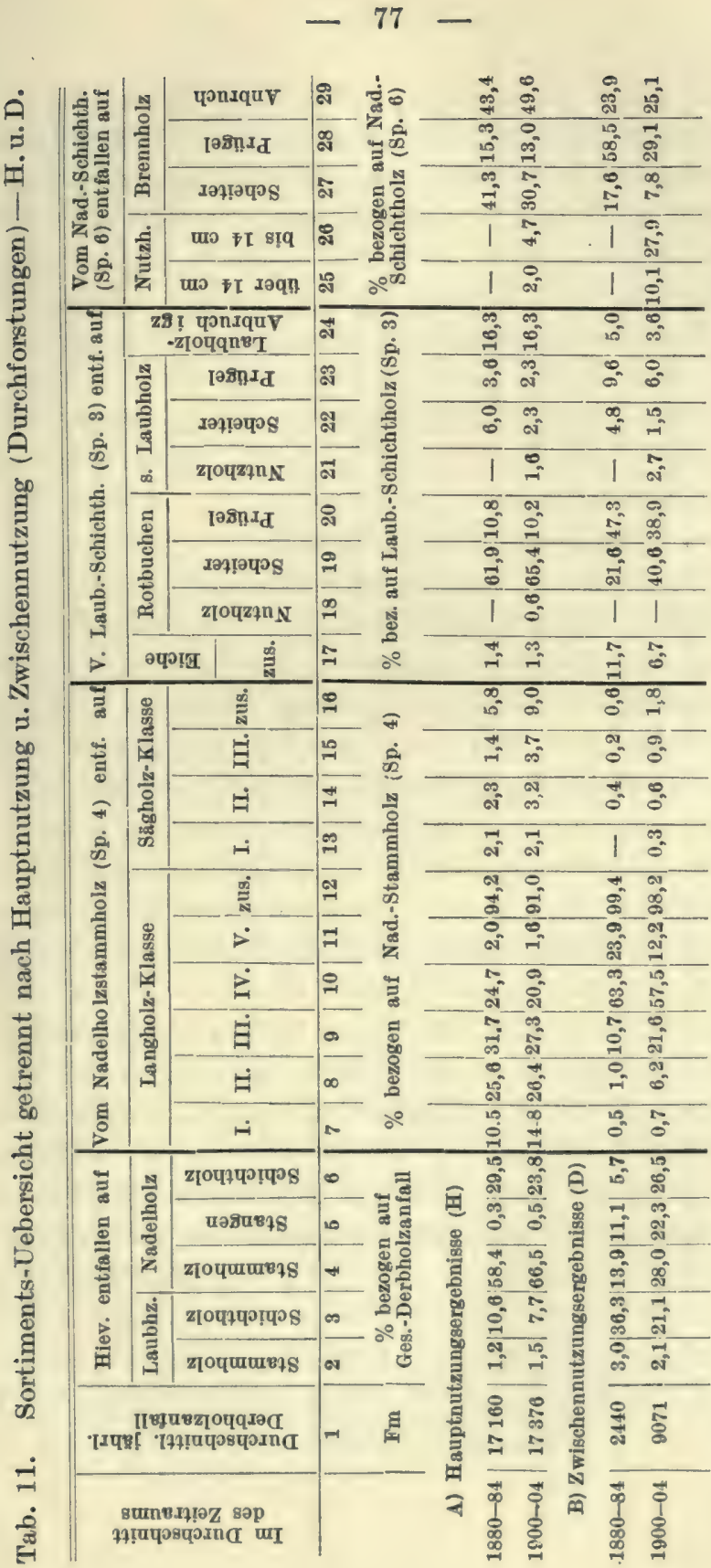


schnittswert des Stammholzes herabdrückt, kann zum Teil mit sorgfältigerer Ausformung kurzer und anbrüchiger, früher zu Brennholz (Scheiter bezw. Anbruch) aufbereiteter Stammteile erklärt werden (auch der Rückgang des Anfalls an Nad.Scheiter weist darauf hin); die Verwertungsmöglichkeit geringer Säghölzer hat sich tatsächlich erweitert (Kistenfabrikation). Die Einheitswerte des Nadelholzstammbolzanfalls g etrennt nach Haupt- und Zwischennutzung (H und D) berechnen sich nach den 1898er Taxpreisen

für

$\mathrm{H}$

D

im Zeitraum 1880/84 zu M. 18.- $\quad$ M. 14.70

$1900 / 04 \mathrm{zu} \quad$ M. $18.20 \quad$ M. 15.65

Auf die kleineren, teils mehrend teils mindernd wirkenden Aenderungen bezüglich der Wertsklassen der anderen Sortimente ist nicht weiter einzugehen; die auf seiten des Nadelholzstammholzes feststellbaren Mehrungselemente, insbesondere aber das erhebliche Vordringen dieser S o r t i m entsg r u p e im ganzen, geben den Ausschlag ${ }^{1}$ ).

Diese tatsächlich vorhandene Qualitätsmehrung sowohlder Haubarkeits- als der Zwischennutzung kommt in den Werten der Gesamtnutzung nicht zum Ausdruck, weil die geringwertigere Nutzungsart verhältnismäßig mehr zugenommen hat.

Im Vergleich zu dem im 1. Abschnitt besprochenen Einflußdes Durchforstungsbetriebs auf die Ertragsteigerung gewinnt dieses Ergebnis der Sortimentsstatistik ganz besonderes Interesse. Es muß deshalb noch kurz auf die Wechselbeziehungen zwischen quantitativem und qualitativem Mehrungseff e k t der D u c hforstungen eingegangen werden.

1) So sagt auch M a r t i n (Folgerungen der Bodenertragstheorie s. Fichte S. 131): ,Unter diesen Umständen wird es auch bei der Fichte häufig genügen, wenn die Wertsnachweise auf das Stammholz .... beschränkt werden." 
Als Ursachen des Ansteigens der Durchforstungsmassenerträge waren abgesehen vom Holzartenwechsel (s. a) S. 43) Veränderungen im Altersklassenverhältnis und in der Wirtschaftsweise angegeben worden. Beide Momente kommen auch in dem eben besprochenen Beispiel zur Geltung: Nach der Einrichtungsstatistik von 1908 gestaltet sich im Forstbezirk Baindt das Altersklassenverhältnis (Einrichtungszeitraum 1901 bis 1910) folgendermaßen:

prozentuales Verhältnis der Altersklassen

$\begin{array}{cccccc}100 \text { u. m. } & 81-100 & 61-80 & 41-60 & 21-40 & 1-20 \\ 13 & 8 & 17 & 14 & 24 & 24\end{array}$

Daraus geht hervor, daß für die Periode 1901/10 wesentlich mehr Fläche zur Erhebung von Vornutzungen verfügbar war, als 20 Jahre vorher. Vorgesehen waren nach dem Wirtschaftsplan ${ }^{1}$ ) 1901/10 2330 ha mit einem Derbholzanfall von 11200 Festmeter, nach dem Plan für 1878/87 nur 930 ha mit einem Derbholzanfall von $1480 \mathrm{Fm}$.

Dieser große Abstand ist durch das Altersklassenverhältnis allein nicht erklärt; man wird darin a $\mathrm{u} \mathrm{ch}$ d i e F olg en veränderter Wirtschaftsweised. h. intensiveren Durchforstungs betriebs erblicken können: Nach Abzug der Kulturflächen (1-20jähriger Bestände) und der in die I. Periode eingestellten Flächen berechnen sich zur einmaligen Durchforstung innerhalb Jahrzehnts 3018$(716+616)=1686 \mathrm{ha}$; es sind also offenbar $(2330-1686=)$ 650 ha zur zweimaligen Behandlung vorgesehen, was für die sehr bescheidene Durchforstungsfläche des früheren Zeitraums nicht angenommen werden kann.

Mag nun aber die eine oder andere Ursache vorwiegen, d i e Tatsache steht fest, daß die ge genüber d er Ha ubarkeitsnutzung stärkere Erhöhung der Zwischennutzungserträge qualitätsmindernde

1) Vergl. die Forsteinrichtungsstatistik in den Forststat. Mitteilungen aus Württemb. 1884 und 1908. 
Tendenz a uf den Wert der Gesamtnutzung ge t t end gemacht hat. Wird diese Minderung nicht durch Erhöhung der letzteren oder durch andere Mehrungselemente (der Gruppe 1 oder 2) ausgeglichen, so ergibt sich (abgesehen von der Preissteigerung) eine g e ring wertig e r e Nutzung. Liegt die Schuld mehr am Altersklassenverhälthis, so weist das momentane Sinken a uf k ünftige Mehrung (wie bei den Massenerträgen) hin, liegt sie am Durchforstungsgrad so gilt - entgegengesetzt dem Einfluß a uf die künftigen Massenerträge - dasselbe; Schwap$\mathrm{pach}^{8}$ ) weist ja für Fichte und Kiefer die ausschließliche $q u$ a $l$ i t ä $t$ s mehrende Bedeutung der Durchforstungen nach. Wird nun in Befolgung des oben aufgestellten - fast allgemein anerkannten - Grundsatzes, daß der Ges a m t n u tzungssatz allein von der Ertragsregelung in bindender Weise festgelegt werden sollte, die Hauptnutzung mit Rücksicht auf höhere Durchforstungserträge beschränkt, so ergibt sich möglicherweise, abgesehen von Ansammlung hiebsreifer Althölzer, eine Benachteiligung der gegenwärtigen Nutznießer zu Gunsten lachender $\mathrm{E} r \mathrm{~b} \in \mathrm{n}$; denn die Hauptnutzung wird später in zwar massenärmeren, aber dafür qualitativ wertvolleren Beständen erhoben werden können, welche ${ }^{1}$ ) , unter dem Regime intensiverer Bestandespflege erwachsen" sind. An dem $\mathrm{ma}$ agebenden Charakter des Gesamtabnutz ungs atzes ändert diese Erwägung durchaus nichts; sie weist uns aber auf die z. Zt. viel erörterte Frage der Schaffung von A usgleichsfonds hin; denn nicht bloß die Erträge aus überalten Hölzern dürfen als Quelle zur Speisung solcher Fonds in Betracht gezogen werden, sondern ganz allgemein alle Nutzungsteile, welche aus wald1908.

1) S c hw a p a c h, Fichte 1902 (insbes. S. 103); Kiefer 
baulichen oder ökonomischen Gründen über den ordentlichen, nachhaltig beziehbaren Gesamtabnutzungssatz hinaus erhoben werden müssen, bei Umtriebsherabsetzung ebensogut wiebeim Uebergang zu intensiverem Durchforstungsbetrieb.

Andererseits sollten dem Waldbesitzer solche Fonds zur Verfügung stehen, wenn er, bei abnormem Altersklassenverhältnis, genötigt ist, die Gesamtnutzung in höherem Maß als früher aus den qualitativ minderwertigen Vorerträgen zusammenzusetzen. Daß die württembergische Staatsforstverwaltung einer solchen Zeit entgegengeht, wurde schon oben erwähnt.

Man ersieht aus der eben angestellten Erwägung, w $\theta 1 \mathrm{ch}$ hohe Bedeutung dem Altersklassenverhältnis a u ch für das Verständnis der im Geldwertskomponenten wirkenden Wertse l e m ente z u k m m t, und daß eine nach Altersklassen gegliederte Ertragsbuchung, wie sie im I. Teil gefordert wird, auch von dieser Seite aus betrachtet, wichtige Anhaltspunkte für die Erfassung der Wertsveränderung zu geben vermag.

In dem als Beispiel angezogenen Spezialfall dient die Altersklassenübersicht nicht bloß zur Erklärung der in der Sortimentsverteilung der Gesamtnutzung sich geltend machenden W ert $m$ in d er u ng s tendenz, sondern läBt uns auch die Elemente der Wertsmehrung verstehen, welche den Durchforstungsertrag von 1900/04 verglichen mit den entsprechenden Zahlen von 1880/84 qualitativ wertvoller gestaltet haben.

Das Ueberhandnehmen der stärkeren Sortimente ist nach der Altersklassenübersicht ${ }^{1}$ ) darauf zurückzuführen, daß 1900/04 wesentlich mehr ältere $(61-80$ jährige) Bestände zur Erhebung der Vorerträge verfügbar waren als im Zeitraum 1880/84. Die auffallende Zunahme des Stangensortiments findet ihre Erklärung durch die im Vergleich zu früher reichere Ausstattung der 21 bis 40jährigen Fichtenklasse. Volle Klarheit könnte nur

1) Nach dem Stand von 1901 verteilte sich die Fichtenfläche folgendermaßen auf die einzelnen Altersklassen:

Alter: 100 u. m. $81-100 \quad 61-80 \quad 41-60 \quad 21-40 \quad 1-20$

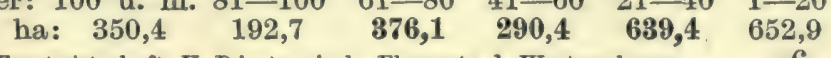

Forstwirtschaft. V. Diet exich, Elemente d. Wertsmehrung. 
eine nach Holzart und Altersklassegegliederte Nachweisung der Erträge schaffen.

Dasselbe gilt auch bezüglich der Qualitätsmehmung, welche (s. S. 77) für die $H \mathrm{aub}$ arkeits $\mathrm{nutzung}$ festzustellen war. Immerhin läßt sich aus den Fällungsnachweisungen soviel wenigstens ${ }^{1}$ ) ermitteln, daß die Haubarkeitsnutzung im Zeitraum $1880 / 84$ sich teils in 100 und mehrjährigen, teils in $81-100$ jährigen Beständen, 1900/04 dagegen teilweise zwar auch noch in $61-80$ jährigen, in der Hauptsache aber in über 100 jährigen Beständen bewegt hat; das Altersklassenverhältnis von 1884 weist nur 5, dasjenige von $190813 \%$ über 100jährige Bestände auf.

Es wäre nun zu untersuchen, o b d i e $V$ er ä $n d$ e r u n g des Altersklassenverhälnisses zur Erhöhung der Einheitswertedes Holzanfalls b e i g etrag en hat; andererseits fragt sich auch, ob nicht - dank der forstwirtschaftlichen Tätigkeit (intensiverer Bestandespflege o. ä.) - die im Zeitraum 1900/04 verjüngten Bestände an sich wertvolleres Holz trugen als die 1880/84 zum Hieb gebrachton.

Um hierüber Aufschluß zu geben, wurde eine Sor t imentsstatistik über die Haubarkitserträge des Nadelholzes getrennt nach Altersklassen je für die Zeiträume 1880/84 und 1900/04 angelegt ${ }^{2}$ ). (Tab. 12 siehe nächste Seite).

Wie aus Tab. 12 ersichtlich, hat sich $\mathrm{d} u \mathbf{r c h}$ w e $\mathrm{d}$ i e St a m m o l z a s b e u t $\mathrm{m}$ erheblich erhöht, außerdem sind, insbesondere in den 81-100jährigen Beständen, die s t ä r k e r e n Sortimentsklassen 1900/04 reichlicher vertreter als 1880/84, während allerdings das Sägholz überhaupt und besonders an schwächerem Material einen höheren Prozentsatz aufweist. Im ganzen scheint aber doch der Holzertrag nach den Ergebnissen

1) Genau läßt sichs aus der Buchführung nicht ermitteln, weil die Fällungsergebnisse der einzelnen Altersklassen nicht immer getrennt in den Wirtschaftsbüchern vorgetragen sind; vielmehr werden häufig, namentlich in der Vollzugsnachweisung der Durchforstungen, nur die Gesamtbeträge einer Abteilung unter Zusammenfassung der mehreren Unterabteilungen angegeben.

2) Diese Statistik umfaßt aus den eben (unter ${ }^{1}$ ) angeführten Gründen nicht sämtliches in den einzelnen Altersklassen angefallene Holz. Es kommt ja hier auch weniger auf Gewinnung sicherer Rechnungsergebnisse als vielmehr darauf an, zu zeigen, was aus einer zweckmäßig angelegten Statistik alles herausgelesen werden kann. 
v o n 1900/04 bezüglich der Altersklassen 100 und mehr und 81-100 höhere Werte darzustellen als die entsprechenden Haubarkeitsnutzungen des Zeitraums 1880/84.

Tab. 12.

\begin{tabular}{|c|c|c|c|c|c|c|c|c|c|c|c|c|c|c|c|c|c|}
\hline \multirow{4}{*}{ 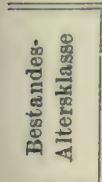 } & \multirow{4}{*}{ 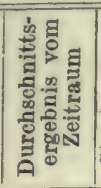 } & \multirow{3}{*}{$\begin{array}{c}\text { V.Derb- } \\
\text { holz- } \\
\text { Ertrag } \\
\text { entf.auf }\end{array}$} & \multicolumn{10}{|c|}{ Vom Gesamt-Stammholzertrag entfallen auf } & \multirow{2}{*}{\multicolumn{5}{|c|}{$\begin{array}{l}\text { Vom Beigholz } \\
\text { entf.a.d. Sortimente } \\
\text { Nutzh. Brennholz }\end{array}$}} \\
\hline & & & \multicolumn{6}{|c|}{ Langholz der Klasse } & \multicolumn{4}{|c|}{ Săgholz d. Klasse } & & & & & \\
\hline & & & & & & & & & & & & & & & & & \\
\hline & & 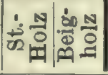 & I. & II. & & & v. & & & & & zus. & 电 & है & 造 & की & 这告 \\
\hline & & $\begin{array}{l}\% \text { des } \\
\text { Derbh. }\end{array}$ & \multicolumn{10}{|c|}{$\%$ des Gesamt-Stammholzanfalls } & \multicolumn{5}{|c|}{$\begin{array}{c}\% \text { des Beigholz- } \\
\text { Anfalls }\end{array}$} \\
\hline \multirow{5}{*}{$\left.\begin{array}{c}100 \mathrm{u} . \\
\text { mehr } \\
81 \text { bis } \\
100 \\
61-80\end{array}\right\}$} & & & & & & & & & & & & & & & & & \\
\hline & & & & & & & & & & & & & & 1,4 & & & \\
\hline & & & & & & & & & & & & & & & & & \\
\hline & & & & & & & & & & & & & 2,7 & & & & \\
\hline & & 70, & & & & & 4,1 & & & & & & & 20,9 & 10,8 & 23. & \\
\hline
\end{tabular}

Zur Ermittlung der Werts u n ter s c h i ed e wurden die Einheitswerte sowohl für 1 Festmeter Nadelholz-Derbholz im ganzen als für Stammholz und Schichtderbholz getrennt berechnet und zwar je zweifach, unter Zugrundelegung der Durchschnittserlöse von 1880/84 und der entsprechenden von 1900/04. - S. Tab. 13 nächste Seite. -

Nach Ausweis der Tab. 13 haben die beiden Altersklassen im Zeitraum 1900/04 qualitativ wertvollere Nutzungen als früher ergeben. Die Mehrung, welche sich für die Altersklasse 100 u. m. zu 0,17\%, für $81-100$ zu 0,46 (bezw. 0,35) \% pro Jahr berechnet, ist in erster Linie auf die verhältnismäßig $\mathrm{h}$ ö h e re Sta m m hol za u s b u t e zurückzuführen (Erschließung von Nutzholzwerten für Hölzer, die früher zu Brennholz aufbereitet wurden). Was aber den Einheitswert des Stammholzes und des Beigholzes, je für sich allein betrachtet, anlangt, so läßt sich bei der Altersklasse 100 und mehr ein Rückgang feststellen, der mit Zunahme des geringwertigeren Sägholzes bezw. (beim Beigholz) des Ergebnisses an Anbruchholz zu begründen sein dürfte; dagegen hat sich

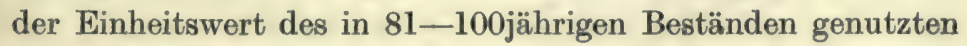

1) Rugel = über $14 \mathrm{~cm}$ starkes, Roller $=$ bis $14 \mathrm{~cm}$, Scheiter $=$ über $14 \mathrm{~cm}$, Prügel = bis $14 \mathrm{~cm}$ starkes Beigholz. 


\section{- $84-$}

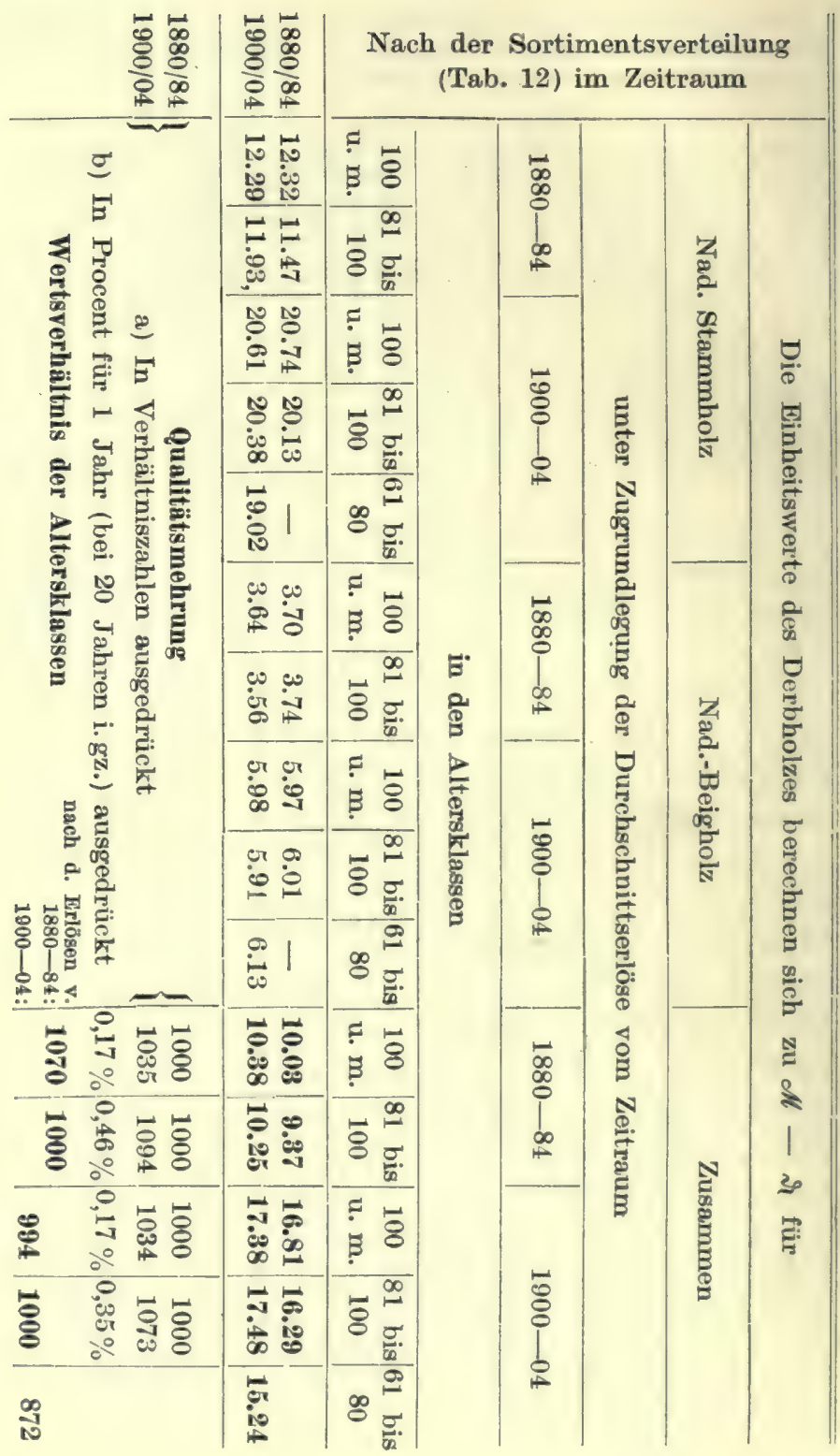

है 
Stammholzes infolge der auffallend stärkeren Vertretung der Langholzklassen I-III erhöht. Der letztere U mstand ist ins of ern bemerkenswert, als die qualitätsfördernde Wirkung der intensiveren Bestandeserziehung sich in der Sortimentsstatistik gerade auf diese Weise gel tend $m$ a chen $m \ddot{u} B$ te. Ob das für den vorliegenden Fall zutrifft, muß dahingestellt bleiben; die Mehrwertigkeit des Stammholzes der Altersklasse 81-100 als Folge des Vorherrschens der stärkeren Klassen könnte an sich auch auf $\mathrm{höh} \in \mathrm{r} \Theta \mathrm{Durchsehnittsboni-}$ tät der Hiebsflächen hindeuten. So äußert z. B. Philip p ${ }^{1}$ ), ,daß der Gedanke nahe liege, von den Sortimenten auf die Bonität zu schließen". Gerade dieses Mehrungselement mü $B$ te aber eliminiert werden und kann eliminiert werden auf Grund der im I. Teil geforderten Abrechnung über alten Vorrat, neuen Vorrat und die Nutzungsergebnisse, mit Hilfe der Angaben über den durchschnittlichen $\mathrm{Massen}$ a n all pro ha Voll$\mathrm{b} e \mathrm{standsfläche}$ und einer altersklassenweise gegliederten Bonitätsübersicht. Viel wichtiger als jene von $\mathrm{Ph}$ h l ipp gezogene Schlußfolgerung müßte ja gerade d e r N a c h w e i s d a rüber sein, ob die veränderte Sortimentsverteilung a uf Aenderung der Wirtschaftsweise zur ückzuführen ist. Denn es kann als eine der wichtigsten Aufgaben der modernen Forstwirtschaft bezeichnet werden, die höchsten Werte in kürzester Zeit (in kürzerer als bisher) zu produzieren; wir müssen deshalb auch in der Lage sein, an der Hand der Wirtschaftsergebnisse festzustellen, ob die Waldwirtschaft in dieser Richtung sich weiter entwickelt hat bezw. ob sie auf dem Weg ist, dem genannten Ziel näher zu kommen.

1) Vergl. die Forstl. Verhältnisse Badens (1909) S. 9. 
Der Einfluß, welchen eine Verschiebung des Altersklassenstands auf die Erlöse der Haubarkeitsnutzung ausgeübt haben könnte, ist in Tab. 13 durch Angabe des Wertsverhältnisses der Altersklassen (nach Maßgabe der Sortimentserlöse von 1880/84 bezw. 1900/04) angedeutet; hiebei fällt besonders auf die (wenn auch unbedeutende) M i n e r w e rtigkeit der $100 \mathrm{und}$ m e h r jährigen Bestände gegenüber den 80-100jährigen nach dem Stand von 1900/04 (994: 1000), während sich für 1880/84 noch ein Mehrerlös berechnete (1070: 1000); diese Erscheinung dürfte nach der Sortimentsstatistik, Tab. 12, mit der verhältnismäßig geringeren Stammholzausbeute (nur 77,9\% gegen 79,9\% in den 80-100 Best.) zu erklären sein; bezeichnend ist auch der höhere Sägholz- und beim Beigholz der höhere AnbruchholzAnteil der älteren Bestände.

Es wäre gewiß verlockend, aus den Zahlen der Tab. 13, insbesondere mit Bezug auf das zuletzt besprochene Ergebnis derselben, Wertszuwachsuntersuchungen abzuleiten; aber einmal sind die Unterlagen nicht voll beweiskräftig, weil nicht festgestellt ist, ob die durchschlagenen Bestände dem mittleren Zustand der hiebsreifen Hölzer je der betr. Altersklasse entsprechen; man möchte bei dem hohen Flächenanteil der 100 und mehrjährigen Bestände (13\% nach der Altersklassentabelle oben) eher vermuten, daß zunächst die im Wertszuwachs ohnehin rückständigsten zum Hieb gebracht wurden. Aber abgesehen von diesem Bedenken ist darauf aufmerksam zu machen, daß die 100 und mehrjährigen Bestände möglicherweise noch unter dem Regime einer weniger intensiven Bestandespflege herangewachsen sind, während sich in den 80-100jährigen schon ein Erfolg der stärkeren Durchforstung geltend machen könnte. Eher ließe sich durch Vergleich der 1880/84 80-100jährigen mit den 1900/04 100 und mehrjährigen Altersklassen ein Wertszuwachs - vorbehältlich des ersteren Bedenkens - berechnen; nach Tab. 13 würde der Wertszuwachs betragen M. $17.38-16.29=0,8 \%$ für $1 \mathrm{Jahr}$. W e r t s z u w a c h sErmittlungen gehören hier eigentlich nicht zur Sache, vielmehr nur Wertsmehrungs-Ermittlungen d. h. Erhebungen über die Entwicklung des Wertszuwachses; Qualitätsmehrung in dem bisher besprochenen Sinne ist ja doch nur denkbar, wo der Wertszuwachs im Steigen begriffen ist. Die Wertsmehrungsberechnungen bedeuten demnach eine wichtige Kontrolle der Wertszuwachs-Untersuchungen.

Endlich ist noch ein bisher nicht ausdrücklich erwähntes Element der Qualitätsmehrung zu besprechen: D i e Verbesserung des Gesundheitszustandes und der nicht me $\beta$ baren Formeigenschaft e n der Hölzer, also z. B. der Geradschaftigkeit, Astreinheit usw. unter dem Einfluß sorgfältigerer Bestandesbegründung und -erziehung, ausgedehnteren Forstschutzes und dergl. 
In den oben mitgeteilten Proben einer Sortimentsstatistik (Tab. 9 ff.) wird dieses Element teilweise als Ursache der erhöhten Nutzholzausbeute angenommen werden dürfen; bestimmteren Ausdruck findet es nur bei der Beigholz-Gruppe in dem Sortiment „Anbruch"; der hohe Anteil, welcher dieser Warenklasse nach Tab. 10 und 11 zukommt, deutet allerdings an, daß dem genannten Element der Qualitätsmehrung besondere Beachtung geschenkt werden sollte. Auf wunde Punkte dieser Art vermag nur eine Sortimentsstatistik den Finger zu legen.

Bezüglich des Stammholzes sind in der Tab. 10 keine Güteklassen ( $\mathrm{a}, \mathrm{b}$ usw. oder Normal, Ausschuß) ausgeschieden; die Lokalstatistik sollte sich aber auch hiermit befassen, denn es ist doch die Aufgabe der Forstwirtschaft, immer mehr v oll wertiges Holz (a-Qualität, Normal-Langholz) zu erziehen. Mit Bezug auf größere ${ }^{1}$ ) Waldgebiete dürfte allerdings, zumal beim Nadelholzlangholz, eine einwandfreie statistische Behandlung dieser Wertsunterschiede noch nicht spruchreif sein; erst müßten - im Benehmen mit Holzhandel und -Industrie - feste Normen (Usancen) aufgestellt ${ }^{2}$ ) werden; solang dies nicht der Fall ist, wirkt örtlich wie zeitlich die Verschiedenartigkeit der Ausscheidung störend.

Beim Uebergang zu intensiverer Bestandeswirtschaft werden die $\mathrm{Nutzungsergebnisse} \mathrm{selbst} \mathrm{vielfach}$ zunächst eine wertsmindernde Tendenz zum Ausdruck bringen, sofern, mehr als vorher, den schlechten Stammformen und beim Verjüngungsbetrieb den wertszuwachsträgen Beständen nachgegangen wird im Interesse $d$ e $r \quad Q u$ a $i-$ täts verbesserung des stehenden Holzvorrats und der Mehrung der künftigen Gelderträge.

1) In den ,Mitteilungen" der braunschweig. Forstverwaltung (Tab. 4) sind auch die Güteklassen ausgeschieden.

2) Dies gilt wenigstens für den Bereich der württemb. Forstverwaltung. Der Mangel an holzfachlicher Ausbildung der Forstleute erschwert eine einheitliche und sachgemäße Behandlung dieses Gegenstands z. Zt. noch. 


\section{Folgerungen.}

Ehe aus der Qualitätszunahme der bis herigen Erträge Schlußfolgerungen auf die Ertrags fähigkeit des Waldes und somit auf die Wertigkeit der künftigen Renten gezogen werden, sind noch Erhebungen über die Beschaffenheit der z. Zt. nutzbaren Teile des Holzvorrats anzustellen.

Es kann als besonderer Vorzug der im I. Teil entwickelten Methode der Zuwachsermittlung bezeichnet werden, d a B s i e durch Vergleich der Inventaraufahme mit den Aufschrieben über die Nutzungsergebnisse, jegesondert nach Holzartund Altersklasseauch indie Werts-nicht bloß in die Zuwachsverhältnisseder Betriebsklasse hineinleuchtet: so sind es vor allem die a uf Holz- und Betriebsartenwechsel zurückzuführenden Elemente der Wertsgestaltung, deren Einfluß auf $\mathrm{die} k$ ü n f t ig e n Erträge bei Anwendung jener Methode ohne weiteres beurteilt werden kann. Auch läßt sich hienach ermessen, ob zur Nutzbarkeit für absehbare Zeit Bestände derselben oder anderer Altersklassen, als im abgelaufenen Zeitraum, heranstehen; weiter kann, sofern Aufzeichnungen über den bisherigen Sortimentsanfall der einzelnen Altersklassen vorliegen, beurteilt werden, in welcher Richtung sich durch Verschiebung des Altersklassenverhä]tnisses die Wertigkeit der Rente ändern wird. Die Zahlen einer derartigen Sortimentsstatistik lassen sich aber auf das jeweils nutzbare Waldinventar nur unter den 2 Voraussetzungen unmittelbar übertragen, daß für dasselbe $d i e g l e i c h \theta$ mittlere Bonität (Bestandesbonität) wie für die seither durchschlagenen Waldteile angenommen werden kann und $d a B$ in der Wirtschaftsweise (hinsichtlich Bestandesbegründung und Erziehung) keine für die Holzqualität wesentlichen Aenderungen eingetreten sind. Aber gerade die Wirt- 
schaftsweise soll sich ja fortgesetzt in dem Sinn weiter entwickeln, daß Qualitätsware in verhältnismäßig immer grösserer Menge und kürzerem Zeitraum produziert werden kann; zum Nachweis solcher Wertsmehrung soll, wie oben betont, eben die eingehende Sortimentsstatistik dienen.

Aus diesen Gründen lassen sich b e s o n d e re S o r t imentsuntersuchungen am stehenden Holz - auch in Revieren mit annähernd gleichartigen Standortsund Bestandesverhältnissen - nicht umgehen.

Zahlreiche Arbeiten der Versuchsanstalten und einzelner im Versuchswesen tätiger Forstmänner befassen sich teils unmittelbar mit der Aufstellung von Sortiments- und Geldertragstafeln, teils mit Vorarbeiten hiezu, z. B. über Formquotienten, Rindenstärke u. a. ${ }^{1}$ ). Die Unzulänglichkeit der Normaltafel macht sich aber auf diesem Gebiet noch in weit höherem Ma B geltend als hinsichtlich des Massenertrags, weil allerhand lokal auftretende Störungen, insbesondere die Krankheitserscheinungen des Holzes, ganz erhebliche Abweichungen im Gefolge haben können. $\mathrm{H}$ ä hn $\mathrm{e} \mathrm{e}^{2}$ ) erwähnt insbesondere die Rotfäule, ,wodurch nicht nur Brennholzabgänge sondern meist auch Verschiebungen innerhalb der Sortimente hervorgerufen werden".

Da solche Abnormitäten vielfach geradezu als typische Erscheinungen zu betrachten sind, $\mathrm{m}$ üs s e $\mathrm{n}$ d i e $\mathrm{N}$ or $\mathrm{m}$ altafeln durch lokale Sortimentsuntersuchungen unbedingt kontrolliert und ergänzt w erden. Die Bedeutung der Normaltafeln soll dadurch in keiner Weise herabgewürdigt werden; als Vergleichsmaß-

1) Vergl. die eingehenden Angaben in Dr. H ä h n les Sortimentstafeln (Ulm 1905) über die seither veröffentlichten Sortimentsuntersuchungen.

2) Sortimentstafeln S. 23. 
stab für das, was eventuell an Werten geleistet werden könnte, verdienen sie volle Beachtung und lassen sich $\mathrm{zu}$ statischen Untersuchungen für den Bereich größerer Waldverbände mit Vorteil verwenden.

Erhebungen über die Sortimentszugehörigkeit des Holzvorrats sind zur Ermittlung des Wertszuwachses ohnehin unentbehrlich; das längst anerkannte Bedürfnis nach sorgfältiger Veranschlagung dieses wichtigsten Weisers der Waldwirtschaft ist freilich in die Praxis ${ }^{1}$ ) des Forsteinrichtungswesens noch nicht überall eingedrungen, aber die Forstwirtschaft des 20. Jahrhunderts wird sich mit der Phrase allein nirgends mehr begnügen können.

Zur Vornahme von Sortimentsuntersuchungen sind die bereits im I. Teil erwähnten Weiser- oder Lagerbuchsbestände zu dienen bestimmt; solche müssen je nach Revierverhältnissen (Verschiedenartigkeit der Boden- und Bestandesarten etc.) in genügender Größe (im allgemeinen nicht unter 1 ha) und Zahl angelegt werden. Es wird Aufgabe der Forsteinrichtungsanstalten sein, die einfachsten und zugleich zuverlässigsten Verfahren a u ch für diesen Teil der Inventaraufnahmen auszuproben; dabei wird je nach der Verschiedenartigkeit der forstlichen Verhältnisse im einzelnen Fall bald dieses bald jenes Verfahren zur Geltung kommen können. So eignet sich z. B. für Brennholzwirtschaften besonders das U ri c hs c he Verfahren ${ }^{2}$, das bei zweckmäßiger Auswahl der Probestämme in der Sortimentsverteilung des Probesta m m olzes zugleich diejenige der Gesamtmasse des Weiserbestandes anzugeben vermag; für Aufnahmen

1) Das württemb. Forsteinrichtungswesen weist in dieser Hinsicht noch eine empfindliche Lücke auf; in der offiziösen Schrift „Die Forstverwaltung Württembergs" von Dr. Fr. G r a n e r ist von Wertszuwachsuntersuchungen in dem Abschnitt über Forsteinrichtung (§ 21) nichts zu lesen.

2) Die Anwendung dieses Verfahrens wird auch in der neuen Anweisung für die Forsteinrichtung in den Bayr. Staatswaldungen empfohlen. 
in der Nadelholzbetriebsklasse wird das von $\mathrm{Hähnle}$ vorgeschlagene Verfahren bezüglich der Sortimente des $\mathrm{S} \mathrm{t}$ a $\mathrm{m} \mathrm{m-}$ holzanfalls zu empfehlen sein, während die anderen Sortimente (Schichtderbholz und Reisig) gleichfalls dem U r i c h schen Verfahren entsprechend behandelt werden könn$\operatorname{ten}^{1}$ ). Beim $\mathrm{Laubnutzholz}$, insbesondere in den $\mathrm{Ei}$ ch e $\mathrm{n}$ beständen, werden $\mathrm{n}$ och $\mathrm{eing}$ ehendere Erhebungen über den Inventarwert anzustellen sein, indem hier nicht bloß die Stärkeklassen sondern auch die G ü tek la ssen (etwa im Sinn der $\mathrm{H}$ e c k schen Schaftformklassen) zu berücksichtigen wären. Es ist hier nicht der Ort, weiter auf diese Fragen einzugehen, deren Besprechung allein Gegenstand einer besonderen Abhandlung sein müßte.

Die Aufnahme der Weiserbestände wird am einfachsten jeweils aus Anlaß der Forsteinrichtungsarbeiten zu erfolgen haben; man sollte aber jeden Materialanfall auf diesen Flächen dazu benützen, um Ermittlungen über die Faktoren des Massenertrags (Alter, Formhöhe, Zuwachs) sowohl als der Wertsbildung (Sortiment, Güteklasse etc.) anzustellen und in den Lagerbüchern niederzulegen.

Fassen wir die Ergebnisse dieses Abschnitts zusammen, so sind kurz folgende $\mathrm{V}$ orschläge zum weiteren A usbauder Statistikund der Buchführung $\mathrm{zu} \mathrm{m}$ a chen:

1. Die im I. Teil angeregte Ertragsstatistik getrennt nach Holzart bezw. Holzartengruppen und Altersklassen is t $\mathrm{z} u$ ergänzen $\mathrm{durch}$ eine Sortimentsstatistik, in welcher sowohl der Sortimentsanfallals der Durchschnittserlös der im

1) Wenn abnorme Erscheinungen, wie die oben angedeuteten, nicht vorliegen, wird es sich häufig nur darum handeln, bestehende Sortimentstafeln (wie eben die von $H$ ä $h \mathrm{n} l \mathrm{e}$ ) auf ihre lokale Anwendbarkeit zu prüfen. 
einzelnen Revier wichtigsten Wertsklassen zur Darstellung gebracht wird ${ }^{1}$ ).

2. Die im I. Teil angeregte Inventarauf$\mathrm{n}$ a h $\mathrm{me}$ (in derselben Gliederung) is t $\mathrm{zu}$ er $\mathrm{g}$ ä $\mathrm{nz}$ en durch Erhebungen über die Sortimente des Holzvorrats, wenigstens derzur Nutzbarkeit heranstehenden Teile desselben, als deren Versuchsfelder Weiser-oder L a gerbuchsbeständezudienen haben.

3. Wie bezüglich des Massenertrags (I. Teil), so sind a u ch zur Untersuchung über die Qualitätsmehrung aus Anlaß der Wirtschaftseinrichtungsarbeiten die Nutzungsergebnisse an der Hand der Ertrags-bezw. Sortimentsstatistik in Beziehung und Vergleich zu setzen zu den entsprechenden Ergebnissen der Inventaraufnahme (Sortimentsuntersuchung).

4. Auf diese Weise läßt sich nicht nur der voraussichtliche Einheitswert der künftigen Erträge (je nach Holzart, Altersklasse und im ganzen) auf der Grundlage des dermaligen Preisstands ermitteln sondern auch die Frage mit annähernder Zuverlässigkeit lösen, ob die E rt r a g s f ä h i g k e it der Waldwirtschaft bezüglich des Geldwertskomponenten in der $\mathrm{Zu}$ - oder $\mathrm{Abnahme}$ begriffen ist, ob Einsparungen oder Kapitaleingriffe in dieser Richtung seither zu verzeichnen sind.

1) Bei entsprechender Anordnung und Einteilung der Ertragsbuchführung läßt sich das ohne viel Mehrarbeit durchführen. Man brauchte z. B. in den Materialrechnungsformularen der württemb. Staatsforstverwaltung nur gesonderte Spalten für die einzelnen Holzarten (Fi-Ta, Fo, Eiche, Bu, sonst. Laubholz o. ä.) vorzusehen und die Einträge so vorzunehmen, daß die Bestände der gleichen Altersklasse je unmittelbar untereinander zu stehen kommen, dann ließe sich am Ende eines Jahrs oder der Periode eine Sortimentsstatistik leicht auch $n$ a ch Altersklassen g e trennt zusammenstellen. 
5. Die Wertigkeit eines g r ö $B$ e r en $W$ a $l d g$ a $n z$ en, die Mehrung oder Minderung seiner Einheitswerte, läßt sich aus den Angaben der einzelnen Reviere zusammenstellen. Es empfiehlt sich zwar eine zusammenfassende Uebersicht über den Sortimentsanfall des ga n z e n Gebiets anzulegen, um im großen und ganzen den Gang der Entwicklung verfolgen zu lassen (ganz abgesehen von der großen Bedeutung, welche eine zusammenfassende Sortimentsstatistik für die Zentrale der Verwaltung hat), aber genauere Berechnungen können auf Grund derselben nicht gut angestellt werden, umso weniger, je verschiedenartiger die Verhältnisse sind, welche das betr. Waldganze umfaßt.

\section{A bsehnit t.}

\section{Die Preisentwicklung.}

\section{Die bisherige Preissteigerung im Licht der Preisgesetze.}

Während bei Untersuchung der Qualitätsmehrung die in der Sortimentsbildung zum Ausdruck kommenden G eb r a u c h s w e r t e des Holzes als Vergleichsmaßstab dienten, steht hier die Entwicklung des $\mathrm{T}$ a u $\mathrm{s} \mathrm{ch}$ werts der Holzprodukte zur Diskussion. Da aber Tauschwert und Gebrauchswert keine scharf gegen einander abgegrenzten Begriffe sind, läßt sich auch die Scheidung zwischen Qualitätsmehrung und Preissteigerung nicht streng durchführen. Es sind auch teilweise dieselben Ursachen, welche nach beiden Richtungen mehrenden Einfluß auf die Erträge unserer Forste ausgeübt, vorteilhaftere Verwertbarkeit der Hölzer durch Ents teh ung neuer Gebrauchswerte und durch Erhöhung des T a s c h werts veranlaßt haben ${ }^{1}$ ).

Aus Gründen der Uebersichtlichkeit und in Anbetracht

1) So hat z. B. das Zeitalter der Elektrizität dem Nadelholzwald neue Verwertungsmöglichkeiten in Form von Leitungsstangenund Masten eröffnet, dadurch die Nutzholzausbeute gefördert und zugleich belebend auf die Langholz-Preise eingewirkt. 
der Bedeutung, welche dem Begriff ,,Teuerungszuwachs" im forstlichen Rechnen eingeräumt ist, empfiehlt sich aber doch eine gesonderte Besprechung der Preissteigerung, zumal wenn man ermessen will, inwieweit $d$ er Forstwirt selbst auf die Wertsmehrung einzuwirken vermag. Vermutlich war ja die bisherige erhebliche Geldertragssteigerung in den deutschen Forstverwaltungen weit mehr auf Preiszunahme als auf Qualitätsmehrung zurückzuführen.

Gehen wir zur Ergründung der Mehrungsursachen von den Preisgesetzen aus ${ }^{1}$ ), so hat das Verhältnis von Nachfrage und Angebot wohl in erster Linie preissteigernde Tendenz ausgeübt. Denn unter dem Einfluß des wirtschaftlichen Aufschwungs, der Bevölkerungszunahme und der Verbesserung der Lebenshaltung erweiterte sich der Umfang der begehrten Holzprodukte, die $\mathrm{Z}$ ah 1 der begehrenden Personen und die Inten$s$ i ät der Nachfrage. Parallel damit ging freilich auch eine Verstärkung des Angebots (Erhöhung des Holzmassenertrags); auch die Zahlder Anbietenden hat ständig zugenommen, indem mit der Entwicklung des Verkehrs die früher in sich abgeschlossenen Tauschgebiete der Ein- und Ausfuhr geöffnet wurden; (selbst das o s tpreußische Stammholz drohte in der Saison 1910 mit

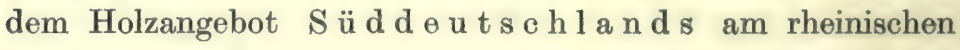
Holzmarkt in Konkurrenz zu treten). Endlich hat sich auch die Intensität des Angebots belebt, d. h. die Bemühung der Produzenten um bestmögliche Verwertung der vorhandenen Holzgüter durch sorgfältige Ausformung und Sortierung, das Bestreben der Waldbesitzer, die Bringung des Holzes in- und außerhalb Waldes zu fördern, die Zoll- und Verkehrspolitik zu ihren Gunsten zu beeinflussen. Daß aber

1) Verfasser folgt hiebei den Preisgesetzformulierungen des † Tübinger Nationalökonomen $\mathrm{N}$ e u man $n$ (vergl. die diesbezüglichen Abschnitte in $\mathbf{S} \mathrm{ch}$ ö $\mathbf{n}$ berg s Handbuch.) 
die auf seiten der $\mathrm{N}$ a c h f r a g e wirkenden Kräfte im großen ganzen die Oberhand gewannen, bestätigt die Holzhandelsbilanz ${ }^{1}$ ) Deutschlands durch fortgesetztes Anwachsen der Mehreinfuhrziffern mit Bezug auf das deutsche Zollgebiet bezw. Rückgang der Mehrausfuhrziffern in den exportierenden Reichsländern Bayern und Württemberg b e i g l e i c h z e itiger Nutzungs- und Preissteigerung.

Auch die sog. Gravitationsgesetze kommen für die Holzpreisentwicklung in Betracht, die Einwirkung der Preise und Kosten anderer Produkte und Produktionsarten, so der übrigen Brennmaterialien bezw. Kraft- und Wärmequellen, wie Kohle, Oele, Gase, Elektrizität u. a., anderer Baumaterialien, wie Eisen, Steine, Beton und neuerdings des das ganze Hoch- und Tiefbauwesen beherrschenden Eisenbetons. Gerade der letztere Artikel droht das Holz aus seinen sichersten Domänen teilweise $\mathrm{zu}$ verdrängen. Mit Bezug auf einzelne Holzsortimente, so insbesondere Brennholz und Schwellenholz, hat die Konkurrenz der Surrogate entschieden preisdrückend gewirkt; der Forstwirt hat allen Grund, diese Entwicklung der Dinge eingehend zu verfolgen. Mehr noch als auf jene E r s a $t$ z s t of $f e$ finden die Gravitationsgesetze Anwendung auf die Konkurrenz der a usländis chen Hölzer, teils in dem Sinn, daß die billiger zu verschaffenden Auslandwaren (z. B. Schleifholz aus Oesterreich und Rußland) die Preis e ${ }^{2}$ ) der in lä ndis chen Ware im Bann halten, teils z u Gunst e n der ei $\mathrm{n}$ h ei m is ch en Produktion, sofern die Preise nach den geringsten Kosten derjenigen teuersten Produktions-

1) Vergl. die diesbezüglichen Mitteilungen in E n d r e s Forstpolitik und die fortlaufenden Mitteilungen hierüber in dem von E n dres redigierten Allg. Anzeiger für den Forstproduktenverkehr.

2) Vergl. ferner die jeweiligen Mitteilungen über Preisofferte bei den Submissionen der preußischen Eisenbahn- und Postdirektionen betr. Lieferung von Schwellenholz und Telegraphenstangen im Allg. Anz. für den Forstproduktenverkehr (die ausländische Ware wird immer billiger offeriert). 
art (also der mit hohen Fracht- und Zollspesen teilweise auch Risikoprämien belasteten Auslandhölzer) gravitieren, die zur Deckung des Gesamtbedarfs noch in Anspruch genommen werden muß. In Anbetracht der Tatsache, daß Deutschland auf Holzeinfuhr angewiesen ist, mag in dem letzteren Moment ein nicht zu unterschätzendes Element der Preissteigerung zu begrüßen sein.

E n d r es hat bei der Ulmer Forstversammlung (September 1910 ) in der Debatte zum Thema über die Kartellbestrebungen darauf hingewiesen, daß der internationale Holzhandel keine Schleuderkonkurrenz treibt, vielmehr durch seine Festigkeit die Preisdepression von 1908/1909 für Deutschland gemildert hat.

Bei Besprechung des Produktionsaufwands wird sich noch Gelegenheit geben, die Gravitationsgesetze vom Standpunkt der Produktionskosten (für Ersatzstoffe und konkurrierende Hölzer) aus zu beleuchten.

Aus dem bisher Gesagten erhellt, daß die Preisgestaltung weit weniger in die Hand des Waldbesitzers und seiner Organe gegeben ist, als die anderen, den Holzmassenertrag und die Holzqualität betreffenden Elemente der Wertsmehrung, sowie daß es viel schwieriger ist, als dies für jene möglich war, aus dem bisherigen Verlauf der Entwicklung Schlüsse für die Zukunft zu ziehen.

Es mag durch kaufmännisches Geschick gelingen, die vorübergehenden Schwankungen mehr und mehr in die Hand zu bekommen, günstige Konjunkturen besser auszunützen, Preisrückgänge zu mildern, aber den Preisgesetzen gegenüber ist die Waldwirtschaft, wenn auf sich allein angewiesen, ziemlich ohnmächtig, jedenfalls ohnmächtiger als Landwirtschaft und Industrie, die wenigstens in der Lage sind, durch Verlegung des Schwerpunkts der Produktion bald auf diesen bald auf jenen Artikel dem Zug der wirtschaftlichen Vorgänge, der Zeitbedürfnisse, dem Verhältnis von Angebot und Nachfrage einigermaßen zu folgen; der Forstwirtschaft aber ist eine solche Anpassung nur in sehr beschränktem Umfang möglich: sie 
vermag wohl in einzelnen Jahren, zumal bei Vorhandensein eines Reservefonds, das Angebot des einen oder anderen Sortiments einzuschränken oder zu erweitern (z. B. Eichenstammholz, in Mischwaldrevieren bald mehr Nadelholz bald mehr Laubholz), auch wohl schwächere Ware durch Aenderung der Wirtschaftsweise (stärkere Durchforstung, Herabsetzung der Umtriebszeit) in nachhaltig größeren Mengen anzubieten; aber weitere Anpassungen, so namentlich die baldig e Erweiterung des Angebots in Starkholz (Eichen) und seltenerer Qualitätsware (Forchen mit rotem Kern u. ä.) hindert $d$ e $r$ Produktionsfat or ,Z $\mathrm{Z}$ it $\mathrm{t}^{\prime 6}$ oder verbieten es gewisse waldbauliche und ökonomische Rücksichten. Die FälIung und Verwertung des stärkeren Nadelholzstammholzes zum Beispiel, das in großen Waidgebieten Deutschlands noch in beträchtlicher Menge vorhanden ist, läßt sich wegen des Fortschreitens der Verjüngung bezw. zur Verhütung der Bodenverwilderung, wie auch mit Rücksicht auf die Hiebsnotwendigkeit der im Wertszuwachs rückständigen Althölzer nicht so leicht einschränken; ebenso könnte auch nur vor übergehend die Einschränkung der Erziehungshiebe in jüngeren Nadelholzbeständen gebilligt werden, obwohl dies angesichts des Rückgangs der Preise für die schwachen Nadelholzsortimente (teils infolge Ueberangebots teils infolge Wirkung der Gravitationsgesetze) da und dort vielleicht erwünscht wäre.

Wegen dieser Ohnmacht bedarf die Waldwirtschaft mehr als andere Produktionszweige des Schutzes der staatlichen Zoll- und Verkehrspolitik (durch Bau von Wasserstraßen, Bahnen, Gestaltung des Tarifwesens).

In Anbetracht der geschilderten Umstände dürfte der Preisgestaltung mit Bezug auf die künftige Wertsmehrung ein gewisses Mißtrauen entgegenzubringen sein, wenngleich auch Anzeichen vorhanden sind, wie eben die Holzhandelsbilanz, welche Preisrückgänge zunächst nicht befürchten lassen; aber die Preisgeschichte lehrt, daß ihr Weg nicht bloß wellen- 
förmig auf und abgeht, sondern stellenweise über jähe Abgründe und langanhaltende Depressionen führt. Wenn man die bisherige Preissteigerung durch Annahme eines niederen Zinsfußes gewissermaßen als Kapitalteil der dermaligen Waldwerte behandelt, so ist darauf aufmerksam zu machen, daß keinenfalls der volle Teuerungszuwachs am landesüblichen Zinsfuß in Abzug gebracht werden darf, s ondern $\mathbf{n}$ u r gekürzt um eine jener Unsicherheit angemessene Risikoprämie.

Bei vergleichenden Preisuntersuchungen müssen wir endlich auch daran denken, daß außer jenen Preisgesetzen noch andere Gesichtspunkte hereinspielen, die bisher meist steigende Tendenz geltend machten. Vielfach hat sich der Charakter der Ware, der Grad der Zubereitung geändert: dureh sorgfältigere Ausformung, Entrindung u. ä. ist dem Käufer die Ware mundgerechter gemacht worden als früher oder anderswo; durch Berücksichtigung der Hauerlöhne bezw. der e r n t ekostenfreien Erlöse kann die Einwirkung dieses Moments teilweise eliminiert werden. Einschneidendere Veränderung im Marktwert der einzelnen Waren hat die Verbesserung der Absatzverhältnisse veranlaßt; insoweit dies zutrifft, geben die dermaligen Preise verglichen mit früheren nicht den absoluten Preismehrungsbetrag (Teuerungszuwachs) an, enthalten vielmehr zugleich eine Rückerstattung der vom Waldbesitzer aufgewendeten Bau- und Unterhaltungskosten. Es wäre von Interesse, den auf $d$ i e s e Mehrungselemente entfallenden Anteil der Preissteigerung zu ermitteln; handelt es sich doch hiebei um Pre i s-E l e m e n t e von größter Z u verlässigkeit, welche, im Gegensatz zu den bisher besprochenen als wichtiges Mehrungsmittel in die Hand des Waldbesitzers gegeben sind. Die absolute Tauschwertsmehrung des Holzes festzustellen, ist mehr nur ein akademisches Problem, das als Vorarbeit bei Begutachtung großer wirtschaftlicher Fragen, z. B. 
betr. Geldwährung, Zollgesetzgebung, Handelsverträge etc. immerhin eine bedeutungsvolle Rolle spielen mag; der eigentlich praktische Wert von Preisuntersuchungen besteht aber vielmehr in der Ermittlung der vom Wirtschafter selbst durch die oben bezeichneten Maßnahmen erreichten Wertserfolge.

Es wird deshalb in den weiteren Erörterungen weniger auf B e r e ch n u $\mathrm{ng}$ der Preissteigerung der Nachdruck zu legen sein, als auf die für Anstellung solcher Preisuntersuchungen geeignetsten Methoden und statistischen Einrichtungen; außerdem wird zu zeigen sein, für welche Zwecke sonst noch Preisaufschriebe nutzbar gemacht werden können.

\section{Methoden zur Feststellung der Holzpreisänderung. (Preis- statistik.)}

Ueberblickt man die in den alljährlich erscheinenden statistischen Mitteilungen der deutschen Staatsforstverwaltungen niedergelegten Erlösangaben, so findet man nur wenig für die vorliegenden Zwecke brauchbares Material: die Preisstatistik geht großenteils nur auf verhältnismäßig kurze Zeit zurück; vielfach werden nur einzelne Sortimente behandelt; noch häufiger werden nur die Durchschnittserlöse gewisser Sortimentsgruppen (ohne Ausscheidung der einzelnen Wertsklassen) angegeben.

So sind im Handbuch der Forstpolitik von E n d r e s (S. 124 und 125) die Mitteilungen aus Preußen, Bayern, Baden, ElsaßLothringen und Württemberg betr. Nutzholz- und Brennholzpreise im ganzen und getrennt nach Holzarten zusammengestellt. Aehnlich summarische Angaben finden wir in dem Werk ,Die forstlichen Verhältnisse Preußens (v. H a g e n-D o n n e r) in Tab. 96; die Unbrauchbarkeit dieser bis 1800 zurückreichenden Preisstatistik für wissenschaftliche Untersuchungen - aus den oben genannten und anderen Gründen - ist v. Lehr überzeugend nachgewiesen worden; dagegen sind in den, $\mathrm{Pr}$ e u B is c he $\mathbf{n}$ A m t lichen Mitteilunge $n^{6 "}$ seit 1903 (in Tab. $9 \mathrm{c}$ ) die wichtigeren Sortimente im einzelnen und gesondert nach Massenanfall, Gesamt- und Durchschnittserlös je für die einzelnen Regierungsbezirke vorgetragen. Aus $\mathbf{B}$ a yern liegt eine detaillierte Erlösstatistik zum erstenmal vom Jahr $1909^{1}$ ) vor (i. 9. Heft

1) S. auch oben Seite 70 . 
d. Mitt. a. d. Forstverw. Bayerns); außerdem werden die einzelnen Verkaufserlöse der Forstämter ausführlich, seit Herbst 1910 tabellarisch geordnet, in der Fachzeitung Allg. Anz. für den Forstproduktenverkehr bekannt gegeben. Wertvolle Angaben aus dem Bereich der $\mathbf{s}$ ä $\mathbf{c h} \mathbf{h}$ is $\mathbf{c} \mathbf{h}$ en Staatsforstverwaltung bieten der 42. und 51. Band des Tharander forstlichen Jahrbuchs mit Arbeiten von Flem ming bezw. Pursche über Versteigerungserlöse der hauptsächlichsten Nadelholzsortimente, ferner, allerdings mit Beschränkung auf das Erzgebirge, ein Vortrag von Oberförster $\mathbf{P}$ a $\mathrm{u} \mathrm{s}^{\mathbf{1}}$ ) gehalten aus Anlaß der 53. Versammlung des sächsischen Forstvereins. Sehr eingehende Nachweisungen über Durchschnittserlöse finden sich in der b a d i s c $\mathbf{h}$ e $\mathbf{n}$ Forststatistik (Tab. II 8), leider fehlen hiebei die entsprechenden Angaben über den Sortimentsanfall. Die einzelnen Verkaufserlöse der badischen Forstämter werden in den Fachzeitungen (Wochenblatt für den deutschen Holzhandel) und teilweise auch im Allg. Anz. für den Forstproduktenverkehr mitgeteilt. Die h es s is c h e Statistik enthält nur Erlösangaben für Nutz- und Brennholz im ganzen; dagegen können aus den Holzfachzeitschriften Mitteilungen über die Aufstreichsverkäufe der einzelnen Aemter und aus den forstlichen Zeitschriften allerhand wertvolle Preisnotizen (insbesondere $v$. Oberforstrat W alt h er) entnommen werden. Die E Is a BL o t h r i n g n s c h e Statistik war schon oben mit ihrer Nachweisung der Erlöse für die verschiedenen Holzarten erwähnt. Die forststatistischen Mitteilungen der w ü $\mathrm{rt}$ e $\mathrm{mb}$ e r g i s c h e n Staatsforstverwaltung lassen die d u r c s ch n it t li chen A ufstreichserlös e des Gesamtnadelholzstammholz- und Eichenstammholzanfalls sowie für das n or m a l e Brennholz der Buche und des Nadelholzes bis zum Jahr 1850 zurück verfolgen, aber o h n e Ausscheidung weiterer Wertsklassen. Die neuerdings (seit 1902) von dieser Verwaltung herausgegebenen detaillierten Erlösmitteilungen über die einzelnen Nutzholzverkäufe enthalten wertvolles statistisches Material, müssen aber für die vorliegenden Zwecke, weil nicht weit genug zurückreichend, zunächst außer Betracht bleiben. Die b r a $\mathrm{n}$ s c hweigis che Forstverwaltung veröffentlicht vollständige Sortiments- und Gelderlösangaben je für sämtliche Wertsklassen und Reviere, bis zum Jahr 1909 die ausführlichste Erlösstatistik unter den genannten Verwaltungen.

Unterzieht man diese verschiedenartigen Preisnachweisungen einer kritischen Beleuchtung, so kann allen denen, welche ganze Sortiments g r u p e n zusammenfassen (wie in der württemb. Statistik) nur sehr beschränkter Wert beigemessen werden; denn sie vereinigen in sich $\mathrm{W}$ a ren $\mathbf{v}$ ersehiedener, ja verschiedenster Güte (z. B.

1) Vergl. Bericht über die Versammlung (Tharandt 1909) S. 104 . 
Eiche I a und VI. K1.), die jeweils in verschiedenen Mengen und Mengenverhältnissen ange boten werden. Für größere Gebiete wird bei Beschränkung der Beobachtung auf $\mathrm{k} u \mathrm{rz}$ en Zeitraum immerhin anzunehmen sein, daß sich die $Q u$ antitäts vers c h i ed e $\mathrm{n} h$ e i t en der Einzelsortimente im großen ganzen ausgleichen, umsomehr, je größer der G e s a m t a $\mathrm{n}$ f a 11 ist; bei Vergleichung weit auseinander liegender Zeitabschnitte dagegen dürfte diese Annahme zum mindesten zweifelhaft erscheinen; so werden z. B. die schwächeren Stammholzsortimente, speziell des Nadelholzes, neuerdings infolge des intensiveren Durchforstungsbetriebs, besserer Verwertungsmöglichkeit und infolge des Heranwachsens der an Stelle umgewandelter Laubwälder nachgezogenen Nadelholz(Fi-)waldungen immer mehr zur Geltung kommen. Damit derartige, für die Qualitätsveränderung ausschlaggebende Verschiebungen nicht übersehen werden, sollte die Preisstatistik stets mit Angaben über den Sortimentsanfall versehen oder jedenfalls (wie z. B. in der braunschweigischen Statistik) von einer gesonderten Sortimentsstatistik begleitet sein. Für $\mathrm{k} l$ e i n e r e Gebiete, insbesondere die einzelnen Reviere, ist eine $\mathrm{m}$ e hr e r e Wertsklassen zusammenfassende Erlösstatistik wegen des ständigen Wechsels der Sortimentsverteilung so gut wie wertlos, häufig sogar irreführend. Daß bei vergleichenden Untersuchungen über längere Zeitzwischenräume hinweg erhebliche Verschiedenheiten auftreten, zeigt das Beispiel der Tabelle 9/11 oben; auch innerhalb kurzer Frist wechseln die Mengenverhältnisse der einzelnen Wertsklassen zum Teil recht beträchtlich ${ }^{1}$ ).

Für Erforschung der Preis en $t$ wi c kl ung bed a r f man deshalb einer, die einzelnen Werts-

1) So ergab z. B. die Sortimentsstatistik, welche vom Verf. für den württ. Forstbezirk Baindt angelegt wurde, im Jahr 1900: $9 \%$ I. K1. Langholz, 34\% IV. u.s.f., dagegen 1901: 11 \% I., 24 \% IV.; 1902: 14\% I., 24 IV.; 1904: 14 I., 32 IV. u. s. f. 
klassen getrennt behandelnden Erlösstatistik, wie es, mit Rücksicht auf andere Zwecke, schon in den Folgerungen des vorigen Abschnitts verlangt war. Voraussetzung für Anlegung einer solchen Sortiments-Erlösstatistik ist eine Holzverwertungsweise, bei der jedes einzelne Sortiment gesondert zum Verkauf gebracht wird. Für große Waldgebiete fehlen leider gerade deshalb brauchbare Preisaufzeichnungen, weil, wie es früher großenteils gehandhabt wurde und auch heute noch teilweise gebräuchlich ist, das Stammholz s c hl ag w e i s e verkauft, d. h. bei der Loseinteilung auf die Ausscheidung der Wertsklassen verzichtet wird. Ohne auf die Frage der Zweckmäßigkeit dieser Verkaufsart näher einzugehen, die in manchen Fällen nicht ganz zu vermeiden ist, möchten wir doch den Wunsch aussprechen, daß, soweit irgend möglich, $\mathrm{kl}$ a s se $\mathrm{n}$ wei se Loseinteilung durchgeführt wird, nicht bloß mit Rücksicht auf die für statische Untersuchungen und Wertsberechnungen unentbehrliche Erlösstatistik, sondern auch zur Gewinnung zuverlässiger Anhaltspunkte für Bemessung der Taxen und der Zuschlagspreise.

Es fragt sich nun, wie die Holzpreisstatistik weiterhin zu organisieren ist. Man muß dabei unterscheiden zwischen der innerhalb Reviers zu führenden Statistik und der Verarbeitung der einzelnen Erlösnotizen an der Zentrale einer Verwaltung. Zur Orientierung über den Holzkurs bei der Entscheidung von Holzverwertungsfragen, ferner als Material für Werts- und Rentabilitätsberechnungen müssen ja der leitenden Behörde jederzeit Erlösangaben zur Verfügung stehen; kommen für jene Fragen mehr die Erlöse der e i n z el n e n g r ö B er en Verkaufstermine in Betracht, so sind für Arbeiten der letzteren Art die Jahresdurchschnittser1 ö s e maßgebend; während die ersteren rom $\mathrm{Holzp}$ reis$\mathrm{n}$ a c hrich tend i ens t ${ }^{1}$ ) weiter zu behandeln sind, wären

1) Ein solcher Nachrichtendienst ist seit 1902 bei der Württ. Forstdirektion eingerichtet, indem dem Holzverkaufsreferat ein 
die jährlichen Durchschnittserlösberechnungen der $\mathrm{H} \mathrm{ol} \mathrm{z} \mathrm{er-}$ tragsstatistik einzuverleiben; die Forstwissenschaft wird es gewiß mit Freuden begrüßen, wenn die Forstverwaltungen diese Durchschnittserlöse alljährlich in ihrer Forststatistik veröffentlichen.

So wichtig und unentbehrlich die $\mathrm{R}$ e $\mathrm{vi}$ er - Preisstatistik ist, so dürfte die $\mathrm{B}$ erechnung von $\mathrm{Durch}$ schnittserlösen für größere Waldverbände nicht uneingeschränkt als wünschenswert zu bezeichnen sein, da sie, wenn nicht mit Vorsicht behandelt, leicht irrtümliche Folgerungen veranlassen können. Denn die Durchschnittserlöse, rechnerisch richtig nach der Formel ${ }^{1}$ ) $\mathrm{dp}=\frac{\mathrm{m}_{1} \mathrm{p}_{1}+\mathrm{m}_{2} \mathrm{p}_{2}+\ldots . \mathrm{m}_{\mathrm{n}} \mathrm{p}_{\mathrm{n}}}{\mathrm{m}_{1}+\mathrm{m}_{2}+\ldots .} \mathrm{m}_{\mathrm{n}}$ erhoben, lassen vergleichende Preisuntersuchungen nur unter der Voraussetzung anstellen, daß das Verhältnis des M assen a $\mathrm{f}$ all s der einzelnen Reviere jeweils annähernd das gleiche ist, oder daß die Einzelpreise derselben keine erheblichen Unterschiede ergeben. Dieselbe Voraussetzung muß auch erfüllt sein, wenn aus den Durchschnittserlösen eines größeren Waldverbands (mehrerer Reviere) das Wertsverhält $\mathrm{n}$ is $\mathrm{der}$ e inzelnen Sortimente abgeleitet werden will. Andernfalls stehen $W$ aren vers chiedener Güte zum

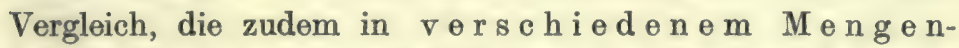
verhält $\mathrm{n}$ is angeboten werden; daß für solche ein Durchschnittspreis nicht nach obiger Formel berechnet werden darf, hat L e h r ("Beiträge“" usf. S. 20 f.) an Beispielen ausführlich dargelegt. Die Verschiedenheit der Güte der an sich gleichen Sortimente liegt - abgesehen von gewissen inneren Eigen-

Holzverkaufsbüro angegliedert ist, dessen Aufgabe außer in der Vermittlung der Verkaufsausschreiben hauptsächlich darin besteht, die Forstämter über die Holzpreise auf dem laufenden zu halten und eingehende Holzpreisaufzeichnungen für die Handelssortimente (Stammholz, Stangen, Schleifholz u. s. f.) zu führen.

1) Vergl. L e hr, Beiträge etc. (a. a. O.) S. $10 \mathrm{ff.}$ 
schaften des Holzes, welche je nach Standort verschieden ausgebildet sind - hauptsächlich in der Ungleichheit ihrer Lage zum Markt (Abfuhr- und Frachtkosten) begründet.

Das folgende, den Erlösmitteilungen der württembergischen Staatsforstverwaltung entnommene Beispiel zeigt beim Vergleich der Jahre 1909 und 1910 ein Zurückflauen des Durchschnittspreises für IV. Kl. Buchenstammholz um $39 \mathrm{Pf}$. an, trotzdem in 3 Revieren eine ausgesprochene Steigerung und in einem (St. Johann) ein Rüickgang um nur 27 Pf. vorliegt; dieses scheinbar auffallende, die Brauchbarkeit der $\mathrm{D} u \mathrm{rchschnit} \mathrm{tserlös-}$ $\mathrm{b}$ e r e c h n u $\mathrm{g}$ für Preisbeobachtung verneinende Ergebnis erklärt sich ganz einfach aus der veränderten Verteilung des Gesamtanfalls auf die hinsichtlich Absatzlage offenbar ziemlich verschiedenen Reviere; der Durchschnittserlös von 1909 erscheint zu hoch, weil ein Revier mit schlechter Absatzlage (Lichtenstein) überhaupt nicht beteiligt war und der von $1910 \mathrm{zu}$ nieder, weil die Reviere mit an sich besseren Preisen (Urach und Hengen) weniger Material als im Jahr vorher zur Verfügung stellten. Auch eine Vergleichung der arithmetisch mittleren Erlösziffer (Sp. 13) $\left(\mathrm{d} p=\frac{\left.\mathrm{p}_{1}+\mathrm{p}_{2}+\ldots \mathrm{p} \mathrm{n}\right)}{\mathrm{n}}\right.$ würde kein richtiges Bild der Preisveränderung geben, weil ein Revier mit extremer Preisgüte (Lichtenstein) 1909 überhaupt nicht beteiligt war.

Tab. $\left.14^{1}\right)$.

Nach den Erlösmitteilungen über die alljährlich stattfindenden Rotbuchen-Stammholzverkäufe des Forstverbands Urach wurden erlöst für IV. K1. $(30-39 \mathrm{~cm} \mathrm{~m} . \mathrm{Dm}$.$) :$

\begin{tabular}{|c|c|c|c|c|c|c|c|c|c|c|c|c|c|}
\hline \multirow[b]{3}{*}{$\begin{array}{c}\text { Im } \\
\text { Wirt- } \\
\text { schafts- } \\
\text { jahr }\end{array}$} & \multicolumn{10}{|c|}{ Bei den Forstilmtern } & \multirow{2}{*}{\multicolumn{3}{|c|}{$\begin{array}{l}\text { Im Durch- } \\
\text { schnitt d. Forst- } \\
\text { verbandes }\end{array}$}} \\
\hline & \multicolumn{2}{|c|}{ Hengen } & \multicolumn{2}{|c|}{ Kohlstetten } & \multicolumn{2}{|c|}{ Lichtenstein } & \multicolumn{2}{|c|}{ St. Johann } & \multicolumn{2}{|c|}{ Urach } & & & \\
\hline & 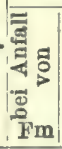 & 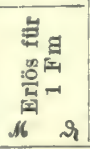 & 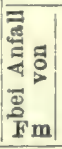 & 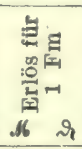 & 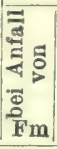 & 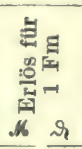 & 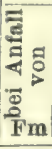 & 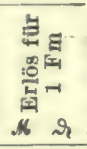 & 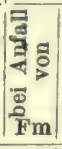 & 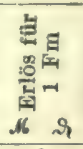 & 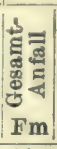 & | & 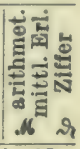 \\
\hline & 1 & 2 & 8 & 4 & 5 & 6 & 7 & 8 & 9 & 10 & 11 & 12 & 18 \\
\hline & 37 & 18.91 & 183 & & 108 & & 101 & & 74 & & 592 & 9.45 & \\
\hline & & & & & 45 & 19.92 & 65 & & 77 & & & & \\
\hline & 70 & 20.3 & & 18. & -1 & - & 98 & 20 & 101 & & & 20. & \\
\hline & 59 & & & & 50 & & 78 & & 70 & & 578 & & \\
\hline 1911 & 112 & 22.73 & 522 & 19.44 & 43 & 20.15 & 84 & 22.40 & 113 & 21.14 & 874 & 20.40 & 21.17 \\
\hline
\end{tabular}

In den $\mathrm{D}$ u r c h s c h n it $\mathrm{s}$ erlösberechnungen der Tabelle 14, Sp. 12 wird das Bild der Preisentwicklung vollständig

1) Wegen der im Jahr 1906 eingetretenen Aenderung der Sortimentseinteilung für Laubstammholz kann diese Zusammenstellung nicht weiter zurückgeführt werden. 
verwischt; die Verzeichnung wird in anderen Fällen, zumal bei Sortimenten, die mehr als Massenartikel anfallen, wie z. B. Nadelholzstammholz, nicht so auffallend sich bemerkbar machen, aber bei vergleichenden Preisuntersuchungen $\ddot{\mathrm{u}} \mathbf{b}$ e $\mathbf{r}$ 1 än g e r e Z e it hinweg ist mit jenem Fehler doch sehr wohl zu rechnen. Zwar ist nicht zu leugnen, daß sich $\mathrm{Du} \mathbf{r} \mathrm{ch}$ s chnit tserlöse aus gröBeren Waldgebieten vielfach mit Vorteil zur Orientierung über den Preisstand des Handelsnutzholzes verwenden lassen; so werden z. B. in den fortlaufend veröffentlichten Erlös-Mitteilungen über die Nutzholzverkäufe im Bereich der württembergischen Staatsforstverwaltung jeweils die monatlichen Durchschnittserlöse für normales Nadelholzlangholz getrennt nach den 4 Haupteinkaufsgebieten (Schwarzwald, Nordostland, Oberschwaben, Mittel- und Unterland) angegeben, um die Forstämter in den Stand zu setzen, an der Hand der entsprechenden Mitteilungen von den Vorjahren sich ein Urteil über den Kurs des Nadelholzstammholzes zu bilden; die angedeutete Fehlerquelle ist hiebei, wenigstens während der $\mathrm{H}$ a u p t verka uf ss a i so $\mathrm{n}$, fast bedeutungslos, weil sich bei der großen Zahl der Einzelfälle Veränderungen im Massenanfall und in der Sortimentsverteilung der Reviere großenteils ausgleichen; jedenfalls genügt der Genauigkeitsgrad für den praktischen Zweck der Orientierung über den ungefähren Preisstand. Je kleiner aber die Zahl der Einzelfälle und die verkaufte Menge ist, umso $\mathrm{m} \theta \mathrm{h} \mathrm{r}$ macht sich die in Tab. 14 veranschaulichte Verzeichnung geltend. Bei Erforschung der Preisentwicklung w ährend längerer $\mathrm{Z}$ eit dürfte der Fehler häufig umso größer werden, je weiter der Waldverband genommen ist; denn sowohl das Verhältnis des Massenanfalls in den Einzelrevieren als dasjenige der Sortimentsverteilung wird sich vielfach immer mehr - nach einer Richtung zu verschieben. Als Beweismittel für diese Annahme kann auf 
Tab. 4 (S. 28) Bezug genommen werden; aus den dortigen Zahlen geht hervor, daß die Nadelholznutzung der württembergischen Staatsforste nach Verlauf von etwa 30-40 Jahren (vielleicht auch schon früher) nicht mehr in $\mathrm{d}$ er ü b erwiegenden Mehrheit wie heute oder gar noch vor Jahren aus den $\mathrm{S}$ c h w a r z wald revieren zu beziehen sein wird; vielmehr werden auch andere Landesteile und damit andere Absatzlagen (zumal mit Bezug auf das Hauptabsatzgebiet am Rhein) in den Vordergrund treten, insbesondere $\mathrm{Alb}$ und Unterland; man würde deshalb kein richtiges Bild von der Preisentwicklung bekommen, wollte man s. Zt. den Landesdurchschnittserlös der Nadelholzstammholzsortimente mit dem entsprechenden von heute vergleichen. Auch für kleinere Gebiete ist mit solchen Verschiebungen zu rechnen; zeigen doch die Altersklassentabellen, daß der Altholzbestand der Finzelreviere recht verschieden gestaltet ist. Wenn man einmal den verfehlten Grundsatz der $\mathrm{Nachhaltigkeit}$ innerh a l b R e vi ers endgültig abgeschüttelt hat (soweit es die Rücksicht auf die Arbeiter erlaubt), wird sich mit der Zeit immer mehr eine Verschiebung jenes Mengenverhältnisses geltend machen; durch Wegbauten usw. wird die Verschiedenheit der Absatzlagen allerdings teilweise ausgeglichen werden. Man wird also gut tun, bei Preisuntersuchungen möglichst von kleinen und kleinsten Waldverbänden a usugehen. Dem ganz richtigen Grundsatz, daß nur die Masseder Einzelfällezu einem zuverlässigen Resultat verhelfen kann, ist dabei natürlich immer Reehnung zu tragen, abernicht so sehrdadurch, daßman wenige Durchschnittsberechnungen aus einer großen Anzahl von Einzelfällen vergleichend an einander miBt, als vielmehr, in- 
dem man zahlreiche Einzeluntersuchungen über die Preisbewegung anstelltund a us der Fülledieser Ermittlungen die Gesetz mä Bigkeit hera usliest. Wenn man aber doch Durchschnittserlösberechnungen verwerten will, sollte man nicht versäumen, zur Kontrolle auch die arithmetisch mittleren Beträge ${ }^{1}$ ) (nach der Formel $d p=\frac{p_{1}+p_{2}+\ldots p_{n}}{n}$ ) zum Vergleich heranzuziehen; diese Größen geben zwar bezüglich des Effekts der tatsächlichen Erlösveränderung leicht ein ganz falsches Bild, aber die Preisentwicklung selbst lassen sie häufig doch weit eher erkennen, wenn nicht gerade, wie im obigen Beispiel (Tab. 14) die Zahl der Einzelfälle sich verändert (einzelne Reviere hinzukommen oder wegfallen) oder einzelne Abnormerscheinungen und Zufallsergebnisse (kleines Quantum mit auffallend hoch getriebenem Liebhaberpreis) unverhältnismäßig großen Preisunterschied verursachen.

Sehr zweckmäßig sind Durchschnittserlösberechnungen aus einer größeren Anzahl von Revieren mit annähernd gleichartigen Preisverhältnissen wenigstens für $\mathrm{k} u \mathbf{r z f r i s t i g e ~ B e o b a c h t u n g e n . ~ A u c h ~ d e r ~ R e v i e r v e r - ~}$ walter wird gut daran tun, die Preisbewegung nicht bloß an einzelnen Nachbar-Revieren zu verfolgen, die bei sonst ähnlichen Verhältnissen vielleicht doch recht verschiedene Absatzlagen haben, sondern auf alle die Bezirke zu achten, welche nach der Erfahrung der Vorjahre ähnliche Preise erzielen. Vom zentralen Nachrichtendienst werden derartige Zusammenstellungen von Revieren ähnlicher Preisgüte anzulegen sein, damit man prüfen kann, ob im einzelnen Fall nur lo ka le Preisveränderungen (Störungen) vorliegen oder ob sich der Kurs der betreffenden

1) Berücksichtigt in der Preisstatistik aus der sächsischen Staatsforstverwaltung (Thar. Forstl. Jahrb. Bd. 42 und 51). 
Ware überhaupt geändert hat ${ }^{\mathbf{1}}$ ).

Für la ngfristige Beobachtungen dagegen werden nur die Einzel-Reviere als Vergleichsgebiete dienen können, da die Preisähnlichkeit mehrerer Reviere vielfach nur vorübergehender Natur ist, durch Weg-, Bahnbauten, Entwicklung lokaler Industriezweige u. a. im Lauf der Zeit verloren geht.

Aber selbst die D u r chs chnittserlöseder einz e In en Reviere sind nicht immer zuverlässige Weiser der Preisgestaltung. Die Buchenstammholzpreise der Tab. 14 lassen beim Vergleich der Jahre 1908 und 1909 in den einen Bezirken Preiszunahme, bei den andern Rückgang erkennen, ebenso beim Vergleich der Jahre 1907 und 1909; da jeweils der gesamte in der Tabelle vorgetragene Buchenstammholzanfall der beteiligten Aemter in Einer Versteigerungsverhandlung verkauft wurde, kann man sich diese Erscheinung nur daraus erklären, daß die einzelnen Bezirke selbst wieder verschiedene Preis gü teklassen (Absatzlagen) umfassen, von denen bald mehr die eine oder andere den größeren Teil des Verkaufsquantums lieferte. Faßt man, wie es zur Erforschung der Gesamtpreisentwicklung einer 1 ängeren Zeitperiode erforderlich ist, mehrere Jahre zur Berechnung von Durchschnittsbeträgen zusammen, so gleicht sich jener Wechsel der verschiedenen Waldteile, der guten und geringen Absatzlagen, großenteils wieder aus. Wenn man aber die Erlöse der einzelnen Jahre miteinander vergleichen und zugleich ermitteln will, ob etwa eine Verbess er ung der $\mathbf{L}$ age z u m M r k a ls Preismehrungsursache angenommen werden kann, so empfiehlt es sich in der Lokalpreisstatistik eine Ausscheidung mehrerer Preisgüte$\mathrm{klassen}$ vorzusehen (insbesondere in den Gebirgsrevieren)

1) So werden in den Erlösaufschrieben des Holzverkaufsbüras der württ. Forstdirektion die Reviere nach Preisgruppen zusammengestellt. 
d. $\mathrm{h}$. die Waldteile zu sog. Absatzlagen ${ }^{1}$ ) zu gruppieren, für welche die natürliche bezw. die durch Wege, Waldbahnen und dergl. künstlich geschaffene Lage zu den Verbrauchsorten, zur Bahn, zu den Wasserstraßen, Einbindstellen und dergl., daneben vielleicht auch gewisse Eigenschaften des Holzes, bestimmend sind. Diese Art der Geschäftsbehandlung würde auch dem Verkaufswesen zugut kommen, indem sie zuverlässigere Grundlagen für das Kalkulieren der Zuschlagspreise an die Hand gibt, als eine nur den jeweiligen Gesamterlös des Jahres bezw. des einzelnen Verkaufs berücksichtigende Preisnotierung; heutzutage, wo der freihändige Verkauf als wichtigstes Kampfmittel des Waldbesitzers gegenüber der preisdrückenden Tendenz der Kartellbestrebungen proklamiert wird, und die natürliche Preisbildung teilweise ausgeschaltet ist, dürfte es für die Forstverwaltungen von Wichtigkeit sein, möglichst $\theta \mathrm{ing}$ ehende Preisstatistik zu treiben.

Untersuchungen über die Preisveränderung und über den auf Preiserhöhung zurückzuführenden Betreff der Wertsmehrung erfordern somit viel Kleinarbeit und setzen sorgfältige auf lange Zeit zurückreichende detaillierte Preisaufschriebe voraus.

Diese Voraussetzungen treffen leider im allgemeinen nicht $\mathrm{zu}$. Verfasser hatte die Absicht, die Preisentwicklung wenigstens des Nadelholzstammholzes an mehreren Einzelfällen $\mathrm{zu}$ verfolgen, konnte aber nur schwer ein einigermaßen brauchbares Zahlenmaterial sich verschaffen; für große Nadelholzgebiete der württembergischen Staatswaldungen, insbesondere für den Schwarzwald, ist eine Nachweisung über die Durchschnittserlöse der Stammholzklassen wegen der s c hl a g w e is e n Verkaufsform überhaupt nicht, oder nur von einzelnen Jahren und kleinen Quantitäten vorhanden. Dagegen standen von dem im vorigen Abschnitt erwähnten Forstbezirk Baindt Erlösaufzeichnungen zur Verfügung. die den Eindruck der $^{2}$ ) Zuverlässigkeit zu erwecken vermögen,

1) In den neuesten tabellarischen Erlösmitteilungen der bayrischen Staatsforstverwaltung (veröffentlicht im Allg. Anz. f. den Forstproduktenverkehr) finden wir bei einer Reihe von Revieren gesonderte Angaben für Absatzlage I, II, III usf.

2) Was für die bis vor kurzem von den Kameralämatern $\mathbf{z u}$ fertigenden Durchschnittserlösberechnungen sehr häufig nicht zutrifft; dieses Material darf, zumal beim Nutzholz, nur mit größter Vorsicht benützt werden. 
Es soll deshalb die Preisentwicklung gewissermaßen an einem ty $\mathrm{p}$ is chen Fall besprochen werden; hiefür eignet sich das genannte Revier in besonderem Maß; der preisändernde EinfluB der Verkehrsentwicklung ist, soweit Wasserstraßen und Bahnlinien in Betracht kommen, ausgeschlossen, weil sich innerhalb des Beobachtungszeitraums in dieser Hinsicht nichts geändert hat, dagegen lassen sich die Wegnetzausdehnung und der Ausbau der Fahrstraßen als wertsmehrende Elemente nicht eliminieren. Dafür ergeben sich in anderer Hinsicht bemerkenswerte GesetzmäBigkeiten.

\section{Ergebnisse und Nutzanwendungen der Preisstatistik}

(besprochen an einem ty $\mathrm{p}$ is chen $\mathrm{B}$ e is $\mathrm{p}$ i el).

Die Preisentwicklung der Nadelholzlangholzsortimente im württembg. Forstbezirk Baindt ist in Fig. 2 (S. 111) graphisch dargestellt. Um die aus dem Zickzack des Preisverlaufs deutlich heraustretende $\mathrm{nach} \mathrm{haltige} \mathrm{Preissteigerung} \mathrm{in} \mathrm{Zah-}$ len auszudrücken, mußten entsprechend den in der Einleitung aufgestellten Grundsätzen große Zeitabschnitte gewählt werden; aus der graphischen Darstellung geht ja hervor, daß sich die Periode 1900/09 allein so wenig wie 1870/79 oder 1880/89 als Vergleichsobjekt eignet; es wurden deshalb je die Durchschnittsziffern von 1870/89 und 1890/1909 einander gegenübergestellt; zeichnet man die entsprechenden Kurven ${ }^{1}$ ) ein, so zeigt sich, daß die Höhen und Tiefen der gebrochenen Linie annähernd ausgeglichen werden. Zur Kontrolle wurde außerdem noch der Verlauf der Minima und Maxima, wenigstens für 2 Sortimentsklassen beobachtet. Die Ergebnisse sind in der nachfolgenden Tabelle 15 (s. 112) zusammengestellt.

Zum Nachweis dessen, daß diese ganz beträchtlichen Preismehrungen nicht als abnorme Zufallserscheinungen des. einzelnen Reviers anzusehen sind, wurden die Berechnungen auf die Nachbarreviere B ettenreute, Weingarten, W e i $\mathbb{B}$ en a u ausgedehnt; auch auf die Absatzverhältnisse dieser Bezirke hat während der Beobachtungszeit kein Bahnbau preisändernden Einfluß ausgeübt; neben dem Nadelholz-

1) Der Uebersichtlichkeit halber nur für I. und IV. Langholzklasse durchgeführt. 
Figur 2. Durchschnitts-Erlöse für Nadelholz-Langholz im Württ. Forstbezirk Baindt (1870-1909).

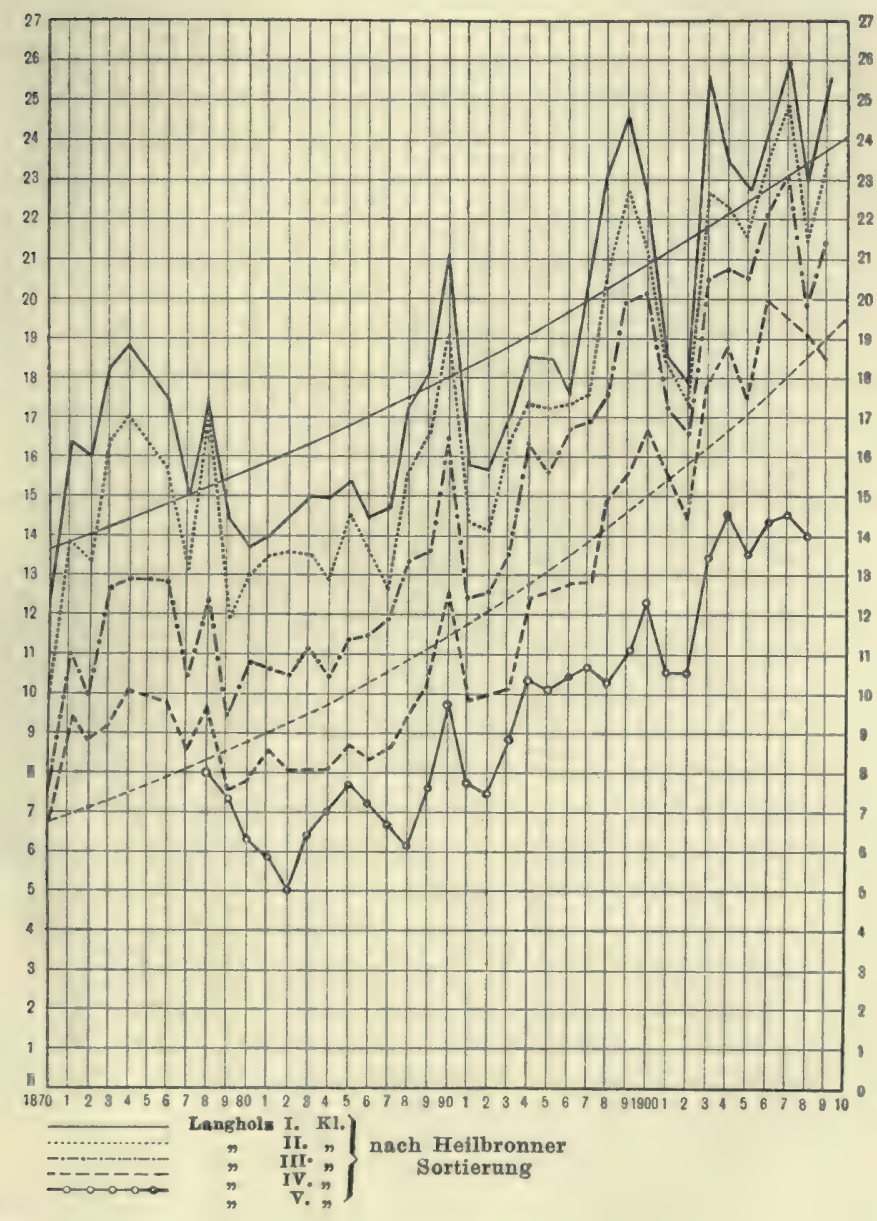




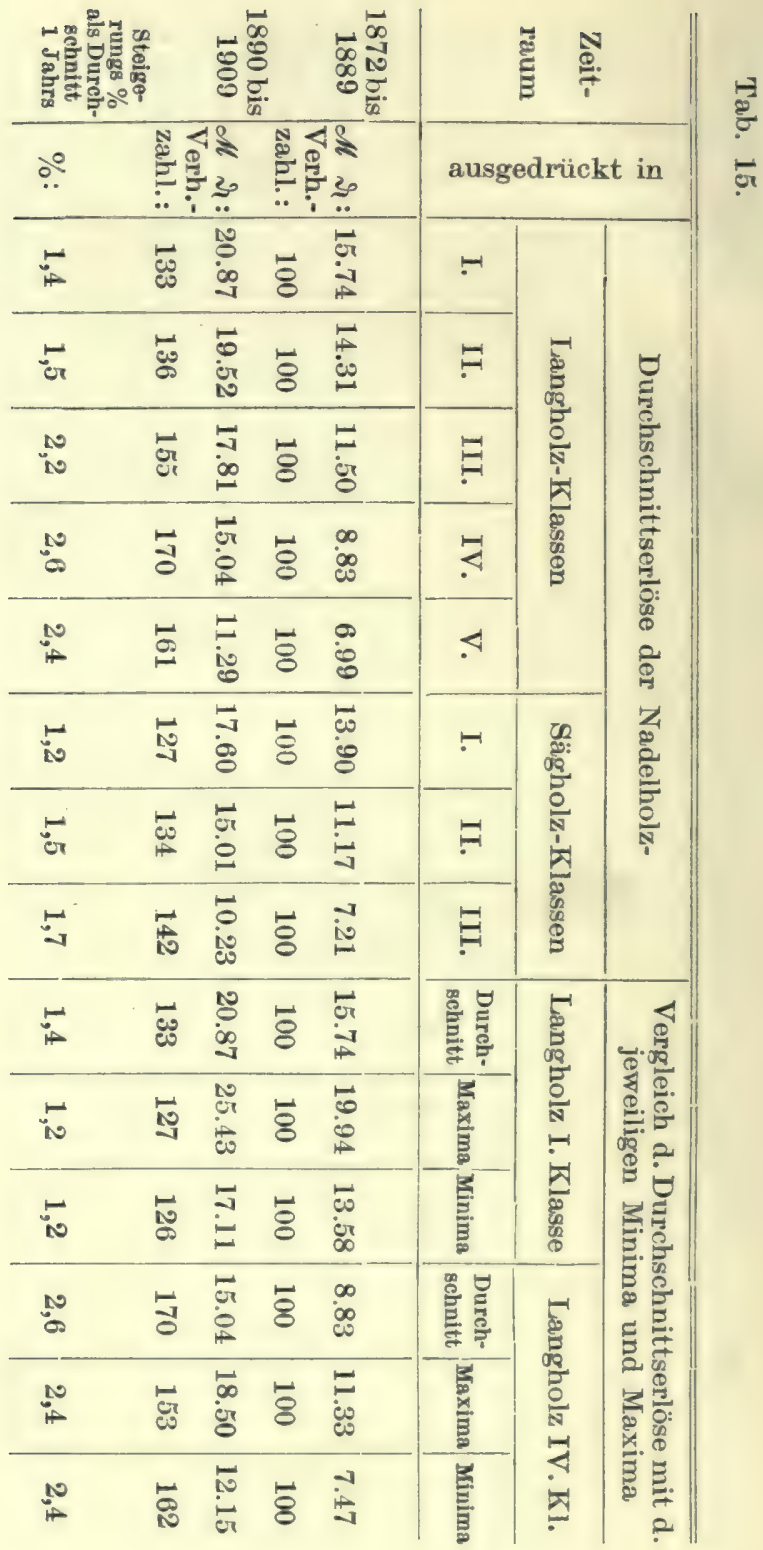


langholz wurden auch die normalen Brennholz-Sortimente (Buchen-Scheiter-Prügel, Nadelholz-Scheiter- und Prügel) berücksichtigt.

Tab. 16.

Preismehrungs-Uebersicht.

\begin{tabular}{|c|c|c|c|c|c|c|c|c|c|c|c|c|}
\hline \multirow{4}{*}{ Forstbezirk } & \multicolumn{12}{|c|}{ Durchschnittl. Preismehrungs-Procent berechnet a. 1 Jahr } \\
\hline & \multicolumn{8}{|c|}{ für Nadelholz-Stammholz } & \multicolumn{4}{|c|}{ für norm. Brennholz } \\
\hline & \multicolumn{5}{|c|}{ der Langholzklasse } & \multicolumn{3}{|c|}{ der Sägh.-Kl. } & \multicolumn{2}{|c|}{ Nadelh. } & \multicolumn{2}{|c|}{ Buchen } \\
\hline & I. & II. & III. & IV. & V. & I. & II. & III. & Sch. & Pr. & Sch. & Pr. \\
\hline Baindt & 1,4 & 1,5 & 2,2 & 2,6 & 2,4 & 1,2 & 1,5 & 1,7 & 1,2 & 1,7 & 0,3 & 1,1 \\
\hline Bettenreute & 1,5 & 1,7 & 2,4 & 2,6 & 2,2 & - & - & - & 1,9 & 1,9 & 1,0 & 1,2 \\
\hline Weingarten & 1,3 & 1,4 & 2,1 & 2,4 & 2,5 & 1,2 & 1,7 & 1,3 & 1,5 & 2,3 & 0,6 & 0,6 \\
\hline Weißenau & 1,4 & 1,6 & 2,2 & 2,3 & 2,0 & 1,4 & 1,7 & 1,4 & 1,7 & 2,0 & 0,8 & 0,8 \\
\hline
\end{tabular}

Aehnliche Erhebungen wären nun auch in anderen Waldgebieten - sofern die Hilfsmittel zur Verfügung stünden vorzunehmen; aus der Fülle der Einzeluntersuchungen ließe sich gewiß mancher gemeinsame Charakterzug herausfinden. Man könnte weiterhin auch noch die Preissteigerung des $\mathrm{Ge}$ samtholzertrags der Betriebsklasse aus obiger Tabelle ableiten, indem man unter Berücksichtigung der Sortimentsmassenverteilung nach der Formel $d p=\frac{p_{1} m_{1}+p_{2} m_{2}+\ldots p_{n} m_{n}}{m_{1}+m_{2}+\cdots m_{n}}$ ein durchschnittliches Mehrungsprozent berechnete. Ein Bedürfnis hiefür würde dann etwa vorliegen, wenn man den pekuniären Vorteil ermessen wollte, den ein Bahnbau oder eine sonstige Verkehrsverbesserung (Weg, Kanalbau, Waldbahn und dergl.) gebracht hätte; man müßte zu diesem Zweck das betreffende Revier (bezw. die betr. Waldteile, oder größeren Waldverbände) in Vergleich stellen zu einem, seither ähnliche Absatzverhältnisse und Preisentwicklung aufweisenden Nachbarn. In dieser Hinsicht scheint aber keines der oben genannten Reviere besonders bevorzugt worden zu sein, da sie eine aufForstwirtechaft. V. D i eter ic h, Elemente d. Wertsmehrung. 
fallende Aehnlichkeit der Preisentwicklung erkennen lassen. Die durchschnittlich-jährliche Preismehrung mag etwa $2 \%$ betragen. Dieser sehr erfreuliche Teuerungszuwachs könnte leicht den Glauben an einen gleich flotten Fortgang aufkommen lassen; zu einer solchen Annahme liegt aber kein innerer Grund ${ }^{1}$ ) vor; für die obigen Berechnungen ist ja auch ziemlich willkürlich ein Stück Preisgeschichte (sowcit eben die Erlösnachweisung reicht) aus dem Zusammenhang herausgerissen. Die graph. Darstellung in Fig. 2 läßt viel eher vermuten, daß über kurz oder lang wieder einmal eine länger dauernde Depression wie 1879/87 und 1891/96 eintreten könnte. Daß die Kapitalien, welche die württembergische Staatsfinanzverwaltung in den oben angeführten Revieren stecken hat, sich bisher gut rentiert haben, ist außer Zweifel, da sie ja allein jährlich etwa $2 \%$ Preiszuwachs trugen; aber dieser Umstand berechtigt noch lange nicht zu dem Schluß, daß nun überhaupt für jene Gebiete mit einem um $2 \%$ niedrigeren forstlichen Zinsfuß zu rechnen ist, oder daß man Rentabilitätsberechnungen etwa für unnötig erklärte, weil der Teurungszuwachs allein schon beinahe eine Verzinsung des Waldkapitals ergibt. Das oben (S. 97 f.) der Preissteigerung als Wertsmehrungsfaktor gegenüber ausgesprochene Mißtrauen ist durch die sehr erfreulichen Ergebnisse der Tab. 16 nicht zerstreut. Wir dürfen diese Botschaft ad notam nehmen, zu weiteren Schlußfolgerungen aber berechtigt sie noch nicht; als $\mathrm{nachhaltig}$ wirkendes Wertsmehrungselement dürften wir nur eine in obigen $\mathrm{Zahlen}$ leider nicht nachweisbare Verbesserung der Absatzlagen durch Wegbau und dergl. anerkennen.

In anderer Hinsicht gibt uns aber die obige Preismehrungsübersicht doch recht wertvolle Fingerzeige für Beurteilung der

1) Wie etwa bei einzelnen Elementen der Wertsmehrung mit Bezug auf Massenertrag und Qualität, für welche im dermaligen Altersklassenverhältnis, Holzartenverteilung u. dergl. die Begründung künftiger Mehrung enthalten ist. 
in der Waldwirtschaft sich abspielenden Wertsänderungen und erlaubt gewisse Schlußfolgerungen zu ziehen, auch wenn die zum Vergleich einander gegenüber gestellten Zeiträume 1872/89 und 1890/1909 nicht zutreffend ausgesucht wären. Mehr als die Tatsache der Preismehrung selbst fällt doch das verschiedenartige Verhalten der einzelnen Wertsklassen auf, umso mehr, als auch in dieser Beziehung weitgehende Uebereinstimmung unter den vier Revieren besteht. Insbesondere ist es das Preisverhältnis der einzelnen Langholzklassen, das unsere Aufmerksamkeit verdient. Die Tabelle weist in beredter Sprache eine Verschiebung des Preisverhältnisses zu Ungunsten der stärkeren Langholzklassen (insbesondere der Klasse I) nach. Bei der Wichtigkeit dieses Ergebnisses mögen hierüber noch einige Bemerkungen angebracht erscheinen.

Für 2 Forstbezirke, deren Preisnotierung am vollständigsten erhalten ist, wurde das Preisverhältnis der Langholzklassen in der Weise veranschaulicht, daß die Durchschnittserlöse des Einzeljahrs bezw. je eines 5jährigen Zeitraums auf diejenigen der Langholz-Klasse IV, diese $=100$ gesetzt, bezogen wurden . Hiernach berechneten sich die Verh.-Zahlen d. Tab. 17.

Daß die Wertsspannung zwischen starkem und schwachem Nadelholzstammholz schon seit geraumer Zeit im Rückgang begriffen ist, wurde in der forstlichen Literatur schon vielfach erörtert; für statische Untersuchungen über das finanziell zweckmäßigste Haubarkeitsalter (Feststellung des Wertszuwachsgangs) spielt diese Tatsache eine sehr gewichtige Rolle.

Es sei auf folgende, diese Fragen behandelnde Arbeiten und Aeußerungen hingewiesen:

1. Tannen-Ertragstafel von Lorey 1897 S. 150: ,Nicht die stärksten Stämme, diejenigen der I. Kl., finden den flottesten Absatz, sondern diejenigen der II., III. und IV. etc. ${ }^{\text {* }}$

2. Aufsatz von W a $\mathrm{g} \mathbf{n}$ er in A. F. und J.Z. 1902 S. 221 ff. : ,Ein einfacher Weiser der finanziellen Hiebsreife von Fichte etc". W a g n e r weist hier an der Hand von Langholzerlösen und von Schnittwarenpreisen nach, daß die 
Tab. 17.

\begin{tabular}{|c|c|c|c|c|c|c|c|c|c|c|}
\hline \multirow{4}{*}{$\begin{array}{l}\text { Im Durch- } \\
\text { schnitt des } \\
\text { Jahrfünfts }\end{array}$} & \multicolumn{10}{|c|}{ Durchschn.-Erlöse der Langh.-Kl. in Verh.-Zahl. bez. auf die der IV. Kl. = 100} \\
\hline & \multicolumn{5}{|c|}{ im Forstbezirk Baindt } & \multirow{2}{*}{\multicolumn{5}{|c|}{$\begin{array}{c}\text { im Forstbezirk Bettenreute } \\
\text { der Langholzklasse }\end{array}$}} \\
\hline & \multicolumn{5}{|c|}{ der Langholzklasse } & & & & & \\
\hline & V. & IV. & III. & II. & I. & V. & IV. & III. & II. & I. \\
\hline $1870-74$ & - & 100 & 120 & 155 & 185 & - & 一 & 一 & $\longrightarrow$ & 一 \\
\hline $1875-79$ & 一 & 100 & 126 & 149 & 181 & - & 100 & 128 & 168 & 182 \\
\hline $1880-84$ & 76 & 100 & 132 & 163 & 178 & 一 & 100 & 129 & 158 & 182 \\
\hline $1885-89$ & 77 & 100 & 135 & 161 & 176 & - & 100 & 144 & 167 & 189 \\
\hline $1890-94$ & 81 & 100 & 130 & 150 & 161 & 82 & 100 & 128 & 147 & 170 \\
\hline $1895-1900$ & 77 & 100 & 125 & 140 & 152 & 86 & 100 & 125 & 141 & 156 \\
\hline $1900-1904$ & 74 & 100 & 115 & 124 & 130 & 78 & 100 & 122 & 128 & 186 \\
\hline $1905-1909$ & 73 & 100 & 112 & 123 & 130 & 76 & 100 & 116 & 125 & $130^{1}$ \\
\hline $1909-1910$ & - & 100 & 116 & 127 & 138 & - & 一 & - & - & - \\
\hline
\end{tabular}

Hiebsreife nach finanziellen Rücksichten eingetreten ist bei einem Brusthöhendurchmesser von $40 \mathrm{~cm}$, mit welchem der Stamm je nach Standort der III. oder II. Langholzklasse angehört; mit einem guten Stamm III. Kl. lassen sich die meisten Bedürfnisse des Konsums befriedigen.

3. M a r i $\mathrm{n}$, Die Folgerungen der Bodenreinertragstheorie 5. Bd. (8. die Fichte) S. 132: ,,daB die Wertszunahme des Stammholzes beim Uebergang aus der 5. in die 4. Kl. am stärksten ist, daß aber auch mit dem Eintritt in die 3. K1. noch eine erhebliche Wertszunahme stattfindet, während. dies bei den stärkeren Klassen nicht mehr in gleichem. Maß der Fall ist".

4. $\mathrm{S} c \mathrm{~h}$ w a p a $\mathrm{ch}$, Wachstum und Ertrag normaler Fichtenbestände in Preußen (1902) S. 108: ,die Stämme I. und II. K1. werden nur wenig teurer bezahlt wie jene der II. K1."

5. Unafragen, welche Graf Tör ring bei süddeutschen Großholzhandlungen veranstaltete, ergaben, daß die II. bis IV. Kl. nach Heilbronner Sortierung die begehrteste Ware ist (s. Allg. Anz. f. d. Forstproduktenverkehr 1908 Nr. 31).

6. P a u $\Theta$ weist in seinem schon oben erwähnten Vortrag bei der 53. Versammlung des sächs. Forstvereins und in einem Aufsatz der A. F. und J.Z. 1908 S. 345 ff. nach,

1) $1905-08$. 
daß die Klötzer der Klasse $16 / 29$ (speziell 23/29) Oberstärke verhältnismäßig am besten bezahlt werden.

7. W a lth $\mathrm{er}$ zeigt in mehreren Aufsätzen (s. insbesondere A. F. und J.Z. 1903 Sept.), daß die Höchstpreise für die Fichte zwischen $35-40 \mathrm{~cm}$ mittlerem Durchmesser liegen und daß nach oben das Verhältnis von Mittelpreis zu mittlerem Durchmesser rasch nachläßt.

Die Zahlen der Tab. 17 zeigen, daß sich dieses Mißverhältnis erst a $1 \mathrm{~lm}$ ä h l i c h herausgestaltet und immer mehr zugespitzt hat. Als Bestätigung dieses Entwicklungsprozesses mag die Angabe in dem W a g $\mathrm{n}$ e r schen Aufsatz (A. F. und J.Z. 1902 S. 226) dienen, daß die Differenz zwischen der schmalsten und breitesten B r e t t e r sorte $1880-\because 12$ M., 1901 nur - $\because 4$ M. betrug; für Sachsen läßt sich Aehnliches an Hand der Fle m m i n g - P u s c h e'schen Preisstatistik (Thar. Jahrb. 42. und 51. Bd.) nachweisen. Ergänzt man die dort für die Forstbezirke des Erzgebirgs (Bärenfels, Marienberg, Schwarzenberg und Eibenstock) nachgewiesenen Erlöse durch die von Pause (s. S. 115 Z. 6) für den Zeitraum 1900/08 berechneten, so erhält man die in Tab. 18 eingetragenen absoluten Beträge und Verhältniszahlen (bezogen auf die Klasse 16/22 = 100 gesetzt). Als Parallele soll endlich auch das von $\mathrm{W}$ i $\mathrm{m} \mathrm{m}$ e $\mathbf{r}^{1}$ ) angegebene Spannungsverhältnis angeführt werden (entsprechend umgearbeitet, Verhältniszahlen auf IV. Kl. = 100 bezogen) - Tab. 19. -

Tab. 18. Durchschnittserl. für Fichtenstämme in d. Forstbez. d. sächs. Erzgebirgs

\begin{tabular}{|c|c|c|c|c|c|c|c|c|c|c|}
\hline \multirow{3}{*}{$\begin{array}{l}\text { im Durch- } \\
\text { schnitt des } \\
\text { Zeitraums }\end{array}$} & \multicolumn{10}{|c|}{ der einzelnen Stammklassen mit Oberstärke } \\
\hline & \multicolumn{2}{|c|}{ bis $15 \mathrm{~cm}$} & \multicolumn{2}{|c|}{$16-22 \mathrm{~cm}$} & \multicolumn{2}{|c|}{$23-29 \mathrm{~cm}$} & \multicolumn{2}{|c|}{$30-36 \mathrm{~cm}$} & \multicolumn{2}{|c|}{ über $36 \mathrm{~cm}$} \\
\hline & $\mathscr{N} \cdot M$ & $\begin{array}{l}\text { Verb.- } \\
\text { zahl. }\end{array}$ & $\mathscr{N} \cdot 2$ & \begin{tabular}{|} 
Verh.- \\
zahl,
\end{tabular} & AN. N & $\begin{array}{l}\text { Verh. } \\
\text { zahl. }\end{array}$ & - $N$. & \begin{tabular}{|c|} 
Verh.- \\
zahl.
\end{tabular} & $\mathscr{N} \cdot M$ & $\begin{array}{l}\text { Verh.- } \\
\text { zahl. }\end{array}$ \\
\hline $1880-1889$ & 11.60 & 88 & 13.24 & 100 & 16.01 & 121 & 18.22 & 138 & 18.51 & 140 \\
\hline $1890-1899$ & 13.38 & 84 & 15.79 & 100 & 19.23 & 122 & 21.25 & 134 & 21.07 & 133 \\
\hline $1900-1908$ & 15.24 & 83 & 18.44 & 100 & 21.79 & 118 & 24.18 & 131 & 24.59 & 133 \\
\hline
\end{tabular}

1) Dr. W i m m er, ,Mannheims Stellung im Nutzholzverkehr" (vergl. auch $\mathrm{Ph}$ il i p p, Die Forstl. Verhältnisse Badens 1909 S. 27). 
Wiewohl die sächsische Stammklasseneinteilung sich mit der Heilbronner Sortierung nicht ohne weiteres vergleichen läßt, kann die Tabelle 18 doch als Bestätigung der obigen Ausführung dienen. Ganz auffallend aber ist die Aehnlichkeit der Tabellen 17 und 19. Hier wie dort zeigt sich die IV. Kl. nicht bloß der I. K1., sondern auch der II. und III. Langholzklasse gegenüber hinsichtlich Preissteigerung überlegen; das Schwergewicht des Wertszuwachses wurde infolge dieser Preisentwicklung immer mehr dem schwächeren Holz zu verlegt.

Tab. 19. Spannungsverhältnis der Stammh.-Kl. (nach Heilb. Sort.)

\begin{tabular}{|c|c|c|c|c|c|}
\hline \multirow{2}{*}{$\begin{array}{c}\text { Nach den Erlösen } \\
\text { vom Jahr }\end{array}$} & \multicolumn{5}{|c|}{ In Verhältniszahlen $(I V .=100)$} \\
\hline & V. & IV. & III. & II. & I. \\
\hline 1888 & 77 & 100 & 127 & 160 & 200 \\
\hline 1893 & 81 & 100 & 122 & 147 & 166 \\
\hline 1898 & 74 & 100 & 114 & 134 & 144 \\
\hline 1904 & 92 & 100 & 113 & 123 & 131 \\
\hline
\end{tabular}

Der in Tab. 17-19 veranschaulichte Prozeß des allmählichen Nachlassens der Preisspannung zwischen starkem und schwachem Langholz bedeutet in gewissem Sinn eine der Qualitätsmehrung entgegenwirkende Tendenz, indem er den Gewinn beeinträchtigt, welcher der Waldwirtschaft durch Beschleunigung des Qualitätszuwachses (infolge pfleglicher Bestandesbegründung- und Erziehung) entstehen kann. Andererseits war diese Preisentwicklung insofern vorteilhaft, als sie das Heruntergehen auf niedrigere Umtriebe und den Uebergang zu intensiverer Durchforstung in den Fichtenwaldungen erleichterte.

Es fragt sich nun, ob wir dieses WertsmißverhäJtnis der Stammholzklassen auch für die Zukunft gelten lassen sollen, ob es sich vielleicht gar noch weiter zuschärfen wird; es müßte ja schon in 10-20 Jahren, wenn der Prozeß unaufhaltsam weiterginge, eine Wertsgleichheit der Langholzklassen I-IV eintreten. Solch' utopistische Ideen dürfen wir mit Recht zurückweisen; jene $\mathrm{Preis} \mathrm{abnormität} \mathrm{wird} \mathrm{wohl} \mathrm{ihren}$ 
Tiefstand erreicht haben; die Erlösmitteilungen der letzten Jahre lassen bereits eine leichte, teilweise sogar eine auffallende Besserung des Spannungsverhältnisses erkennen (vergl. auch Tab. 17: 1909 und 1910).

In Oberschwaben und teilweise auch in den andern württ. Nadelholzgebieten läßt sich diese Erscheinung deutlich beobachten. Vergleicht man z. B. Klasse I mit III (wegen der Aenderung der Sortierung im Jahr 1907 kann eine Vergleichung von I. und IV. streng genommen nur bis 1906 fortgeführt werden), so ergibt sich folgendes Preisverhältnis für Kl. I bezogen auf III = 100 nach den Durch-

schnittser-

$\begin{array}{lrrrrrrr}\text { lösen von }{ }^{1} \text { ) } & 1904 & 1905 & 1906 & 1907 & 1908 & 1909 & 1910 \\ \text { Oberschwaben } & \mathbf{1 1 1} & 111 & \mathbf{1 1 3} & \mathbf{1 1 3} & \mathbf{1 1 5} & \mathbf{1 1 5} & \mathbf{1 1 9} \\ \text { Nordostland } & \mathbf{1 0 9} & \mathbf{1 1 0} & \mathbf{1 1 0} & \mathbf{1 1 1} & \mathbf{1 1 1} & \mathbf{1 1 0} & \mathbf{1 1 4}\end{array}$

Auch $\mathrm{P}$ a u s $\Theta$ erwähnt in seinen Ausführungen, daß die Preiszunahme ,einerseits bei den schwächeren Sortimenten $16 / 22 \mathrm{~cm}$ - und andererseits bei den stärksten - über $36 \mathrm{~cm}$ am meisten" sich geltend machte; das $\mathbf{S t a r k h o l z ~ h a b e}$ im Preise angezogen, ,weil das Angebot nach1 i e B." Er fährt aber fort: ,,Trotzdem sind die Preise hierfür nicht hoch. Der Händler bezieht starke Ware billiger aus dem Auslande.“

Uebrigens wäre es zum mindesten übereilt, wollte man diesen Anzeichøn einer Besserung der Preiskalamität bezüglich des Nadelholzstarkholzes größere Bedeutung beilegen. M ö glicherweise trägt die derzeitige Nadelholzwirtschaft mit ihrer auf Herabsetzung der Umtriebszeit und Verschärfung der Durchforstungsgrade gerichteten Tendenz sehon den Keim der Heilung in sich. Denn infolge der immer weiter gehenden Erhöhung des Angebots schwacher Ware und der teilweisen Einschränkung der Starkholzproduktion werden die Preis gesetze selbst mit der Zeit umgestaltend auf jenes allmählich herausgebildete Wertsmißverhältnis einwirken. Vielleicht leidet das Starkholz

1) Diese Berechnung beruht auf den periodischen Erlösmitteilungen, welche vom Holzverkaufsbüro der württ. Forstdirektion herausgegeben werden; halbjährlich werden die klassenweisen Erlösangaben über Fichten- und Tannenlangholz für die 4 Haupteinkaufsgebiete zusammengestellt. 
auch nur, wie aus obiger Bemerkung $\mathrm{P}$ a u s es geschlossen werden könnte, unter der Ungunst der dermaligen Zollsätze. Jedenfalls wärees von größtem Wert, Erhebungen dar über anzustellen, wiehoeh sich ungefähr in Deutschland der Bedarf an starker W a re im ganzen und einzelnen (z. B. f. Uferu. Hafenbauten) stell t, wieviel inländisches, wieviel ausländisches Holz hiezu Verwendung findet. Hier liegt ein noch ganz unbebautes Feld der Forststatistik ${ }^{1}$ ) vor uns, der $\mathrm{N} \mathrm{a} \mathrm{c} \mathrm{h-}$ weis über die Verwertung der a us unseren Waldungen bezogenen Hölzer. Wenn Oberforstrat Gretseh-Karlsruhe ${ }^{2}$ ) als wirksamstes Gegenmittel zur Fernhaltung von Verlusten, welche dem Holzverkaufswesen seitens der Kartellbestrebungen des Holzhandels drohen, die Bestellung besonderer $\mathrm{H} \mathrm{ol} \mathrm{z} \mathrm{h} \mathrm{a} \mathrm{n} \mathrm{dels} \mathrm{s} \mathrm{e} \mathrm{k} \mathrm{re-}$ t ä r e empfiehlt, deren Aufgabe es wäre, die Verhältnisse des Holzhandels etc. fortgesetzt zu erforschen, so möchte vielleicht als wichtigste Programm-Nummer ihrer Tätigkeit eben das erwähnte Gebiet der Verbrauchsstatistik in vorderste Linie zu stellen sein. Auch als Gegenstand der holzfachlichen Ausbildung und Fortbildung des Forstverwaltungspersonals dürfte jenes Thema Berücksichtigung verdienen. Viele Waldbesitzer Deutschlands, vor allem die bayrischen, badischen und württembergischen Forstverwaltungen, haben ja ein sehr lebhaftes Interesse daran, daß die Starkhölzer, deren Abtragung aus finanziellen Rücksichten zunächst nicht eingeschränkt, eher ausgedehnt, werden sollte, sich nicht als Hemmnis der Werts- und Preismehrung fühlbar machen. Mandarfabernicht übersehen, daßdie-

1) Das Bedürfnis nach einer Holzverbrauchsstatistik ist auch von dem K. W. Oberförstex Dr. K ö n i g nachdrücklich betont worden in einer Arbeit über ,Die Kanalisierung des Neckars"6 usf. vergl. A. F. und J.Z. 1906 S. $205 \mathrm{ff}$.

2) In seinem Referat bei der deutschen Forstversammlung in Ulm 1910. 
selbe Unsicherheit, welehe der Preisgestaltung überhauptanhaftet, a uch bez üglich der Veränderung des Preisverhältnisses einzelner Wertsklassen angenommen werden muB. Indem wir die Wirtschaftsgrundsätze einseitig auf die seitherige Entwicklung der Preisverhältnisse abstimmen, belasten wir die künftige Wertsmehrung mit einer hohen Risikop r ä mi e. Es kann sich deshalb in der forstlichen Produktion nicht darum handeln, die Erzeugung gewisser Waren (also z. B. Fichten- und Tannen s t a r k h ol z) ganz einzustellen - das wäre eine sehr gewagte Spekulation - $\nabla$ i $e l \mathrm{~m} \in \mathrm{hr}$ s in d alle Werte neben einander, we $n$ a $u$ ch in $g$ egen früher modifiziertem Mengenverhältnis, zu schaffen. Dagegen wird es sich allerdings empfehlen, die Produktion zeitraubender Artikel auf diejenigen Gebiete einzuschränken, wo der Wertszuwachs am lebhaftesten vor sich geht, der Schwerpunkt der Produktion in verhältnismäßig kurzer Frist von der einen auf die andere Stärkeklasse verlegt werden kann und auch bei geringem Preisabstand nicht viel - geldwerte - Zeit verspielt wird ${ }^{1}$ ). Um diese Frage beurteilen zu können, bedürfen wir aber fortgesetzter Untersuchungen über den Sortimentsanfall der verschiedenen Altersklassen und andererseits eingehender Aufklärung über die Preisverhältnisse und die Verwendungsfähigkeit der Hölzer.

Kehren wir zu den Preismehrungsziffern der Tab. 16 zurück, so muß noch auf einige andere für die Frage der Wertsmehrung bedeutsame Punkte aufmerksam gemacht werden:

1) Vergl. M a r t in, Die Folgerungen etc. Fichte S. 132: ,Die planmäßige Erzeugung der stärksten Sortimente hat sich in der Regel auf die besten Standorte zu beschränken". 
daß das Preisverhältnis der Sägholzklassen weniger Regelmäßigkeit aufweist, kann nicht überraschen, wenn man bedenkt, daß diese Sortimente, mehr als das Langholz, auf den Lokalabsatz angewiesen sind; immerhin tritt das Mißverhältnis zwischen stärkeren und schwächeren Klassen (I. und II. Kl.) auch hier zutage. Das Nachhinken der Säghölzer gegenüber der Preismehrung der (nach den württ. Taxpreisen) homologen Langholzsortimente (S I. gegen L II., S II. gegen L III., S III. gegen L V.) bestätigt von neuem die Richtigkeit der Auffassung von $\mathrm{Pursche}{ }^{1}$ ), daß, die Aufbereitung und der Verkauf von Stammholz hinsichtlich des finanziellen Erfolgs der Verwertung in Klotzholzform bis auf weiteres im. großen und ganzen vorzuziehen" sei.

Weiterhin fällt in Tabelle 16 die Verschiedenartigkeit der Preismehrung bei den Brennholzsortimenten auf. Das $\mathbf{N}$ a d e lh ol z ist durchweg bei weitem im Vorzug und hier wieder speziell das P r ü g el sortiment (Rundholz von 7-14 $\mathrm{cm}$ Stärke). Diese Erscheinung erklärt sich aus dem Umstand, daß eine, inmitten jener Reviere gelegene, große Holzstoff- und Papierfabrik (Baienfurt A. G. bei Ravensburg) einen sehr beträchtlichen Teil auch des Anfalls an Nadelholzbrennholz bezieht. Es liegt also in der Preissteigerung teilweise eine Qualitätsmehrung (Uebergang von Brennholz- zu Nutzholzverwertung) angedeutet oder im Sprachgebrauch der Preisgesetze ausgedrückt: die Preise jener Nadelholzsortimente (Scheiter und Prügel) gravitieren jetzt nicht mehr ausschlieBlich nach den Kosten für Beschaffung anderer B r e n nmaterialien, sondern teilweise nach den geringsten Kosten für Ankauf anderer $\mathrm{Rohst}$ offe zur Verwendung in der $\mathrm{Holz}$ $\mathrm{st}$ of $\mathrm{f}-$ und $\mathrm{P}$ a p i e r fabrikation.

Dieses sowie das eingangs dieses Abschnitts angeführte Beispiel (s. S. 93 Fußnote) lassen erkennen, d a B die. G ebrauchswertigkeit des Holzes in der Sortimentsbildung nicht erschöpfend zum A usdruck gebracht wird. Auch von diesem Gesichtspunkt aus macht sich das Bedürfnis nach einer statistischen Nachweisung über die Verwertungsart der $\mathrm{H}$ öl z er und über den Holzverbra u ch einzelner

1) S. Thar. forstl. Jahrbuch $1901 \mathrm{~S} .1 \mathrm{ff}$. Häh n l e, (Sortimentstafeln S. 28). 
Zweige der Holzindustrie und verwandter Sparten geltend. Nicht bloß zur Ergründung der Preismehrungsvorgänge, sondern auch als Grundlage für Begutachtung der Holzzollund Tariffragen wäre eine Ergänzung der Forststatistik nach dieser Richtung wünschenswert. Voraussetzung für Gewinnung der bezüglichen Zahlen ist allerdings ein $\mathrm{f} \mathrm{r} \mathrm{e} \mathrm{u} \mathrm{nd}$ nachbarliches Verhältnis zu den Holz verbrauchenden und Holz verarbeitenden Kreisen von Industrie und $\mathrm{Hande1}$, wie es ja aus kaufmännischen Rücksichten - unbeschadet friedlicher Gegenmittel gegen Kartellbestrebungen - von den Forstverwaltungen ohnehin anzustreben ist ${ }^{1}$ ).

So kann uns die Preisstatistik trotz aller Unsicherheit, trotz ihres schwankenden Charakterbilds, doch eine sehr wertvolle Fundgrube für Studien über die Wertsmehrung werden, sofern sie uns zu vergleichenden Untersuchungen über die Preisentwicklung der einzelnen Sortimente, einzelner Absatzlagen und größerer Absatzgebiete anregt.

\section{Folgerungen.}

Die wichtigsten. Schlußfolgerungen, zu denen die bisherige Besprechung über die Preissteigerung uns ermächtigen dürfte, sind im folgenden noch einmal kurz zusammenzufassen:

1. Erforderlich ist die Führung einer detaillierten. Preisstatistik in den einzelnen Revieren, womöglich getrennt nach Preisgüteklassen (Absatzlagen - zumal in Gebirgswaldungen).

2. Zweck derselben ist:

a) Orientierung über den Stand des Holzmarkts zur Bemessung der Tax- und Zuschlagspreise (insbesondere für freihändige Abgaben),

1) Dies der Standpunkt eines $Q$ u a et - F a s l e m, R i e b e l und anderer in der Praxis der Holzverwertung stehender Männer, mit dem gewiß mehr Frfolg zu erreichen ist als durch Zuwerfen des Fehdehandschuhs an Holzindustrie und Holzhandel. 
b) Ergründung der auf die Preisgestaltung einwirkenden Faktoren,

c) Gewinnung von Erfahrungszahlen für forstliche Wertsund Rentabilitätsberechnungen.

3. Sowohl die Preisentwicklung im groBen und ganzen wiediePreisschwankungen innerhalb kurzer Zeit müssenzunächst a m kleinen Wald verband (Revier bezw. Absatzlage) $\mathrm{b}$ e o b a c h t $\in \mathrm{t}$ werden. Zusammenfassungen zur Durchschnittserlösberechnung sind nur insoweit zulässig, als die Einzel-Verkaufsmengen jeweils in annähernd gleichem Verhältnis stehen oder innerhalb solcher Gebiete, die keine nennenswerten Verschiedenheiten bezüglich der Absatzverhältnisse aufweisen. Im übrigen ist $\mathrm{d}$ i e $\mathrm{Prei}$ s änderung an zahlreichen Einzelfällen zu untersuchen und aus den einzelnen Aenderungsziffern wäre nach dem Verhältnis des Massenanfalls ein Durchschnittsergebnis abzuleiten.

4. Die a u Grund soleher Untersuchungensich ergebendePreiszunahmekannals zuverlässiger Faktor der Wertsmehrung nur insoweit a ufefaßt und a u ch der Zukunft zugut geschrieben werden, als gewisse, der Waldwirtschaft selbst innewohnende Ursachen nachweisbar sind, 80 insbesondere die Verbesserung der Abs a tzverhältnisse.

5. Abgesehen hievon bringt die Preisentwick$1 \mathrm{u} \mathrm{n} \mathrm{g} \mathrm{,} \mathrm{nach} \mathrm{den} \mathrm{besprochenen} \mathrm{Beispielen} \mathrm{im} \mathrm{ganzen} \mathrm{neben}$ der Massenertragssteigerung (I. Teil) bisher das mächtigste agens der Waldwertsmehrung, e in $e \mathrm{~g} \theta \mathrm{w}$ is s e Unsicherheit nicht nur in die Wertszunahme überhaupt vermöge ihres Zickzackgangs herein, sondern auch in die Entfaltung der anderen Elemente sowohl der Qualitäts- als 
der Massenertragsmehrung, indem sie das Wertsverhältnis der verschiedenen $W$ aren und $W$ arengattungen der Holzproduktion verändert und teilweise auch auf Zunahme des Massenertrags kraft der Preisgesetze betr. das Verhältnis von Angebot und Nachfrage nachteilig reagiert.

Man wird deshalb - bei einem Ueberblick über die sämtlichen bisher besprochenen Mehrungserscheinungen (I. und II. Teil) - als oberste Bedingung weiterer förderlicher Entwicklung der Waldwerte den Grundsatz a ufstellendürfen, da $B$ sich die Forstwirtschaft vor einseitiger Berücksichtigung einzelner Mehrungselementehüten muB, insbesondereauch nicht a uf deAnzuchteiniger weniger Holzarten oder die Erzeugungderjenigen Sortimente sich beschränken darf, welche nach den zeitweiligen Ergebnissen das Optimum vorstellen; sondern sie sollte auf Erzielung möglichst aller Gebrauchswerte in jeweils bester Beschaffenheit und kürzester Zeit ih $\mathbf{r}$ A genmerk lenken. Auf diese Weise wird es ihr gelingen, auch dem unberechenbaren Wirken der Preisgesetze Trutz zu bieten und die ihr von der Waldnatur selbst wie durch die Gunst der allgemeinen volkswirtschaftlichen Verhältnisse in die Hand gegebenen Mehrungsmittel zu gebrauchen.

6. Zur Erforsehung der a B Brhalb der Waldwirtschaft liegenden Holzpreis-Elemente, so insbesondere des Einflusses der Verkehrs-TarifZollpolitik, des wechselnden Bedarfs der Industrie, der Konkurrenz von ausländischen Hölzern und Ersatzstoffen e mpfiehlt sich a ufmerksames Studium des Holzverkehrs und der Holzhandelsbilanz sowie die Einführung einer Statistik über den Holzverbrauch der beteiligten Industriezweige. 
III. A b s chnitt.

\section{Die Entwicklung des Produktionsaufwands hinsichtlich ihrer Bedeutung für die Wertsmehrung.}

\section{Allgemeines.}

Ausführlich besprochen wurde bis jetzt die Wertsmehrung nur, soweit sie in höheren $\mathrm{R}$ o h erträgen zum Ausdruck kommt als Folge der Verbesserung des Ertragsvermögens der Wälder in quantitativer und qualitativer Hinsicht sowie infolge der Preisentwicklung. Nun geht aber die ganze Untersuchung von der statistisch nachgewiesenen Tatsache einer enormen $\mathbf{R}$ e i n ertragssteigerung aus, welche durch Kapitalisierung der jeweiligen Renten unmittelbar in Wertsmehrung umgerechnet werden könnte, sofern durch eingehende Prüfung festgestellt ist, daß zum mindesten die dermalige Rente auch künftig dem Waldbesitzer zur Verfügung steht; andererseits war für die einzelnen Elemente auch zu untersuchen, ob mit w e i t ergehender Mehrung gerechnet werden darf, ob teilweise vielleicht erst später die Folgen derselben zu erwarten sind. Alle diese Momente können auch auf seiten des Produktionsaufwands zur Geltung kommen, die Rohertragsmehrung bald fördernd bald hemmend. Die seitherige Entwicklung des Produktionsaufwands läßt künftige Ertragssteigerung erhoffen, wenn sie intensivere Ausnützung der Produktionsfaktoren verrät oder wenn die Ausgabensteigerung $v$ er h ä 1 t n i s m ä B i g hinter der Ertragsmehrung zurückbleibt. Das Gegenteil trifft zu, wenn die Produktionskosten der Waldwirtschaft in höherem $\mathrm{Maß}$ als diejenigen anderer, zumal konkurrierender Erwerbszweige und als die Walderträge steigende Tendenz aufweisen oder wenn das seitherige günstige Verhältnis zwischen Ertragsund Kostenmehrung umzuschlagen droht: die Erträge zwar einen Höhepunkt erreichen, die bisherige Wirtse haftsweise aber künftige Erschwerung und Verteuerung des Betriebs zur Folge 
h a t; auch wäre zu erwägen, ob nicht zum Nachteil der späteren Ertragsfähigkeit an Produktionsaufwand allzusehr gespart wurde.

Als Ausgangspunkt der weiteren Erörterung mögen folgende der einschlägigen Literatur entlehnte Gedankenreihen dienen:

$\mathrm{H}$ e $\mathrm{l}$ f f e r i c h zeigt in seiner Abhandlung ,Das Geld“ ${ }^{1}$ ), daß seit Mitte der siebziger Jahre des verflossenen Jahrhunderts ein Rückgang der Großhandelspreise zahlreicher Warengattungen zu verzeichnen war und führt als ausschlaggebende Ursache dieser Erscheinung die erhebliche Verminderung an, welche der zur Beschaffung jener Waren erforderliche Aufwand an Kapital und Arbeit erfahren hat.

Die Verbesserung der Produktionstechnik, Vervollkommnung der Maschinen und Werkzeuge, intensivere Ausnützung der Rohund Hilfsstoffe haben im ganzen, führt $H$ elf $f$ e $\mathrm{i} \mathrm{ch}$ aus, zu einer ,sehr beträchtlichen Ermäßigung der Produktionskosten geführt und das nicht etwa nur auf dem Gebiet der stoffveredelnden Industrie, sondern auch in der landwirtschaftlichen und bergmännischen Urproduktion. Auf dem Gebiet des Bergbaus und der Industrie ist die leistungsfähigere Gestaltung der Organisation der Produktion infolge des Vordringens des mit geringeren Kosten arbeitenden Großbetriebs hinzugekommen.“ „Ferner hat die Verbesserung der Transportmittel den Bezug gewisser Warengattungen aus ihren vom europäischen Markt weit entfernten Produktionsstätten ganz erheblich verbilligt."

Dadurch erklärt sich auch der Widerspruch zwischen der Gestaltung der Arbeitslöhne und der Entwicklung der Großhandelspreise, welcher mit folgenden Worten charakterisiert wird:

(S. 518), Es ist eine allgemeine und durch zahlreiche statistische Untersuchungen erhärtete Beobachtung, daß die Arbeitslöhne in den Staaten europäischer Kultur, namentlich auch in Deutschland, während der Zeit des Rückgangs der meisten und wichtigsten Großhandelspreise eine nicht unerhebliche Steigerung erfahren haben, ganz abgesehen von der indirekten Erhöhung des Arbeitslohns, die bei uns in Deutschland durch die den Unternehmern auferlegten Leistungen für die Arbeiterversicherungen usw. herbeigeführt worden ist."

Trotz des Vorhandenseins wertsmindernder (ertragsschmälernder) Elemente in Gestalt der Belastung durch fort-

1) Hand- und Lehrbuch der Staatswissenschaften 1. Abt. VIII. Bd. Erster Teil (S. 517. 518. 522). 
gesetzte direkte und indirekte Erhöhung der Arbeitslöhne haben wertsmehrende Elemente (die Verfeinerung der Produktionstechnik, bessere Ausnützung der Produktionsmittel usf.) die Oberhand behalten; die Preise sind zurückgegangen, ohne daß wahrhaftig eine Minderung des Werts jener Unternehmungen angenommen werden darf.

Wie verhält sich hiezu die Gestaltung des Produktionsaufwands in den forstlichen Betrieben, können die aufgezählten Mehrungselemente nicht auch der Waldwirtschaft zugut kommen? Die Ausführungen $\mathrm{H}$ elf $\mathrm{f}$ e $\mathrm{r}$ i $\mathrm{ch}$ s bestätigen ja, daß wir den Preisgravitationsgesetzen gegenüber (Verbilligung der Produktion gewisser Ersatzstoffe, der Einfuhr auswärtiger Hölzer) jedenfalls mit Bezug auf einzelne Holzsortimente (Brennholz, Schleifholz, Schwellenholz, teilweise auch Bauholz) gewappnet sein müssen. In Anbetracht des überwiegenden Anteils, den die Arbeitslöhne am forstlichen Produktionsaufwand nehmen, muß sich die Lohnerhöhung als wertsminderndes Element ganz besonders bemerkbar machen.

Als ein Versuch der Lösung vorliegenden Problems erscheinen die Betrachtungen, welche Forstassessor Dr. M ö ll $\mathrm{er}{ }^{1}$ ) über die Anwendbarkeit des Gesetzes ,, vom abnehmenden Bodenertrag" auf die Forstwirtschaft angestellt hat.

Möller führt in Anlehnung an Brentanos Agrarpolitik aus, daB auch in der Forstwirtschaft bei Mehraufwand von Kapital und Arbeit sich zunächst höhere Roh- und Reinerträge erzielen lassen, daß dieser Zunahme aber sehr bald wirtschaftliche Grenzen gezogen sind, nach deren Ueberschreitung wohl noch eine Steigerung des Rohertrags aber nicht auch des Reinertrags möglich ist. Er kommt zu der Schlußfolgerung:

(S. 67) „Obwohl in der Forstwirtschaft der Boden ein sehr ausschlaggebendes Produktionselement ist, und obwohl mechanische Arbeitsleistung und die Erhöhung des flüssigen Betriebskapitals lange nicht so ausgedehnt in nutzbringender Weise angewendet werden können, wie in der Landwirtschaft, so befindet sie sich im allgemeinen hinsichtlich der ertragsbeschränkenden Wirkungen des Gesetzes vom abnehmenden Bodenertrag gegenüber der letzteren doch im Vorteil."

1) Tharander Forstl. Jahrbuch 54. Bd. (1904). 
S. 68 ,Während ....... , ,eröffnet sich für die Forstwirtschaft insbesondere auch mit der Besitzergreifung besserer Böden und günstigerer Lagen zum Markte ein weites Feld für erfolgreichen Mehraufwand."

Nicht so optimistisch faßt Professor $\mathrm{W}$ a $\mathrm{g} \mathrm{n}$ er in seinen „Betrachtungen über Intensität in der Forstwirtschaft" die Steigerung des Aufwands an Kapital und Arbeit auf, wenn er schreibt ${ }^{1}$ ):

,Will die Forstwirtschaft mit höherer Intensität produzieren, so darf sie dies nicht, wie andere Wirtschaftszweige, in erster Linie durch gesteigerte Arbeitsbetätigung und Kapitalbeiziehung versuchen, da diese eine starke Erhöhung der Produktionskosten bedingen, sondern sie muß sich den unentgeltlichen Produktionsfaktoren, den Naturkräften, zuwenden und dabei in Arbeits- und Kapitalaufwendung geradezu so sparsam als möglich verfahren."

Die wertsmehrende und wertsmindernde Bedeutung des Produktionsaufwands ist mit diesen, sich scheinbar widersprechenden Ausführungen Möllers und Wagners in großen Zügen vorgezeichnet. Es wäre nun zu untersuchen, nach welcher Richtung der Produktionsaufwand sich bisher entwickelt hat.

Um vergleichbare Zahlengrößen zu gewinnen, sollte man zunächst den Anteil der $\mathrm{L}$ o hn $\mathrm{n} \mathbf{r} \mathrm{h}$ ö u n g zu eliminieren suchen; dann erst läßt sich ermitteln, ob die Waldwirtschaft die Tendenz zeigt, mit zunehmendem oder abnehmendem Arbeits- und Kapitalaufwand zu produzieren. Wir vermeiden es dabei, den Ausdruck Intensitätssteigerung zu gebrauchen; besteht sie doch, wie die Ausführungen $\mathrm{Helfferichs}$ und $\mathrm{W}$ a g $n$ ers dartun, vielfach gerade darin, daß die Produktionskosten eingeschränkt werden. In dem von $\mathrm{H}$ e l f $\mathrm{f} \theta \mathrm{r}$ i c h besprochenen Beispiel war die Ersparnis so bedeutend, daß sie selbst die erhebliche Zunahme der Arbeitslöhne auszugleichen vermochte. Die Forststatistik der größeren deutsohen Staatsforstverwaltungen zeigt dagegen fortgesetzte Steigerung

1) F. Zentralbl. 1908 S. 383 (vergl. auch die Grundlagen der räumlichen Ordnung im Wald S. 265).

Forstwirtschaft. V. D i terich, Elemente d. Wertsmehrung. 
der Produktionskosten. Ist diese Erscheinung lediglich auf die Lohnerhöhung oder teilweise auch auf das Maß des Arbeitsund Kapitalaufwands zurückzuführen?

Im Handbuch der Forstpolitik von Endres finden wir S. 132 eine Uebersicht über das Anwachsen der Roheinnahmen, der Ausgaben und der Ueberschüsse bezogen auf die Durchschnittszahlen von 1860-64. Da hiebei ein Zeitabschnitt extrem hoher Holzpreise als Ausgangspunkt gewählt wurde, ergibt sich kein zutreffendes Bild; es erscheint richtiger, die Ergebnisse des, mittleren Preisstand aufweisenden, Zeitraums 1855/59 als Grundlage des Vergleichs zu benützen; setzt man die betreffenden Zahlen ${ }^{1}$ ) je $=100$, so sind in den Staatsforstverwaltungen von

Preußen Sachsen Baden Württemberg

a) Die Einnahmen auf $334 \quad 245 \quad 222 \quad 313$

$\begin{array}{llllll}\text { b) " Ausgaben } \quad, & 330 & 275 & 239 & 189\end{array}$

c) ", Ueberschüsse ,, $338 \quad 229 \quad 212 \quad 248$

bis 1900/04 angewachsen

Man ersieht aus den eben angeführten Zahlen, daß bei Sachsen und Baden die Grenze bereits überschritten ist, bei der die Waldwirtschaft infolge erhöhten Produktionsaufwands ${ }^{2}$ ), ,einen zwar absolut noch wachsenden, allein im Verhältnis zum Mehraufwand abnehmenden Ertrag" abzuwerfen beginnt. M öllers Annahme ${ }^{2}$ ), daß diese Grenze vielfach noch gar nicht erreicht, bedarf sonach der Berichtigung. Läßt man den Ros cher schen ${ }^{2}$ ) Satz gelten, wonach Arbeitslohn und Produktenpreis im Verhältnis $1 \frac{1}{2}: 2$ sich bewegen sollen, so dürfte man aus obigen Zahlen ohne weiteres den Schluß ziehen, daß die Ausgabenmehrung $\mathrm{n}$ i $\mathrm{ch}$ t ausschließlich auf Lohnerhöhung zurückzuführen ist, indem das $\mathbf{R} o-$ s c hersche Verhältnis auf seiten der Ausgaben durchweg überschritten wurde, während andererseits die Ertragssteigerung $\mathrm{nicht}$ a.usschließlich von der Preiserhöhung herrührt.

1) Nach der Tabelle in En d res Forstpolitik S. $116 \mathrm{f}$. und den neueren forststatist. Mitteilungen. $\mathrm{Zu}$ bemerken ist (s. ebenda S. 131/132), daß die Ausgaben teilweise nicht genau vergleichbar sind, indem gewisse Posten bei der einen Verwaltung berücksichtigt sind, bei der anderen nicht (Forstgebäude, Forstkassenämter, Forstpolizei u. a.). 67,68 .

2) Vergl. M ö l l e r im Thar. Forstl. Jahrbuch 1904 S. 48, 
Es fragt sich aber, ob der R o s c h er sche Satz, dessen Gültigkeit Möller auf Grund der sächsischen Statistik nachzuweisen sucht, allgemein als zutreffend angenommen und (wie von Möller) als natürliches Schutzmittel gegenüber dem Gesetz ,,vom abnehmenden Bodenertrag " gepriesen werden darf.

Die gesonderte Beobachtung der Lohnbewegung ist, abgesehen von sozialpolitischen Motiven, für die Frage der Wertsmehrung noch aus anderen Gründen von Wichtigkeit: Da nämlich die Löhne der Arbeiter, zumal der ungelernten Waldarbeiter, wie vielfach auch die Beamtengehälter, gewissermaßen als Existenzminimum anzusehen sind, so kann deren Entwicklungsgang als Merkmal und Folgeerscheinung der sog. Lebensverteuerung gelten, derselben Ursache, welche auch fortgesetzt die Bedürfnisse des Waldbesitzers, sei er nun Staat, Gemeinde oder Privatgrundbesitzer durch Entstehen neuer und Anwachsen der alten Ausgabeposten zu erweitern trachtet. Die Steigerung der Vermögenserträgnisse, somit auch diejenigen aus Waldbesitz, wird deshalb soweit nur mit der allgemeinen Lebensverteuerung gleichen Schritt haltend, nicht als besonderer Vorteil, vielmehr müßte der Stillstand als Rückschritt anzusehen sein. Es dürfte sich deshalb empfehlen, von Zeit zu Zeit die Eohnsteigerung an der Preiszunahme der Forstprodukte zu messen.

\section{Die Lohnerhöhung und andere in der Lebensverteuerung} beruhende Ursachen der Ausgabenmehrung.

Die Lohnfrage wird neverdings in der Forststatistik, meist im Zusammenhang mit der Arbeiterversicherung ziemlich eingehend behandelt ${ }^{1}$ ). Die Bedeutung, welche der Arbeiterfrage heutzutage in politischer wie in privatwirtschaftlicher Beziehung zukommt, die Leutenot in vielen Waldgegenden und nicht zuletzt auch Interpellationen im Parlament haben das Interesse der Forstverwaltungen für die Lohnbewegung wachgerufen.

1) Vergl. z. B. 10. Heft d. Mitt. a. d. Forstverw. Bayerns. 
Brauchbare Lohnangaben liegen meist nur von verhältnismäßig kurzer Zeit her vor; für einzelne Zweige des Produktionsaufwands wurden in manchen Verwaltungen schon früher Aufschriebe über durchschnittliche Lohnsätze geführt, so z. B. in den württembergischen und badischen Nachweisungen über die Kulturkosten. Hieraus läßt sich folgende, auffallend gleichartige Lohnsteigerung berechnen:

Beim Vergleich der Zeitabschnitte 1881/85 und 1901/05 erhöhten sich die durchschnittlichen Lohnsätze bei Kulturarbeiten in den württ. Staatswaldungen für Männer von M. 1.80 auf M. 2.28, für Frauen von M. 1.07 auf M. 1.35; das bedeutet ein $\mathrm{d} \mathrm{u} \mathrm{r} \mathrm{c} \mathrm{h-}$ schnittliches jährliches steigerungsprozent v o n je 1,2\% (im ganzen bei 20 Jahren: $24 \%$ ); nach der badischen Kulturstatistik lauten die entsprechenden Zahlen beim Vergleich von $1878 / 82$ mit $1903 / 07$ : M. 1.75 auf M. 2.39 bezw. M. 1.20 auf M. 1.57; Steigerung gleichfalls: 1,2 bezw. 1,1\% pro Jahr (im ganzen bei 25 Jahren: 30 bezw. $27 \%$ ).

Die Angaben der Forststatistik ü b e r S t ü c k löhn e können zur Berechnung der Lohnsteigerung - wie die Preisstatistik mit Bezug auf die Preisbewegung - nur unter der Voraussetzung Verwendung finden, daß entweder nur Sortimente mit gleichen Löhnen zusammengefaßt werden oder die Einzelsortimente jeweils in annähernd demselben Verhältnis angefallen sind.

Die in Tab. III ${ }^{1}$ ) der Forststat. Mitt. aus Württemberg gegebene Uebersicht über den Stand der Holzhauerlöhne läßt sich, weil gegen diese Voraussetzung verstoßend, zu vergleichenden Untersuchungen über die Lohnhöhe weder in örtlicher noch zeitlicher Hinsicht verwerten. Dagegen eignet sich die neuerdings in Tab. VII aufgenommene Uebersicht über den durchschnittlichen

1) Dort sind angegeben: Die Hauerlöhne für $1 \mathrm{Fm}$ NadelholzStammholz, $1 \mathrm{Rm}$ Prügel und Scheiter (ohne Unterschied der Holzart!), 100 gebund. Wellen, $1 \mathrm{Rm}$ Stockholz, Anrückerlohn für $1 \mathrm{Fm}$ Nadelholz und Laubholz.

Da die Tabelle eine andere Einteilung hat, als die Nachweisung über die durchschnittlichen Aufstreichserlöse, so erfüllt sie nicht einmal den Zweck, als Hilfsmittel zur Berechnung der erntekostenfreien Erlöse einzelner wichtiger Sortimente bezw. Sortimentsgruppen oder Holzarten zu dienen. ZweckmäBiger ist in dieser Beziehung die Tab. B 2 und 3 der $\mathrm{h}$ es s is ch en Mitteilungen eingerichtet, welche wenigstens für Brennholz und Nutzholz je getrennt Erlös, Hauerlohn und erntekostenfreien Erlös angibt. 
Stücklohnverdienst bezogen auf 1 Tagewerk recht wohl als Anhaltspunkt für derartige Berechnungen.

Neben den eigentlichen Löhnen sind aber auch die sog. ind i r e t e n L o h n teile zu berücksichtigen, vor allem die auf den Waldbesitzer entfallenden Beiträge zur Arbeiterversicherung; es würde sich empfehlen, auch diese Posten, auf ein Tagewerk berechnet, in der Statistik anzugeben. Auch aus anderen, nachher zu erörternden Gründen sind statistische Angaben über di e $\mathrm{Z}$ a h l d e r $\mathrm{T}$ a ge w er k e ${ }^{1}$ ) erwünscht. Aehnlich wie die Arbeiterlöhne müßten auch die Beamtengehälter auf Erhöhung untersucht werden; denn es kann nicht gleichgültig sein, ob die Zunahme des Verwaltungsaufwands von Gehaltsaufbesserungen oder von Vermehrung des Beamtenstands herrührt. Aber diese Frage ist nicht so einfach zu lösen, weil die Erhöhung der Gehälter teilweise mit organisatorischen Wandlungen zusammenfällt, durch welche sich der Geschäftskreis und die Verantwortung einzelner Beamtenkategorien vermehrt oder einzelne Funktionen von jüngeren auf ältere Beamte, von Personen mit beschränkter Ausbildung auf solche mit Vollbildung bezw. umgekehrt übertragen werden.

Vergleicht man z. B. die Gehälter der württembergischen Revierverwalter, so bezogen nach der Schrift ,Die Forstlichen Verhältnisse Württembergs" die Revierförster im Jahr 1880 ein Durchschnittsgehalt von 2775 M., die Oberförster im Jahr 1908 nach den forststatist. Mitteilungen ein solches von $4010 \mathrm{M}$. (Verhältnis $100: 145$ ); nun ist aber die Stellung und Verantwortung der jetzigen Oberförster infolge Aufhebung des Forstmeistersystems (1902) bedeutungsvoller als jene der ehemaligen Revierförster, welche zu einem größeren Teil aus Beamten des mittleren Dienstes bestanden; auch kommt die tatsächliche Besserstellung der heutigen Revierverwalter in jenen Zahlen deshalb nicht einwandfrei zum Ausdruck, weil das Anstellungsalter sich inzwischen erheblich nach oben verschoben hat; grundsätzlich richtiger wäre es deshalb wohl, die $H$ ö chst gehaltsstufen $\mathrm{zu}$ vergleichen: sie

1) Die Ermittlung der $\mathrm{Zahl}$ der Tagewerke erfordert im Bereich der württ. Staatsforstverwaltung keine besondere Arbeit, da sie für Akkordsarbeiten ohnehin anzustellen ist (Aufschriebe der Forstwarte über die jeden Tag bei Akkordsarbeiten beschäftigten Arbeiter) und da auch über die Taglohnsarbeiten solche Notizen gesammelt werden müssen als Grundlage für Ausfüllung der an die Steuerbehörde einzuschickenden Lohnlisten. 
betrugen 1880: 3200 M., 19084500 M. (100:141); hiebei ist aber zu bedenken, daß früher einem Teil der Beamten die Vorrückung in das höhere Forstmeistersgehalt ermöglicht war. Einfacher ist die Aufbesserung der Bezüge des Forstschutzpersonals zu ermitteln. Das Durchschnittsgehalt der Forstwarte betrug 1880: 910 M., 1908: 1330 (einschl. 70 M. Zulage) - Verhältnis 100: 146, das Höchstgehalt $1880: 1000$ M., 1908: 1450 - Verhältnis $100: 145$.

Die sog. Lebensverteuerung und die Erhöhung des Maßes der Lebenshaltung hat neben den Löhnen natürlich auch die sonstigen Preise beeinflußt, welche der Waldbesitzer jahraus jahrein für allerhand im forstlichen Betrieb erforderliche Waren und Leistungen zu entrichten hat; da die Forstausgaben im allgemeinen überwiegend aus Arbeitslöhnen (einschl. Gehälter) bestehen, spielt dieser Gesichtspunkt zwar keine ausschlaggebende Rolle, muß aber doch der Vollständigkeit halber erwähnt werden; in Betracht kommen die Anschaffungskosten von Samen, Pflanzen, Düngemitteln, Baumaterialien und dergl. Der rechnende Betriebsleiter wird auch die Preisänderung derartiger Bedarfsgegenstände beachten müssen, um sich Klarheit darüber zu verschaffen, welche Ursachen im einzelnen erhöhend auf die Produktionskosten einwirken. Eine Materialpreisstatistik, insbesondere über Kultur- und Wegbaumaterialien, wird deshalb - wenigstens als Revierstatistik — nicht zum überflüssigen Schreibwerk zu rechnen sein.

Faßt man den Begriff ,Preis" in einem weiteren Sinn, so fallen hierunter auch die $S$ te u ern und ste uerartigen $\mathrm{B}$ e iträge (z. B. an die Berufsgenossenschaften für Unfallversicherung, Feuerversicherung und dergl.). Die fortgesetzte ganz beträchtliche Steigerung des Steueraufwands fällt ja teilweise denselben Elementen zur Last, welche die Lohnerhöhung veranlaßt haben, wenngleich daneben auch politische ${ }^{1}$ ) Vorgänge und die Entwicklung ${ }^{2}$ ) der Rechtsanschauungen die Steuerhöhe beeinflußt haben; auch ist nicht

1) So z. B. die Gründung des deutschen Reichs.

2) Der Uebergang von einem Steuersystem zu einem anderen, wie in Württemberg, wo im Jahr 1903 das Ertragssteuersystem durch Einkommensteuern ergänzt wurde. 
zu übersehen, daß die Wertsmehrung der Waldungen selbst steuererhöhend wirkt (insbesondere beim Einkommenssteuersystem).

So erklärt es sich, daß die Ausgaben für Steuern sowohl nach der preußischen als württembergischen Forststatistik weitaus am meisten von allen Ausgaben zugenommen haben. Nach den amtl. Mitt. aus der Abt. für Forste des K. Pr. Min. für Landw. etc. war der Steueraufwand im Jahr 1908, verglichen mit 1868, von 100 auf 522 angewachsen (Gesamtausgaben auf 294), für Württemberg berechnet sich die entsprechende Verhältniszahl auf 492 (Gesamtausgaben 198); im Durchschnitt des Zeitraums 1855/64 betrug der Steueraufwand auf 1 ha berechnet 0,72 M., 1895/1904 2,42 und 1908 4,09 M. Die erhebliche Zunahme im letzten Jahrzehnt rührt von der Mehrbelastung her, welche die neue Steuergesetzgebung von 1903 mit Einführung der Einkommensteuer insbesondere den „fundierten" Einkommensquellen gebracht hat.

Die Lebensverteuerung als aufwandsteigerndes und darum wertsminderndes Element wird auch weiterhin ihre Wirkung ausüben; weisen doch die Zeichen der Zeit darauf hin, daß Lohn-, Gehalts- und (als Folge) Steuererhöhungen in immer weiterem Umfang zu erwarten sind und jedenfalls mit größerer Sicherheit - vielleicht auch mit höherem Zunahmeprozent eintreten werden, als die Preissteigerung der Forstprodukte. Auf den Verlauf dieses Prozesses selbst hat der Waldbesitzer im großen und ganzen keinerlei Einfluß. Es wird aber noch zu zeigen sein, wie er die Folgen desselben teilweise für sich unschädlich machen kann. Jedenfalls ist Grund genug vorhanden, den Vorgang mit Aufmerksamkeit zu. verfolgen und statistisch klarzustellen, ob jener oben angeführte Roschersche Satz auf die einzelnen Waldwirtschaften Anwendung findet und wie sich das Verhältnis von Lohnerhöhung zur Preissteigerung verä $\mathrm{nd}$ er t.

\section{Das Maß des Arbeits- und Kapitalaufwands.}

Es ist nun weiterhin zu untersuchen:

a) In welchen Zahlengrößen der forstlichen Buchführung und Statistik das Ma B des Arbeits- und Kapi- 
t a l a u f w a nds ermittelt werden kann bezw. zum Ausdruck gebrachit werden sollte,

b) auf welche Ursachen etwaige $A$ end er ungen zurückzuführen sind, und welcherlei Folgen dieselben für die Höhe der Produktionskosten und für die Entwicklung der Waldwerte gezeitigt haben bezw. voraussichtlich noch zu äußern vermögen.

Zur genaueren Ergründung dieser Vorgänge müssen die wichtigsten Ausgabeposten zunächst getrennt behandelt werden, da sie in sehr verschiedenartiger Beziehung zur Wertsbildung und Wertsmehrung stehen. Leider gestattet die forst-

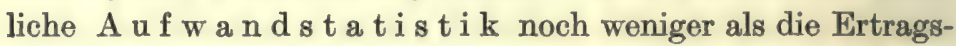
statistik vergleichende Beobachtungen von 1 ängerer Zeit her anzustellen, teils wegen Mangels an Zahlen, teils wegen der vielfachen Aenderungen in der Organisation der Verwaltungen und in der statistischen Behandlung selbst. Erst in jüngster Zeit ist man an den weiteren Ausbau der Aufwandstatistik herangetreten.

Die weiteren Erörterungen knüpfen zunächst an die w ürttem bergis che Forststatistik an: Tab. 20 zeigt den Entwicklungsgang der wichtigsten Ausgabeposten; herausgegriffen wurden die Zeitabschnitte, welche bisher schon als Vergleichsobjekte dienten, oder im weiteren Verlauf noch zur Besprechung heranzuziehen sein werden (s. S. 137).

Faßt man zunächst die Zunahme der Ges a m t a u sgaben bezogen a uf die Einheit der Nutz u n g m a s s e (Sp. 7) ins Aug (0,3\%), so wird sich angesichts der oben (wenigstens für Kulturarbeiten) nachgewiesenen Lohnsteigerung um über $1 \%$ pro Jahr die Vermutung nahe legen, daß das Maß des Arbeits- und Kapitala uf ands neuerdings eingeschränkt wor$\mathrm{d}$ e $\mathrm{n}$ is t. Sicheres hierüber läßt sich aus der Statistik nicht entnehmen; es müßte denn die Summe des auf Arbeitslöhne entfallenden Teils der Gesamtausgaben sowie die Gesamtzah] 


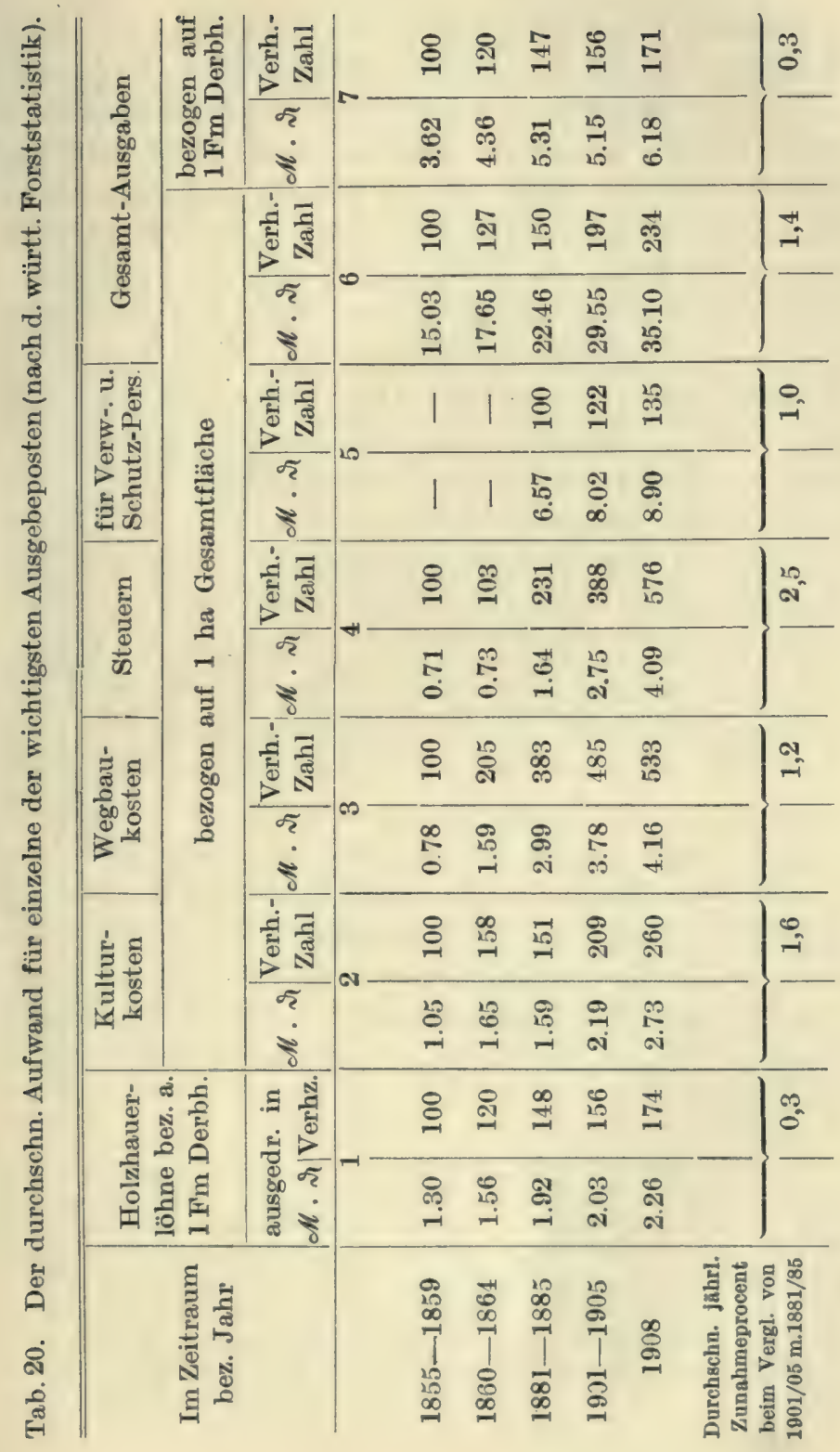


der Tagewerke nachweisbar sein ${ }^{1}$ ). Daß der Ge s a $m$ t a u sgabenbetreff bezogen a uf die Flächeneinh e it (Sp. 6) um 1,4\% pro Jahr zugenommen hat, kann nicht wundernehmen, wenn man bedenkt, daß die Derbholznutzung in der Zwischenzeit allein um etwa $1 \%$ pro Jahr gestiegen ist. Mehrnutzung hat aber $\mathrm{nicht}$ in $\mathrm{gleichem} \mathrm{Ma} \mathrm{B}$ Mehraufwand zur Folge. Denn bekanntlich liegt der Vorteil vieler industrieller Betriebe gerade in der Verbilligung der Produktionskosten bezogen auf die Wareneinheit durch Ausdehnung der Produktion (Herstellung von Massenartikeln); wenn $\mathrm{Helfferich} \mathrm{(s.} \mathrm{oben)} \mathrm{von} \mathrm{intensiverer} \mathrm{Ausnützung} \mathrm{der}$ Roh- und Hilfsstoffe und von den Vorzügen des Großbetriebs spricht, so wird wohl zumeist an diese Vorteile zu denken sein. So wird auch bis zu einem gewissen Grad die Nutzungssteigerung in der Waldwirtschaft (s. I. Teil) von verh. Verringerung (Nicht-Erhöhung) des Produktionsaufwands begleitet sein. Man darf aber diesen Gewinn nicht gutschreiben, ohne Rechenschaft darüber gefordert zu haben, ob es sich hiebei nicht bloß um vermeintliche Ersparnisse handelt, welche tatsächlich infolge Unterlassung dringlicher Arbeiten wertsmindernde Tendenz auf das Waldkapital ausgeübt haben.

Bei Besprechung der einzelnen Ausgabetitel wird die Aufwandsentwicklung demnach einerseits zur Lohnerhöhung, andererseits zur Nutzungssteigerung in Beziehung zu setzen und außerdem der Effekt der geleisteten Arbeit in der Hinsicht zu prüfen sein, ob die Anforderungen der Nachhaltigkeit erfüllt worden sind.

1) $\mathrm{Daß}$ sich die Zahl der Tagewerke leicht feststellen läßt, wurde vorhin erwähnt; auch die Summe der Arbeitslöhne kann im Bereich der württemberg. Staatsforstverwaltung ohne viel Mühe getrennt berechnet werden, da in den sog. Zahlungsanweisungsübersichten besondere Rubriken für Akkordslöhne, Tagelöhne und Materiallieferungen ausgefüllt und für sich abgeschlossen werden müssen; man brauchte diese sehr zweckmäßige Einteilung nur auf die forstamtliche Aufwandsstatistik zu übertragen. 
Man folgt am zweckmäßigsten dem von Sieber ${ }^{1}$ ) vorgeschlagenen Einteilungsprinzip, indem zuerst die Ausgaben besprochen werden, ,die nur eine bestimmte Einnahme belasten", also als Abgang dieser Einnahmen aufzufassen sind, d. h. die Werbungskosten.

a) Die Werbungs k osten.

Die in Tab. 20 (Sp. 1) angegebenen, für $1 \mathrm{Fm}$ Derbholzanfall berechneten Holzhauerlöhne stellen nicht die reinen Werbungskosten vor, enthalten vielmehr allerhand sonstige Kosten, so vor allem für Maßnahmen der Bestandespflege u. ä., die nicht als Abgang bestimmter Einnahmen zu betrachten sind. In der bayrischen und badischen Statistik werden die hierauf entfallenden Beträge in besonderer Rubrik unter den Kulturkosten vorgetragen, was sachlich richtiger ist als die Behandlungsweise der württembergischen Statistik. Da in letzterer, wie schon früher erwähnt, nur die Akkordslöhne e i n z el n e r Sortimente berücksichtigt sind, lassen sich die tatsächlichen Werbungskosten im ganzen überhaupt nicht ermitteln.

Streng genommen sind als $W$ er b u n $\mathrm{s}$ - oder Ernt e k os t e n der Holznutzung allein zu betrachten: die Hauerlöhne für sämtliches der Materialkontrolle unterliegende Holz (in Württemberg das Derbholz) und für die im Akkord aufbereiteten anderen Sortimente (Reisig, Stockholz usf.), im übrigen aber nur insoweit, als sie durch Holzerlöse gedeckt werden; soweit dies nicht zutrifft, müßten die Hauerlöhne als Kosten der Bestandespflege o. ä. unter Angabe und Abzug etwajger Materialerlöse gebucht werden (Kulturmittel). M a n sollte überhaupt in der forstlichen Buchführung und Statistik, soweit irgend möglich, darauf bedacht sein, die un mittelbar

1) Vergl. Aufsatz von Si e b e r, ,Ueber die Bedeutung und die Aufgaben der forstlichen Buchführung" in der A. F. und J.Z. 1908 S. 167. 
belastenden Ausgaben den betr. Einnahmen und ebenso gewisse Einnahmen unmittelbar den Ausgabebeträgen gegenüberzustellen, als derenteilweiser Ersatzoder Entlastung sie a ufzufassen sind. Es kann ja geradezu als Merkmal einer intensiven Wirtschaft angesehen werden, wenn es gelingt, die Produktionskosten durch bestmögliche Verwendung aller etwa anfallenden Nebenprodukte, Abfälle usf. (durch volle Ausnützung aller „Rohund Hilfsstoffe") zu verbilligen. Bei den anderen Ausgabeposten wird sich noch Gelegenheit geben, an der Hand von Beispielen auf den letzteren Punkt näher einzugehen. Hier steht zunächst das Gegenstück, die Art der Behandlung der sog. unmittelbar belastenden Ausgaben, zur Diskussion.

Für alle Kalkulationen im forstlichen Betrieb dürfen $\mathbf{n} \mathbf{~ u ~} \mathbf{r}$ erntekostenfreie Erlöse zur Berechnung herangezogen werden, da der Grad der Ausformung und der $\mathrm{Zu}$ bringung an Wege usw., (Wasserstraßen, Waldbahnen, Bahnhöfe und dergl.), örtlich, zeitlich und mit Bezug auf die einzelnen Sortimente sehr verschieden ist. Man sollte deshalb in den Nachweisungen über den Holzgeldertrag, jedenfalls in der Revierstatistik, neben den Roherlösen auch die erntekostenfreien Durchschnittserlöse angeben, wie es in mehreren forststatistischen Veröffentlichungen (so von Baden und Hessen) gehandhabt wird; es kann sich nur fragen, ob man sich nicht überhaupt auf Berechnung der erntekostenfreien Durchschnittserlöse beschränken soll. Nur so läßt sich einwandfrei das Wertsverhältnis der Holzarten und Sortimente berechnen und die im Lauf der Zeit erfolgende Qualitätsmehrung veranschlagen. Die oben angestellten Erhebungen über die Qualitätsmehrung sind insofern nicht ganz richtig, als sie die Verschiedenheit der Werbungskosten bei verschiedener Sortimentsverteilung außer acht lassen. 
Die an sich wertvolleren Stammholzsortimente verursachen meist weniger Erntekostenaufwand als die Schichthölzer; nach den forststat. Mitt. aus Württemberg betrug im Durchschnitt der Jahre 1901/05 der Hauerlohn je für 1 Festmeter: Laubstammholz M. 1,24, Nadelholzstammholz M. 1,01, Schichtderbholz M. 2,13 (für $1 \mathrm{Rm}$ M. 1,34; diese Zahl mit 0,63 reduziert). Die Erweiterung des Stammholzanfalls, wie sie bei Besprechung der Qualitätsmehrung an Beispielen nachgewiesen werden konnte (Tab. 9 ff.), hat demnach zugleich Verbilligung der Erntekosten und Vereinfachung der Fällungsarbeiten zur Folge; durch letzteren Umstand wird, zumal bei Arbeitermangel, der ganze Betrieb ohnehin schon günstig beeinflußt.

Wie für die Holznutzung, müßte auch der Ernteaufwand der $\mathrm{Neb}$ e $\mathrm{n} \mathrm{nu} \mathrm{tz} u \mathrm{ng}$ en nicht bloß in Bausch und Bogen, sondern gesondert nach den wichtigeren Nutzungsarten gebucht und zum Ertrag derselben in Beziehung gesetzt werden, soweit dieser nicht als Nebenprodukt eines anderen Produktionsaufwands bei dem betr. Ausgabeposten in Abzug $\mathrm{zu}$ bringen ist.

Während die eigentlichen Werbungskosten in dem oben umgrenzten Sinn eigentlich nur vermöge der $\mathrm{L} \mathrm{o} \mathrm{h} \mathrm{n} \mathrm{s} \mathrm{t} \mathrm{e} \mathrm{i} \mathrm{g} \mathrm{e-}$ $\mathrm{r}$ u $\mathrm{ng}$ die Entwicklung der Waldwerte beeinflussen, bezüglich der darauf verwendeten $\mathrm{Arb}$ e its $\mathrm{men}$ ge aber mehr nur die Höhe der einzeln en J a hresrent e belasten, sind einzelne, den Werbungskosten nahestehende Ausgabeposten in Hinsicht auf die Waldwertsmehrung von wesentlich einschneidenderer Bedeutung, so vor allem der A u f w and f ür B est a n d espflege, ferner derjenige für Wohlfahrtseinrichtungen zugunsten der Holzhauer (Zelte, Schlaf- und Wohnhäuser), etwaige Anschaffungskosten für Geräte und Maschinen zum Holzhauereibetrieb und dergl. Diese Posten gehören nach dem Sieberschen Einteilungsprinzip bereits zur II. Abteilung d. h. zu denen, ,die nicht als Abgang bestimmter Einnahmen zu betrachten sind". Mag die Verrechnung derselben unter diesem oder jenem Etatstitel erfolgen, in der wirtschaftlichen Buchführung und Statistik müssen sie jedenfalls von den reinen Erntekosten getrennt gehalten werden. 
Als wichtigste Kategorien der II. Abteilung erscheinen die Kultur-, Wegbau- und Verwaltungskosten.

\section{b) Der Kulturaufwand.}

Aus Tab. 20 Sp. 2 geht hervor, daß der durchschnittliche Kulturaufwand der württembergischen Staatsforstverwaltung beim Vergleich der Zeiträume 1881/85 und 1901/05 von M. 1,59 (pro ha Gesamtf]äche) auf M. 2,19, somit um 1,6\% im Jahresdurchschnitt sich erhöht hat; nach der badischen Statistik ergibt sich ein durchschnittliches jährliches Zunahmeprozent von $1,9 \%$ (1878/82: M. 1,47, 1903/07: M. 2,36). Angesichts des oben S. 131 zu 1,2 berechneten Lohnsteigerungsprozents lassen diese Zahlen auf e r höh ten A r beits- und Kap it a la $\mathrm{u}$ f w a n d schließen (bei Württemberg um rund 1,016: 1,012 $=0,4 \%$, bei Baden um rund $0,7 \%$ ). Es wäre nun zunächst zu untersuchen, wie sich die Entwicklung des Kulturaufwands zur Zunahme der Massenabnutzung verhält. Der auf Bestandesbegründưng gerichtete Kulturaufwand ist ja bis zu einem gewissen Grad Funktion der Haubarkeitsnutzung; denn wird mehr Holz gehauen, so müßte - ceteris paribus - auch mehr kultiviert werden. Rührt aber die Nutzungssteigerung $\mathrm{nicht}$ von $\mathrm{Zun}$ ahmeder Abnutz ungsflächen sondern lediglich daher, daß auf der Flächeneinheit mehr $\mathrm{Holz}$ gehauen werden konnte (infolge Uebergreifens der Nutzung in massenreichere, z. B. Nadelholzbestände), so liegt an sich keine Ursache für ausgedehntere Kulturarbeit vor; insoweit dies zutrifft, würde die $\mathrm{Erw}$ e iterung der Produktion entlastend auf den $\mathrm{Kul}$ t u rkostena u f and, bezogen auf die Einheit der Nutzungsmasse, einwirken. Nun ist aber nach den Ausführungen des I. Teils (s. S. 35) als wahrscheinlich anzunehmen, daß die Nutzungssteigerung speziell der württembergischen Staatswaldungen auf beiderlei Ursachen zurückzuführen ist. Man müßte also annehmen, daß sich die Kulturtätigkeit in 
neuerer Zeit auf größere Gesamtfläche erstreckt hat. Diese Annahme wird aber durch die Kulturstatistik widerlegt. Die Größe der Kulturflächen betrug nämlich im württembergischen Staatswald 1881/85 zusammen 12782 ha (9031 ha Erstausführung, 3751 ha Wiederholung), 1901/1905 dagegen nur 10516 ha $(8246+2270)$.

Die auf $\mathrm{k} u ̈ \mathrm{nstli} \mathrm{ch}$ e Bestandesbegründung gerichtete Kulturarbeit ist somit dem Fläehen-Umfang $\mathrm{n}$ a ch zur ückgegangen. Angesichts der Tatsache, daß sich gleichzeitig die $A \mathrm{~b} n u t z u n g s f l a ̈ c h e$ eher vergrößert als verringert hat, dürfte man zu dem Schluß berechtigt sein, daß entweder mehr mit natürlicher Verjüngung gearbeitet wurde oder Kulturaufgaben versäumt worden sind. D i e Statistik vermag hier über keine befriedigende A uskunft zu geben:

Aus den württ. Kulturnachweisungen (Tab. V der Forststat. Mitt.) erfahren wir über natürliche Verjüngung überhaupt nichts, nicht einmal den Aufwand für Bodenvorbereitung. Ausführlicher ist in dieser Hinsicht die Forststatistik von Elsaß-Lothringen (Z. 13), wo unter Kapitel I behandelt wird: a) Anbahnung der natürlichen Verjüngung, b) Vervollständigung derselben, je mit Flächen- und Kostenbetreff. Die badische Statistik enthält ähnliche Notizen wenigstens über die Bodenvorbereitung. Es mag dahingestellt bleiben, ob es zweckmäßig ist, alljährlich in der Statistik auch die natürlich verjüngten (d. $h$. wohl endgültig geräumten) Fläch en vorzutragen; jedenfalls müßte aber der $\mathrm{A} u \mathrm{f}$ w a n d auf Unterstützung der natürlichen Verjüngung angegeben sein; ferner sollte in den Vorbemerkungen zum Wirtschaftsplan (mit Bezug auf den abgelaufenen Wirtschaftszeitraum) und dementsprechend auch in der Forsteinrichtungsstatistik eingehend Rechenschaft über den Umfang der verschiedenen Verjüngungsformen nach Fläche und Kostenbetrag abgelegt werden. Wie schon im I. Teil dargetan wurde, geben ja auch die Altersklassentabellen der württ. Einrichtungsstatistik 1908 (Tab. D 2) keinen zuverlässigen Ausweis über den Verjüngungsgang der abgelaufenen Periode.

Auch die $\mathrm{N}$ e u a u f f o r s t u n g e n sind in der Kulturnachweisung nicht getrennt gehalten, obwohl es sich hiebei um einen gegenüber den übrigen Kulturkosten w e s e n s vers c hi ed e $n$ e $n$ Arbeits- und Kapitalaufwand, um $\mathbf{E} \mathbf{r}$ w e r b u $\mathbf{n g}$ u n d Sch a f f n g n e u er V e r mögensobjekte, nicht bloß um Erhaltung und Mehrung des überkommenen Vermögens handelt. Da endlich auch Angaben über den Vollkommenheitsgrad 
der Jungwüchse ${ }^{1}$ ) und über die Größe der Verjüngungsflächen (d. h. der durch Reduktion von Vollbestandsflächen berechneten Jungwüchse) fehlen, bleibt die Frage ungelöst, ob bezüglich des bisherigen Kulturaufwands $\mathrm{n}$ ic $\mathrm{h}$ t s versäumt wurde, was zur Erhaltung des Vermögensstands erforderlich gewesen wäre, bezw. inwieweit es gelungen ist, durch Anspannung der unentgeltlichen Produktionsfaktoren einen Teil der Kulturaufgaben zu erfüllen und den Arbeits- und Kapitalaufwand einzuschränken.

Es wird gewiß kein übertriebenes Verlangen sein, wenn man von der Statistik und Buchführung volle Aufklärung über diese wichtigen Fragen durch Nachweis der ges a $\mathrm{m}$ ten Verjüngu ngsflä che und des entsprechenden Aufwands fordert.

Auch nach der badischen Forststatistik ist die künstliche Bestandesbegründung hinsichtlich der Fl ä c h e n ausdehnung zurückgegangen: die Größe der Kulturflächen betrug nämlich 1878/82 im ganzen 4122 ha (Erstausführung 2101, Wiederholung 2020), 1903/07 dagegen nur 3730 ha (2969 bezw. 761). Die Fläche der Erstausführung hat zwar zugenommen, aber die Wiederholungen sind erheblich zurückgegangen.

Aus den bisher besprochenen Ergebnissen der württembergischen und badischen Kulturstatistik (über die Lohnsteigerung hinausgehende Zunahme des Kulturaufwands bei gleichzeitigem Rückgang der Kulturflächen) kann geschlossen werden, daß die Kulturarbeit selbst neuerdings teurer, sei es nun, ,intensiver" oder unvorteilhafter betrieben wurde.

Zum Beweis wurden folgende Durchschnittsbeträge berechnet:

a) Der durchschnittiche Aufwand für künstliche Bestandes begründung (Saat + Pflanzung + Pf́lanzschulkosten) bezogen auf die Einheit der in Kultur gebrachten Flächen (Saatfläche im ganzen + Pflanzungsfläche im ganzen). (Tab. 21. siehe nächste Seite).

b) Der durchschnittliche Aufwand für

1. 1 ha Saatfläche (Tab. 22 Sp. 1)

2. 1 ha Pflanzungsfläche (Tab. 22 Sp. 2)

3. Pflanzenerziehung bezogen auf 1 ha $\mathrm{Pfl}$ anzung sfläche (Tab. 22 Sp. 3)

1) Eine nach Altersklassen gegliederte Uebersicht des Vollkommenheitsgrads, wie sie in den Vorschriften für die Wirtschaftseinrichtung in den württ. Staats- und Körperschaftswaldungen von 1898 Z. 5 c vorgesehen ist, würde diesem Bedürfnis entsprechen. 
Tab. 21.

\begin{tabular}{|c|c|c|c|c|c|}
\hline $\begin{array}{c}\text { Im } \\
\text { Staats- } \\
\text { wald von }\end{array}$ & $\begin{array}{l}\text { Im Zeit- } \\
\text { raum }\end{array}$ & $\begin{array}{l}\text { Durchschnittl. } \\
\text { Aufwand } \\
\text { oll. } 2\end{array}$ & $\begin{array}{l}\text { Im Zeit- } \\
\text { raum }\end{array}$ & $\begin{array}{l}\text { Durchschnittl. } \\
\text { Aufwand } \\
\text { oll . M }\end{array}$ & $\begin{array}{l}\text { Drchsch. } \\
\text { jährl. } \\
\text { Zunahm- } \\
\text { procent }\end{array}$ \\
\hline Württbg. & $1881-85$ & $\frac{1279638,62}{12782}=100.10$ & $1901-05$ & $\frac{1708846,89}{10515,7}=162.60$ & ca. $2,3 \%$ \\
\hline Baden & $1878-81$ & $\frac{513616}{4122}$ & $1903-07$ & $\left|\frac{867117}{3730}=232.50\right|$ & ca. $2,4 \%$ \\
\hline
\end{tabular}

4. Pflanzung im ganzen (2., + 3.,) bezogen auf 1 ha Pflanzungsfläche (Tab. 22 Sp. 4).

Nach der württ. Statistik ergeben sich folgende Zahlen:

Tab. 22.

\begin{tabular}{c|c|c|c|c|}
\hline & \multicolumn{3}{|c}{ Durchschnittlicher Aufwand für } \\
Im Zeitraum & Z. 1) & Z. 2) & Z. 3) & Z. 4) \\
& \multicolumn{3}{|c|}{ in Mark und Pfennig } \\
\hline 1881-1885 & 51.65 & 63.40 & 42.60 & 106.00 \\
1901-1905 & 75.95 & 83.42 & 83.60 & 167.00 \\
Drchschn. jährl.Zunahme \% & 1,9 & 1,3 & $\mathbf{3 , 2}$ & 2,3
\end{tabular}

Während Tab. 21 die Verteuerung des Kulturbetriebs im allgemeinen illustriert, zeigt Tab. 22, da $B$ dieser Vorgang weitaus am meisten der Pflanzen erzi ehung (dem Pflanzschulbetrieb) zur Last fällt. Weitere Erklärungsgruinde (abgesehen von. der Lohnsteigerung) bietet die Kulturstatistik nicht.

Am wenigsten und kaum über den Rahmen der Lohnsteigerung hinaus haben die $\mathrm{P} f \mathrm{l}$ a $\mathrm{nzung}$ s $\mathrm{k}$ ost e $\mathrm{n}$ zugenommen; wir entnehmen zwar weiter noch der württ. Statistik, daß das Tausend Pflanzen 1901/05 um 1,7\% teurer zu stehen kam als 1881/85 (1881/85: 7,91 M., 1901/05: 11,13); aber durch Verminderung der auf 1 ha verwendeten Pflanzenzahl von 8 Tausend auf 7,7 Tausend wurde di es e Erhöhung zum größten Teil wieder ausgeglichen. (Tab. 22 Z. 2)

Was die Verteuerung des Pflanzschulbetriebs (Z. 3 in Tab. 22) betrifft, so legt sich die Vermutung nahe, daß die Anzucht von versehulten Pflanzen zugenommen hat; die württ. Statistik gibt hierüber leider keine Auskunft; sie unterscheidet nur zwischen Laubholz- und Nadelholzpflanzen im ganzen. Die badische Statistik ${ }^{1}$ ) dagegen gliedert die Laubholzpflanzen

1) Die badische Statistik hat auch den weiteren Vorzug, da. $B$ sie die durchschnittlichen Kosten der verschiedenen $K$ u l t u r$m$ et hod en angibt.

Forstwirtschaft. V. D i e terich, Elemente d. Wertsmehrung. 
nach Heister und sonstige Pflanzen, die Nadelholzpflanzen nach Ballenpflanzen- und ballenlose und letztere wieder in verschulte und unverschulte.

Ein Vergleich der betreffenden Zahlen vom Zeitraum 1878 bis 1882 mit denen von 1903/07 zeigt denn auch, daß neuerdings mehr Laubholzh $\mathrm{e}$ is ter pflanzen und mehr verschulte $\mathrm{N}$ a d el holzpflanzen verwendet werden, während die Zahl der sonstigen Laubholz- und der unverschulten Nadelholzpflanzen zurückgegangen ist.

Ein solches Ueberhandnehmen der a r b eits r e i cheren Kulturmethoden läßt sich sowohl nach der württ. als bad. Statistik auch hinsichtlich des Anteils der Pflanz u n g e n an der Gesamtkulturfläche im Gegensatz zu den $\mathbf{S}$ a a$t \in \mathbf{n}$ feststellen.

Tab. 23

Uebersicht über die Größe der Kulturflächen ausgedrückt in ha.

\begin{tabular}{|c|c|c|c|c|c|c|c|}
\hline \multirow[b]{2}{*}{$\begin{array}{l}\text { bei der Staats- } \\
\text { forstverw. von }\end{array}$} & \multirow[b]{2}{*}{$\begin{array}{l}\text { im Zeit- } \\
\text { raum }\end{array}$} & \multicolumn{3}{|c|}{ der Saaten } & \multicolumn{3}{|c|}{ der Pflanzungen } \\
\hline & & \begin{tabular}{|} 
erste \\
Aus- \\
führg.
\end{tabular} & $\begin{array}{l}\text { Wie- } \\
\text { der- } \\
\text { holg. }\end{array}$ & zus. & $\begin{array}{l}\text { erste } \\
\text { Aus- } \\
\text { führg. }\end{array}$ & $\begin{array}{l}\text { Wie- } \\
\text { der } \\
\text { holg. }\end{array}$ & zus. \\
\hline \multirow{2}{*}{ Württbg. } & $1881-1885$ & 1309 & 79 & 1388 & 7721 & 3672 & 10393 \\
\hline & $1901-1905$ & 519 & 29 & 548 & 7727 & 2241 & 9968 \\
\hline \multirow{2}{*}{ Baden } & $1878-1882$ & 445 & 342 & 787 & 1657 & 1678 & 3335 \\
\hline & $1903-1907$ & 340 & 9 & 349 & 2629 & 752 & 3381 \\
\hline
\end{tabular}

Ehe ein abschließendes Urteil über die Ursachen der $\mathrm{K}$ u lt u ra $\mathrm{f}_{\mathrm{w}} \mathrm{nds} \mathrm{mehrung}$, insbesondere der Verteuerung des Pflanzschulbetriebs abgegeben wird, sind noch etwaige, den Ausgaben gegenüberstehende Barein a h m en zu berücksichtigen. Die Buchführung und Statistik ist vielfach ungeschickt genug, derartige Entlastung der Produktionskosten totzuschweigen; in der württembergischen Forststatistik wurde diesem Gedanken schon seit 1887 Rechnung getragen, indem der Angabe des baren Kulturkostenbetrags der ,für die Vergleichung maßgebende Gesamtaufwand" (Sp. 21 in Tab. V der Forststat. Mitt.) gegenübergestellt wird, d. h. der Aufwand nach Abzug des Ertrags aus Pflanzenverkauf.

In den Jahren 1901/05 ermäßigt sich auf diese Weise der Kulturaufwand von 2041726 M. auf 1930322 M. also um 111404 Mark $=6 \%$ der Ausgaben; im Zeitraum 1887/91 betrugen 'die Einnahmen 20900 M. pro Jahr bei 331100 M. Kulturkosten, 
also gleichfalls $6 \%$; eine Veränderung, vor allem eine den erheblichen Mehraufwand deckende Steigerung dieser $\mathbf{N e -}$ beneinnahmen hat sich also nicht ergeben. In einzelnen Revieren können sie immerhin eine sehr beachtenswerte Rolle bei Anstellung von Rentabilitätsberechnungen über Pflanzenerziehung spielen: nach den Forststat. Mitt. 1908 hat z. B. das Forstamt Steinwald 3800 M. Einnahmen für Pflanzenverkauf zu verzeichnen, eine Summe die beinahe zur Deckung der Pflanzschulkosten (3970 M.) hinreichte, das Forstamt Mergentheim 1600 M. gegenüber 2000 M., Hohenberg 1550 bei 1690 M., Ochsenhausen 2100 bei 2500 M. Pflanzenerziehungsaufwand usf. Aehnliche Einnahmequellen bieten natürlich bei sachgemäßer Behandlung auch der Saatbetrieb (Verkauf von Ballen-Pflanzen aus der Saatfläche), ebenso auch die natürliche Verjüngung ${ }^{1}$ ). Je intensiver die Waldwirtschaft betrieben werden muB, umso mehr wird auch auf Erzielung solcher Nebeneinnahmen - u $\mathbf{n}$ beschadet sonstiger Rüksichten zu achten sein.

Fassen wir das Ergebnis der bisherigen Untersuchung über das $M$ a $B$ des Arbeits- und Kapitalaufwands beim Kulturbetrieb kurz zusammen, so ergibt sich nach den angeführten Beispielen von Württemberg und Baden etwa folgendes: Der Fläche nach ist der Umfang der auf künstliche Bestandesbegründung verwendeten Arbeit zurückgegangen, die Kulturarbeiten selbst verursachten aber infolge Anwendung arbeitsreicherer Kulturmethoden mehr Aufwand als früher. Es fragt sich nun, welcherlei Folgerungen hinsichtlich der Mehrung oder Minderung der Waldwerte hieraus gezogen werden können.

Liegen diese Vorgänge in der Veränderung des Waldzustands begründet? Hat etwa die seitherige Wirtschaftsweise dazu geführt, daß man teilweise in größerem Maßstab als früher natürliche Verjüngung anwenden kann, in anderen Waldgebieten oder Waldteilen aber gezwungen ist, teurere Kulturmethoden anzuwenden, um überhaupt den Wald erhalten zu können? Wenn sich die Sache so verhielte, dann stellte der erstere Vorgang ein Element der Wertsmehrung, der andere

1) Vergl. den Aufsatz von Oberförster Dr. E b e r h a r d , A. F. und J.Z. 1908 Aprilheft (S. 121). 
ein Element der Wertsminderung vor. D i e $V$ er jü $\mathrm{ng}$ ungsfähigkeit des Waldes ist ein Wertsf a k t or , eine Förderung derselben bedeutet Wertsmehrung, die Erschwerung Wertsminderung. Beiderlei Elemente werden sich da und dort in der Waldwirtschaft geltend machen; jeder Waldteil und jeder wirtschaftliche Eingriff in den Holzbestand wird nach diesen Gesichtspunkten zu prüfen sein. Umgekehrt ist aber auch jeder Akt der Bestandesbegründung und jede Kulturmethode daraufhin zu untersuchen, ob sie wertsmehrenden oder mindernden Einfluß auf die künftige Er$\mathrm{t} \mathbf{r}$ a $\mathrm{g}$ s $\mathrm{f}$ ä $\mathrm{h}$ i g k e it des Waldes auszuüben vermag; die mit größerem Arbeits- und Kapitalaufwand verbundene Verjüngungsweise könnte eventuell höheren Massenertrag, bessere Holzqualität ergeben, vielleicht auch durch Verbilligung des späteren Aufwands (auf Nachbesserung, Bestandespflege, Forstschutz) von Vorteil sein. So läßt sich auf Grund von Tab. 23 die Verteuerung des Kulturbetriebs teilweise mit dem ganz auffallenden $\mathrm{R}$ ü ckgang der Kulturwiederhol u n g e n rechtfertigen; daß in dieser Beziehung die Pflanzung sich vielerorts als der Saat überlegen zeigt, braucht nicht weiter ausgeführt zu werden. Außerdem wird die arbeitsintensivere Pflanzmethode (verschulte Pflanzen, Heister usf.) vielfach Ersparnis a n Z eit, dem kostspieligsten Produktionsfaktor der Forstwirtschaft, zur Folge haben. Aus diesen Gründen ist man in den Fichtenhochwaldungen großer Waldgebiete von der natürlichen zur Kunst-Verjüngung, von der Saat zur Pflanzung, von der Sämlingspflanzung zur Verwendung verschulter Pflanzen übergegangen. In der Schrift von Dr. Speide $1^{1}$ ) „Waldbauliche Forschungen in würt-

1) Speidel bezeichnet als Nachteile der Saat auf Grund eingehender Erhebungen (insbesondere in Oberschwaben): Zweifelhaftigkeit des Gelingens, träges Jugendwachstum und geringere Wuchsleistung im Stangenholzalter, Ungleichförmigkeit der Bestandesbildung und Erschwerung der Bestandespflege, und kommt zu dem Schluß, ,daß sowohl im waldbaulichen als finanziellen Interesse der Uebergang zum Pflanzbetrieb angezeigt"sei (s. S. 36ff.). 
tembergischen" Fichtenbeständen (1889) liegt das Ergebnis diesbezüglicher Forschungen vor, welche unzweifelhaft die wertsmindernde Wirkung der Saat erkennen lassen. Derselbe nachteilige Einfluß (Unsicherheit der Wiederbestockung, Bodenverschlechterung etc.) wird in den amtlichen Wirtschaftsregeln ${ }^{1}$ ) für die württembergischen Nadelholzgebiete Oberschwaben und Nordostland der rein natürlichen Verjüngung der Fichte zur Last gelegt ${ }^{2}$ ). M a $\mathbf{n}$ d a r f - bei voller Würdigung dieser im Wald nachweisbaren Ergebnisse - n u r nicht übersehen, da $B$ jene Wertsminderung nicht so sehr der Verjüngungsmethode (Saat bezw. natürliche Verjüngung) a ls s ol c h $\theta \mathrm{r}$, a ls vielmehr der Art und Weise ihrer Anwend un $\mathrm{g}^{3}$ ) wird zugeschrieben werden müssen. Wenn daher die Forstwirtschaft dem von $H$ elfferich gezeichneten Vorbild der Industrie nachzueifern und Verbilligung des Produktionsprozesses durch Verbesserung der Produktionstechnik zu erzielen sich bemühen will, so wird sie ihr Augenmerk in erster Linie auf $V$ erfeinerung der mit geringstem Arbeitsaufwand belasteten Verjüngungsmethoden und intensivere Ausnützung der natürlichen Produktionsfaktoren sowie der von der Natur unentgeltlich gespendeten Roh- und Hilfsstoffedes Samens der Mutterbäume - zu richten haben. Das ist ja gewissermaßen der Grundton, der durch W a g n e r s Buch „Die Grundlagen der räumlichen Ordnung im Walde“ hindurchklingt. W a g $\mathrm{n}$ er gibt darin auch bestimmte Vorschläge zur Verfeinerung der Produktionstechnik und zeigt,

1) Amtsblatt der Oberfinanzkammer, Jahrgang 1862 und 1864.

2) Vergl. auch M a $\mathrm{r}$ t i n, Folgerungen der Bodenreinertragstheorie 5. Fichte (S. 137 und 143).

3) Vor allem wohl ihrer Anwendung nach dem ,,Großflächenprinzip" (vergl. Wagner, Die Grundlagen der räumlichen OrdnungS. $99 \mathrm{ff}$.). 
da $B$ die Natur- (bezw. Saat-)Verjüngung richtig angewendet (,Kleinflächenwirtschaft") nicht bloß massenreichere Bestände, höhere Vornutzungs- und Enderträge, sondern auch qualitativ wertvolleres, durch natürliche Zuchtwahl und den Konkurrenzkampf der dichten Jungwüchse geläutertes Holz zu erzeugen verspricht, sowie daß durch Anbahnung der räumlichen Ordnung eine Vereinfachung, d. i. Verbilligung des ganzen Betriebs sich erreichen läßt. Demgegenüber wären kostspieligere Kulturmethoden doppelt im Nachteil: einmal durch Belastung der Waldrenten mit den $\mathrm{h}$ ö $\mathrm{h}$ er e n Zinsen aus dem Kulturkostenkapital, die u $\mathrm{ms}$ o höh $\mathrm{r}$ (gewissermaßen mit progressivem Zinsfuß) angesetzt werden müßten, je g r ö B e r der Aufwand ist und je ungewis ser der Rückersatz ${ }^{1}$ ) erscheint, außerdem durch Schmälerung der einstigen Holzmassen- und Gelderträge. Nun wird aber der Waldbesitzer häufig gar nicht in der Lage sein, die an sich billigsten Kulturmethoden anwenden zu können, vielmehr notgedrungen zu arbeits- und kapitalintensiverem Verjüngungsbetrieb schreiten müssen, sei es um frühere Fehler wieder gut zu machen, drohenden Rückgang der Bodenkraft hintanzuhalten (ungünstige Humusformen, Ortstein und dergl.), oder weil künftige Wertsmehrung zunächst durch Erhöhung des Kulturaufwands erst angebahnt werden $\mathrm{mu} ß$, so bei Umwandlung von Niederwald in Hochwald, Verjüngung reiner Buchenwaldungen, Einführung von Nutzhölzern usw.

Insoweit sich diese Gesichtspunkte in der Statistik und Buchführung nicht unmittelbar zum Ausdruck bringen lassen, wäre hierüber in einem am Ende des Wirtschaftszeitraums, aus Anlaß der Einrichtungsarbeiten, abzufassenden Rückblick

1) Vergl. die Rechnungsbeispiele, welche $\mathrm{W}$ e b e $\mathrm{r}$ in einem Aufsatz, ,über den Einfluß der Kulturkosten auf die Rentabilität" etc. (A. F. und J.Z. 1905 S. 221 und 261 ff.) bezüglich Eiche und Kiefer näher ausgeführt hat; er zeigt, wie die Wirtschaft sich bei zunehmendem Kulturkostenaufwand finanziell ungünstiger gestaltet. 
Rechenschaft abzulegen und über den wertsmehrenden Erfolg des Kulturaufwands ein Gutachten zu erstatten.

Aehnlich wie die Kosten der Bestandesbegründung sind auch diejenigen für Pflege und Schutz zu untersuchen.

Erhebungen über den Erfolg des Kulturaufwands hinsichtlich Ertragsmehrung, Abkürzung des Produktionsprozesses und Förderung der Verjüngungsfähigkeit des Waldes lassen sich auch wiederum an der Hand der sog. ,W e i s e rbestände" vornehmen; es ist deshalb für solche $\mathrm{Be}-$ stände eine besonders eingehende Buchführung anzulegen und durch fortlaufende Massen- und Wertszuwachsuntersuchungen der Kausalzusammenhang zwischen Einnahmen und Ausgaben, A ufwandsmehrung (bezw. Aufwandsbeschränkung) und Wertsmehrung zu erforschen.

c) Der W e g b a a u f w a d.

Wesentlich anders als der Kulturaufwand verhalten sich zur Mehrung der Waldwerte die Ausgaben für $\mathrm{B}$ a u und Unterhaltung von $W$ eg en und sonstigen Bringungsanstalten. Mit Recht rügt es deshalb $\mathrm{S}$ i $\theta \mathrm{b} \theta \mathrm{r}^{1}$ ), daß die Wegbaukosten in einzelnen statistischen Veröffentlichungen unter dem Begriff „Forstverbesserungen“ mit Kulturkosten u. a. Aufwand zusammengeworfen werden. Wenn aber Si eb e r Wegbaukosten als Ausgaben charakterisiert, die im Interesse der zu Abt. I seiner Einteilung (Erntekosten) gehörigen Arbeiten geschehen und im Gegensatz hiezu die Kulturkosten als zur Erhaltung und Mehrung des Waldvermögens dienende, so ist die Wesensverschiedenheit der beiderlei Aufwandskategorien auch nicht richtig erfaßt, zum mindesten schief dargestellt. Für den Wegbauaufwand sind vielmehr folgende 3 Gesichtspunkte charakteristisch:

a) Ein - nach Lage des Falls - verschieden hoher, meist aber beträchtlicher Teil des Aufwands wird durch $\mathrm{M}$ e h reinnahmen des 1 a ufenden Jahrs und der

1) A. F. u. J. Z. 1908 s. 167. 
nächstfolgenden Zeit unmittelbar gedeckt, während solche Deckung beim Kulturaufwand nur ausnahmsweise zutrifft.

b) Daneben dienen diese Ausgaben aber a $\mathrm{u} \mathrm{h}$ z u r nachhaltigen Erhaltung und Mehrung des W a l d vermögens, wie die Kulturkosten,

c) unterscheiden sich von den letzteren jedoch dadurch, daßsie unmittelbar zur Mehrung der Bodenw e r t e beitragen, indem durch Wegbauten die anliegenden. Waldteile dem Markt, den Verbrauchsorten wie den Bezugsquellen (insbesondere von Arbeitskräften und Materialien), näher gerückt und befähigt werden, $\mathrm{nachhaltig} \mathrm{höhere}$ Gelderträge abzuwerfen. Die in Wegen und sonstigen Bringungsanstalten angelegten Gelder sind deshalb als ausgesprochen f i $x$ es Kapital anzusehen, während der Kulturaufwand mehr als umlaufendes Kapital wird gelten können; der Bestandeswert, für dessen Erhaltung und Mehrung die Kulturkosten zuvörderst bestimmt sind, wird ja auch von manchen Schriftstellern nur als Betriebskapital bezeichnet, während ihm andere eine Art Zwitterstellung anweisen ${ }^{1}$ ). Ohne die Unterscheidung der beiden Kapitalbegriffe mit Bezug auf Bestandesund Bodenwert streng durchführen zu wollen, möchten wir doch glauben, daß sie geeignet ist, die Wesensverschiedenheit von Kultur- und Wegbaukapital einigermaßen zu erklären.

Diese Charakterisierung bezieht sich speziell auf die Baukosten; der Unterhaltungsa f a a d dagegen belastet und begünstigt in der Hauptsache nur den laufenden Betrieb, den Ertrag des Einzeljahrs. B a u- und Unterhaltungskosten müssen deshalb in der Buchführung und Statistikstetsgetrennt gehalten werden.

In Tab. 20 (S. 137) ist der Gesamtaufwand für Wegbau und Unterhaltung, bezogen a u 1 h a W a ld flä che, angegeben (die württ. Forststatistik hatte nämlich vor dem Jahr

1) Vergl. M a r t in, Forstliche Statik S. 148/149. 
1891 diese zweierlei Ausgabeposten nicht getrennt gehalten). A u f 1 Fm $D$ erbholz n t z n $\mathbf{g}$ berechnet sich für den Durchschnitt des Zeitraums 1881/85 ein Wegbau- und Unterhaltungsaufwand von M. 0,70, für 1901/05 auffallenderweise nur M. 0,72. Angesichts der oben, wenigstens für Kulturarbeiten, nachgewiesenen $\mathrm{L}$ o h n $\mathrm{s}$ e ig e r ung um ca. 1,2\% pro Jahr zeigt diese Gegenüberstellung, daß die inzwischen eingetretene Erhöhung der Derbholznutzung (von 4,23 Fm auf 5,23 Fm pro Jahr und ha, s. I. Teil) nicht in gleichem Maß den Wegbauaufwand vermehrt hat. Bis zu einem gewissen Grad mag ja auch in dieser Hinsicht die Erweiterung der Produktion vollere Ausnützung des ohnehin erforderlichen Aufwands ermöglichen ${ }^{1}$ ).

Was nun das Maß des Arbeits- und Kapitala $u f w$ a $\mathrm{nds}$ anlangt, so muß zunächst die Menge und Art der jeweils geleisteten Arbeit ermittelt werden, d. h. die Länge (oder Fläche) und die Beschaffenheit der gebauten und unterhaltenen Wege.

Aus der württembergischen Forststatistik (Tab. VI der Forststat. Mitt.) geht hervor, daß 1901/05 im ganzen weniger Wegstrecke neu in Angriff genommen wurde als 1891/95 (Herstellung von Wegkörpern mit einer Gesamtlänge von $335661 \mathrm{~m}$ gegen 351112 in den Jahren 1891/95); dafür wurden aber verhältnismäßig mehr befestigte Wege gebaut bezw. vorhandene Erdwege mit Befestigung versehen (Befestigungen von Fahrbahnen 1901/05: 30792 1m, 1891/95: 242 564). Hand in Hand mit der Ausdehnung des Wegenetzes hat natürlich auch die zu unterhaltende Wegfläche zugenommen (1891/95 befestigte: $12261059 \mathrm{~m}$, nicht befestigte: $34948536 \mathrm{~m}, 1901 / 05$ befestigte: $15108855 \mathrm{~m}$, nicht befestigte: $35769511 \mathrm{~m}$ ). Ueber die Kosten dieser Wegarbeiten erfahren wir weiterhin folgendes: Der durchschnittliche Bau-Aufwand bezogen auf $1 \mathrm{~m}$ Weglänge betrug 1891/95 für Befestigung von Fahrbahnen M. 2,22, Herstellung von Wegkörpern M. 1,84, 1901/05 für Befestigung von Fahrbahnen M. 2,41, Herstellung von Wegkörpern M. 1,94.

1) Jedenfalls darf man sich auf die lediglich durch Lohnerhöhung bedingte Zunahme der Wegbau- und Unterhaltungskosten nichts zugute tun; solange es noch schlecht aufgeschlossene Waldteile gibt, könnte ein solcher Stillstand eher Bedenken erregen. 
Das bedeutet ein durchschnittlich-jährliches Zunahmeprozent von 0,8 bezw. 0,5 , während die Löhne vermutlich um mehr als $1 \%$ pro Jahr in die Höhe gegangen sind: man könnte also auf billigere $B$ a u weise oder einfachere A r b e its meth od en schließen. Die zuletzt angeführten Zahlen sollen zeigen, wie die Statistik das Maß des Kapi$\mathrm{t}$ a $\mathrm{l}$ a $\mathrm{u} \mathrm{f} \mathrm{w}$ a $\mathrm{n} d \mathrm{~s}$ in vergleichbaren Größen ausdrücken kann.

Nun ist daran zu denken, daß durch Verwendung von Geräten und Maschinen sowie durch zweckmäßige Unternehmungsformen sich immerhin eine Verringerung des Kapitalaufwands, unbeschadet der Güte der Arbeit, erzielen läßt; der Ausbau des Wegenetzes, insbesondere die Befestigung der vorhandenen Erdwege wird auch zur Ermäßigung des Unterhaltungsaufwands beitragen, während andererseits die letztere Rücksicht teilweise zu an sich teureren W e gb a u a r b e i t e n Veranlassung geben könnte; beispielsweise ist anzuführen das Walzen streng befahrener Hauptabfuhrwege, die Verwendung härteren und solideren, aber vielleicht durch höhere Beifuhr- und Bearbeitungskosten verteuerten Gesteinsmaterials (so Porphyr statt Sandstein, Kalksteinvorlage statt bloßem Kiesschotter und dergl.). Da es aber wichtig genug erscheint, die Veränderung der Wegbaukosten begründen zu können, sollten diese Gesichtspunkte in der RevierStatistik durch Notizen über Bauart und Baumaterialien auch zum Ausdruck gebracht werden.

Auch etwaige, den Aufwand belastende Einnahmen sind unmittelbar in der Wegbaubuchführung und -Statistik anzugeben ${ }^{1}$ ). Andererseits müssen in der statistischen Nachweisung der Wegkosten auch die Beiträge vermerkt werden,

1) Z. B. Wegbaubeiträge von Angrenzern und Fahrberechtigten, Einnahmen aus Grasverkauf von z. Zt. weniger stark benützten Wegen, aus Fischnutzung von Stauweihern, die zum Schutz gegen Hochwasserschäden aus Wegbaumitteln angelegt wurden und dergl. 
welche der Waldbesitzer selbst zum Bau und zur Unterhaltung fremder Wege leistet.

In der preußischen und badischen Statistik werden diese Posten gesondert aufgeführt; in der württembergischen dagegen sind sie unter den Rubriken "Sonstige Neubau-“ bezw. ,Sonstige Unterhaltungskosten" inbegriffen, während die Einnahmen aus Wegbaubeiträgen unter ,Außerordentliche Einnahmen“" verrechnet werden und statistisch in der Geldertragsübersicht (Tab. VIII), nicht in der Wegbaukostennachweisung, erscheinen.

Nachdem die Ursachen der Erhöhung oder Verringerung des Wegbauaufwands kurz besprochen sind und gezeigt worden ist, in welchen Zahlen das Maß der hierauf verwendeten Arbeits- und Kapitalmenge zum Ausdruck gebracht werden kann, sind nunmehr die Beziehungen dieses Gegenstands zum Waldwert und dessen Mehrung zu erläutern. Eine Erhöhung des Wegbau-Aufwands kann entweder durch w e it e re A u sdehnung des Wegnetzes zu dem Zweck erfolgen, um baldmöglichst große Teile des Waldbesitzes dem Markt zugänglicher zu machen, oder d u r e h solidere B a u a r t und flachere Wegtracen, um die Vorteile des Wegbaus noch mehr zur Geltung zu bringen und um den Aufwand späterer Jahre für Ausbesserung und Unterhaltung zu ermäßigen ${ }^{1}$ ). Vor allem aber wird die Waldwirtschaft den wertsmehrenden Erfolg mit höheren Preisen quittieren dürfen; wir hörten ja schon bei Besprechung der Preisentwicklung, daß der Forstwirt am ehesten durch Wegbauten die Preise selbst beeinflussen kann. In entlegenen Waldgebieten, wo einzelne geringwertige Hölzer vorher überhaupt nicht abgesetzt werden konnten, erfährt auch der $\mathrm{H} \mathrm{olz} \mathrm{m} \mathrm{a} \mathrm{s} \mathrm{s} \mathrm{e} \mathrm{n-}$ ertrag eine Bereicherung; noch mehr aber werden Elemente der Qualitäts mehrung als Folgeerscheinung auftreten, indem die vorhandenen Gebrauchswerte besser zur Geltung gebracht werden können; das gilt vor allem von den

1) Auch andere Ausgabentitel, wie Ernte-, Kultur- und teilweise Verwaltungskosten, werden gelegentlich durch Wegbauten, wenigstens im gebirgigen Gelände, entlastet. 
s chweren und langen Nutzhölzern (z. B. Rotbuchenstammholz statt Brennholz, Nadelholzlangholz statt Schichtholz und Sägholz). W e r t s m i n d e r n d e Wirkung dürfte ein Wegbau wohl kaum ausüben, es müßten denn grobe technische Fehler begangen werden (Schädigung des Grundwasserstands); eher läßt sich denken, daß ein ungeschickter Wegbau die erhoffte Wertsmehrung gar nicht oder nicht in vollem Maßerfüllt. Im allgemeinen aber haben wir es hier mit zuverlässigen, rasch und nachhaltig wirkenden Elementen der Wertsmehrung z u t u n.

Wenn nun auch mit Rücksicht auf künftige Wertsmehrung das Maß der auf Wegbau zu verwendenden Kapital- und Arbeitsmenge noch füglich erweitert werden kann, ist doch angesichts der voraussichtlich immer mehr sich geltend machenden Lohnsteigerung fortgesetzt auf Vereinfachung und Verbilligung hinzustreben ${ }^{1}$ ). Die Ausnützung n atürlich er Produktionsfaktoren kann in größeren Waldgebieten mit Bezug auf die vorhandenen $\mathrm{W}$ asserkräfte in Frage kommen, sei es durch zweckmäßige Einrichtung des Wassertransports oder durch Umsetzung der Wasserkräfte in elektromotorische Kraft zum Betrieb von Waldbahnen.

Auf die wertsmehrende Bedeutung des Wegbauaufwands ist neuerdings besonders eindringlich aufmerksam gemacht worden aus Anlaß der Erörterungen über die Abnutzung von Vorratsüberschüssen, Herabsetzung der Umtriebszeit usf., so in den Tör r i n g schen Anträgen, in den Veröffentlichungen v. B e n theims, Fiesers und Philipps, ferner von Wagner in seiner Schrift "Unsere Forstwirtschaft im 20. Jahrhundert", wo es u. a. heißt (S. 25):

„Hier" (d. h. im Ausbau des Wegnetzes) ,,wäre also Gelegenheit, dem Wald entnommene unproduktive Kapitalteile demselben wieder zuzuführen und zwar in einer bei diesem Betrieb nach jeder Richtung hin denkbar nutzbringendsten Form."

1) Wie schon S. 154 ausgeführt (Verwendung arbeitssparender Maschinen), ferner auch kaufmännisch geschickte Interessenvereinigung mit Bezug auf Angrenzer, Fahrberechtigte usf. 
Auch in der Begründung des neuen württ. Forstreservefondsgesetzes ${ }^{1}$ ) wird die Verwendung der Zinsen des Fonds ,vor allem zu Wegbauten", ,für Nutzbarmachung der Torfiede" u. a. Forstverbesserungen vorgeschlagen.

Die verantwortlichen Organe der forstlichen Betriebe werden sich aber nicht damit begnügen dürfen, im Vertrauen auf diesen wertsmehrenden Charakter des Wegbauaufwands fort und fort höhere Mittel zu verlangen bezw. zur Verfügung zu stellen; vielmehr sollte auch über den $\mathrm{Er}$ f o $\mathrm{g}$ g der hiedurch erzielten Rentensteigerung Rechenschaft abzulegen sein. Es wird sich deshalb empfehlen, in den einzelnen Revieren von Zeit zu Zeit, am zweckmäßigsten wohl bei der allgemeinen Abrechnung am Schluß des Einrichtungszeitraums, genaue Erhebungen über die Wegbau- und Unterhaltungskosten des abgelaufenen Zeitabschnitts sowie über die Ursachen der Erhöhưng oder Verringerung derselben anzustellen. Dabei wird auch über den Einfluß der Wegbauten auf die Gestaltung der Waldrente ein Gutachten abzugeben sein; eingehende Rentabilitäts-Untersuchungen sollten wenigstens mit Bezug auf einzelne grö Bere Wegbauten vorgenommen werden; wenn in der Preisstatistik mehrere Preisgüteklassen (Absatzlagen) innerhalb Reviers ausgeschieden sind, so müßte der Mehrungserfolg eventuell an dem Vorrücken einzelner Waldteile in die höhere Klasse zu beobachten sein.

Ein solches Gutachten gibt auch Gelegenheit, die Erfahrungen schriftlich niederzulegen, welche man mit der bisherigen Bauweise gemacht hat und auf verfehlte Unternehmungen aufmerksam zu machen. So gut beim Abschluß des Wirtschaftsplans in großen Zügen der we i tere A u s b a u des Wegenetzes vorgemerkt und die im allgemeinen bezüglich Bauart einzuhaltenden Grundsätze angegeben werden, ebenso wichtig ist es, auch einen Rückblick über die seitherigen A r beiten, ihren Erfolg und ihre Nachteile zu werfen.

1) Vergl. Bericht im F. Zentralbl. 1910 Oktober- und November-Heft. 
Mit Bezug auf die Mehrung der Waldwerte verhalten sich in mancher Hinsicht den Wegbaukosten ähnlich die Ausgaben für Meliorationen insofern wenigstens, als auch sie dazu bestimmt sind, die Ertragsfähigkeit des Bodens zu fördern bezw. gewisse Ertragseigenschaften dem Boden erst beizubringen; das andere Merkmal des Wegbauaufwands (s. S. 151), die baldige $\mathrm{K}$ ost $\operatorname{conde} \mathrm{ckung}$, trifft dagegen nur ausnahmsweise zu (z. B. Riedentwässerung in Verbindung mit Torfabnutzung); es handelt sich meist um langfristige Wechsel auf eine ferne Zukunft. Andererseits ähneln die Meliorationskosten noch mehr als die Wegbaukosten den eigentlichen Gru nds t o cksa u s lagen (Ankäufe, Ablösungen usf.), da sie in erster Linie auf $S \mathrm{ch}$ aff ung n e u $\mathrm{r}$ W e r t $\mathrm{e}$ gerichtet sind. Mit Rücksicht hierauf dürfte es keinem Anstand unterliegen, wenn man zu ihrer Bestreitung Vorschüsse ${ }^{1}$ ) dem Waldkapital entnimmt, sofern nicht ausschließlich allgemeine Landeskulturinteressen in Betracht kommen, während die Schaffung von Waldwerten in den Hintergrund tritt und von Rentabilität für absehbare Zeit überhaupt nicht die Rede sein kann.

Die Meliorationskosten sind deshalb, e b e n s o wie die eigentlichen Grundstocksauslagen (Zuführung neuer Vermögensteile), soweit es sich um größere selbständige Arbeiten handelt, gewissermaßen als außerordentlicher Dienst in der Statistik und Buchführung $\mathrm{g}$ e s o n d e r t vorzutragen und jedenfalls $\mathrm{nicht}$ mit den laufenden Ausgaben (Kulturmittel) zu verquicken. So finden wir in den Preußischen Amtlichen Mitteilungen usf. in Tab. $46 \mathrm{~b}$ eine Anzahl von Rubriken mit der gemeinschaftlichen Ueberschrift: ,Einmalige und außerordentliche bezw. außeretatsmäßige Ausgaben" (z. B. Ablösung von Servituten, zum Ankauf von Grundstücken, Beschaffung von Insthäusern für die Arbeiter usf.).

d) Der Verwaltungskostena u w a d.

Den Verwaltungskosten fällt meist der Löwenanteil am Gesamtaufwand zu, so nach der preußischen Statistik (Tab. 49) in den letzten Jahren ca. 37-39\%; in der württembergischen Staatsforstverwaltung werden sie nur von dem Ausgabeposten „Hauerlöhne ${ }^{66}$ übertroffen (1908: 2422133 M. Hauerlöhne, 1744607 M. Verwaltungskosten).

Um die Ursachen feststellen zu können, welche die allmähliche Erhöhung des Verwaltungsaufwands veranlaßt haben,

1) Vergl. die Törringschen Vorschläge betr. Verwendung von Vorratsüberschüssen (zitiert von Prof. Wagner in der Schrift Unsere Forstwirtschaft im 20. Jahrhundert I.) ferner die oben (S. 156) angeführte Stelle aus der Begründung des württ. Reservofondsgesetzes. 
müßte eine Personalstatistik angelegt werden mit Angaben über die jeweilige Beamtenzahl und die durchschnittlichen Bezüge der Beamten (Gehalt, Wohnungsmiete usf.) jo gesondert nach Kategorien (Betriebsleiter, Hilfspersonal, Beamte mit Vollbildung, empirisch geschultes Personal). Diese Zahlen wären dann entsprechend der von Professor Dr. v. B ü h l e ${ }^{1}$ ) angewandten Methode in Beziehung zu setzen zur jeweiligen Größe der Verwaltungsbezirke, zum Ges a $\mathrm{m} \mathrm{tholzanfall}$ unter Berücksichtigung der Sortimentsverteilung bezw. Nutzholzausbeute, des Umfangs, eventuell auch der Zahl, der Arbeitsfelder (Hiebsorte, Nutzungsfläche usf.), ferner zu den Einnahme- und A usgabeb e trägen. Die bisherigen Erörterungen boten ja Gelegenheit, an Beispielen die Entwicklung dieser Vergleichsobjekte zu verfolgen. Die Ertragsmehrung braucht allerdings $\mathrm{n} \mathrm{i} \mathrm{ch} \mathrm{t}$ unbedingt von einer gleich lebhaften Zunahme der Verwaltungskosten begleitet zu sein; denn die schon wiederholt erwähnten Vorteile der Produktionserweiterung mit Bezug auf bessere Ausnützung der Produktionsmittel werden in besonderem Maß beim Verwaltungsaufwand zur Geltung kommen.

Aus Tab. 20 (S. 137) ist ersichtlich, daß trotz der $\mathrm{Nut}$ zungs s t $\theta$ i g e r ung einerseits und der $\mathrm{G}$ e halts e r b öhu $\mathrm{ng}$ andererseits der Verwaltungskostenaufwand in der württ. Staatsforstverwaltung ${ }^{2}$ ) eine Zunahmeziffer von nur 1\% pro Jahr aufzuweisen hat; a u 1 Fm $D$ erbholznutzung berechnet sich für 1881-85 wie 1901-05 derselbe B et r a g von M. 1,54. Der Verwaltungsaufwand hat sich also relativ verbilligt.

1) In seinem bei der Düsseldorfer Forstversammlung (1908) erstatteten Referat über das Thema: ,Welche Gesichtspunkte sind maßgebend für die Bestimmung der Größe der Oberförstereien ?"

2) Dabei darf allerdings nicht übersehen werden, daß der durchschnittliche Verwaltungsaufwand von 1901/05 einen für die Vergleichbarkeit etwas zu niederen Betrag angibt, weil der in jenen Zahlen $\mathbf{n}$ i c h t inbegriffene Kostenbetreff der Zentralverwaltung durch die Organisationsänderung von 1902 (Abschaffung des Forstmeistersystems) zwar erhöht, dafür aber der Aufwand für die Bezirksverwaltung (um die Gehälter etc. der Forstmeister) sich vermindert hat. 
So erfreulich an sich dieser Vorgang für den Nutznießer des Waldes ist, so sehr er als Symptom intensiverer Ausnützung ${ }^{1}$ ) der vorhandenen Arbeitskräfte zu begrüßen ist, so muß doch auch die Frage aufgeworfen werden, ob nicht zugleich wertsmindernder oder doch weitergehende Wertsmehrung hemmender Einfluß davon ausgeht. Es dürfte sich erübrigen, auf diese in letzter Zeit, zumal aus Anlaß der Düsseldorfer Forstversammlung lebhaft erörterten Fragen ${ }^{2}$ ) einzugehen; meßbar oder auch nur annähernd schätzbar ist ja die Rentabilität des Verwaltungsaufwands und ebenso der wertsmehrende Einfluß der Erhöhung oder Erniedrigung di eses Ausgabepostens nicht ohne weiteres; nur das Negativ des Bildes kann gelegentlich erfaßt werden, die Verluste durch ungenügende Beaufsichtigung, flüchtige Geschäftsbehandlung bei unzweckmäßiger Größe der Bezirke oder bei Verwendung weniger gut ausgebildeten und weniger leistungsfähigen Personals. $\mathrm{B}$ ü hle $\mathrm{r}$ sagt im Zusammenhang diesbezüglicher Erwägungen: „Der Verlust erscheint nicht direkt in den Wirtschaftsbüchern, sondern wird als Mindererlös gebucht und oft anderen Ursachen zugeschrieben". Berücksichtigen wir, daß weitere Wertsmehrung nur durch Steigerung des Massen- und Wertszuwachses und insbesondere wie oben ausgeführt durch Verbesserung der Produktionstechnik z u verlässig garantiert wird, so dürfte die Bedeutung der immensurablen, im Verwaltungsaufwand tätigen Wertsmehrungselemente gerech-

1) Es läßt sich für die württ. Staatsforstverwaltung berechnen, da $B$ auf 1 Beamten mit Vollbildung im Jahr 1886 ein Flächenbetreff von 1445 ha, 1906 dagegen ein solcher von 1540 ha entfällt, auf 1 Forstschutzbeamten 1880 eine Hutfläche von $\mathbf{r}$ u n d 400,1910 von r und 427 ha; außerdem hat sich eine Verschiebung von an sich kostspieligerem Arbeitsaufwand auf die Schultern billigerer Arbeitskräfte ermöglichen lassen, insofern die Gesamtzahl der Inspektoren und Betriebsleiter (Forsträte und Oberförster) mehr und mehr abgenommen hat vergl. Müller i. A. F. u. J. Z. 1907 S. $391 \mathrm{ff}$.).

2) Vergl. auch Uns. Forstw. i. 20. Jahrh. IV: d. zweckmäßige Größe d. Forstbez. i. Württ. 1911 (v. Dr. Wörnle). 
tere Würdigung finden, als der Tätigkeit der Forstverwaltungsbeamten häufig und leider nicht immer bloß von Laien, entgegengebracht wird. Auch die Frage der Ausbildung und Fortbildung des Forstpersonals muß in erster Linie unter dem Gesichtswinkel künftiger Wald-Wertsmehrung besprochen werden; neuerdings haben insbesondere $W$ a g $\mathrm{n}$ er, $\mathrm{W}$ a $\mathrm{p} p$ es und v. Benthei m solchen Gedanken lebhaften Ausdruck verliehen.

Zweckmäßige Ausnützung der vorhandenen Arbeitskräfte läßt sich vielfach auch durch Zusammenschluß mehrerer Verwaltungen oder durch Anschluß kleinerer Waldbesitzungen an die Verwaltungseinrichtungen der Großbetriebe ermöglichen. Es sind deshalb in der Statistik auch beim Verwaltungsaufwand etwaige durch derartige Verhältnisse begründete Einnahmen vorzutragen.

In der württ. Forststatistik wird in den Anmerkungen zu Tab. VIII der Ersatz für die Kosten der Bewirtschaftung von Körperschaftswaldungen am Aufwand für das Forstverwaltungspersonal, die Einnahmen aus Schutzkostenbeiträgen an dem Kostenbetreff des Forstschutzpersonals in Abzug gebracht.

Durch solchen Anschluß wird, zumal bei parzelliertem Waldbesitz, leicht eine im Verhältnis zum Mehraufwand beachtenswerte Einnahmequelle zu erschließen sein. Auch bei den besonderen Verwaltungsinstituten des Großwaldbesitzes, wie Forsteinrichtungsanstalt, wegbautechnisches Bureau usf. sollte dieser dem kaufmännischen Denken und Handeln ganz geläufige Gesichtspunkt praktisch eine Rolle spielen. So werden z. B. in den Mitteilungen über die Ergebnisse der sächsischen Staatsforstverwaltung (im Tharander Forstl. Jahrbuch veröffentlicht) alljährlich auch die Arbeiten der Forsteinrichtungsanstalt in Nichtstaatswaldungen nach Flächenausdehnung und Gelderlös aufgeführt.

\section{Folgerungen.}

Kehren wir zum Ausgangspunkt der Diskussion über den Produktionsaufwand zurück, so können wir feststellen, daß die von Helfferich als Merkmal für die Entwicklung der Großindustrie gekennzeichnete Verbilligung der Produktion bis zu einem gewissen Grad und in manchen Stücken auch in der Forstwirtschaft nachweisbar ist und jedenfalls als Element der Rentensteigerung vielfach noch in höherem 
Maß als bislang zur Geltung gebracht werden könnte. In Anbetracht des überwiegenden Anteils, welcher der menschlichen Arbeitskraft naturgemäß an der forstlichen Produktion zufällt, ist freilich die Lohnsteigerung bis jetzt a usschlaggebend für Erhöhung der absoluten Produktionskostenbeträgegewesen und wird auch künftig die Ertragszunahme beeinträchtigen, umso mehr, als die Lohnkämpfe heutzutage viel Unsicherheit in das wirtschaftliche Leben und so auch in Holzhandel- und Industrie (mit der Zeit möglicherweise auch in die Waldwirtschaft unmittelbar) hereintragen, und gerade in Zeiten aufsteigender Konjunktur (z. B. Frühjahr 1910) als Hemmschuh der Ertragsmehrung sich fühlbar machen. Die Forstwirtschaft wird deshalb ihr Augenmerk auf möglichste Eins chr än$\mathrm{kung} d e \mathrm{~s}$ A r beits a ufwands lenken müssen, um den Wettkampf zwischen Ertrags- und Kostenzunahme zu ihren Gunsten zu entscheiden und die nachteiligen Folgen des Gesetzes vom ,abnehmenden Bodenertrag" von sich abzuwenden; dabei wird insbesondere auf tunlichste Erleichterung des $\mathrm{k} \ddot{\mathrm{u}} \mathrm{n} \mathrm{f} \mathrm{t}$ i g o n Produktionsaufwands durch entsprechende Wirtschaftsweise (Bestandesbegründung und -Erziehung) zu achten sein. Soweit aber $\mathrm{nachhaltige} \mathrm{Wertsmeh-}$ r u n g infolge Mangels an unentgeltlichen oder billigsten Hilfsmitteln und Rohstoffen oder infolge Versagens der natürlichen Produktionsfaktoren nur durch Einsetzung erhöhten Arbeitsund Kapitalaufwands zu erhoffen ist, so beim Uebergang zu ertragsreicheren Bestandesarten und soweit es sich um Verbesserung dor Bodeneigenschaften (durch Wegbauten und Meliorationen) handelt, muß die Rücksicht auf Erhöhung der zeitweiligen Rente gegenüber der Fürsorge für die Zukunft zurücktreten, soll die Kostenersparnis nicht zum Element der Wertsminderung auswachsen. In diesem Sinn kann auch die oben zitierte Aeußerung Möllers (s. S. 129), daß sich der Forstwirtschaft noch ein weites Feld für erfolgreichen 
Mehraufwand eröffne, unsere Zustimmung erhalten können: nur müßte die, im allgemeinen für Ausnahmefälle zutreffende Bemerkung ,insbesondere mit der Besitzergreifung besserer Böden und günstiger Lagen zum Markt" abgeändert werden in: insbesondere $\mathrm{durch}$ Verbesserung der Böden und der Lage zum Markt. Damit wäre auch die Brücke zu den scheinbar widersprechenden Ausführungen $\mathrm{W}$ a g n e r s (s. S. 129 oben) geschlagen.

Inwiefern die forstliche Buchführung dazu beitragen kann, die Entwicklung des Produktionsaufwands aufzuklären und die wertsmehrende Wirkung desselben meßbar und nachweisbar zu machen, ist mit Bezug auf die wichtigsten Forstausgaben besprochen worden. Zusammenfassend sollen nur noch folgende Punkte besonders betont werden, als Wegweiser zur weiteren Ausgestaltung der Buchführung und der Aufwandsstatistik:

1. Zur Klarstellung der für die Wertsbildung und Wertsmehrung entscheidenden Vorgänge sind die einzelnen Aufwandskategorien bezw. innerhalb der Kategorie die einzelnen Ausgabeposten getrennt zu halten nach:

a) Ausgaben, die bestimmte Einnahmen unmittelbar belasten (wie Abt. I der S i e b e r schen Einteilung), die eigentlichen Werbungskosten;

b) solche, die zwar nicht als Abgang bestimmter Einnahmen anzusehen sind, aber doch in der Hauptsache nur die laufenden Erträge belasten, z. B. die Wegunterhaltungskosten;

c) solche, deren wesentliches Merkmal in der $\mathrm{Erhal-}$ tung und Verbesserung des vorhandenen W a ldvermögens besteht und hier wieder

a) diejenigen, welche mehr nur auf $\mathrm{Erh}$ a $1 \mathrm{tung} \mathrm{der}$ H o l z v or r a t s w e r t e gemünt sind (Kosten der Bestandesverjüngung, -pflege und des Waldschutzes),

ß) welcheaufdie Ertragseigens chaften des Bodens, auf die Gestaltung der Bodenwerte Be- 
zug haben (Wegbauten, sonstige Transportanstalten, Meliorationen);

d) solche, welche der Waldwirtschaft $n$ e u e V e r m ögensteile zuführen, wie: Aufforstungen landwirtschaftlichen Geländes, Ankäufe, Ablösung von Berechtigungen u. a., außerordentlicher Aufwand für erstmalige Anschaffung von Maschinen, Waldbahnen und dergl.

2. Bei den betreffenden Ausgabeposten müssen jeweils auch jene Einnahmen vorgetragen werden, welche als Ersatz oder Entlastung derselben gelten können.

3. Zum Nachweis der eine Mehrung oder Abnahme der Produktionskosten veranlassenden Ursachen sollten sich folgende Daten ohne umständliche Berechnung aus der Buchführung bezw. Statistik (jedenfalls aus der Revierstatistik) erheben lassen:

a) Die Höhe der jeweiligen Lohnsätze und der indirekten Lohnteile (Versicherung, Prämien und dergl.) und zwar der Stücklöhne sowohl als Taglöhne sowie der Anteil der Arbeitslöhne an den einzelnen Ausgabetiteln.

b) Das Ma $B$ des Arbeitsaufwands bezeichnet durch die Zahl der Tagewerke bezw. die Anzahl der beschäftigten Beamten, ferner durch Angaben über den A rb e i t s e r f o l g ausgedrückt in der Flächengröße der Arbeitsfelder (Kulturfläche, Wegstrecke usf.) oder in Kubikmaßen (Holz, Steine etc.), in der Stückzahl (Pflanzen) und dergl.

c) Die Art und Besehaffenheit der Arbeitsaufgabe durch getrennte Angabe über die Zahl, die Arbeitsleistung und Entlöhnung der verschiedenen Arbeiter- und Beamtenkategorien (männliche, weibliche, erwachsene, jugendliche Arbeiter, Beamte mit Vollbildung, nur empiriseh geschulte usf.), ferner durch Notizen über den Materialverbrauch (Samen, unverschulte, verschulte Pflanzen, Schottermaterial der verschiedenen, gegendüblichen Gesteinsarten). 
4. Der Erfolg der Wertsmehrung ist von Zeit zu Zeit, insbesondere a s AnlaB der Wirtschaftseinrichtungs a r beiten, durch Probeuntersuchungen an Weiserbeständen und durch Rentabilitätsberechnungen zu ermitteln, oder, soweit nicht zahlenmäßig ausdrückbar, gutächtlich zu erläutern; dabei sind vergleichende Untersuchungen über Ertrags- und Ausgabenmehrung anzustellen und der voraussichtliche künftige Aufwand in großen Zügen zu veranschlagen.

\section{Rückblick.}

Wie im I. Teil (vergl. Folgerungen S. 47), so waren auch im II., und zwar hier mit Bezug auf den Ein heit s w ert der nachhaltig aus dem Wald beziehbaren Nutzung, die zwei Fragen ins Auge zu fassen:

a) Worin zeigt sich das Vorhandensein und die Wirkung wertsmehrender Elemente bezw. entgegengerichteter Kräfte?

b) Wie kann der Effekt dieser Mehrungs- (bezw. Minderungs-) Vorgänge ermessen und von der forstlichen Buchführung zum Ausdruck gebracht werden ?

Zur Lösung der ersteren Frage wurde der Versuch gemacht, die bisherige Erhöhung der Reinerträge (bezogen auf die Einheit der Holzmassennutzung) zu erklären, und zu prüfen, ob dieser Mehrungsprozeß im Waldkapital selbst festen Fuß gefaßt hat, m. a. W., o b die Reinertrags steigerung a uf Mehrung des Wertszuwachsesder Waldungen zur ückzuführen ist. Es gelang wohl, einzelne Mehrungserscheinungen und ebenso einige entgegenwirkende Tendenzen herauszuschälen, aber der volle Einblick in das feine Räderwerk der Kausalbeziehungen blieb verhüllt. Vor allem konnten diejenigen Wertsveränderungen $\mathrm{n}$ i c h t genau ergründet werden, welche in in n ere $\mathrm{n}$ Vorgängen der Waldwirtschaft begründet und von der forstwirtschaftlichen Tätigkeit ausgelöst, al s z u v erläs s i g u nd 
$\mathrm{n}$ a ch haltig. wirkend angesehen werden dürfen; mancherlei Anzeichen, so vor allem beim Vergleich der Holzartenübersicht mit der Ertragsstatistik, deuten allerdings auf derartige Einflüsse hin.

Der Schwerpunkt der Untersuchungen mußte deshalb, wie im I. Teil, auf die Lösung der a n d e r e n Frage gelegt werden, indem auf die der Forschung entgegenstehenden Hindernisse hingewiesen und gezeigt wurde, auf welche Weise Abhilfe geschaffen werden könnte, um die einzelnen Mehrungsvorgänge erfaßbar und wenn möglich zahlenmäßig ausdrückbar zu machen. Die betreffenden Vorschläge bezogen sich auf Ausbau und Gliederung der wirtschaftlichen Buchführung, a uf Weiterbildung der Statistik, sowie auf Ergänzung der Waldinventarisierung mit Bezug auf die Wertigkeit des Holzvorrats. In den heutigen geordneten forstichen Betrieben wird ja als wiehtigster Z we k der Forsteinrichtung nicht mehr die Waldeinteilung, sondern die Abreehnung zwischen dem Soll und Haben der Wirtsehaft gelten können.

So führt uns auch der II. Teil auf die Forderung hinaus, da $B$ der Taxator so viel als möglieh die Ergebnisse der seitherigen Wirtsehaft studieren, für Ermessung des Ertragsvermögens der Betriebsklase nutzbar machen und zu den entsprechenden oder ergänzenden Teilender Bestandesaufnahme in Beziehung setzen muß. Die wirtschaftliche Buchführung andererseits und die Statistik sollten so eingerichtet werden, daß die $m a ß g e b e n d e n$ Wertaelem en te auch erfaßt werden können. Forstverwaltung und Forsteinrichtung dürfen nicht als fremde oder gar feindliche Mächte einander gegenüberstehen, sondern sich gegenseitig 
weiterbildend, sollen sie als treue Bundesgenossen den Elementen der Wertsmehrung in der Waldwirtschaft zum Sieg verhelfen.

Es könnte als gewagtes Unternehmen erscheinen, heutzutage, wo alles auf Vereinfachung hindrängt, Erweiterung und Vertiefung der Buchführung, Statistik und Taxationsarbeiten zu verlangen. Demgegenüber ist zu bemerken, daß die vorgeschlagenen Ergänzungen und Verbesserungen sich bei zweckmäßig angelegter und geordnet fortg e f ührter Buchung ohne viel Mehraufwand an Zeit vollziehen lassen. Die Forstwirtschaft bedarf in höherem Maß als andere Zweigeder Volkswirtschaft eingehender Statistik, dasie es mit sehr langen, schwer zu überblickenden Produktionszeiträ umen und größtenteils mit Zukunftswerten zu tun hat. Nur eine genaue Untersuchung der Wertsmehrung führt, wie gezeigt, zur Erfassung dessen, was als Rente angesehen werden kann und damit zum Verständnis der Werte selbst. Für größere, im Nachhaltbetrieb stehende Waldverbände läßt sich ja der Wert am einfachsten durch Kapitalisierung der nachhaltig beziehbaren Rente ermessen, wobei etwaige im Ueberfluß vorhandene Altersklassen, sei es nun Kultur oder Altholz, für sich, gewissermaßen als außerordentliche Vermögensteile nach anderer Rechnungsweise (Verkaufswert, Kostenoder Erwartungswert) zu veransehlagen und ebenso, wie ev. in Ausgleichs- oder Reservefonds angelegte Kapitalteile dem Rentierungswert zuzuschlagen wären. Zur Kapitalisierung der Rente darf aber, wie neuerdings insbesondere von $\mathrm{Pi} 1 \mathrm{z}$ und $\mathrm{Martin}{ }^{1}$ ) betont worden ist, $\mathrm{nicht}$ ein einheitlicher zeit- oder gegendüblicher Zinsfuß

1) Vergl. Aufsatz von M a r t i n , über die Umtriebszeit der Kiefer" usf. (Forstw. Zentralbl. 1910 Heft 7, insbesondere S. 382 ff., wo auch weitere Literaturstellen angegeben sind). 
verwendet werden; derselbe ist vielmehr von Fall zu Fall gutächtlich einzuschätzen nach Maßgabeder vorausichtlichen Ertrags steigerung und unter Berücksiehtigung vor allem der zuverlässigen, in inneren Vorgängen der Waldwirtschaft wirkenden Elemente der Wertsmehrung. 



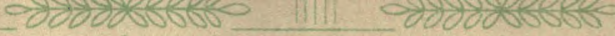

$0000 * 15560$ 
